BIROn - Birkbeck Institutional Research Online

Enabling Open Access to Birkbeck's Research Degree output

\title{
Sentencing 'unwanted' migrants: the border, racism, and narrating punishability
}

https://eprints.bbk.ac.uk/id/eprint/46761/

Version: Full Version

Citation: Lousley, Gemma (2021) Sentencing 'unwanted' migrants: the border, racism, and narrating punishability. [Thesis] (Unpublished)

(C) 2020 The Author(s)

All material available through BIROn is protected by intellectual property law, including copyright law.

Any use made of the contents should comply with the relevant law. 


\section{Sentencing 'Unwanted' Migrants:}

\section{The Border, Racism, and Narrating Punishability}

\section{Gemma Lousley}

Department of Criminology, School of Law

Birkbeck, University of London

Thesis submitted for the degree of Doctor of Philosophy

July 2020 
I hereby declare that the work presented in this thesis is my own, except where explicit reference is made to the work of others.

Gemma Charlotte Lousley

$1^{\text {st }}$ July 2020 


\begin{abstract}
Criminologists researching migration and border control have documented how, in recent years, the police, courts and prisons in England and Wales have been reshaped and transformed as they have been injected with practices of immigration enforcement. In this thesis I suggest that alongside such overt changes, the border might also be permeating the criminal justice system in a more subtle and insidious way. Specifically, I focus on the racialised narratives circulated by the United Kingdom government and media in the contemporary era, which problematise non-white and 'not quite white' migrants and justify their targeting by the direct activities of border enforcement: we can understand these as dominant or hegemonic narratives of bordering. In the thesis, I explore how these dominant, racialised narratives are being tapped into and appealed to by legal professionals involved in one specific stage of the court process: the practice of the sentencing hearing.
\end{abstract}

Through Crown Court observations, I show how racialised narratives of bordering are being mobilised in the individual narratives delivered during sentencing hearings, to portray nonwhite and 'not quite white' migrants as inherently suspect and deviant, to fix them as undesirable in themselves - in order to help produce them as punishable. Conversely, I also demonstrate how these racialised narratives are being negotiated and negated in various ways to insist that defendants are not intrinsically bad and deviant but, in fact, are naturally good and deserving migrants - in order to assert that they can be sanctioned less severely. I argue, therefore, that in sentencing hearings for these 'unwanted' migrants, dominant, racialised narratives of bordering are being deployed and countered as part of the construction and negotiation of defendants' punishability. In uncovering how these racialised narratives are being utilised in sentencing hearings my research contributes to the rapidly expanding criminological sub-field of 'border criminology', as it aids our understanding of the ways in 
which border control is imprinting itself on the contemporary criminal justice system. At the same time, the thesis can be situated in relation to the literature on racism, the courts and sentencing, as it demonstrates how racial demarcation and racist expression facilitate and enable sentencing proceedings for some 'unwanted' migrant defendants. 


\section{Acknowledgements}

I owe the most enormous thanks, first of all, to my supervisors, Sarah Lamble and Mike Hough. You have been incredibly patient with me, and have provided so much support and encouragement over the past seven years. You have also pushed me intellectually, and have helped me to write what I hope is a much more critically adventurous and questioning thesis than the project I proposed to you when I first started. I have learned so much while studying at Birkbeck, and really cannot thank you enough.

I would also like to thank Neske Baerwaldt and Hindpal Singh Bhui, who kindly agreed to read chapters from this thesis despite their own busy work schedules, and who provided me with very detailed and immensely helpful comments. Across the period that I have been writing this thesis, I have also been lucky enough to receive feedback on my work from other scholars whose research I have learned a huge amount from and whom I very much respect: Monish Bhatia, Alpa Parmar and Sarah Turnbull. I hope that, from the final thesis I have produced, it is clear how much I appreciate and value all of the comments and feedback I have been given.

Lastly - but, to be clear, not least importantly! - I would like to thank my family. My brother-in-law Bert has given me hours of IT advice and support, even when he has been very far from the UK, and has answered my numerous and annoying questions with great patience. My brother Edward has ensured that I have always had enough programmes to watch in the evening after a long day's writing, and has also kept me entertained with a steady stream of amusing animal videos. My sister Jessica has listened to me endlessly, and has encouraged and reassured me more times than could reasonably have been expected of her. Even when I know I have been pretty awful and difficult to talk to, she has been there for me. I feel very 
lucky to have someone to whom I know I can say anything.

Finally, I would like to thank my mum and dad, Kathryn and Christopher. You have supported me in so many ways: without you, quite simply, I wouldn't have been able to complete this thesis. It's very difficult to put into words how grateful I am to you, for everything that you have done. So, I will simply say: I love you both very much. 


\section{Contents}

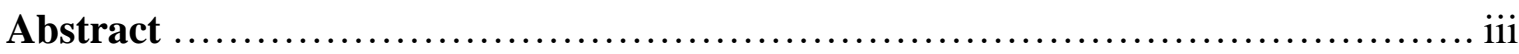

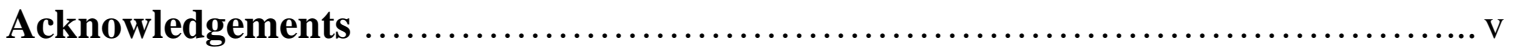

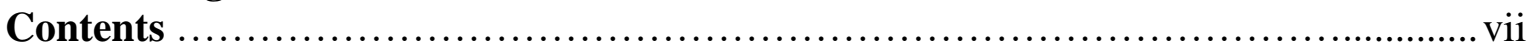

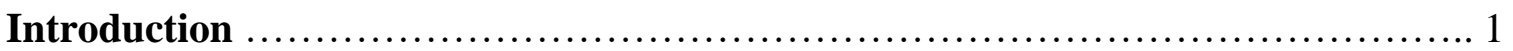

Overview of chapters ....................................................... 4

\section{Part I: Conceptual Foundations}

1 Setting the Scene: Centring Narratives and Race in Border Criminology ........ 14

Introduction ............................................................... 14

The changing contours of the criminal justice system under mass migration

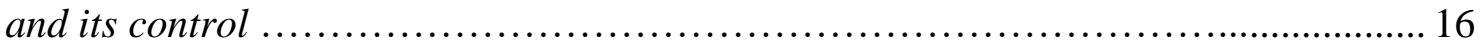

The prison and immigration enforcement ................................. 16

The police and the border ................................................. 21

The courts and immigration control ........................................ 26

Immigration enforcement and the changing nature of punishment

for non-citizens ........................................................... 29

Narratives of bordering, and pushing back the boundaries of border

criminology .............................................................. 32

Moving past the language of 'migrants' and 'non-citizens': The centrality

of race to research on borders and bordering ..................................... 47

Conclusion ........................................................................ 57

2 The Problematisation of 'Unwanted' Migrants: Dominant, Racialised

Narratives of Bordering ..................................................... 59

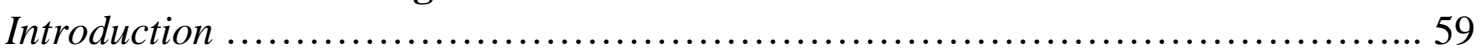

'I am seeing a great growth of people abusing the system': The narrative

of the manipulative immigration cheat ........................................ 62

The abusive and manipulative immigration cheat: A racialised

narrative of bordering .................................................. 70

Opening up the border selectively: The 'genuine' refugee as a narrative

of limited inclusion ....................................................... 77

'Gold-diggers searching for an easy life': The narrative of the parasitical

scrounger .................................................................. 80

Making unwanted migrants desirable through class: Opening up the

border to the 'brightest and the best' and those who 'work hard and

contribute to the UK' ................................................... 89

Narratives of immediate danger and threat: The criminal, the terrorist

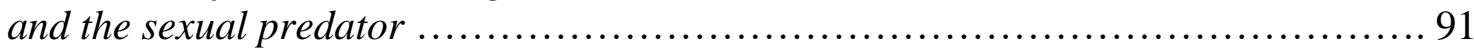

Conclusion ................................................................... 100

3 Racialised Narratives of Bordering and the Practice of the Sentencing

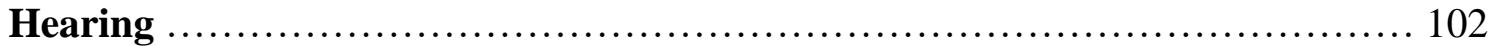

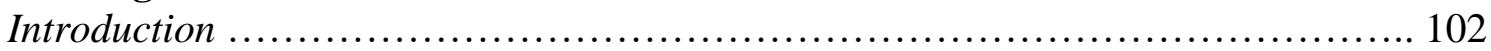

The practice of the sentencing hearing: The story so far ........................... 104

Narrative: A framework for understanding the practice of the sentencing

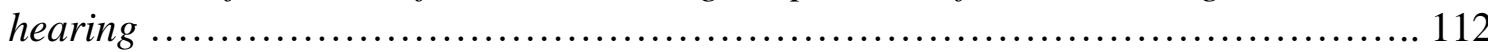


Making defendants punishable in legal terms: Stories of prohibited

acts and forbidden intentions ............................................... 120

Making defendants punishable through gender and race: Stories of

intrinsically problematic people

Conclusion

\section{Part II: Sentencing Hearings}

4 Research Methods and Ethics: Observing Sentencing Hearings ................. 145

Introduction ....................................................................... 145

Starting the research process (I): Why court observations? ....................... 145

Starting the research process (II): Accessing the courts, identifying

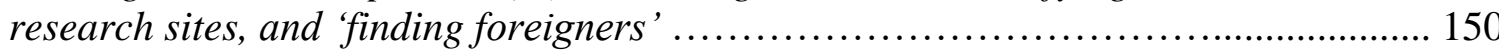

Data collection and analysis: Capturing 'what happens' in court and the

impact of my social positioning, observing 'enough' sentencing hearings,

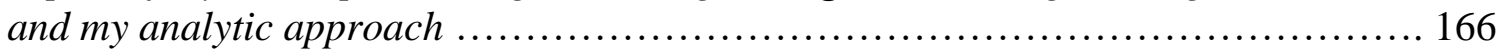

The ethics of observing sentencing proceedings ................................ 177

Writing up sentencing hearings and presenting my findings ....................... 179

5 Racialised Narratives of Bordering, and the Construction and Negotiation

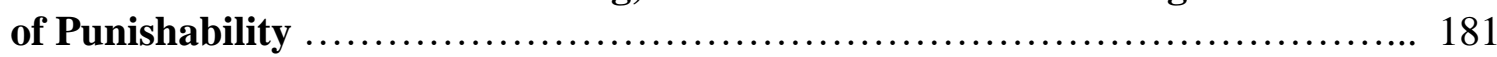

Introduction .................................................................. 181

The narrative of the abusive immigration cheat in immigration offence

hearings: Agnesa and Tomás ................................................. 184

Constructing and negotiating the defendant as an abusive immigration

cheat in non-immigration offence hearings: Joseph, Farid and Gloria .............. 202

The narrative of the parasitical scrounger in non-white and 'not quite

white' migrant sentencing hearings: Marek, and many others .................... 224

Conclusion .................................................................. 238

6 Challenging Racialised Narratives of Bordering:

Defence Barristers and Defendants' Practices of Resistance ...................... 241

Introduction ................................................................... 241

Telling subversive stories and refusing to accept racialised depictions:

Defence barristers' practices of resistance ...................................... 243

Narrating outside the framework of racialised narratives of bordering:

Tamir's hearing ............................................................ 244

Refusing to accept a judge's racialised depiction: Daniela's hearing ............... 255

Understanding the emergence of resistance to narratives of bordering

in sentencing hearings .............................................. 266

'The mute always speak': The communication of resistance by defendants

during sentencing proceedings .............................................. 270

Conclusion ................................................................. 284

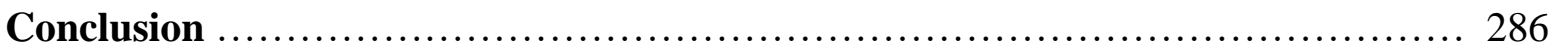

The significance of my findings to border criminology ............................. 289

The significance of my findings to research on racism in the

criminal justice system ..................................................... 298

The significance of my findings more broadly ............................... 303

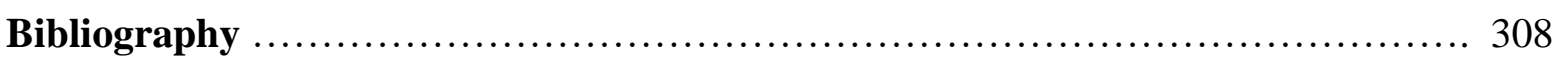




\section{Introduction}

I write the introduction to this thesis just over a month after the United Kingdom (UK) has following a referendum held in June 2016 - formally left the European Union (EU). In the aftermath of the vote to leave there was a tendency within the liberal press to frame 'Brexit', as the UK's departure from the EU has come to be known, as a dramatic shift in our contemporary history, an unexpected turn of events that could not have been foreseen. Thus, writing in the Guardian the day after the referendum vote, Jonathan Freedland (2016) opined: 'We have woken up in a different country'. In the same paper Suzanne Moore wrote, 'This country is not what many thought it was and now we will find out what we are really made of', and Polly Toynbee likewise lamented that 'Britain has turned its back on the world' (The Guardian, 2016). Yet, far from signifying change, Brexit actually represents perfect continuity with the recent past: for several decades now, the UK has been 'turning its back on the world'. Since the late 1980s and the beginnings of the current era of mass mobility, as migration across national territories has become an increasingly normal feature of human life, the UK - like other Western nation-states - has been pushing back against this development by cultivating different ways to fortify its borders. Brexit, therefore - which, following the completion of the current 'transition period' at the end of December 2020, will end 'free movement' for European Economic Area (EEA) nationals ${ }^{1}$ coming to the UK (Home Office, 2020) - can simply be seen as the latest measure designed to restrict the entry of 'unwanted' outsiders into the country. Similarly, the stigmatising depictions of migrants that were persistently circulated during the referendum campaign (Moore and Ramsay, 2017), which

\footnotetext{
${ }^{1}$ The European Economic Area (EEA) includes the 28 EU member states and also Iceland, Liechtenstein and Norway. Though Switzerland is neither a member of the EU nor the EEA, it is part of the single market, which means that Swiss citizens have the same rights as EEA nationals. At present, while the Brexit transition period is ongoing, rights of free movement for EEA nationals coming to the UK are still in operation - meaning that they can live and work here without obtaining a visa. Following the end of the transition period, however, on $31^{\text {st }}$ December 2020, these rights will come to an end (although not for Irish nationals) (Home Office, 2020).
} 
were aimed at justifying and ensuring the UK's departure from the EU, should be understood not in terms of a descent into 'anti-foreigner sentiment ... [that is] unprecedented in our lifetime' (Toynbee, 2016). Rather, the portrayals disseminated by politicians and large sections of the media in the run-up to the vote demonstrated a striking continuity with those mobilised at other points in the recent past (Burnett, 2016). Consequently, the negative representations of migrants that dominated during the Brexit campaign can be viewed more accurately through the lens of consolidation and intensification; that is, as the reinvigorating and re-energising of present-day anti-immigration narratives. ${ }^{2}$

As border control has solidified as a contemporary obsession for the UK - just as, as I have suggested, it also has for other Western nation-states - criminologists have increasingly paid attention to these developments. In particular, scholars within criminology have focused on the growing entanglements between immigration enforcement and the criminal justice system, and the changing nature of criminal justice under conditions of mass migration and its control. Indeed, during the seven years that I have been researching and writing this thesis, 'border criminology', as this new area of criminological study has come to be known, has really come of age. A significant literature now exists, which has thus far taken in an array of empirical developments and conceptual concerns, and covered a range of national jurisdictions. In the most recent edition of the Oxford Handbook of Criminology, border criminology, for the first time, has been assigned its own chapter (Bosworth, 2017) - and a number of UK universities, including the university at which I am studying, now offer criminological courses on migration and border control. Even as the study of border criminology has developed significantly, however, little sustained attention has been paid

\footnotetext{
${ }^{2}$ In identifying continuity between the negative depictions of migrants disseminated during the Brexit referendum campaign and those circulated at various other points in the recent past, I should make it clear that I do not mean to downplay or minimise the effects of Brexit's consolidation and reinvigoration of antiimmigration narratives. As I go on to explain in this introduction, anti-migrant depictions should be understood through the lens of race and racism - and, as the Institute for Race Relations has documented (Burnett, 2016), there was a surge in racist attacks in the immediate aftermath of the Brexit referendum, which targeted people who had migrated to the UK as well as British citizens from racially minoritised groups.
} 
within the existing literature to anti-immigration narratives - despite the fact that, as the example of Brexit indicates, these depictions are an integral element of the machinery of present-day border enforcement. That is, they function to legitimise and make possible the restrictions and exclusions of actual immigration control. In this thesis, therefore, I attempt to start filling this gap in the literature. Thus, I centre the anti-immigration narratives that are disseminated by the UK government and media in my analysis, and I ask how these might be percolating and permeating into one particular aspect of the criminal justice process: the practice of the sentencing hearing. In doing so, my research works to uncover and reveal some of the more subtle effects that the current obsession with migration control might be having on England and Wales' criminal justice system.

Race and racism are also central to this thesis. As Coretta Phillips and colleagues have recently argued, criminology as a discipline remains 'analytically white' (2019, p.13): almost twenty years on from Phillips and Bowling's (2003) proposal for the formulation of minority perspectives in criminology, it is still the case that race is 'typically relegated to the periphery of the discipline' (Phillips et al., 2019, p.4). Criminology's neglect and marginalisation of race and racism has been inherited by border criminology. Although some of the more recent interventions within this new sub-field have begun to challenge criminology's 'silence of race' (Parmar, 2016b, p.61), in many of the earlier and foundational contributions to criminological scholarship on migration and border control considerations of race were 'usually implicit but seldom explicit' (Garner, 2015, p.202; see also Phillips et al., 2019; Parmar, 2018a; Bowling, 2013). Outside of the academy, indeed, there has also been a persistent reluctance to centralise race in the understanding of the anti-immigration narratives circulated by the government and media in the contemporary era, and to name these specifically as racist depictions. During the so-called refugee 'crisis' 3 in 2015 , for example,

\footnotetext{
${ }^{3}$ I explain in Chapter One why I refer to the significant increase in the number of refugees making their way to Europe in 2015 as a so-called 'crisis'.
} 
leading non-governmental organisations censured the UK government for its 'de-humanising language' (Refugee Council, 2015) and 'nasty rhetoric' (Amnesty International UK, 2015) in describing the refugees trying to make their way to Europe. It was noticeable, however, that within these critiques the term 'racist' was never explicitly used.

Yet, as I explain in the thesis, it is almost only ever people migrating from the Global South, most of whom are not white, as well as those from Southern and Eastern Europe, who have often been deemed to be 'not quite white', who are targeted by these problematising narratives. Moreover, anti-immigration depictions disparage and stigmatise those whom they target in a very particular way: that is, by racialising them, by constituting them through the socially constructed category of race - in order to insist that they are inherently different and deviant (Garner and Selod, 2015; Murji and Solomos, 2005). Recognising the specifically racialising properties of these narratives, and how they essentialise and fix non-white and 'not quite white ${ }^{4}$ migrants as intrinsically deviant, is critical for then understanding how these depictions - which, as I show, can be detected in sentencing proceedings - are being put to work in this particular context. As I demonstrate, racialised narratives about 'unwanted' migrants are being mobilised during sentencing hearings in order to frame non-white and 'not quite white' migrant defendants as naturally suspect and as problematic in themselves - and, through this, to help produce them as punishable.

\section{Overview of chapters}

The thesis is divided into two parts. In the first part, I lay out the conceptual foundations for my research. Thus, I begin in Chapter One by situating my thesis in relation to the existing

\footnotetext{
${ }^{4}$ I use the terms 'non-white' and 'not quite white' throughout the thesis, as a convenient way of demarcating which migrants, specifically, racialised narratives of bordering target and stigmatise - and which migrants, therefore, my research is concerned with and focused on. As I use the term 'non-white', however, I fully recognise its problematic nature: that it 'brings with it a suggestion of something lacking, and of a deficiency' (Eddo-Lodge, 2017, p.xvi), and reinforces whiteness as the norm. I recognise, too, that the term 'not quite white' is also problematic.
} 
literature in border criminology. As I explain, in tracing the effects of immigration enforcement on the established criminal justice system, criminologists have typically imagined border control as a series of policies and legislative measures and focused on the overt changes wrought on the police, courts and prisons by the literal activities of immigration control. By looking outside of criminology, however, towards the literature on 'everyday bordering', I argue that we can start to conceptualise border enforcement in a more expansive manner. Specifically, I suggest that we can begin to understand the antiimmigration narratives circulated by the UK government and media in the current era as themselves a form of bordering practice - that these depictions can be seen to constitute 'bordering work' (Johnson et al., 2011, p.61). From this perspective, therefore, if we are interested in how the contemporary criminal justice system is being touched and marked by immigration enforcement, we should also be paying attention to its potential penetration by these narratives - which, I suggest, we can understand as dominant or hegemonic narratives of bordering. This chapter also begins to address the 'silence of race' that has marked much of the criminological literature on migration and border control. As I explain, from their very inception the literal immigration controls implemented by the UK have been structured by racism. It seems clear, then, that - as some of the more recent contributions to border criminology have set out - race should provide a central analytical frame for criminologists researching borders and bordering.

In Chapter Two, I proceed to map some of the key dominant narratives of bordering disseminated by the UK government and media in the contemporary period. Following on from my emphasis on the centrality of race to research on borders and bordering in Chapter One, I demonstrate how these narratives can be most fully understood through the framework of racism. As I highlighted above, therefore, these narratives almost only ever target people from the Global South, most of whom are not white, and those from Southern and Eastern Europe, who have often been deemed to be 'not quite white'. Crucially, moreover, the way 
that they stigmatise these 'unwanted' migrants is by racialising them - that is, by constituting them specifically in terms of racial 'otherness' and difference. Importantly, though, as these narratives do this they never utilise the overt language of race; even when they are problematising people with darker skin they never categorise and disparage through reference to biological or somatic difference. Instead, I document how narratives of bordering fix unwanted migrants as racially deviant using more coded language. Sometimes, then, they achieve this through ideas about 'culture', or via the register of nationality - as well as by means of a more 'abstract' (Garner, 2013, p.504) racialising process, which essentialises and homogenises non-white and 'not quite white' migrants as 'a group with similar pathological characteristics' (2013, p.508). Drawing on David Goldberg's (2015) work, I suggest that one way of understanding the more muted and sanitised nature of these racialised depictions is through the lens of post-raciality.

In Chapter Three, I introduce the final layer of my conceptual foundations by turning my attention to the specific stage of the criminal justice process on which my research is focused: the practice of the sentencing hearing. In the first half of the chapter, I suggest that by continuing to use the framework of narrative we can develop an understanding of what is going on during sentencing proceedings. Thus, by approaching the accounts delivered by legal professionals during the hearing as individual narratives, we can start to see that these are not straightforwardly factual or representational. Rather, we can understand them as plotted, purposive versions of the incident being dealt with by the court, each of which is concerned with what I refer to as the defendant's punishability.

In the second half of the chapter, I connect racialised narratives of bordering and the sentencing process, arguing that by approaching individual sentencing narratives from a sociological perspective and understanding them as 'social acts' (Ewick and Silbey, 1995, p.197) it is possible to see how dominant depictions of unwanted migrants might be seeping into them. I then theorise how, specifically, these hegemonic representations might be being 
put to work in the particular context of sentencing proceedings. Thus, I explain that from the existing literature on gendered and racialised narratives in the trial, it seems likely that racialised narratives of bordering will be mobilised to produce defendants as inherently bad and deviant, and so as problematic in themselves - in order to help construct them as punishable. And, conversely, it also seems likely that these racialised narratives will be negotiated, and negated, to insist that defendants are not intrinsically bad and deviant but rather that they are good and deserving migrants - in order to assert that they can be sanctioned less severely. I argue, therefore, that in sentencing hearings for non-white and 'not quite white' migrants, racialised narratives of bordering are likely to be mobilised and navigated by legal professionals as part of the construction and negotiation of defendants' punishability.

In the second part of the thesis, I move from conceptual foundations to my empirical data: the sentencing hearings that I observed in three Crown Courts in London - Isleworth, Southwark and Wood Green - across a two-year period. I begin, in Chapter Four, by giving an account of how I conducted my observations, and the methodological, epistemological and ethical issues that I encountered. One of the most significant issues that I faced during my fieldwork was identifying relevant sentencing hearings to observe. At the time that I was carrying out my observations, the criminal courts were not routinely identifying and recording the nationality of defendants. ${ }^{5}$ So, there was no clear way to ascertain prior to a specific hearing if it was for someone originally from the Global South or Southern and Eastern Europe, who are the focus of my research. As I explain, I initially resisted relying on racialised and stereotyped assumptions - for instance, selecting hearings on the basis that an interpreter had been requested, and/or because the defendant's name 'sounded foreign' - in my efforts to 'find foreigners' (Kaufman, 2012, p.701). Ultimately, however, practical issues

\footnotetext{
${ }^{5}$ As I explain in Chapter One, this has now changed. Following the implementation of the Policing and Crime Act 2017, defendants are now required to state their nationality at their first court appearance.
} 
that arose - including the volume of data I was beginning to collect and the need to complete my fieldwork within a 'reasonable' period of time - meant that I did end up adopting this approach.

Another critical issue considered in this chapter is the impact of my privileged racial identity on my research. As I explain, during the research process I have received important reminders about how my position as someone who is white and British, and who has therefore never experienced racist discrimination, is influencing and indeed limiting my investigation of racism in the courts against migrants who are deemed unwelcome. In exploring this in this chapter, then, my aim is not to 'solve' the impact of my social positioning simply by acknowledging or 'confessing' it (Phillips and Earle, 2010). Rather, I attempt to take its effects seriously and to think through carefully how it will have shaped the knowledge that I have produced.

I also explain in Chapter Four that across the two years I was conducting observations, I watched 25 sentencing hearings for people originally from countries in the Global South or Southern and Eastern Europe - and that in 16 of these hearings, it was possible to detect racialised narratives of bordering. In Chapter Five, I begin my analysis of the 16 hearings where narratives of bordering could be traced. Thus, I focus in this chapter on 13 hearings where two of the key dominant narratives of bordering - that of the abusive immigration cheat who manipulates the UK's immigration system, and that of the parasitical scrounger who exploits the welfare benefits system - came through. As I show, the pattern theorised in Chapter Three about how these racialised depictions might be being put to work in sentencing proceedings was detectable. Across these hearings, then, defendants were framed through the narrative of the immigration cheat, or the parasitical scrounger, in order to essentialise them as recognisably and inherently deviant and so to help produce them as punishable. They were also negotiated and negated as intrinsically problematic like this in various ways, in order to insist that they were good and deserving migrants and so that they 
could be afforded leniency. I highlight, too, that in a number of hearings what I refer to as narratives of limited inclusion came through. In particular, the narrative of migrants who 'work hard', 'pay taxes' and 'contribute to the UK' - which has been disseminated by the government to separate limited numbers of unwanted migrants from the figure of the scrounger - was mobilised in several hearings. This functioned as another way of insisting on defendants as worthy and desirable in themselves, and so asserting that they could be punished less severely.

Alongside this overarching pattern I also document some smaller patterns and routines across these hearings - including when, or in what sort of circumstances, racialised narratives of bordering tended to be deployed. As I explain, ideas of inherent deviance often seemed to be appealed to by the prosecution, or the judge, in quite particular circumstances. Specifically, then, such ideas often seemed to be mobilised when a defendant's presence in court appeared to be based on questionable charges, or when a severe sanction was being pushed for or imposed; thus, on occasions when more than legal legitimation for the punishment seemed to be needed. Against this pattern of specificity and context, however, I also saw a series of hearings where defence barristers worked to insist that their client was not a parasitical scrounger simply as a matter of course. So, they countered this racialised narrative even though there had been no suggestion that the defendant might be viewed in this way. From these hearings, therefore, it seemed that distancing the defendant from the figure of the scrounger might be emerging as a standard feature of mitigating pleas in nonwhite and 'not quite white' migrant sentencing proceedings. That is, contesting this dominant, racialised narrative appeared to be developing as a staple way of constructing these defendants as less punishable.

In Chapter Six, I turn my attention to defence barristers and defendants' practices of resistance. As I explain in Chapter Five, when defence barristers contested the framing of their clients as abusive immigration cheats, or parasitical scroungers, they typically did this 
by negating or inverting these racialised narratives, or by appealing to narratives of limited inclusion. In this way, then, they inadvertently reinforced the racist framework of narratives of bordering. As they insisted that their individual clients were good and deserving migrants, they implicitly upheld the legitimacy of the idea of inherently bad and deviant migrants - and so they acknowledged that abusive immigration cheats and freeloading spongers definitely exist. In the three remaining hearings where narratives of bordering could be detected, however, which I examine in this chapter, I traced something different. Thus, in two of these hearings, I saw defence barristers take a more oppositional approach, as they challenged the construction of their clients through such racialised depictions more radically and subversively than I witnessed in other proceedings. In the third hearing, I saw the defendant himself behave in a resistant manner, as - in spite of the routine marginalisation of defendants during court proceedings - he appeared to refuse legal professionals' racialised portrayal of him through his non-verbal reactions and behaviour. As I explain in this chapter, it is important not to romanticise or overplay the effects of the resistance displayed by the defence barristers and defendant during these hearings. Nonetheless, in all three hearings there was some disruption to the process of sanctioning the defendants. That is, as the framing of these defendants through racialised and 'othering' depictions was more clearly unsettled and challenged by the more resistant interventions that were detectable in these hearings, the imposition of punishment on them began to seem less natural and inevitable.

I bring the thesis to a close in the Conclusion by asking: what is the significance of what I have conceptualised and traced across the previous six chapters? What do my research findings actually mean? In one sense, as I set out from the very start of the thesis, my research builds on the knowledge that has thus far been produced by border criminologists. So, by uncovering how racialised narratives of bordering are being deployed during sentencing hearings, my research aids our understanding of the ways in which immigration control is imprinting itself on the contemporary criminal justice system. 
Alongside this, what I have traced might also be viewed in relation to other fields of criminological research: specifically, to the literature on racism and the criminal justice system - and, in particular, to research that has examined racist discrimination in the courts and sentencing. As I explain in the Conclusion, over the past few decades quantitative analyses of racism in sentencing decision-making have produced mixed findings. My qualitative approach, then, and focus on sentencing proceedings, might be understood as examining and revealing racism in sentencing in a different way. As my research demonstrates how racialised narratives of bordering were mobilised and countered as part of the construction and negotiation of defendants' punishability, indeed, it can be seen how - in those hearings where these narratives were detectable - racial demarcation and racist expression played a significant role. That is, in these hearings, racialised depictions of unwanted migrants were appealed to and navigated by legal professionals to help facilitate the proceedings and keep them moving.

Finally, I argue that what I have documented in sentencing hearings has consequences that reach beyond the confines of the criminal justice system. As narratives of bordering are mobilised during sentencing proceedings, what is playing out is more than simply the court's reproduction and repetition of these racialised ideas. Rather, through this the court has become part of 'the constitution of its own context' (Ewick and Silbey, 1995, p.211). In other words, criminal courts can be understood as sites where notions of the racial difference and inferiority of non-white and 'not quite white' migrants are being produced and sustained and, therefore, courts can be seen as participating in the wider normalisation and naturalisation of the racist border. Yet, as I also emphasise, resistance to these racialised ideas can sometimes be detected in sentencing proceedings. As defence barristers and defendants challenge narratives of bordering, then, they do not simply disrupt the practice of the sentencing hearing. They also dispute the reality of racially different 'unwanted' 
migrants, and so refuse the inevitability of the racist border. In doing so, they point towards the possibility of a world in which such oppression and exclusion does not exist. 


\section{Part I:}

\section{Conceptual Foundations}




\section{Chapter 1}

\section{Setting the Scene: Centring Narratives and Race in Border Criminology}

\section{Introduction}

We live in an age of mass migration. According to the United Nations (2017), almost 260 million people currently live outside the countries they were born in. As the sociologist Les Back has noted, in the twenty-first century, 'The human population is more mobile than at any point in its history' (2007, p.31). And yet, as he also highlights, 'there remains profound anxiety about the global movement of persons' (2007, p.38). Though the movement of people across national territories is a defining characteristic of the contemporary era, claims that we now inhabit a borderless world are obviously misplaced (Johnson et al., 2011; Garner and Moran, 2006). As human migration has become commonplace and normal, Western nationstates have increasingly taken steps to shore up and secure their borders.

While the prominence of the border in the current age has been identified and scrutinised by scholars across a range of academic disciplines, criminologists, as Katja Franko Aas and Mary Bosworth point out, have been 'relatively slow' (2013, p.vii) to turn their attention this way. In recent years, however, the initially sparse criminological literature on mass migration and its control has transformed into a rapidly expanding sub-field, marked out in its earlier stages as the 'criminology of mobility' (Pickering, Bosworth and Aas, 2014; Aas and Bosworth, 2013) but now more often referred to as 'border criminology' (Bosworth, Parmar and Vázquez, 2018; Bosworth, 2017, 2016). Seeking to 'bring migration and borders to the criminological home front' (Aas and Bosworth, 2013, p.viii), critics working in this field have drawn attention to the growing convergence between immigration enforcement and the criminal justice system in the present era and the way that mass mobility and its control is reconfiguring and reshaping criminal justice (Aliverti and Bosworth, 2017; Bosworth, 2016). On the one hand, as border criminologists have highlighted, criminal justice practices and 
powers now reach beyond their traditional realms and functions, as they are being deployed in immigration systems. The 'coercive and intrusive powers' (Weber and Bowling, 2004, p.207) that were previously the preserve of the police, for instance, have been extended to immigration officers and border agents (see also Bowling, 2013) and the prison, in the form of the 'new carceral space' (Bosworth, 2017, p.374) of the immigration detention centre, is being used to effect expulsion (see also Bosworth and Turnbull, 2015; Bosworth and Kaufman, 2011; Bosworth, 2008). At the same time, it has been documented how the core agencies and institutions of the established criminal justice system - including the police, courts and prisons - have been altered and transformed, as they have been injected with policies and practices of border control.

It is the second trend identified here that provides the starting point for my thesis: the changing shape and contours of traditional criminal justice agencies and institutions under conditions of mass migration and its control. In this opening chapter, then, I survey the literature that has developed in this area, focusing specifically on analysis of the impact of border enforcement on the criminal justice system in England and Wales, and I situate my own research in relation to this. As I explain, in tracing the effects of border control on criminal justice agencies and institutions, criminologists have typically imagined border enforcement primarily in terms of policies and legislation and as contained within the literal activities of immigration control. I suggest, however, that by conceptualising border control more expansively, it is possible to think about further, more insidious ways in which the contemporary fixation with immigration regulation might be marking and permeating the established criminal justice system.

Alongside this, I distinguish my approach in this thesis from much of the existing criminological research on migration and borders in one other key way. Although critics in this field have not ignored issues of race and racism, it is nonetheless the case that, as Alpa Parmar puts it, race has often been positioned at 'the borders of border scholarship' (2018b, 
p.187). In line with some of the more recent interventions in border criminology my analysis emphasises, conversely, that race runs through and is integral to the project of migration control. In this thesis, therefore, I take the position that in criminological research on borders and bordering, race and racism must provide a central analytical frame (Parmar, 2018a; Garner, 2015; Bowling, 2013).

\section{The changing contours of the criminal justice system under mass migration and its control}

A growing literature within the recently established criminological sub-field of border criminology has, as I suggested above, drawn attention to the changing contours of the traditional criminal justice system in England and Wales in the contemporary era and the way that it is being altered and reshaped by the border. Within this, one of the key developments that has been pointed to is how, through a raft of immigration-focused policies and legislation, criminal justice agencies and institutions are increasingly moving away from conventional imperatives in their dealings with non-British citizens and are being 'redirected toward the project of migration control' (Kaufman and Bosworth, 2013, p.177). The prison, arguably, has undergone the most significant changes in this respect and offers the clearest example of this shift. Thus, I begin, somewhat counter-intuitively, with the institution that functions as the endpoint of the criminal justice system and the research that has documented its changing function in recent years.

\section{The prison and immigration enforcement}

Prisons in England and Wales have, in fact, long been linked to border control. Before the development of a separate immigration detention estate, for instance - which began in earnest during the 1990s as the number of asylum applications in the UK started to increase significantly - the relatively small number of people locked up under immigration powers at this point were generally held in prison (Bosworth, 2014; Kaufman and Bosworth, 2013). 
Alongside this, legislation that ties imprisonment for a criminal offence to being expelled from the UK has been in place for some time. The 1971 Immigration Act introduced 'conducive' deportation, giving the Home Secretary the power to deport a non-British citizen where it is deemed to be 'conducive to the public good' - a provision that has often been used against people convicted of criminal offences and especially those imprisoned as a result (Dubinsky, 2012; Cheney, 1993; Gordon, 1983b). Research conducted during the 1990s and early 2000s also documented associated developments in prison policy and practice, including restrictions on day release and transfer to open conditions for non-citizens, which were aimed at facilitating the expulsion of these prisoners from the UK (HM Inspectorate of Prisons, 2006; Cheney, 1993; Tarzi and Hedges, 1990).

While links between the prison and the border go back over decades, then, in more recent years they have intensified considerably and become much more formalised. In April 2006 the then Home Secretary, Charles Clarke, was forced to reveal that over the preceding seven years around 1,000 non-British citizens had been released from prison without being considered for deportation. The foreign national prisoner 'crisis', as it came to be known, resulted in Clarke's resignation and 'catalysed legislative and policy shifts' (Kaufman and Bosworth, 2013, p.174) which saw the prison explicitly oriented towards border control.

Soon after the so-called 'crisis' hit the then Labour government introduced legislation which meant that the pursuit of deportation when a non-citizen is sent to prison shifted from a discretionary decision to, in many instances, a mandatory requirement. Under 'automatic' deportation - a measure which is contained in the UK Borders Act 2007, and which came into force in 2008 - deportation must be pursued in all cases where a non-British citizen is sent to prison for 12 months or more, 'unless certain exemptions or exceptions are made out' (Dubinsky, 2012, p.70). These exceptions include if deportation would breach the person's rights under the European Convention on Human Rights or the Refugee Convention, or if it would breach their rights under EU treaties. According to Laura Dubinsky, this latter 
exception means that "arguably, it is never lawful to make an "automatic" deportation order against an EEA national' (2012, p.75). While they are not subject to automatic deportation, however, EEA nationals do not escape the threat or actuality of ejection from the UK. European law - which, at the time of writing this thesis at least, continues to govern their deportation ${ }^{1}-$ simply means that a slightly higher threshold has typically been applied in these cases, with the Home Office ${ }^{2}$ normally pursuing expulsion where an EEA national is sent to prison for two years or more (Bosworth, 2017, 2016). ${ }^{3}$ The legislative change of automatic deportation was coupled with an increased focus on deporting foreign prisoners generally: following the 2006 'crisis' the Criminal Casework Directorate, which is the Home Office unit responsible for the deportation of imprisoned non-citizens, 'grew to thirty-five times its original size' (Kaufman, 2015, p.89). Alongside this, in 2009 a new prison policy was also introduced. This policy, known as 'hubs and spokes', was implemented with the aim of identifying all foreign nationals in prison and ensuring that any prisoner liable to deportation would be ejected from the UK (Kaufman, 2015, 2013).

In her research on the 'new purpose of the prison' (2015, p.iii), Emma Kaufman documents how this policy has played out. Under 'hubs and spokes', the prison estate in England and Wales has been 'reorganized ... around the concept of foreignness' (2015,

\footnotetext{
${ }^{1}$ As I highlighted in the Introduction, following a referendum that was held in June 2016 the UK formally left the EU at the end of January 2020. However, at the time of writing this thesis the Brexit transition period is still ongoing; thus, the UK will remain subject to EU law until $1^{\text {st }}$ January 2021.

${ }^{2}$ In April 2013 the executive agency responsible for border control, the UK Border Agency (UKBA), was abolished by the then Conservative Home Secretary, Theresa May, and immigration functions were brought back into the central government department of the Home Office. Currently, two separate Home Office divisions, UK Visas and Immigration (UKVI) and UK Immigration Enforcement (UKIE), deal with all immigration matters. To avoid confusion, I simply refer to the 'Home Office' throughout the thesis (rather than to the specific agencies and divisions involved in immigration control at various points over the years) as the Home Office has always retained overall responsibility for immigration matters. I also sometimes refer to 'the immigration authorities', or simply to 'immigration'.

${ }^{3}$ In fact, the Home Office has also applied thresholds lower than two years' custody in the deportation of EEA nationals. From April 2009 Home Office policy was to consider deportation where an EEA national received one year or more in prison for a sexual, violent or drug-related offence; in January 2014, this one-year threshold was broadened out and applied to all convictions. More recently, from October 2015 Home Office policy has required that all EEA nationals convicted of a criminal offence - whether they receive a custodial sentence or not - are referred for consideration of deportation (Home Office, 2019b). It is important to note, too, that even if a non-EEA national who has been convicted of an offence does not meet the criteria for automatic deportation, they will still be considered for deportation under the 'conducive to the public good' provisions of the 1971 Immigration Act (Home Office, 2015c).
} 
p.89); thus, non-citizens have been concentrated in specific prisons, known as 'hubs', which include some prisons designated as 'foreign national-only'. In each 'hub', there are immigration staff who work there permanently; these staff members liaise regularly with immigration 'case owners', based in the Criminal Casework Directorate, who are responsible for taking decisions on prisoners' immigration cases. Prisons marked out as 'spokes' hold smaller numbers of non-citizens, and although immigration staff have not become a regular part of their workforce immigration officers nevertheless visit these prisons. Indeed, in both hubs and spokes immigration staff routinely hold 'surgeries' during which they carry out tasks to 'progress' prisoners' immigration cases, such as fingerprinting and photographing them, as well as interviewing them to ascertain, for example, their nationality (see also Kaufman, 2013).

Alongside the increasing presence of immigration staff in prisons, the prison's traditional workforce has also been co-opted to perform immigration-focused duties. In prisons where immigration officers are not 'embedded' permanently, for instance, prison staff are expected to identify all non-British citizens received into custody and refer them to immigration. More broadly, in both hubs and spokes prison officers are also regularly required to carry out tasks such as collecting prisoners' travel documents, searching prisoners' cells for passports, contacting embassies, serving legal notices to prisoners on behalf of the Home Office and promoting 'voluntary departure' programmes, such as the Facilitated Return Scheme (Kaufman, 2015, 2013). As Kaufman explains, then: 'It is simplifying only slightly to say that the policy has recast Prison Service staff as quasiimmigration officers' (2015, pp.94-95). Under the hubs and spokes policy prisons, moreover, are also required to help 'maximize' $(2015, \mathrm{p} .91)$ the capacity of the immigration detention 
estate by continuing to hold foreign nationals even after they have completed their criminal sentences, who are being detained under immigration powers only. ${ }^{4}$

Through this policy, then, as well as the legislative changes already traced, Kaufman contends that prisons in England and Wales have been 'transformed ... into sites for border control' (2015, p.7). As she acknowledges, foreign nationals are, overall, a minority within prison $^{5}$ - and, thus, '[f]or many people concerns about citizenship, nationality, and expulsion may never enter into prison life'. Nevertheless, as she argues, 'for a significant group of prisoners, penal institutions now serve as detention centres, staff are basically border agents, and the end of the criminal sentence is "removal" from the United Kingdom' (2015, p.111). Indeed, following the introduction of automatic deportation and the hubs and spokes policy there has been a five-fold increase in the number of foreign prisoners expelled from the UK. ${ }^{6}$ Analysing this 'new kind of prison' (Kaufman, 2015, p.111) against the goals and objectives to which imprisonment has traditionally worked, some border criminologists have contrasted the increasing emphasis on containment and expulsion in the present era with the prison's conventional focus on rehabilitation and reintegration. Bosworth and Kaufman, for instance, have argued that the new purpose we see emerging in the prison 'marks a notable shift away from the post-Enlightenment use of imprisonment as a tool to correct and ultimately return citizens to the polity' $(2011, \mathrm{p} .453){ }^{7}$ As other scholars have suggested,

\footnotetext{
${ }^{4}$ As Kaufman highlights, the practice of keeping non-citizens in prison following the end of their sentence under immigration powers is not a new one. The hubs and spokes policy did not introduce this practice, then; rather, it 'condones it in explicit terms' (2015, p.91). A report by the charity Bail for Immigration Detainees (2014) highlighted that at the end of 2013 over 1,000 people were being held as immigration detainees in prison. More recently, however, this number has dropped. At the end of September 2019, for instance, there were 304 people detained under immigration powers in prison (Home Office, 2019d).

${ }^{5}$ Foreign nationals currently make up about $11 \%$ of the prison population in England and Wales (Prison Reform Trust, 2019).

${ }^{6}$ In 2005, prior to the foreign prisoner 'crisis', around 1,000 non-citizen prisoners were deported from the UK (Fekete and Webber, 2010); the annual figure now hovers between 5,000 and 6,000 (Migration Observatory, 2019).

${ }^{7}$ As critics writing from a postcolonial perspective have emphasised, although 'within the metropole throughout most of the twentieth century the dominant penal discourse was reformative with a focus on social inclusion ... in the colonial context state punishment was predominantly exclusionary' (Moore, 2014, p.36). Thus, the focus on exclusion and incapacitation that, as I note below, has been identified as now more characteristic of imprisonment in England and Wales can be seen not as 'a reactionary departure from a previously civilising and
} 
however, Foucault's (1977) classic conception of the prison as a site of training and reform now looks rather outdated. With its extended modes of confinement, and its 'warehousing' of prisoners, locked up in their cells for much of the day, the prison today functions more often as a 'circuit of exclusion' (Rose, 2000, p.333) or a 'death-world' (Lamble, 2013, p.244) for those held within it. Even if we reject the idea of the general purpose of the contemporary prison as rehabilitation and reintegration, however, it can still be argued that, in its dealings with non-citizens, imprisonment has shifted away from conventional imperatives. As immigration-focused policies and practices have been injected into them, prisons, for noncitizens, have become less linked to sanctioning for a criminal offence, 'less tied to punishment and to the terms of the criminal law' (Kaufman, 2015, p.111), and more focused on securing the border.

\section{The police and the border}

Other branches of the criminal justice system in England and Wales have also found themselves increasingly geared towards border control - take, for instance, the police. As with the prison it is, first of all, important to highlight that police involvement in immigration enforcement 'is not a new phenomenon' (Parmar, 2018a, p.121) and that this also goes back a long way. Bowling and Phillips note, for example, how research conducted during the 1960s and 70s 'uncovered evidence that ordinary policing often involved checking immigration status, such as asking for passports, for instance, when people from ethnic minorities reported crimes of which they had been victims' (2002, p.130; see also Chigwada, 1991). This is a practice which continues, albeit in a slightly different form, in the present day. A 2018 BBC investigation found that more than half of UK police forces said they referred victims and

progressive social history'. Rather, it can be understood as a continuation of the British state's 'long history of penal excess' (Moore, 2014, p.31; see also Fonseca, 2018). 
witnesses of crime to the Home Office for immigration checks (Nye, Bloomer and Jeraj, 2018). ${ }^{8}$

Alongside these 'opportunistic' practices, during the 1970s and 80s the police were also involved in immigration enforcement in a 'more systematic' (Weber and Bowling, 2004, p.204) way. The Metropolitan Police's Illegal Immigration Intelligence Unit, for instance, carried out major immigration raids on workplaces as well as on people's homes (Weber and Bowling, 2004; Gordon, 1983b). Additionally, until the early 1990s the Metropolitan Police operated the Alien Deportation Group which, as its name indicates, carried out forced deportations. It was only following the attempted deportation of Joy Gardner in July 1993, and her death as a result of the restraint the police used on her, ${ }^{9}$ that this unit was disbanded (Bowling and Phillips, 2002; Weber, 2002). While the police's earlier links to border control were by no means negligible, then, in recent years - as with the prison - these have intensified and formalised, and immigration activities have become more clearly embedded as 'part and parcel of everyday police work' (Aliverti, 2015, p.218; see also Parmar, 2018a; Bowling, 2013).

Increasingly central to the police's involvement in migration control is Operation Nexus, an initiative that was first introduced in London in 2012 and has subsequently been rolled out by police forces in other parts of England and Wales, including the Midlands and Greater Manchester (Parmar, 2018a). As Parmar explains, Operation Nexus 'formally partners the police with immigration control'; its basic premise is that 'immigration officers are now stationed at police custody suites ... in a bid to identify foreign national offenders

\footnotetext{
${ }^{8}$ Following the $\mathrm{BBC}$ investigation new guidance was issued to the police to apparently halt this practice. However, the 'revised' policy continued to permit the referral of victims of crime to the immigration authorities (National Police Chiefs' Council, 2018). The campaign groups Liberty and Southall Black Sisters have now lodged a 'super complaint' against this practice (Grierson, 2019), and have also issued legal proceedings specifically against the Metropolitan Police (Townsend, 2019).

${ }^{9}$ Bowling and Phillips describe what happened to Joy Gardner in the following way: 'Joy Gardner, a black woman of Jamaican origin, had overstayed her visa and was visited by the Alien Deportation Group. Her wrists were handcuffed to a leather strap around her waist, bound by a second belt around her thighs and a third one around her ankles. As she lay on the floor, 13 feet of adhesive tape was wound around her head and face. Mrs Gardner collapsed and died in hospital a few hours later' (2002, p.131).
} 
more swiftly and arrange their detention pending removal from the UK' (2018a, pp.111-

112). Within this overarching approach, there are two distinct 'strands' (Home Office, 2017, p.4) to the scheme. Under the first strand, 'Nexus Custody', the police work alongside immigration officers in custody suites to identify foreign nationals, conduct immigration checks on them and, if they do not have valid leave to remain, ensure their expulsion via administrative removal ${ }^{10}$ from the UK. A report by the Chief Inspector of Borders and Immigration into how Operation Nexus was operating two years after it had been introduced pointed to the significant rise in removal rates following contact with the police as a result of this aspect of the scheme. In 2011-12, when the Metropolitan Police were still relying on an immigration 'callout service' - that is, immigration officers could be contacted to attend police custody but were not permanently stationed there -418 non-citizens were removed from the UK after originally being encountered in London by the police. In 2013-14, however, after Operation Nexus had been introduced, there were 1,077 of these removals an increase of $158 \%$ (ICIBI, 2014).

Under the second strand of the scheme, 'Nexus High Harm', the police and immigration work together on the deportation of foreign nationals who have criminal convictions. Those who have had contact with the police but have not been convicted of anything are also targeted under this strand - so, deportation is pursued on the basis of police 'intelligence' (Home Office, 2017; Webber, 2015). The Chief Inspector of Borders and

\footnotetext{
${ }^{10}$ Legally, administrative removal is a different category of expulsion to deportation. Removal is used when someone has breached the UK's immigration regulations and legislation - for instance, if they have 'overstayed' a visa, or if they entered the UK without permission and so had no leave to remain in the first place (as I explain in the following section, many of these immigration breaches are also now criminal offences). Deportation is used when someone has been convicted of a criminal offence - or, as I document below, when they have not actually been convicted of an offence but it is claimed there is other evidence of their 'criminality'. As Bosworth explains, however, while removal and deportation are distinct legally, in practical terms they both 'have the same effect, banishing individuals and restricting their return within a period of time' (2017, p.384). It is worth highlighting, though, that while removal and deportation both come with bans on re-entry to the UK, usually for a period of 10 years (Right to Remain, 2019), if you are deported from the UK you will also be subject to a deportation order. This means that, even once the 10-year re-entry ban period has passed, you cannot re-enter the UK until the deportation order has been revoked. Moreover, the revocation of a deportation order is, ultimately, at the discretion of the Home Office (Dubinsky, 2012). Thus, a deportation order effectively constitutes an indefinite ban on re-entering the UK.
} 
Immigration has highlighted that, although some people dealt with under 'Nexus High Harm' are identified while they are in police custody, 'the majority of referrals will be generated by the police examining historic records' (2014, p.9). In fact, the legal charity the AIRE Centre, which brought a legal challenge against Operation Nexus in 2016, has emphasised that people targeted for deportation in this way include those whose criminal convictions are very old, who have not been re-convicted of an offence recently (Mogan, 2016). Under 'Nexus High Harm' foreign nationals without valid leave to remain may be targeted for deportation, rather than administrative removal, to enact a more robust form of ejection; deportation, unlike removal, comes with an indefinite ban on re-entry to the UK. ${ }^{11}$ Significantly, moreover, this strand is also being used to eject non-citizens who have leave to remain, including those who are permanent residents, as well as EEA nationals (Home Office, 2017) - who, for the moment at least, continue to have free movement rights and are permitted to enter and live in the UK.

As can be seen in the name it has been given, this aspect of Operation Nexus has been framed not so much in terms of immigration enforcement but as in keeping with the conventional activities and remit of the police - that is, as concerned with public protection and crime control. Indeed, the official guidance on the scheme emphasises that 'Nexus High Harm' is focused on 'foreign national offenders' whose 'conduct incurs significant adverse impact, whether physical, emotional or financial, upon individuals or the wider community' (Home Office, 2017, p.5). Yet, the low threshold adopted by this strand of the scheme - as I have highlighted, people can be targeted for deportation because of very old convictions or even when they have no convictions at all - should alert us to how little, in fact, concerns about addressing and preventing 'adverse impact' underpins its pursuit of expulsion. The cases of people actually targeted for deportation under 'Nexus High Harm' demonstrate this,

\footnotetext{
${ }^{11}$ See the explanation of the difference between administrative removal and deportation in Footnote 10, above.
} 
as well. Melanie Griffiths highlights that during her observations of Nexus-related appeals, one of the hearings she saw was for 'a 20 -year-old facing deportation to a country he left aged 5. He had four small convictions; for possession of a knife and failing to surrender to the police. His longest prison sentence was just eight weeks and he justified the knife as wanting protection after being victim of a stabbing for the third time' $(2017, \mathrm{p} .537)$.

I would suggest, then, that rather than accepting the official line on its crime prevention aims, 'Nexus High Harm' can be more accurately understood in terms of the growing density of the UK's border controls. In one of the earlier contributions to border criminology, Leanne Weber and Ben Bowling (2004) highlighted the increasingly diffuse nature of the border in the present period; that is, how border control no longer simply happens at the point of entry into the UK but is enacted through internal mechanisms, as well. They situated the police's involvement in immigration activities in terms of the expanding network of internal controls, alongside measures such as the recently introduced requirement, at that time, for employers to verify prospective employees' immigration status. As such, Weber and Bowling argued that police and employers' immigration checks could be seen as part of a 'second line of defence' (2004, p.199) against those who had managed to get past the UK's external border and into the country.

I say more about what has now been identified as 'everyday bordering' (Yuval-Davis, Wemyss and Cassidy, 2018), and connect the growing literature in this area with the criminological research on migration control, later in the chapter. At this point, however, understanding how the border has spread in the current era, and utilising the lens of a 'second line of defence', helps us to see how initiatives like 'Nexus High Harm' function as part of the UK's network of internal immigration controls. Using any form of 'criminality' - no matter how old, trivial or even unproven - to justify expulsion significantly expands the opportunities for ejecting people who have managed to get into the UK. Indeed, as it often targets people with valid immigration status, 'Nexus High Harm' might be seen as providing 
a 'third line of defence'. That is, even for those who have entered the country legitimately and have secured the right to stay permanently there is, nevertheless, the possibility of using ideas of criminality and supposed threat or harm as a way of later ejecting them.

\section{The courts and immigration control}

Migration control has also made its way into the branch of the criminal justice system that this thesis is focused on: the courts. In her analysis of immigration 'crimes' - that is, border violations which have also been converted into criminal offences - Ana Aliverti (2013a) highlights that immigration breaches have been part of the criminal law for a long time. From the mid-1990s, however, as the number of asylum applications in the UK started to increase, the number of immigration offences legislated for also grew significantly - and, alongside this, there was 'an enhanced and more systematic enforcement of such crimes' (2013a, p.37). While it remains the case that the majority of immigration breaches are not prosecuted, but are dealt with through immigration processes instead, since about 2000 onwards the courts have, therefore, been dealing with immigration offences on a much more regular basis.

Aliverti highlights that, as they oversee immigration-related hearings and sanction people who plead guilty to or are convicted of these offences, magistrates and judges never question the legality of immigration 'crimes' and in fact often refer to the need to maintain the integrity of the UK's border controls in their sentencing remarks. In this way, she argues, they can be understood as essentially participating in border enforcement themselves. As she explains: 'In practice, the embracing of these policies by judges and magistrates has the effect of extending the exercise of immigration controls onto them' (2013a, p.116). Indeed, her research reveals how judges and magistrates participate in border control not simply by overseeing and upholding the prosecution of immigration offences - but also by actively working to eject those being sanctioned for these offences from the UK, through the specific punishments they choose to impose. As Aliverti (2013b) sets out, immigration status and 
whether someone is 'removable' from the $\mathrm{UK}^{12}$ are factors that are formally irrelevant to criminal sentencing. In practice, however, people being sanctioned for immigration offences who have leave to remain, or who are not removable from the UK, typically receive suspended prison sentences; those who do not have valid immigration status and who are removable, on the other hand, are generally sent to prison. She argues, therefore, that in the latter type of cases, immediate custody is imposed by sentencers in order to facilitate immigration processes and help ensure the defendant's expulsion from the UK (see also Canton and Hammond, 2012).

More recently, Aliverti's research has looked beyond the prosecution of immigration 'offenders' towards the treatment of non-citizens more broadly, and other ways in which immigration enforcement has made 'significant inroads into the courthouse' (2016, p.77). Just as with the prison, the introduction of automatic deportation has bound border control to the courts in a more sustained and systematic way. While previously magistrates and judges had a discretionary power to recommend expulsion (Dubinsky, 2012), the 'automatic' provision means the pursuit of deportation is now mandatory whenever the courts impose a custodial sentence of a year or more on a non-citizen. ${ }^{13}$ Alongside this, as Aliverti highlights, processes have also been introduced to ensure that defendants given sentences which mean they are facing deportation are, ultimately, ejected from the UK. Thus, courts are now 'obliged to inform the Home Office about the sentences passed against foreign nationals, and their systems have been adapted accordingly to ensure the smooth routing of this information' (2016, p.77). Following the introduction of the Policing and Crime Act 2017,

\footnotetext{
12 There are a number of reasons why someone might not be 'removable' from the UK. To give just a few examples: they may not have a valid travel document and may be a national of a country which typically takes long periods to issue passports; they may be stateless; or they may be the national of a country to which the UK is not legally allowed to forcibly remove people, because of the dangers faced by people who are 'returned'. ${ }^{13}$ As I highlighted earlier, EEA nationals are not subject to automatic deportation. However, as I also noted, since there has been a greater focus overall on the deportation of foreign prisoners the Home Office has typically pursued deportation in cases where EEA nationals are sentenced to two years or more in custody - and, in fact, more recently this threshold has been lowered. Thus, while EEA nationals are not formally subject to automatic deportation, the increased emphasis on the deportation of foreign 'offenders' in recent years has in practice led to a tighter link between the punishments imposed by the courts and expulsion from the UK.
} 
moreover, defendants must now state their nationality at their first court appearance (Aliverti, 2017). ${ }^{14}$ Through this requirement, then, court processes have been reorganised around 'finding foreigners' (Kaufman, 2012, p.701) - and the courts, therefore, have been more explicitly oriented towards border control in their dealings with non-citizens.

Aliverti notes that - just as some of the prison officers who Kaufman interviewed for her research insisted that immigration issues were, in fact, 'outside the scope of the prison' (2015, p.109) - court staff to whom she spoke were 'keen to emphasize the strict division of labour between criminal adjudication and immigration enforcement' (2016, p.77). In one of the sentencing hearings that I observed (which I explore in greater depth later in the thesis, as part of the analysis of my empirical data) the judge presiding over the hearing seemed at one point to be doing something quite similar. That is, he seemed to be insisting on a clear separation between the practices of the criminal court and border control. As I explain in Chapter Five, where I begin the examination of my empirical material, I actually saw very few hearings where it was specified by the judge that the defendant was also likely to be deported after serving their sentence. In this particular hearing, however, the judge did explain that the sentence he had passed crossed the threshold for automatic deportation. As he did this, though, he seemed also to be emphasising that what happened in the end was outside his jurisdiction - that any immigration action subsequently taken was nothing to do with him.

Thus, the judge told the defendant: 'The sentence I have passed means that you are subject to the deportation provision of the UK Borders Act, but what actually happens is a matter between you and the immigration authorities' (Hearing 8, Isleworth, 2015). What the judge set out in this hearing was technically correct: the decision to deport lies, ultimately, with the Home Office. Yet, I would suggest that his formulation here also worked to situate immigration enforcement at a distance from the court - to obscure the way in which any

\footnotetext{
${ }^{14}$ As I explain in Chapter Four, where I write about my research methods and how I conducted observations of sentencing hearings, this requirement was introduced after I had completed my fieldwork.
} 
subsequent deportation would, in fact, be a direct result of the sentence he passed. The insistence by judges, and other staff, on border enforcement as separate from the practices of the court does not provide an accurate assessment of how things actually are, of course. Rather, it functions 'to deny how the criminal court has changed under conditions of mass migration and its control' (Aliverti, 2016, p.78; see also Kaufman, 2015).

\section{Immigration enforcement and the changing nature of punishment for non-citizens}

Alongside analyses identifying the shift towards migration control within the police, courts and prisons in the current era, some border criminologists have emphasised how, even as immigration-focused measures have increasingly made their way into the criminal justice system, its agencies and institutions have nevertheless persisted with their traditional functions as they deal with non-citizens. Against Kaufman's argument, for instance, that for foreign nationals, imprisonment in England and Wales has become less linked to sanctioning for an offence, 'less tied to punishment and to the terms of the criminal law' (2015, p.111), others have emphasised how these prisoners continue to serve their sentences, handed to them by the courts. The punishment of them for criminal infractions, therefore, undoubtedly continues. Importantly, however, as immigration policies and practices have been injected into the prison, the criminal sentences served by non-citizens have started to look different. Their sanctioning, then, is being inflected and reshaped by border control.

In their analysis of 'the carceral trajectories of foreign national prisoners' (2017, p.135), Sarah Turnbull and Ines Hasselberg explore how, in the contemporary prison, border control measures are intersecting and coalescing with criminal sentences - and, consequently, the nature of confinement and punishment for non-British citizens is changing considerably. As they explain, for instance, foreign nationals facing deportation are usually kept in higher security prisons and are rarely transferred to open conditions, even as they progress through and come towards the end of their criminal sentences (see also Bhui, 2007). As highlighted 
earlier, moreover, when their prison sentences come to an end they are generally not released but remain locked up, as they are detained post-sentence under immigration powers. Finally, when non-citizen prisoners are eventually released, this often takes the form of expulsion with an indefinite ban on re-entry - from the UK. As Turnbull and Hasselberg emphasise, the immigration measures applied to non-citizens are not 'official penal sanctions' (2017, p.147). Yet, being kept in more restrictive prison conditions, the indefinite extension of confinement - there is no time limit on detention under immigration powers in the $\mathrm{UK}$ - and exile from family, friends and the lives that they have built are nonetheless experienced by those subjected to them as punitive. Thus, as immigration enforcement bleeds into and blends with the criminal sentence, a harsher, aggravated form of sanctioning, which Turnbull and Hasselberg identify as 'double punishment' (2017, p.143; see also Phillips, 2012; Fekete and Webber, 2010), is produced. In many instances, in fact, border control alters and exacerbates criminal sanctioning to create something rather more than 'double punishment'. Reports by advocacy groups and inspection bodies are littered with cases of people detained postsentence under immigration powers for much longer than the criminal sentence that was initially imposed on them (Bail for Immigration Detainees, 2019; HM Inspectorate of Prisons and ICIBI, 2012; Detention Action, 2009). ${ }^{15}$

While, as I have highlighted, Turnbull and Hasselberg explain that deportation is not an 'official penal sanction', others have suggested that - more than simply exacerbating the punishment imposed on a non-citizen for a criminal offence - expulsion is, in fact, coming to constitute a form of sanctioning in itself (Aas, 2014; see also Bowling, 2013). Indeed, in contrast with the sentencing hearing that I referred to earlier, where the judge framed the expulsion of the defendant as entirely a matter for the Home Office and separate from the practices of the court, in another hearing I observed the judge seemed to suggest deportation

\footnotetext{
${ }^{15}$ In one particularly shocking case, the Prisons Inspectorate discovered a man who had been detained for a further nine years following the end of his criminal sentence during an inspection of Lincoln Prison in 2012 (HM Inspectorate of Prisons, 2012).
} 
as another intervention available to him. That is, he appeared to present ejection from the UK as a punishment that he could impose directly himself. Passing a sentence of six months' imprisonment, the judge told the defendant that if he had received a sentence of 12 months' custody or more he would have been subject to automatic deportation. ${ }^{16}$ The judge then said, using a phrase more commonly deployed by judges to warn defendants that they had narrowly avoided the sanction of being sent to prison, 'You're getting a second chance today' (Hearing 1, Wood Green, 2014). The insertion of border control measures into the criminal justice system might be seen, therefore, to be resulting in entirely new forms of penal intervention, which are much harsher and more exclusionary than the penalties and disposals that have conventionally been imposed (Aas, 2014).

Border criminologists, then, have pointed to a striking set of changes to the criminal justice system in England and Wales in the current era, effected by mass migration and its control. On the one hand the police, courts and prisons have increasingly begun to look like agencies and institutions concerned with immigration regulation, as they have been injected with policies and practices focused on border enforcement. At the same time, however, it can also be seen how the prison, for instance, continues with its traditional function of punishment as it deals with non-citizens - and yet the punishment it inflicts on them now looks different, as their criminal sentences have been reshaped and aggravated by processes of immigration control. As I now go on to explain, alongside the overt shifts that have thus far been documented, it might also be possible to detect more subtle changes to the criminal justice system as a consequence of immigration enforcement. By thinking beyond policies and legislation and imagining border enforcement more expansively, we might be able to

\footnotetext{
${ }^{16}$ As the defendant was originally from Poland and thus an EEA national, what the judge said to him at this point was in fact legally incorrect. However, although EEA nationals are not subject to automatic deportation, the judge was nonetheless right to suggest that if the defendant had received a sentence of a year or more in prison the Home Office would probably have tried to deport him. This sentencing hearing took place in $2014-$ and, as I highlighted earlier, from January 2014 Home Office policy was to pursue deportation in all cases where an EEA national received a custodial sentence of a year or more.
} 
trace the mark of immigration control on contemporary criminal justice in a more covert and insidious way.

\section{Narratives of bordering, and pushing back the boundaries of border criminology}

I noted in the previous section that in one of the earlier contributions to border criminology, Weber and Bowling (2004) drew attention to the increasingly diffuse nature of the border in the current era, and situated the police's involvement in immigration activities in terms of a wider network of internal, 'in-country' border controls. Indeed, there now exists a growing literature on the proliferation of the internal border in the UK in the contemporary period: research in this area has identified the increasing range of in-country immigration enforcement practices in terms of 'everyday bordering' (Yuval-Davis, Wemyss and Cassidy, 2018; see also Johnson and Jones, 2014). The idea of 'everyday bordering' might seem to particularly emphasise the temporal prevalence of the border in the current age; that is, the way that people now come into contact with immigration controls on a much more frequent basis than they did previously (Johnson and Jones, 2014). Alongside this, though, the literature in this area also draws attention to the spatial spread and ubiquity of the border in the present day. Thus, it highlights how border control has 'root[ed] itself in the everyday existence of people as they negotiate their way around state and quasi-state institutions and agencies in their local communities' (Flynn, 2016, p.64). Reflecting this aspect more fully, Yuval-Davis, Wemyss and Cassidy have also referred to the increasing density and reach of internal immigration controls as 'everyday/everywhere bordering' (2018, p.239).

The growth of internal immigration controls in the UK has intensified in recent years since the announcement of the Conservatives' 'hostile environment' policy in 2012 (Kirkup and Winnett, 2012) and the subsequent introduction of the 2014 and 2016 Immigration Acts (Yuval-Davis, Wemyss and Cassidy, 2018).Following this, it is now the case that border checks are not only a staple part of getting a job (as I noted earlier, Weber and Bowling's 
2004 analysis highlighted the requirement for employers to verify prospective employees' immigration status as a relatively recent development. Thus, such employment checks have been in place for some time). Checks on immigration status are also now part of renting accommodation from a private landlord, opening a bank account and having a driving licence, as well as accessing public services such as the NHS (Griffiths and Yeo, 2021; Potter, 2018; Yuval-Davis, Wemyss and Cassidy, 2018, 2016; Flynn, 2016). Within recent analyses of internal bordering mechanisms in the UK, the injection of immigration control measures into the agencies and institutions of the established criminal justice system has not often been identified as a further example of the spread of 'everyday/everywhere bordering'. Yet, as Weber and Bowling's earlier analysis indicates, it might be situated in this way. That is, the increasing involvement of the police, courts and prisons in immigration enforcement practices might be viewed not solely in terms of how criminologists have generally framed it - as demonstrating the contemporary convergence between criminal justice and border control. From the perspective of 'everyday/everywhere bordering' and the widening reach of in-country immigration regulation, the insertion of immigration measures into law enforcement bodies and institutions might also be understood as yet another instance of the proliferation and intensification of the border across people's lives and existences broadly (see Griffiths and Yeo, 2021; Johnson and Jones, 2014).

There is a connection, therefore, between the criminological research on migration control and the literature on everyday bordering. Yet, there is also a notable divergence - and this divergence, I would suggest, can help us to think differently, and more expansively, about the impact of border enforcement on the criminal justice system and to consider further and more subtle ways in which the mark of immigration control might be detected and traced. As I documented in the previous section, in their examination of the changing contours of the criminal justice system in the current era criminologists have typically conceptualised border enforcement as a series of policies and legislative measures and as contained within the direct 
practices of immigration control. In analyses focused on everyday bordering, on the other hand, the proliferation and pervasiveness of immigration regulation in the present period has been identified not only in terms of it being encountered more frequently, across many different areas of life. Some scholars have also highlighted that the everyday/everywhere nature of contemporary border control can be seen through its materialisation via multiple practices and forms. Thus border enforcement, some research from this perspective has emphasised, appears and is enacted in numerous and varying ways (Wemyss and Cassidy, 2017; Johnson and Jones, 2014; Johnson et al., 2011).

Within this more extensive imagining, a key materialisation of border enforcement beyond the literal practices of immigration control that has been identified by critics is 'bordering discourses' or 'border narratives' (Wemyss and Cassidy, 2017, p.1136-1137). That is, the negative narratives that are circulated by Western governments and the media in the contemporary era, which function to problematise migrants and justify their targeting by the direct activities of immigration control, have been recognised as 'bordering processes' (Wemyss and Cassidy, 2017, p.1136) or 'bordering work' (Johnson et al., 2011, p.61) in themselves. Thus, starting from Étienne Balibar's assertion that 'borders are everywhere' (1988, cited by Johnson et al., 2011, p.61), Corey Johnson and colleagues have identified 'exclusionary narratives in media and popular culture' as one form of present day 'bordering work that marks some bodies as legitimate and others as out of place' (2011, p.61). Similarly, Georgie Wemyss and Kathryn Cassidy have argued that, when 'transitional controls' aimed at reducing the number of Romanian and Bulgarian migrants arriving in the UK ended in January 2014, stigmatising and racialised political and media narratives about these migrants nonetheless 'extended [the transitional controls'] reach' (2017, p.1136). Wemyss and Cassidy contend, therefore, that 'the discourses of politicians, amplified via news media contributes to the extension of state bordering practices' (2017, p.1133; emphasis mine). 
Border criminologists, it should be noted, have drawn attention to these government and media narratives and acknowledged their significance: that, by stigmatising and vilifying migrants, they legitimise and make possible increasingly restrictive legislation and policies on immigration control (Bowling, 2013; Gerard and Pickering, 2013; Bosworth and Guild, 2008). At the same time, however, these negative narratives have rarely been foregrounded in criminological analyses. Thus they have been approached and presented, I would suggest, more as an accompanying or subsidiary practice, in contrast to the 'main event' of the actual activities of border control. Analyses from the perspective of everyday bordering, conversely, have positioned government and media narratives about migrants more centrally. In identifying 'border narratives' as an extension of transitional controls, Wemyss and Cassidy do not assert a clear hierarchy between these disparaging depictions and the direct immigration enforcement practices implemented to reduce the number of Romanian and Bulgarian migrants arriving in the UK. Likewise, as Johnson et al. refer both to 'exclusionary narratives' and literal border control activities, including 'immigration raids', as forms of 'bordering work' (2011, p.61), the latter is not obviously prioritised over the former.

From this perspective, then, if we are concerned with the changing contours of the criminal justice system in the current era and the way that it is being touched and marked by border enforcement, we should be paying attention not simply to the explicit changes wrought by policies and legislation and the literal practices of immigration control. We should be thinking, as well, about how negative government and media narratives about migrants, which I suggest we can understand as narratives of bordering, ${ }^{17}$ might also be reaching into criminal justice agencies and institutions - about how these narratives might be

\footnotetext{
${ }^{17}$ As I highlight in Chapter Two, alongside negative narratives of bordering there are also some apparently different government and media depictions, which mark out some migrants as desirable and thus as acceptable to let in. Yet, as I also explain, although such representations are ostensibly more positive and inclusive, they in fact function as an integral part of the bordering regime. By specifying that only a minority of migrants are suitable for entry to the UK, these narratives - which I identify as narratives of limited inclusion - insist that the general rule of exclusion and bordering must remain firmly in place.
} 
percolating through. In this thesis I am specifically concerned with how stigmatising narratives about migrants, disseminated by the UK government and media, might be seeping into the courtroom and, more particularly, the endpoint of the court process, the practice of the sentencing hearing. My research is focused, therefore, on how contemporary narratives of bordering might be marking and permeating sentencing hearing proceedings: that is, on how these narratives might be penetrating the process during which criminal punishments are allocated to and imposed on migrants and non-citizens.

I map out what contemporary narratives of bordering look like, and analyse how they operate - how they problematise migrants, to legitimise actual immigration enforcement against them - in Chapter Two. Here, however, I want to consider in more detail why I have chosen to refer to them specifically as 'narratives of bordering', and to explore what the use of this particular phrase captures and draws out. As indicated in my discussion above, Wemyss and Cassidy (2017) have identified negative government and media depictions of migrants in similar ways, referring to them, for example, as 'bordering discourses' and 'border narratives'. In my framing, I have chosen to emphasise these representations precisely as 'narratives of bordering' because, in the first place, I think that the latter part of this formulation helps to suggest their 'active' nature. That is, it reflects government and media depictions as actually engaged in the practice of bordering. In line with my argument over the previous pages, therefore, it does not portray them merely as a passive accompaniment to the 'main' or 'real' activities of literal immigration enforcement. Rather, it pinpoints these demeaning representations of migrants as centrally involved in delineating and upholding the border; it marks them out as, in themselves, a form of bordering work.

Why, then, might these representations be understood specifically as 'narratives of bordering'? Critics within border criminology, as well as those focused on everyday bordering - and, indeed, scholars outside these literatures - have referred to government and media representations of migrants both as 'narratives', and as 'discourses'. Often, in fact - as 
seen, for instance, in Wemyss and Cassidy's analysis - these terms have been used relatively interchangeably. Political and media depictions of migrants can, certainly, be viewed through the lens of discourse. Describing them like this serves to frame them in terms of Foucault's conception of the inextricable relationship between power, knowledge and truth (Mills, 2004). In their identification as 'discourses', therefore, stigmatising depictions of migrants are underlined as a form of knowledge that has been designated and accepted as true - that has come to function as part of contemporary society's 'regime of truth' (Foucault, 1980, p.131). Moreover, the 'effects of power' (Foucault, 1980, p.133) induced by such accepted 'truths', or dominant discourses, are emphasised. Thus, the 'truth status' of vilifying representations of migrants means that the severity of the UK's actual immigration controls appears as entirely legitimate and reasonable. In other words, the circulation of negative government and media discourses makes it thinkable, and possible, to subject migrants to harsh and exclusionary immigration policies (see also Foucault, 1978; Said, 1978).

'Narratives' have sometimes been emphasised as resistant and subversive. Within the 'narrative turn' that took place within legal scholarship, therefore, some critics highlighted the potential of individual stories, told by people in marginalised social positions, to disrupt established ways of seeing as they 're-present experience' and 'introduce imagination and new points of view' (Scheppele, 1989, p.2075; see also Delgado, 1989). The oppositional possibilities of individual stories have also been explored by narrative criminology, which has emerged as a criminological sub-field over the past decade (Fleetwood et al., 2019) and focuses, primarily, on 'the role the telling and sharing of stories play in committing, upholding and effecting desistance from crime and other harmful acts' (Sandberg and Ugelvik, 2016, p.129; see also Presser, 2016; Presser and Sandberg, 2015). ${ }^{18}$ Recent research

\footnotetext{
${ }^{18}$ It is important to note that, as Jennifer Fleetwood and colleagues explain, while narrative criminology was 'originally explicitly centred on the narratives of offenders', more recently some research within it has explored the 'narrative lives of professionals working in the social control professions' (2019, p.5). However, as I also indicate above, a defining feature of narrative criminology is that it 'takes a constitutive view of stories' (Presser, 2016, p.139). That is, as Lois Presser has emphasised: 'Narrative criminologists are interested in what
} 
by Sveinung Sandberg and Sarah Colvin, for example, investigates how young Muslims in Norway tell individual stories that reject 'dominant cultural narratives' (2020, p.1587) about the inherent aggression and violence of Islam. In line with the particular concerns of narrative criminology, Sandberg and Colvin argue that such individually resistant narratives function to 'constrain or reduce harm' (2020, p.1586) in two key ways. In the first place, they contend that these stories operate as a repudiation of violent practices of 'religious extremism' (2020, p.1585). Secondly, they frame them as a "storied rejection" of mainstream prejudices about Muslims and Islam', which therefore have the potential to 'constrai[n] harm perpetrated against Muslims' (2020, p.1586).

As Sandberg and Colvin's identification of 'dominant cultural narratives' about Islam indicates, however, stories are not always tied to opposition and subversion. Thus, they explain that some narratives "can achieve a type of "master status"' (2020, p.1587). Similarly, some sociologically-oriented investigations have emphasised that narratives can be dominant or hegemonic, functioning to naturalise existing social arrangements and uphold systems of oppression and exclusion (Ewick and Silbey, 1995; Richardson, 1990). It is possible, then, to understand negative government and media depictions of migrants through either lens: both as 'discourses', and as 'narratives'. Yet, I would suggest that identifying them as dominant or hegemonic narratives is particularly appropriate: that is, that viewing these representations through the framework of narrative helps to capture and reflect some of their specific aspects and features.

Referring to them as dominant narratives, for instance, suggests how, as some critics have highlighted, government and media representations of migrants typically centre on

\footnotetext{
stories $d o$ - specifically, how they affect crime and other harm' (2016, p.139). Thus, in Chapter Three, where I explore the individual accounts delivered by legal professionals during the sentencing hearing through the framework of narrative, I do not make use of the now quite significant literature within narrative criminology. Instead, I draw on other critical enquiries into the nature of stories and storytelling that are more directly relevant and useful to my research. These enquiries include Ewick and Silbey's much-cited 1995 article 'Subversive stories and hegemonic tales: Towards a sociology of narrative', which explores 'the ways in which narratives operate in social life, in particular in legal settings' (1995, pp.199-200; emphasis mine).
} 
certain key figures or 'characters' (Kundnani, 2001, p.48) - including, as I document in Chapter Two, the abusive immigration cheat and the parasitical welfare scrounger - who follow clearly defined and well-known 'plotlines’ (Fox, Moroşanu and Szilassy, 2012, p.686). As soon as a particular protagonist is invoked, we often already have a strong sense of what it is they do. The language of 'narrative' evokes, as well, how government depictions often resort to anecdotes, and media reporting frequently relies on individual instances and stories, in order to support the negative claims that they make about migrants broadly. Again, I trace this pattern in Chapter Two.

Identifying contemporary representations of migrants as narratives, or stories, might, moreover, be seen to particularly connote the often misleading and sometimes completely invented nature of the ideas that are disseminated by the government and media. The range of related terms that has been utilised by scholars writing about these depictions, indeed, including 'folklore' (Fekete and Webber, 2010, p.2) and, more often, 'myth' (Philo, Briant and Donald, 2013, p.4; see also Alia and Bull, 2005; Kundnani, 2004; Buchanan, Grillo and Threadgold, 2003; Coole, 2002) clearly intimates a sense that government and media representations of migrants are fabricated and fictitious. In framing them like this, it could be understood that I am reversing my contention, above, that hegemonic depictions of migrants might also be viewed through the lens of 'discourse', as well as 'narrative'. By presenting them in terms of distortion and fabrication, I might be understood as positioning these representations in opposition to the existence of absolute or objective 'truths' - a proposition that Foucault's theorisation of discourse contested (Foucault, 1980). Rather than making such a claim, however, I am trying to suggest how - while all 'truths' can be understood as socially constructed - there are nonetheless some that are produced from more partial and blinkered perspectives, and are therefore less credible and reliable, than others (Haraway, 1988). I document some of the obfuscations, and at times clear falsifications, of government and media representations of migrants in Chapter Two. 
I would suggest, finally, that identifying government and media depictions of migrants specifically as narratives directs our attention towards the act of narration. In this way, we can think about some of the mechanisms by which such fictional, fabricated ideas about migrants come to be believed - how they come to be accepted and established as truth. In The Practice of Everyday Life Michel De Certeau describes how, in modern society, we are surrounded by the nonstop narrations of the media and of politicians speaking in the media, how 'narrations about what's-going-on constitute our orthodoxy' (1984, p.185). As he explains further:

Narrated reality constantly tells us what must be believed and what must be done ... From morning to night, narrations constantly haunt streets and buildings ... Captured by the radio (the voice is the law) as soon as he awakens, the listener walks all day long through the forest of narrativities from journalism, advertising, and television, narrativities that still find time, as he is getting ready for bed, to slip a few final messages under the portals of sleep (1984, p.186).

While De Certeau is very focused on the verbal narrations of the broadcast media, the perpetual narrations of the present might be understood as extending, also, to the written narrations of print and online media. Thus, his idea of the 'forest of narrativities' might be seen to capture how, as the same negative ideas about migrants are endlessly narrated and repeated, and as we are enveloped and surrounded by them, they come to be accepted and believed. De Certeau sets out, then, that 'Our society has become a recited society, in three senses: it is defined by stories (récits, the fables constituted by our advertising and informational media), by citations of stories, and by the interminable recitation of stories' (1984, p.186). As well as drawing out the constant narrations of the present, and the way that negative representations of migrants have become embedded and accepted as they are 
circulated continually, the citation and recitation he points to here also gets at the repetition and recycling that runs through government and media narratives.

As I will show in Chapter Two, since the beginnings of mass migration in the late 1980s successive UK governments - despite the shift from a Conservative administration, to New Labour, and then back to the Conservatives once more - have consistently recited the same tropes, claims and phrases about migrants. Moreover, government and media narratives have also repeatedly borrowed from and repeated each other, consolidating and reinforcing one other as they do. Indeed, the government and media narratives of the present have also borrowed from and recycled the stories disseminated about migrants historically, repeating ideas and claims that can be traced back over decades. As I will demonstrate in Chapter Two, however, as I draw out the specifically racialised nature of contemporary depictions of migrants, in remobilising these older ideas government and media portrayals have reformulated them, stripping them of overtly racist articulation. In this way, therefore, they have coded and sanitised them, and reworked them into a more socially acceptable form.

Before moving onto the final section of this chapter I want to briefly consider the relationship between the government and the media as they produce and disseminate negative narratives about migrants. I also want to explore how the circulation of these dominant portrayals connects with public opinion on immigration. Firstly, the relationship between the government and the media as they disseminate problematising narratives about migrants; as critics writing in this area have suggested, this relationship is not straightforward or one-way. It is undoubtedly the case that large sections of the media have supported the exclusionary response to mass migration by successive UK governments, and have repeated and amplified their negative representations and claims. Yet, as Fox, Moroşanu and Szilassy set out, it would be inaccurate to characterise the media as 'simply an uncritical mouthpiece for public policy' (2012, p.685). On numerous occasions, indeed, media claims about migrants have 
catalysed the government to go further, to take an even more restrictive approach to immigration (Wemyss and Cassidy, 2017; Back, 2007).

Acknowledging this, however, should not mean an equally simplistic insistence upon the media as the primary instigator, generating negative depictions of migrants and forcing the government to adopt increasingly hard-line policies (Kushner, 2003). Since the onset of mass migration UK governments have been actively involved in problematising and stigmatising migrants, as they have worked to justify the severe measures that they have decided upon and introduced. I would suggest, ultimately, that more important than pinning down the precise dynamics of this relationship is identifying the overarching homogeneity of the representations that the government and the media produce. As I suggested above, government and media narratives constantly borrow from, repeat and consolidate one another. Thus, they can be understood as working alongside each other to vilify migrants and justify the UK's policies on immigration control.

How, then, do the stigmatising narratives about migrants that are circulated by the government and media connect with public opinion on immigration? I suggested above that De Certeau's identification of the nonstop political and media narrations of the present offers an insight into one of the possible mechanisms by which dominant depictions of migrants come to be widely accepted and believed. Surveys over the past three decades, indeed, demonstrate a hardening of public attitudes towards immigration since the mid-1990s (Ford and Heath, 2014; Ford, Morrell and Heath, 2012; Lewis, 2005). ${ }^{19}$ Research conducted in the early 2000s, for example, highlighted increasingly negative public views about people seeking asylum, including that they were often perceived as cynically targeting the UK in order to access welfare benefits (Lewis, 2005; Finney and Peach, 2004). More recently, such

\footnotetext{
${ }^{19}$ This is not to suggest that prior to the mid-1990s public attitudes towards immigration were positive. As Ford, Morrell and Heath explain: 'Ever since social surveys and opinion polls began to ask questions on the topic in the 1960s, the British public has always favoured a reduction in the numbers of immigrants' (2012, p.27). As they also note, however, the already high levels of public opposition to immigration recorded in the mid-1990s had increased sharply by the early 2000 s.
} 
attitudes have continued. An Ipsos MORI poll on the so-called refugee 'crisis' of $2015^{20}$ found a majority of respondents in agreement that most refugees were not 'genuine' but in fact were 'economic migrants', who were trying to get to the UK to 'take advantage' of the benefits system (Ipsos MORI, 2017). These negative public views extend beyond asylum seekers to immigration more broadly. Surveys have documented a widespread perception that migrants come to the UK in order to claim benefits (Ford and Lowles, 2016; Ford and Heath, 2014), as well as a belief that increased immigration leads to more crime (Page, 2009). Since the mid-1990s, it has consistently been the case that over $60 \%$ of the population has supported a reduction in immigration (Duffy et al., 2017; Ford, Morrell and Heath, 2012) and, in 2013, this figure reached a striking 77\% (Ford and Heath, 2014).

It is important to note, however, that within these overwhelmingly negative attitudes, some forms of migration attract greater public support. According to a 2017 survey, for instance, just $10 \%$ of respondents said that no one from Australia should be allowed to migrate to the UK, and only $14 \%$ opposed any migration from France. Opposition to migration from the other countries asked about was higher, with the proportion of respondents saying that no one from Poland, Romania, Pakistan or Nigeria should be able to come to the UK standing, respectively, at 21\%, 34\%, 36\%, and 37\% (Migration Observatory, 2020). These findings resonate with previous research that has identified lower levels of opposition to migration from 'Old' Commonwealth countries such as Australia and New Zealand, as well as Western Europe (Ford, 2011b). As Robert Ford explains, the greater support for migration from these countries provides 'strong evidence of a racial division in public attitudes to immigration' (2011b, p.1020).

As we will see in Chapter Two, where I map the key narratives of bordering circulated by the government and media in the present era, the types of negative views that

\footnotetext{
${ }^{20}$ I explain in a footnote in the final section of this chapter why I refer to it as a so-called 'crisis'.
} 
have been expressed by the UK public about immigration correlate clearly with these dominant portrayals. The 'racial division' that has been identified within public attitudes, moreover, links - as I also document in Chapter Two - to how the government and media have targeted these dominant narratives; that is, to which groups of migrants such stigmatising representations have predominantly been attached. Alongside De Certeau's identification of the nonstop political and media narrations of the present, Stuart Hall and colleagues' seminal account of public opinion formation in their 1978 book Policing the Crisis provides another means of understanding how negative government and media depictions of migrants have come to organise and shape the public consciousness. Examining the moral panic around 'mugging' in the early 1970s, Hall et al. explain: “"Public opinion" about crime does not simply form up at random. It exhibits a shape and structure. It follows a sequence. It is a social process, not a mystery' (2013, p.135; emphasis mine).

Thus, as those who operate as the 'primary definers' (Hall et al., 2013, p.60) of a situation - in the case of the immigration 'problem', I would contend, the government and the media $^{21}$ - repeatedly circulate their explanation and interpretation of 'what is happening', 'lay public attitudes' (2013, p.136) emerge within this context. The views expressed by the public are, as Hall et al. argue, 'not socially innocent' (2013, p.135). Rather, '[t]he more ... an issue passes into the public domain ... the more it is structured by ... dominant ideologies ... It is these which form the infrastructure of any public debate' (2013, pp.135-6). What is articulated by the public, then, is 'constrained by the available frameworks of understanding and interpretation' (2013, p.136). As Hall and colleagues set out, therefore, supposedly 'lay attitudes' are, in fact, 'structured in dominance' (2013, pp.136-7).

\footnotetext{
${ }^{21}$ I recognise that in Hall et al.'s analysis the media are positioned as 'secondary definers', since they 'reproduce the definitions of the powerful' (2013, p.60). More in line with the argument I make above, however, that in their dissemination of narratives of bordering the government and media can be understood as working alongside each other to justify the UK's policies on immigration control, I understand both the government and media as primary definers.
} 
Utilising Hall et al.'s ideas to think through the hardening of public attitudes towards welfare over the past decade, Tracey Jensen and Imogen Tyler have emphasised the centrality of certain key characters, or 'revolting subjects' $(2015, \mathrm{p} .479)$, to the contemporary 'cultural and political crafting of anti-welfare commonsense' (2015, p.470). As they argue, the 'benefit brood' family - in which parents allegedly have as many children as possible, to maximise their entitlement to welfare benefits - has become a central character that is repeatedly circulated across political and media sites, to illustrate the supposed problem of 'dependency' on the benefits system. ${ }^{22}$ Such 'repetitive mediations' of the 'benefit brood' family in political speeches, as well as across newspaper articles, magazine exposés and television programmes, operate as a 'central mechanism' (2015, p.479) to organise and shape increasingly negative public perceptions of welfare. Jensen and Tyler's emphasis on the key role of 'repetitive mediations' of certain stigmatised characters connects back, I would suggest, to some of the core features of dominant narratives of bordering that I identified previously in this section. Through this lens, then, it is possible to understand how these specific features of narratives of bordering function in the crafting and procuring of hardened public views on immigration.

As I argued earlier, the government and media's negative depictions of migrants can be understood specifically as narratives partly because they centre on certain key figures or 'characters' - including that of the abusive immigration cheat, and the parasitical welfare scrounger. We can trace the 'repetitive mediation' of these key characters, moreover, in broad terms, through the continual dissemination of narratives of bordering - but also at a more micro-level, in terms of some of the particular tools, or devices, on which government and media portrayals of migrants often rely. Thus, I noted above that government depictions often

\footnotetext{
${ }^{22}$ As I explain further in Chapter Two, the idea of dependency on the welfare benefits system, and additional characters such as the individual figure of the 'scrounger', have long been used to disparage the working class. However, as I also document, ideas of a workshy nature and an appetite for unemployment support have a significant history as a racialising trope, too - which precedes the mobilisation of the narrative of the parasitical scrounger as a core contemporary narrative of bordering, to demonise and vilify migrants.
} 
resort to anecdotes, and media reports frequently make use of individual instances and stories, to support the negative claims that they make about migrants broadly. Through such means, therefore, we can see how, as Jensen and Tyler put it, key stigmatised figures are 'constituted and repetitively accumulated' (2015, p.479; emphasis mine) across political and media sites. As we will see in Chapter Two, figures such as the abusive immigration cheat materialise incessantly and repetitively via anecdotes in government documents and political speeches, and through the numerous individual cases and stories on which the media reports. This process of accumulation and repetition works to fuel and orchestrate public hostility towards the groups of migrants who are targeted by government and media narratives. In this way, public consent for restrictive immigration policies is secured (see Jensen and Tyler, 2015; see also Jensen, 2018).

Finally, and importantly, Hall and colleagues' account of public opinion formation in Policing the Crisis helps us not only to understand how 'lay attitudes' about immigration are politically and culturally crafted - but also how these orchestrations of public opinion help, in turn, to support and maintain government and media narratives. In their examination of newspaper readers' 'letters to the editor' about mugging, Hall et al. explain that, as such expressions of 'lay attitudes' are incited and 'awaken[ed]', they work to 'underpin and support the viewpoints already in circulation'. In doing so, they 'help to close the consensual circle, providing the lynch-pin of legitimation' (2013, p.136; emphasis mine). Building on this observation, in their analysis Jensen and Tyler (2015) highlight how in the present era it is not only in newspaper letters pages where 'lay' support for and public legitimation of the dominant ideas already in circulation materialises. What appear to be 'spontaneous' (Hall et $a l ., 2013$, p.136) articulations of public opinion appear, too, in online comment sections of newspapers, and online message boards - as well as via opinion polls and social attitudes surveys (see also Jensen, 2018). As Jensen and Tyler emphasise, such manifestations and 
orchestrations of 'lay attitudes' function to provide support 'for an already-circulating commonsense ideology’ (2015, p.479).

Writing in the early 2000s about government, media and public reactions to people seeking asylum, Tony Kushner argued: 'In Britain at the start of the twenty-first century, the government, state, media and public have intertwined in a mutually reinforcing and reassuring process to problematize and often stigmatize asylum-seekers' (2003, p.261). To some extent, the idea of the government, media and public 'intertwining' and 'mutually reinforcing and reassuring' one other as they demonise and vilify migrants captures the nature of the process described above. Yet, in emphasising the links between the government, media and public in the dissemination and maintenance of negative narratives about migrants, it is important not to erase the hierarchical dynamics of this process. That is, as Hall and colleagues emphasise, the expressions of 'public opinion' that operate to legitimise and reinforce ideas which are already in circulation are 'subject ... to the shaping power of ... institutional forces' (2013, p.136). We might push back, therefore, at the 'mutuality' that Kushner identifies in the relationship between the government, media and public. Rather, what unfolds in the dissemination and perpetuation of narratives of bordering can be more accurately understood as - in the words of the introduction to the second edition of Policing the Crisis - the primary definers "win[ing] society to their "definition of the situation" (Hall et al., 2013, p.xii).

\section{Moving past the language of 'migrants' and 'non-citizens': The centrality of race to research on borders and bordering}

Throughout this opening chapter, I have set out that it is 'migrants', 'foreign nationals' and 'non-citizens' who are affected by the UK's immigration regime. Somewhat belatedly, I now want to qualify this assertion. As some parts of my analysis have begun to indicate, it is in fact the case that the UK's border controls - like those of other Western nation-states - work 
to problematise the mobility of certain migrants, foreign nationals and non-citizens.

Specifically, they seek predominantly to immobilise and exclude people coming from countries in the Global South, most of whom are not white, as well as, to some extent, those from Southern and Eastern Europe, who are ostensibly white but are often deemed to represent 'a contingent and degraded form of whiteness' (Anderson, 2013, p.45). The UK's border regime, therefore, is structured by racism.

As I suggested in the introduction to this chapter, border criminologists have not ignored issues of race and racism. As Parmar has pointed out, however, scholarship in this area has rarely utilised race as a central analytical frame (2018a, 2018b; see also Garner, 2015). It should be acknowledged, of course, that the unequal effects of the UK's border controls might be understood in other ways. Most obviously, perhaps, their overwhelming targeting of people originally from countries in Africa, the Middle East, South and South East Asia, Central and South America, and Southern and Eastern Europe, might be seen primarily in terms of global class inequality. That is, the border is the means by which rich Western countries maintain their economically privileged status, as they work to keep out the world's poor (Aas, 2014, 2013; Webber, 2004). Yet, although class undoubtedly runs through the contemporary border regime, it is important to recognise that, from their very inception, the UK's immigration controls have been shaped by racism (Parmar, 2018a). While the controls of the current era may effect this discrimination in more complex ways than those that preceded them (Garner, 2018, 2017), the exclusion of those deemed to be racially different, as some of the more recent interventions within border criminology have emphasised, continues to lie at their core (Bosworth, Parmar and Vázquez, 2018; Parmar, 2018a; Bhui, 2016; Bowling, 2013).

The idea of 'race' has always been central to the Western nation-state. As Alana and Ronit Lentin have argued, it was with the birth and development of the modern nation-state that the ideas perpetuated by racial science became important politically, as a way of binding 
together individuals within the national territory in terms of 'a common heritage and shared destiny' (2006, p.5). Since they were first introduced, immigration controls in the UK have been 'deeply implicated' (Anderson, 2013, p.47) in the project of making and maintaining the 'race nation'. This is immediately evident from, for instance, the immigration controls that were eventually implemented following the Second World War, which functioned to curtail non-white migration coming from the British colonies and former colonies. John Solomos (2003) has explained that, in the period leading up the introduction of this legislation, the majority of migrants coming to the UK to fill the significant post-war labour shortages were actually from the Irish Republic, 'Old' Commonwealth countries such as Canada, Australia and New Zealand, and Europe. The number of people migrating from colonised countries who, as British subjects, were legally entitled to enter and settle in the UK - was, by comparison, quite small. Yet, 'almost as soon as they began to arrive they were perceived as a problem' (2003, p.52).

Following years of problematisation of non-white immigration by politicians, as well as the media, the 1962 Commonwealth Immigrants Act was brought in. Under this, all holders of Commonwealth passports - unless they had been born in the UK, or held a British passport issued by the British government - were now subject to immigration controls. While, as Solomos notes, this meant that the Act formally also targeted white Commonwealth citizens, it was clear from the parliamentary debates and media coverage preceding its introduction that it was implemented primarily to reduce the migration of people with darker skin (see also Bhambra, 2016). Legislation introduced following the 1962 Act worked to further reduce non-white migration. The 1968 Commonwealth Immigrants Act, for instance, was brought in to reduce the number of Kenyan Asians arriving in the UK (Anderson, 2013; Solomos, 2003). The 1971 Immigration Act introduced a distinction between 'patrials', who had the right of abode in Britain, and 'non-patrials', who did not. 'Patrials' included Commonwealth citizens who had British parents or grandparents; and, therefore, patriality 
'served as a mechanism to facilitate the entry of white Australians, Canadians, and New

Zealanders but not other Commonwealth citizens' (Anderson, 2013, p.40; see also Aliverti, 2013a; Solomos, 2003).

It is important to acknowledge that, in recent decades, imaginings of British national identity have become more complicated. Ben Pitcher has observed that: 'The state's antagonism towards those marked out as racially different has been transformed into an awkward embrace, such that the title of Paul Gilroy's classic survey of the field of 1980s race politics no longer rings quite true: in contemporary Britain there does indeed seem to be Black in the Union Jack' (2009, p.33; see also Back, Sinha and Bryan, 2012). And yet, when it comes to immigration, the idea of the whiteness of the nation still appears to hold; in the contemporary era, migration continues to be restricted racially (Back, 2007; Lentin and Lentin, 2006). One of the clearest ways that, since the beginnings of the current period of mass mobility, successive governments have impeded non-white immigration to the UK is through asylum policies and legislation.

Although a significant proportion of people seeking protection in the UK from the late 1980s onwards were from Eastern Europe - a point I return to later on - many also came from countries in Africa, the Middle East and South Asia (Schuster, 2003a). As the number of asylum applications in the UK started to increase, the then Conservative government began introducing visa restrictions on nationals of countries "considered to be the main "producers" of asylum seekers' (Aliverti, 2013a, p.32). First, then, visa restrictions were introduced for nationals of Sri Lanka, in 1985, and following this for nationals of Bangladesh, India, Pakistan, Nigeria and Ghana (see also Webber, 2004). Further measures to strengthen these entry restrictions were subsequently introduced, including carriers' liability - that is, fines for airlines and shipping companies for carrying people with false documents or without documentation at all (Webber, 2004; Bloch, 2000). As I noted earlier in the chapter, moreover, it was also in the context of the rising number of asylum applications that more 
immigration 'crimes' began to be introduced, as a way of 'backing up' and strengthening immigration legislation (Aliverti, 2013a).

Reflecting the increasingly diffuse nature of the border in the current era, a series of internal controls on asylum applicants were implemented by New Labour following their election in 1997, aimed at making life hard for those who had managed to get to the UK and forcing them to leave the country. These included mandatory dispersal out of London for anyone going through the asylum process, limited levels of financial support and a prohibition on working, and an increasing use of immigration detention (Schuster and Solomos, 2004). The framework put in place from the 1980s onwards to reduce asylum applications in the UK has been successful: as Victoria Canning notes, 'applications for asylum have decreased significantly, even as the need for sanctuary relating to the Refugee Convention has increased' (2017, p.17). Indeed, the effectiveness of asylum policies and legislation in preventing non-white migration to the UK can be seen through the relative lack of rise in asylum applications during the recent so-called refugee 'crisis' ${ }^{23}$ During the 'crisis' the number of refugees arriving in Europe, who were coming predominantly from countries in the Global South, jumped dramatically, from approximately 280,000 in 2014 to more than a million the following year (BBC News, 2016a). Despite this, however, the number of

\footnotetext{
${ }^{23}$ As I set out below, there was a dramatic increase in the number of refugees arriving in Europe in 2015. And yet, there are a number of reasons to challenge the dominant framing of this increase in numbers as a 'crisis'. For instance, as Canning, who refers to it as a 'so-called crisis', notes: 'A crisis is unforeseeable or unpredictable. The events unfolding at Europe's borders have been wholly predictable: conflict, country occupation and economic dismantlement of any given region creates influxes in migration, and Greece and Turkey had already been experiencing significant increases in refugee populations since the 1990s' (2017, p.9). Moreover, as Gholam Khiabany highlights, the vast majority of refugees do not make it to Europe but, in fact, 'are hosted in developing countries ... The staggering numbers of ... those taking refuge in developing countries puts the "refugee crisis" in Europe in perspective' (2016, pp.756-757). Additionally, as Neske Baerwaldt (2018) points out, in framing the increasing numbers of refugees arriving in Europe as a 'crisis', governments and politicians have typically insisted that the crisis is for Europe, and have foregrounded the alleged problems for 'us' as a result of rising levels of forced migration. The significant harms experienced by those forced from their countries, on the other hand, including the thousands of people who have drowned in the Mediterranean, have rarely been referred to or understood as part of the 'crisis'. As Baerwaldt explains, 'despite border deaths permeating the refugee crisis' imagery, the vast majority of such deaths are positioned outside of its frame of reference'. We might not entirely reject the term 'crisis', then, to describe rising levels of forced migration to Europe; rather, we might repurpose it, to insist on a different understanding of for whom the crisis was taking place.
} 
asylum applications in the UK rose by just 20 per cent across this period, from 32,344 to 38,878 (Canning, 2017).

Another key policy that has blocked non-white migration to the UK in the contemporary era is 'managed migration'. In the early 2000 s, the then Labour government adopted a 'managed migration' approach to employment visas by introducing the Highly Skilled Migrants' Programme for people from outside the EU. Alongside the increasingly restrictive asylum regime, therefore, this worked to limit immigration from the Global South, as well as Southern and Eastern Europe, as only the most educated and skilled people from these parts of the world were able to get in (Fekete, 2001). Then, in 2004, EU enlargement took place: the 15 original Western European member states were joined by eight Eastern European countries, including Poland, meaning that nationals of these 'A8' states acquired rights of free movement within the EU. Following this, the Labour government published plans for a new 'points-based' immigration system for non-EU nationals: the proposed new system continued with the 'managed migration' approach, as it included employment routes for 'highly skilled' and 'skilled' migrants (Home Office, 2005). Labour's plans did also include a further employment route, for 'low skilled' non-EU migrants - but it was indicated that EU enlargement and so the availability of labour from the new 'A8' member states meant that such a route would be phased out over time. In fact, although the points-based system for non-EU nationals has been in place since 2008, the low skilled employment route has never been implemented (Gower, 2018; Anderson, 2013). As Steve Garner (2007a) has noted, therefore, the outcome of the 'managed migration' approach has been the privileging of white European labour, and the limiting of opportunities for entry to the UK for non-white non-EU nationals, unless they have particular skills.

Thus, as Bridget Anderson observes, while policies such as 'managed migration' are framed officially in terms of economic status - and so are unashamedly about class - their apparently 'raceless' nature is entirely contradicted by their actual consequences: in terms of 
their practical effects, they are "unavoidably "race-ful”" (2013, p.46). We see something similar, indeed, through the system of 'visa' and 'non-visa' nationals. I highlighted above that from the mid-1980s onwards, in order to prevent people seeking asylum from coming to the UK, the then Conservative government started to introduce visa restrictions on nationals of certain countries. In fact, as Aliverti (2013a) notes, visa restrictions are now in place for citizens of over 100 countries worldwide - most of which are in the Global South. Nationals of some non-EU countries, however, are not required to apply for a visa before travelling to the UK; predictably, these 'non-visa' nationals include citizens of the United States, Canada, Australia and New Zealand (Home Office, 2019c). The 'visa' and 'non-visa' national system is officially 'raceless', therefore, framed as it is in terms of nationality. Yet, as it effects a divide between people from countries in the Global South, most of whom are not white, and people from non-EU countries in the Global North, many of whom are white, its consequences are wholly 'race-ful' (Anderson, 2013; see also Parmar, 2018a).

I noted earlier that, as asylum applications in the UK started to rise from the late 1980s onwards, many of those seeking asylum were from Eastern Europe, fleeing political upheaval and conflict there. As some critics have highlighted, the fact that many of those seeking protection during this period had lighter skin was used to deny the racism of asylum policies and legislation (Kushner, 2005). Yet, as Liza Schuster (2003a) explains, such denials ignore who, specifically, was being targeted: that is, that it was only certain groups of white people being prevented from entering the UK - people who, despite their skin pigmentation, have often been treated as 'not quite white' and racially different. Indeed, there is a long history within the UK's immigration controls of excluding white minority groups from the country. The first major piece of immigration legislation in the UK, the 1905 Aliens Act, was introduced to prevent the entry of Jewish people fleeing Eastern Europe (Kushner 2005). Similarly, in the post-war period, while Eastern European refugees were brought to the UK as 'European Volunteer Workers', Jewish people were explicitly excluded from this scheme 
(Bhambra, 2016; Kushner, 2005). As scholars have explained, people who are ostensibly white have often been deemed to be racially undesirable in cultural terms - that is, 'by reference to cultural rather than phenotypical difference' (Garner, 2013, p.507; see also Anderson, 2013; Fox, Moroşanu and Szilassy, 2012). ${ }^{24}$

With the enlargement of the EU in 2004 some Eastern Europeans - including some of those who had previously been prevented from entering the UK by asylum policies and legislation - acquired rights of free movement. This demonstrates how groups who have been deemed to represent a 'degenerate' (Anderson, 2013, p.45) form of whiteness can, at points, be elevated out of racial undesirability (Anderson, 2013; Fox, Moroşanu and Szilassy, 2012; Garner, 2007b). Against the post-2004 backdrop of EU enlargement and free movement for many Eastern Europeans, however, it is important to remember that nationals of some Southern European countries, including Albania and Turkey, are subject to the non-EU immigration regime - and, indeed, Albanians and Turks are classified as 'visa' nationals (Home Office, 2019c). When Romania and Bulgaria joined the EU in 2007, moreover, the UK imposed transitional controls on their citizens, which - as I indicated earlier in this chapter - were only lifted in 2014 (Gower and Hawkins, 2013).

Alongside this, some Eastern European EU nationals have had their formal rights of free movement in the UK curtailed by specific policies. For instance, until quite recently the Home Office was operating a programme which targeted EU nationals who were street homeless for administrative removal from the UK, on the basis that they were 'misusing' their free movement rights. Formally the policy applied to all EU citizens; yet, by focusing its expulsion efforts on some of the most socially marginalised, the programme was inevitably tilted towards Eastern Europeans (Jones, 2017). ${ }^{25}$ The deportation of EU nationals caught up

\footnotetext{
${ }^{24}$ I explain further in Chapter Two how the assignment of 'cultural difference' functions to constitute people as racially undesirable.

${ }^{25}$ Following a legal challenge brought by the Public Interest Law Unit and North East London Migrant Action, this policy was ruled unlawful in 2017 (Taylor, 2017b).
} 
in the criminal justice system can be understood as another way in which free movement rights are being cut through for Eastern Europeans. Again, reflecting their broader social marginalisation, people from Poland and Romania make up the two largest groups of EU nationals in prison (Sturge, 2019b), so a policy that is apparently not specifically targeted is actually inevitably skewed towards them. Indeed, the policy of deporting foreign nationals in the criminal justice system more broadly can be seen as another key way in which successive UK governments have controlled and restricted non-white and 'not quite white' migration. Formally, this policy is 'raceless', applying to all non-citizens. In practice, however, their social exclusion - alongside the institutional racism of criminal justice agencies and institutions - means that people originally from countries in the Global South and Southern and Eastern Europe are the non-citizens who are most often criminalised. Thus, the effects of injecting border control measures into the criminal justice system are entirely 'race-ful' - or, we might more explicitly say, wholly racist.

It is important to emphasise, of course, that while the UK's contemporary immigration regime has targeted both people who are not white and those who are deemed to be 'not quite white', there are distinct differences in their treatment. As highlighted earlier, for example, at the point of EU enlargement 'low skilled' workers from Eastern Europe were clearly elevated above those from the Global South. Indeed, the current division between EU and non-EU migration in the UK's border control system means that people who are not white are, overall, subjected to a far more exclusionary regime (Back, 2007). Thus, drawing on Garner's identification that the race-inflected immigration policies of EU member states operate according to a 'three-part division' (2017, p.201), I would suggest that the UK's current migration system might be seen as racially differentiating in the following way.

At the top of the immigration hierarchy is white migration from Western Europe, North America and Australasia, which is rarely deemed to be problematic and is not broadly targeted by specific policies. If individual white people from these countries do get caught up 
in the UK's immigration controls, their treatment often receives negative media attention and is condemned by politicians (see, for instance, Burrows, 2016; Cockcroft and Duell, 2016) and, in many instances, the Home Office reverses its original decision. ${ }^{26}$ Below this comes 'not quite white' migration from Southern and Eastern Europe, which is often deemed to be problematic and is targeted and curtailed by immigration policies in certain ways. Finally, at the bottom of the hierarchy comes non-white migration from the Global South, which is almost always held to be problematic and is restricted and blocked through a wide range of policies and legislation. It is worth highlighting that, following the Brexit referendum and the UK's departure from the EU, plans for a new immigration system - to be implemented from the end of the transition period, and so from January 2021 - have recently been set out. In a policy statement issued in February 2020, the current Conservative government insisted that this new system will be fairer than the present one, as it will ensure that 'EU and non-EU citizens will be treated equally' (Home Office, 2020). Yet, as Frances Webber (2019) has argued, ${ }^{27}$ what the government has proposed seems merely to reproduce the racial hierarchies that are currently in place.

Identifying race and racism as central to the UK's immigration regime is critical for thinking about and understanding contemporary narratives of bordering. As I will demonstrate in the following chapter, these government and media narratives are almost only ever attached to people from countries in the Global South and Southern and Eastern Europe; white migrants from Western Europe, North America and Australasia rarely, if ever, make an appearance (Back, Sinha and Bryan, 2012). Crucially, moreover, we will see that it is through racialisation that narratives of bordering stigmatise the 'unwanted' migrants on whom they

\footnotetext{
${ }^{26}$ In contrast to this, while people of colour who are citizens of countries in Western Europe, North America or Australasia are not targeted by the UK's immigration controls at a structural or policy level, they are frequently problematised individually - for instance, during interactions with immigration officials at the border. ${ }^{27}$ Webber's analysis is actually focused on a White Paper published in December 2018, The UK's Future Skillsbased Immigration System (Home Office, 2018). However, what has subsequently been proposed by the government in the February 2020 policy statement is, broadly, the same.
} 
focus and justify their exclusion. That is, these narratives problematise 'unwanted' migrants by constituting them in racial terms - by disparaging them, specifically, as racially inferior and deviant (Garner and Selod, 2015; Murji and Solomos, 2005).

Importantly, however, as I will show, even when they are problematising people with darker skin dominant narratives of bordering do not use the overt language of race; they do not categorise and inferiorise in terms of biological or somatic difference. Rather, they problematise racially in more coded ways. So, they utilise the 'indirect, subtle' (Phillips and Webster, 2014, p.7) language of culture, for instance, to which I have already referred, as well as the register of nationality. They also engage in a more 'abstract' (Garner, 2013, p.504) racialising process, through which non-white and 'not quite white' migrants are essentialised and homogenised as 'a group with similar pathological characteristics' (2013, p.508). As I suggested earlier, therefore, present-day government and media depictions of unwanted migrants draw on earlier negative narratives about immigration, but render them more acceptable for the current era. Thus, as I now go on to map out and analyse the core narratives of bordering of the present period, I will show how they racialise and 'other' migrants who are unwelcome in a distinctly contemporary and, in fact, 'post-racial' way.

\section{Conclusion}

In this chapter, I have situated my research in relation to the existing criminological literature on migration and border control. Firstly, building on the scholarship that has documented the overt changes to the police, courts and prisons in the current era as they have been injected with practices of immigration enforcement, I have suggested that we might also be able to detect the mark of border control on criminal justice in further, more subtle ways.

Specifically, I have set out my interest in the narratives disseminated by the UK government and media in the present period, which problematise migrants and justify their targeting by the direct activities of border enforcement; and in how these narratives of bordering might be 
percolating into one stage of the court process - the practice of the sentencing hearing.

Alongside this, against the tendency of some of the earlier contributions to border

criminology to sideline the significance of race, I have demonstrated how - as some of the more recent interventions in the field have emphasised - racism runs through and structures the UK's immigration regime. Thus, as I now proceed in Chapter Two to trace and explore the most prominent narratives of bordering of the contemporary era, I centralise this frame of analysis, and show that approaching depictions of unwanted migrants specifically in terms of racialisation is critical to fully understanding them. 


\section{Chapter 2}

\section{The Problematisation of 'Unwanted' Migrants: Dominant, Racialised Narratives of Bordering}

\section{Introduction}

In this chapter, I turn my attention to the narratives disseminated by the UK government and media in the contemporary era that problematise 'unwanted' migrants and justify their targeting by border enforcement. As I suggested in Chapter One, although criminologists have not ignored these dominant narratives, they have not centralised them in their analyses, either; in this way, they have been presented as more of a subsidiary practice, alongside the 'main event' of the direct activities of immigration control. Moreover, when criminologists have focused on these narratives, they have often identified them as functioning through a criminalised imagery. Thus it has been explained that - reflecting the growing convergence between immigration enforcement and criminal justice in the current era - government and media depictions present migrants as disorderly and dangerous, as 'shadowy figures' (Bosworth and Guild, 2008, p.707) and criminals, in order to justify their exclusion (see also Gerard and Pickering, 2013; Bosworth, 2008; Weber and Bowling, 2004; Weber, 2002). Undoubtedly, the negative representations of migrants that are dominant in the current era can be seen as operating in this way. Yet, as I began to set out in the previous chapter, I would suggest that they can be more fully understood through the framework of race and racism.

We will see in this chapter, therefore, how - in line with the UK's actual border controls - contemporary narratives of bordering focus on people from countries in the Global South and Southern and Eastern Europe. The significant number of white migrants who come to the UK from Western Europe, North America and Australasia rarely, if ever, make an appearance. Crucially, moreover, it is through racialisation that narratives of bordering 
problematise the unwanted migrants on whom they focus and legitimise their exclusion; so, by constructing and classifying them in racial terms, by demeaning them, specifically, as racially different and deviant. There is a clear continuity, then, between the narratives of bordering of the present and the racist narratives about immigration of the past. As I indicated in Chapter One, indeed, the narratives that have become entrenched in the current period often draw on the stories disseminated about unwanted migrants historically, recycling the same tropes and claims about them that have gone before. At the same time, however, the narratives that are dominant now also look very different to those that preceded them: the racialisation of unwanted migrants in present-day government and media depictions plays out in a distinctly contemporary way. Critics writing about race have pointed to the 'coding' (Phillips and Webster, 2014; Murji and Solomos, 2005; Solomos and Back, 1996) of racialised expression in the current era, as explicit racism has become socially unacceptable and taboo - and, as I will draw out, such coding is precisely what we see in contemporary portrayals of unwanted migrants. The narratives that I trace in this chapter do not deploy the overt language of race: they do not categorise and stigmatise in terms of biological or phenotypical difference. Rather, they racialise and 'other' migrants who are unwelcome in a range of more subtle and sanitised ways - and, through this, they obscure and disguise their racism.

Building on this, we might also understand the coded, muted racialisation of contemporary narratives of bordering in an additional way. Parmar (2016a) has suggested that the racialisation of unwanted migrants through the 'safe mode of expression' of nationality - a register that I trace running through narratives of bordering later in the chapter - might be seen as 'a continuation of raciological articulation in post-racial times'. This idea - of the coded articulations of race in the present as distinctly 'post-racial' modes of expression - is a very useful way of conceptualising them. Goldberg (2015) has set out that rather than representing the overcoming or end of race, what characterises the 'post-racial' 
present is in fact the denial and dismissal of racism as an ongoing mode of oppression, even as it clearly continues to structure and order our societies. Coded modes of articulation, then - expressions that are not racially explicit and thus are stripped of 'the stain of the racial' (2015, p.55) - facilitate this denial (see also Parmar, 2019). Later in his analysis, comparing the post-racial with the post-colonial, Goldberg also identifies what is specifically 'post' about post-raciality in the following way: 'Racisms reprise at the very moment of racial erasure - only now unmarked, less seen and recognizable. So just as the "post-" in the postcolonial is not the end but the afterlife of the colonial, so too the "post" in postraciality: the afterlife, the ghostly haunting by the racial of the social supposedly rid of the racial' (2015, pp.154-155). There is something here, I think, about Goldberg's particular identification of post-racial racisms in terms of a 'ghostly haunting' - we might say, then, as there, and yet not quite there - that really captures the nature of the racialisation that we see in contemporary narratives of bordering. It suggests the near intangibility of their racism, how this can feel difficult to mark out and pin down clearly - even as they are definitely racially demarcating unwanted migrants, even as they are undoubtedly differentiating and disparaging them in this specific way.

There are, as I started to sketch out in Chapter One, some key narratives of bordering in the current era, each of which centres on a specific protagonist and follows a clearly defined plotline. These include the narrative of the immigration cheat, who defrauds and abuses the UK's immigration system, and that of the parasitical scrounger, who exploits the welfare benefits system as well as other public services and resources including the NHS. There is also a series of narratives that centre on protagonists who constitute a more overt threat: the criminal, the terrorist and the sexual predator. As I trace these narratives and analyse their racialisation of unwanted migrants, I draw attention, too, to some apparently different government and media depictions, which sometimes appear alongside them. Sukhwant Dhaliwal and Kirsten Forkert have highlighted how dominant representations of 
migrants do not only 'devalue' them but also, in fact, 'distinguish between types' (2016, p.50) - so, they differentiate between 'deserving' and 'undeserving' migrants, between those who are good and those who are bad. Bearing this out, contemporary government and media narratives have indeed reclassified some of those who would normally be deemed as 'unwanted' migrants as desirable, or deserving. As we will see, the elevation of some unwanted migrants in this way has usually unfolded along lines of further racial differentiation and stratification, as well as through intersections with gender, and class. While they are ostensibly concerned with inclusion and opening up the border, then, as they stratify and hierarchise unwanted migrants like this, marking out only a minority as acceptable to be let in, these depictions reveal themselves as very much not the converse of narratives of bordering. They function, instead, as an integral part of the overall regime of exclusion, insisting that the entry of unwanted outsiders can only ever happen on a limited or occasional basis - and, therefore, that the general rule of bordering must remain firmly in place (Sales, 2005).

\section{'I am seeing a great growth of people abusing the system': The narrative of the}

\section{manipulative immigration cheat}

I begin mapping the key narratives of bordering of the contemporary era by tracing a narrative that was disseminated for the first time in the 1980s, although, as I will later suggest, its origins can be traced back further than this: the narrative of the immigration cheat, who defrauds and abuses the UK's immigration system. As I will show, claims about the deceptiveness of unwanted migrants and their manipulation of immigration controls have been attached, by successive governments and the media, to a range of different groups.

Since it first emerged, however, the narrative of the abusive immigration cheat has been most prominently and persistently associated with people seeking asylum. 
Government claims about the fraudulence and 'bogusness' of the majority of those seeking asylum started to appear in the mid-1980s, and really gathered pace across the 1990s and 2000s, as the UK dealt with increasing numbers of applications for protection. As critics have noted, the idea of the asylum applicant who is in fact an 'economic migrant' - not fleeing violence, conflict or persecution, but simply in search of a more comfortable and prosperous life - has been central to successive governments' claims. Nick Lynn and Susan Lea (2003) have highlighted how assertions about asylum seekers who are actually economic migrants emerged for the first time in around 1985, under Margaret Thatcher's Conservative government, in relation to Tamils fleeing civil war in Sri Lanka. Following this, as events in Eastern Europe in particular, including the breakup of Yugoslavia, resulted in rising asylum applications in the UK across the first half of the 1990s, the Conservatives introduced the first pieces of primary legislation 'dealing specifically with asylum' (Bloch, 2000, p.30).

Alongside this, they continued disseminating the 'economic migrants posing as asylum seekers’ claim (Bloch, 2000; Kaye, 1994). In 1997 Tony Blair’s landslide general election victory ended almost 20 years of Conservative rule - and yet, the idea of the defrauding and exploitation of the asylum system by economic migrants did not disappear at this point, but was taken up with equal if not increased enthusiasm by New Labour.

New Labour's first major policy document on immigration was the 1998 White Paper Fairer, Faster, Firmer; this led to measures including some of the internal asylum controls that I documented in Chapter One, which were aimed at making life hard for people who had managed to get to the UK. In Fairer, Faster, Firmer, New Labour insisted upon the vital importance of 'modernising our [immigration] controls' - because of the 'large numbers of economic migrants [who] are abusing the system by claiming asylum' (Home Office, 1998, p.3). Later in the document, indeed, this accusation was levelled in even starker terms, as it was explained: 'There is no doubt that the asylum system is being abused by those seeking to migrate for purely economic reasons. Many claims are simply a tissue of lies' (1998, p.12). 
On the day of the document's publication Jack Straw, the then Home Secretary, supported the charge of widespread lying and abuse of the asylum system by pointing to Home Office statistics. The Times quoted him as saying, 'We are going to get tougher. In the past ten years we have seen a tenfold increase in the number of people claiming asylum' (Ford, 1998, p.41). Straw's claim about the rise in asylum applications was accurate. Yet, his use of these figures without any sort of context or explanation - without any acknowledgement of, for instance, the political upheaval and conflict in Eastern Europe, and other world events, that had driven this increase - was deliberately misleading. We see here, therefore, a clear example of the fabrication and invention that, as I suggested in Chapter One, runs through government and media depictions of unwanted migrants, and which makes the use of the term 'narrative' for them particularly appropriate.

Alongside this Straw utilised another tactic which, I suggested in the previous chapter as well, also makes understanding these dominant depictions specifically as stories or narratives fitting. As he insisted, 'As a constituency MP, I am seeing a great growth of people abusing the asylum system simply to evade immigration control or because they are economic migrants to this country' (Ford, 1998, p.41), he deployed 'the technique of personal anecdote' (Kaye, 2001, p.65) to substantiate his allegations about the routine exploitation of the asylum system. The need to tackle the problem of 'abusive claimants' (Home Office, 1998, p.3) who were falsely making applications for protection became, during New Labour's time in government, a key refrain (Schuster and Solomos, 2004; Schuster, 2003a). Indeed, it was also under New Labour that another assertion about the abusiveness of those seeking asylum became embedded - that, by making false claims, applicants were not only taking advantage of the asylum system but were also 'abusing our hospitality' (Gibson, 2007). In this formulation the manipulation of bogus applicants is emphasised even further, as their abuse is directed not simply at a system but at 'our' generosity and kindness; the 
cynical manoeuvring of fraudulent claimants contrasts sharply with the allegedly guileless welcome of the British people.

Since the return to a Conservative government from 2010 and in response, in particular, to the sharp rise in refugees coming from the Global South to Europe in 2015 during the so-called refugee 'crisis', the narrative of the abusive asylum applicant has been reinvigorated and remobilised. In her speech to the Conservative Party conference in October 2015, for example, Theresa May, the then Home Secretary, repeatedly insisted on the longstanding and ongoing abuse of the UK's asylum system. In fact, during the 14 minutes of her speech where she focused on asylum she referred to the 'abuse' or 'manipulation' of the system no fewer than 11 times (The Independent, 2015). Like Jack Straw before her, May pointed to the significant rise in asylum applications during the 1990s to back up her claims. Building on his use of de-contextualised and thus misleading data, moreover, she also emphasised how 'more than half of all asylum claims fail' - deliberately neglecting to situate this high refusal rate in terms of successive governments' determination to prevent asylum claimants from remaining in the UK. ${ }^{1}$ She supported her allegations of fraudulence, as well, by setting out that the majority of people arriving in the UK and claiming asylum were not in fact 'the most vulnerable' but, rather, 'young men' (The Independent, 2015). The idea that the high proportion of men amongst those who manage to make the hazardous journey to the West is evidence of the falsity of many asylum claims was, predictably, disseminated under New Labour, too. In 2002, for instance, Lord Rooker, then Immigration Minister, 'denigrated "most asylum-seekers" as "single men who have deserted their families for economic gain"” (Schuster, 2003a, p.246). Throughout her speech May insisted, as per the convention, that most asylum claimants are in fact 'economic migrants who simply want to live in a more

\footnotetext{
${ }^{1}$ As Alice Bloch (2000) has highlighted, at the beginning of the 1990s around one in five applications for asylum were refused. By 1997, however, the refusal rate on initial applications had jumped significantly, reaching $80 \%$. Since then - while there have been fluctuations over the years - it has consistently been the case that the Home Office has rejected the majority of asylum claims. In 2018, the refusal rate on initial applications stood at $67 \%$ (Sturge, 2019a).
} 
prosperous society'. Alongside this, she also made several references to those trying to reach the UK as 'illegal' (The Independent, 2015) - a term that was deployed routinely under New Labour, as well (Philo, Briant and Donald, 2013; Webber, 2004).

The idea that many of those who seek asylum are liars who are defrauding the system is a claim that, since the early 1990s, has also been made consistently by significant sections of the UK media, both tabloids and broadsheets alike (Philo, Briant and Donald, 2013; ICAR, 2004; Buchanan, Grillo and Threadgold, 2003; Coole, 2002; Kaye, 2001, 1998). In their analysis of UK press coverage of asylum issues during periods in 2006 and 2011, Philo, Briant and Donald highlight the frequent references to 'bogus asylum seekers', 'asylum cheats' and 'frauds', as well as to the 'scamming', 'abuse' and 'exploitation' (2013, p.104) of the asylum system. They point, too, to how the media, like successive governments, have repeatedly insisted that large proportions of those seeking asylum are in fact 'economic migrants', or 'illegal'. These terms also featured heavily in the more recent coverage of the rising levels of forced migration to Europe in 2015 (Bhatia, 2018; Berry, Garcia-Blanco and Moore, 2015), as did the term 'migrant', as well. Importantly, as Seth Holmes and Heide Castañeda have highlighted, the insistence by much of the media reporting that what was unfolding was not a 'refugee crisis' but a 'migrant crisis', instead, 'subtly delegitimize[d] calls for protection' (2016, p.16). Through this, therefore, the duplicity of the majority of people forced to flee their countries and arriving in Europe was relentlessly asserted.

Defrauding and manipulating the UK's immigration system has, then, been very visibly and persistently attached to those seeking asylum. Less well-documented, perhaps, is how the narrative of the deceitful and abusive immigration cheat also extends beyond them. Back, Sinha and Bryan have pointed out how, for instance, the idea of 'bogus students', 'who are accused of using higher learning illegitimately to gain visas' (2012, p.142), has become 
prominent in recent years. ${ }^{2}$ Yuval-Davis, Anthias and Kofman have also highlighted how a concern with 'bogus' or 'sham marriages', raised previously in the late 1970s - which eventually saw the introduction of the 'primary purpose' rule, designed by the then Conservative government 'to reduce the entry of South Asian males' (2005, p.532) resurfaced under New Labour. Indeed, since the re-election of the Conservatives in 2010 this concern has sustained. In 2011, for example, when the government published proposals on family migration, it announced its intention to 'crack down on abuse of the family route' (Home Office, 2011, p.3) including by 'tackling sham marriage' (2011, p.31). To evidence the need for action, the consultation document cited three individual examples - or, we might say, anecdotes - of 'sham marriages' uncovered by immigration officers. Predictably, this duplicitous practice was firmly attached to non-white and 'not quite white' migrants, as two of the three examples given involved women from Eastern European countries in the EU marrying men from India and Pakistan.

Particularly since the 2012 announcement of the Conservatives' 'hostile environment' policy, which I touched on in Chapter One, the government has also repeatedly characterised those who are in the country without valid status - classified as 'illegal immigrants' - as engaged in the 'abuse' of the UK's immigration system (Home Office, 2015d, 2014, 2013). Defrauding the system has likewise been attributed to people the government is trying to expel because of their criminal convictions. That 'foreign criminals' routinely 'use weak human rights claims to dodge deportation' (Home Office, 2012), or lodge 'spurious' appeals to 'delay their removal' and 'cheat the system' (Home Office, 2015b), have become common government refrains. ${ }^{3}$ During her speech at the Conservative Party conference in 2011

\footnotetext{
${ }^{2}$ Providing another example of the fabrication that runs through narratives of bordering, government claims about the routine exploitation of the student visa system - and, in particular, that significant numbers of those coming to the UK as students were not leaving when their visas expired - were found in 2017 to be completely invented. A report published by the Office for National Statistics (2017) set out that 'there is no evidence of a major issue of non-EU students overstaying their entitlement to stay'.

${ }^{3}$ It is worth highlighting that, despite the government's insistence that 'foreign criminals' are routinely working to manipulate and undermine the UK's immigration system, the majority of appeals against deportation on the basis of criminal convictions are not upheld. In 2010, for instance, just $8 \%$ of appeals against deportation on the
} 
Theresa May relayed a series of anecdotes to support her claims of 'foreign criminals' manipulating and cheating the immigration system, as she insisted: 'We all know the stories ... The violent drug dealer who cannot be sent home because his daughter, for whom he pays no maintenance, lives here. The robber who cannot be removed because he has a girlfriend' (Politics.co.uk, 2011). Turning, in her final example, to the abuse allegedly perpetrated not just by those convicted of offences but within the immigration system more broadly, she revived a story that had first appeared in the Sunday Telegraph two years previously (Barrett, 2009). Thus, she recounted with incredulity the case of 'the illegal immigrant who cannot be deported because ... he had a pet cat'. May insisted on the veracity of her anecdote, as she explicitly stated during the speech 'I am not making this up' (Politics.co.uk, 2011). Yet, it later transpired - in keeping with the concoction and invention which, I have suggested, run through government and media narratives about unwanted migrants - that she, and indeed the newspaper that originally ran the story, very much had. ${ }^{4}$

The trope of the scheming 'foreign criminal' who plays and exploits the immigration system runs through media reporting, as well. Since the 2006 foreign national prisoner 'crisis', which I highlighted in the previous chapter, press coverage of 'foreign crime' in the UK has increased dramatically (de Noronha, 2018b) - and, within this, individual cases or stories of non-citizens convicted of offences are often reported on. From a search of national newspapers that I conducted, for instance, covering the period $6^{\text {th }}$ July 2012 to $6^{\text {th }}$ July 2014 , I was able to identify 330 articles reporting on the cases of 86 individual 'foreign criminals' 5

\footnotetext{
basis of criminal convictions were successful (Klug, 2013). Thus, we see another instance of distortion and falsification here: 'foreign criminals' are not managing to 'dodge deportation' or 'cheat the system' at all. ${ }^{4}$ In this case, joint ownership of a cat was cited by a man facing removal from the UK to help evidence that he was in a long-term relationship. However, it was his relationship with his partner, and not their pet cat, that was the reason for him winning his appeal and not being ejected from the UK (Full Fact, 2011). As the Full Fact website highlights, when the case was first covered in the media the Judicial Office released a statement explaining that what was being reported was not true; when Theresa May made the claim two years later in her conference speech, the Judicial Office issued the same statement again.

${ }^{5}$ Using Nexis, I conducted a search of UK national newspapers covering the period $6^{\text {th }}$ July 2012 to $6^{\text {th }}$ July 2014. In the first instance I conducted two separate searches, using the search terms 'foreign criminal' and, subsequently, 'foreign national AND crime', which returned 1,882 and 781 results respectively. Alongside general reports on 'foreign criminals' - which I touch on at later points in this chapter - many of the articles
} 
Importantly, the vast majority of these reports were concerned with people who were not white, or those deemed to be 'not quite white'. Eighty-four of the 86 non-citizens whose cases were covered were originally from countries in the Global South or Southern and Eastern Europe.

Across the reports that I identified, there was often an emphasis on how a particular 'foreign criminal' had supposedly managed to 'dodge deportation' or 'cheat the system'. We see a clear example of this in an article published on the front page of the Sunday Telegraph in April 2013, which focused on the case of Hesham Mohammed Ali, a 'drug dealer immigrant' originally from Iraq. The article explained that Ali had avoided deportation by "convinc[ing] a judge he had a "family life" which had to be respected because he had a "genuine" relationship with a British woman - despite already having two children by different women with whom he now has no contact'. It emphasised his alleged fraudulence and manipulation of the immigration system further as it then added another detail from his deportation appeal. Thus, the article stated: 'Ali also mounted an extraordinary claim that his life would be in danger in his native Iraq because he was covered in tattoos, including a halfnaked Western woman - a claim which was only dismissed after exhaustive legal examination' (Barrett, 2013, p.1).

The article quoted the Home Office as saying that the case showed further legislation was needed 'to prevent foreign nationals remaining in the UK through abuse of the Human Rights Act', as well as Dominic Raab, the Conservative MP, who characterised Ali as 'a convicted drug dealer cheating deportation'. It then concluded by reviving the anecdote referred to above, about the 'illegal immigrant' and his cat. Thus, the article insisted: 'The

\footnotetext{
identified through these searches focused on the cases of individual non-citizens convicted of offences; I subsequently conducted follow-up searches on these individuals to ensure that I gathered all coverage on them over the time period set out above. I fully recognise the imperfections of my method: I would like to have conducted initial searches using a wider variety of search terms, for instance. I also recognise that, as I carried out this search in the earlier stages of researching my thesis, it may now seem rather out-of-date. There are limitations to it, then - but, in spite of this, I believe it still offers an insight into some of the core features of 'foreign criminal' media coverage.
} 
case raises new concerns over the arguments sometimes put forward by foreigners who are seeking to stay in Britain, such as the Bolivian man ... [who] argued that he should not be deported partly because he and his boyfriend had bought a pet cat' (Barrett, 2013, pp.1-2). Here, then, we see how a story that started out in the Sunday Telegraph in 2009, which was subsequently retold by Theresa May in 2011, was recited, once again, by the same newspaper in 2013. This example provides a stark illustration, therefore, of the repetition and reinforcing of one another that characterises government and media narratives about unwanted migrants - which, drawing on De Certeau's (1984) work, I suggested in Chapter One helps to ensure that their fabricated claims are accepted as truth. The mobilisation of this specific anecdote can also be understood through the lens of the repetitive accumulation of key stigmatised figures, a mechanism which - making use of Jensen and Tyler's research on the 'cultural and political crafting of anti-welfare commonsense' $(2015, \mathrm{p} .470)$ - I also underlined in Chapter One. So, as this individual case or story was repeated across political and media sites, it contributed to the recurrent and consistent materialisation of the problematic figure of the abusive and exploitative immigration cheat. Consequently, through such 'repetitive mediations' (Jensen and Tyler, 2015, p.479), disparaging ideas about unwanted migrants become cemented in the public consciousness and emerge as widely believed.

\section{The abusive and manipulative immigration cheat: A racialised narrative of bordering}

On one level, constructing those seeking asylum, in particular, as liars and cheats who are defrauding the system functions to legitimise their exclusion through, quite simply, denial. Such a narrative insists that the vast majority of people seeking protection do not really need it and we are, therefore, fully justified in keeping them out. As Kushner has highlighted, then, 'avoidance or denial of the existence of refugees' (2003, p.265) has become central to enabling harsh policies against them. As part of this strategy, Kushner points also to the practice of re-labelling and reclassifying refugees - which we see clearly, of course, in the 
government and media's repeated claims that the majority of people seeking sanctuary are in fact 'economic migrants' or 'illegal immigrants'. Yet, alongside avoidance and denial, depicting people seeking asylum and, indeed, unwanted migrants more broadly in terms of their persistent duping and scheming, their allegedly endless exploitation of the immigration system, is doing something else, as well. Specifically, it problematises and stigmatises those it targets through racialisation.

As I highlighted in the introduction to this chapter, critics writing about race have explained how, as explicitly racist language and forms of expression have become increasingly socially unacceptable, ideas about racial difference have been 'coded' in various ways in order to 'circumvent accusations of racism' (Solomos and Back, 1996, p.18). One of the key forms of coding that has been pointed to in the contemporary era is the growing reliance on the 'indirect, subtle' (Phillips and Webster, 2014, p.7) language of culture (see also Patel and Connelly, 2019; Lentin and Titley, 2011). ${ }^{6}$ As Lentin and Titley (2011) have explained, those who deploy this language often insist that, since they are not referring to physiognomy or to phenotypical difference, it cannot be racist to speak or write in this way. Yet, as Lentin and Titley go on to highlight, 'culture talk' operates in exactly the same manner as the language of biological race, as undesirable cultural attributes and traits are assigned as 'fixed and unchangeable' (2011, p.63) - and as they are, moreover, attributed on a blanket basis, to huge swathes of people. Thus, the apparently innocent register of culture 'performs the work of race' (2011, p.54); it essentialises and homogenises and, therefore, disparages entire groups of people. What plays out in the assignment of 'cultural difference', then, is a process of racialisation. As groups who are framed in this way are constituted as homogenous masses, with negative qualities and characteristics, 'race' is made, even as the

\footnotetext{
${ }^{6}$ As scholars including Lentin and Titley (2011) have explained, ideas about culture have in fact long been deployed in formulations of racial difference; thus, the positioning by some of 'cultural racism' as the 'new' racism is not entirely accurate. As Lentin and Titley highlight, however, the recourse to the language of culture in contemporary expressions of racialised difference has become increasingly prominent.
} 
overt language of racial difference is never deployed (see also Garner and Selod, 2015;

Kushner, 2005).

The identification of the coding of race in the contemporary era, and the recognition that it is more sanitised registers which might be now effecting racialisation, is critical for understanding government and media representations of fraudulent, abusive migrants in this way. The explicitly racial language of biological or somatic difference is nowhere to be found in this dominant depiction. Nor, indeed, do we see in this instance any recourse to notions of culture or cultural difference - although, as I will show later in this chapter, appeals to ideas of their problematic cultural traits do appear in contemporary narratives about migrants who are unwelcome. Yet, as government and media depictions insist that 'asylum seekers', 'economic migrants', 'illegal immigrants' and 'foreign criminals' are routinely duping and manipulating the immigration system, they ascribe to them a particular propensity, or natural tendency, to dissemble and deceive; they fix them, collectively, as inherent fraudsters and liars. Hence, the narrative of the immigration cheat can also be seen to "perform the work of race'. As it portrays the non-white and 'not quite white' migrants it targets like this, it produces them as a homogenous bloc with undesirable qualities and traits - in order to justify their targeting by border practices and exclusion from the UK. In their analysis of racialisation, Garner and Selod answer the question 'So what does racialization actually do?' with the response 'It draws a line around all the members of a group; instigates 'group-ness', and ascribes characteristics' $(2015, \mathrm{p} .14)$ - and this is precisely what we see in the narrative of the immigration cheat. The distinct processes of essentialisation and homogenisation through which it stigmatises and inferiorises non-white and 'not quite white' migrants means that they are being racialised; that is, that race-thinking and race-making run through this dominant narrative.

Reading the narrative of the immigration cheat like this - uncovering the process of race-making, specifically, that runs through it - finds further support, indeed, from Garner's 
(2013) analysis of the portrayal of asylum seekers by local residents objecting to the building of an asylum processing centre in Portishead, near Bristol, in 2004. In his analysis Garner identifies how people seeking asylum, although 'phenotypically and culturally highly diverse' (2013, p.504) - or, as he puts it later, a “"multi-racial” group' - were nonetheless constructed in the residents' letters of objection as 'a bounded entity', with 'a homogenous set of characteristics' (2013, p.507). He argues, then, that as asylum seekers were essentialised and homogenised by the local residents' depictions, as they were 'transformed discursively into a group with similar pathological characteristics and behaviours' (2013, p.508), they were produced, quite simply, as a 'race' (see also Hubbard, 2005). As Garner explains, therefore, racialisation takes place not only when people are categorised and problematised in terms of their physical appearance, or even - as I have explained happens increasingly - through reference to their culture. It can occur, too, when neither of these registers are present, 'as a more abstract process of attributing innate characteristics to all members of a given group' (Garner, 2013, p.504, see also Garner, 2017).

It might be argued that the processes of essentialisation and homogenisation which are effected through the narrative of the immigration cheat, which work to pathologise and vilify non-white and 'not quite white' migrants, can be better understood through the framework of xeno-racism. Writing in the early 2000s, Sivanandan theorised xeno-racism as 'a racism that is not just directed at those with darker skins, from the former colonial territories, but at the newer categories of the displaced, the dispossessed and the uprooted' (2001, cited by Fekete, 2001, p.23), including people seeking asylum from countries in Eastern Europe. Thus, he explained that the demonisation of asylum seekers as, for instance, a mass of liars and cheats, functions through the same mechanisms as 'the old racism', and so is 'racism in substance', because 'it denigrates and reifies people before segregating and/or expelling them'. However, since such vilifying depictions target unwanted white people as well, and therefore are not 'colour-coded', they are "“xeno" in form' - and hence should be specifically understood in 
terms of 'xeno-racism' (2001, cited by Fekete, 2001, p.24). I fully recognise this argument, of course. I also understand, concomitantly, that describing dominant narratives that target nonwhite and 'not quite white' migrants in terms of racism, rather than xeno-racism, might be viewed as problematic, since it might be seen to deny there are differences between how migrants of colour, and those with lighter skin, are treated.

I do not mean to deny these differences in treatment. As I highlighted in the final section of Chapter One, the actual immigration controls to which migrants of colour are subjected have consistently been harsher and more exclusionary than those imposed on ostensibly white 'unwanted' migrants. Additionally, although I document how narratives of bordering often demarcate non-white and 'not quite white' migrants as a pathological collective throughout this chapter, I also draw attention to the racial differentiation and stratification that can simultaneously be detected within these dominant representations. As we will see, this includes how people with darker skin have consistently been designated as abusive asylum cheats, whereas some groups of white 'unwanted' migrants have, at points, been elevated to the position of 'genuine' claimants. It also includes how black migrant men have been particularly prominently associated with violent and sexual offending. By framing the essentialising and homogenising of non-white and 'not quite white' migrants that is carried out by narratives of bordering unequivocally in terms of racism, then, my aim is more to ensure that I do not dilute or downplay the charge that I am levelling at these dominant depictions. In doing so, I am following scholars like Garner who, as I have explained, presents derogatory narratives targeting 'multi-racial' migrant groups through this lens, as well as others who have argued for more expansive understandings of racialisation, to ensure that the processes at work in such depictions are not trivialised or underplayed (Schuster, 2003a; see also McVeigh and Lentin, 2002).

As I suggested in the introduction to this chapter, the subtle and muted pathologisation of unwanted migrants that unfolds in the narrative of the immigration cheat 
might be understood as a distinctly 'post-racial' form of racialisation. This is because its coded nature facilitates the denial of racism that characterises the contemporary era - but also because the 'post' in post-raciality particularly draws out the near intangibility of such formulations, the 'there and yet not quite there' quality of their racism. ${ }^{7}$ Bearing this near intangibility out, indeed, as I have shown, a significant body of literature has documented how the government and media have persistently portrayed people seeking asylum, in particular, as liars and cheats. Yet, this depiction has not always been clearly identified by the academics tracing it - often migration scholars - as racist (though for an exception see Schuster, 2003a). This can, undoubtedly, be situated in terms of the failure of much contemporary migration scholarship - like border criminology, and criminology more broadly - to foreground issues of race and racism (Erel, Murji and Nahaboo, 2016; Lentin, 2014). But it is also related, I think, to the careful navigation of race that we see in the dominant narrative of the immigration cheat: the way that it invokes and assigns racial undesirability and 'otherness' without ever explicitly speaking its name.

It is, additionally, important to pay attention to the various terms used to classify unwanted migrants, which have become closely associated with the narrative of the immigration cheat: as I suggested above, 'asylum seeker', 'economic migrant', 'illegal immigrant' and 'foreign criminal' - as well as, quite simply, 'migrant' and 'immigrant'. Anderson has highlighted that 'terms like "asylum seeker" are not simply descriptive of legal status'; rather, 'they are value laden and negative' (2013, p.4). Putting it more emphatically, Philo, Briant and Donald have suggested that 'asylum seeker', as well as 'refugee', have 'become generic terms for what is perceived as bad behaviour by new groups of people'

\footnotetext{
${ }^{7}$ I recognise, of course, that by identifying a narrative that emerges in the mid-1980s as a specifically post-racial form of expression I might be seen to be stretching the beginnings of post-raciality somewhat; Goldberg (2015) suggests, for instance, that we see the emergence of the post-racial present from the late 1990s onwards. As my analysis indicates, however, it was really following the election of New Labour in 1997 that the narrative of the immigration cheat became widespread and embedded - and, therefore, recognising it as a distinctly post-racial depiction feels appropriate.
} 
(2013, p.133); even more starkly, Arun Kundnani has argued that 'asylum seeker' has 'become little more than a term of abuse' (2001, p.43; see also Kaye, 2001). While the recognition that such labels are more than technical or legal descriptions is important, I would suggest, however, that these analyses do not go far enough - that they do not fully capture what is going on here. Terms such as 'economic migrant', 'illegal immigrant' and 'foreign criminal' are not simply deprecating and derogatory. More than this, as they have been repeatedly tied to negative traits and essentialised deviance they have come to connote, by themselves, racial undesirability and 'otherness'. In this way, then, these terms might be understood as now forming, on their own, a novel and euphemistic language of race - as having come to constitute a contemporary and covert code of racial difference and inferiority.

Alongside its lack of overt racial reference, we might also understand the narrative of the abusive immigration cheat as subtle and muted in its stigmatisation of unwanted migrants in one further way. The idea of the fraudulent migrant, duping and deceiving the UK's immigration controls and system is, as I have highlighted, very much a contemporary formulation, emerging from the mid-1980s onwards in response to the onset of mass mobility. Yet, at the same time - to borrow Eithne Luibhéid's observation about present-day depictions of pregnant asylum-seeking women in Ireland - this formulation 'did not materialize from thin air' (2013, p.52). Rather, in another example of the recycling and repetition that characterises narratives of bordering this dominant depiction draws, I would suggest, on long-established ideas about the rule-breaking and criminal proclivities of unwanted foreigners, which have been mobilised in earlier moments to justify restricting and preventing their migration to the UK.

Such ideas were deployed, for instance, in relation to Jewish refugees from Eastern Europe at the beginning of the twentieth century (Kushner, 2005), as well as black Commonwealth citizens coming to the UK following the Second World War (Schuster and Solomos, 2004; Solomos, 2003). As I explore later on in this chapter, ideas about the criminal 
propensities of migrants who are unwelcome undoubtedly still exist. Yet, as I also highlight, in the current era they tend to be circulated most enthusiastically by certain sections of the media, and more explicitly right-wing (though nonetheless mainstream) politicians; they are relied on less centrally, I would suggest, within official government claims. We might, then, see the contemporary narrative of the manipulative immigration system cheat as a less strident reworking of the longer-standing narrative of inherent criminality - related to, but nonetheless sufficiently distant from this established racist trope, and thus acceptable for the government to routinely disseminate.

Opening up the border selectively: The 'genuine' refugee as a narrative of limited inclusion I noted in the introduction to this chapter that, alongside contemporary narratives of bordering, the government and media also disseminate some apparently different depictions, in which some of those who are normally understood as 'unwanted' migrants are reclassified from bad and deviant to good and desirable - and, thus, as acceptable to be let in. A key example of this can be seen in relation to people seeking asylum as, alongside the dominant narrative of the abusive asylum cheat, the existence of some 'genuine' refugees has also been pointed to - who, it is set out, the UK should not exclude but instead actively welcome. Demarcating some people seeking asylum as good and desirable and letting them in has been integral to preserving the UK's idea - or, perhaps, 'myth' (Gibson, 2007, p.160) - of itself as a civilised and humane country. As Sara Ahmed notes, it 'enables the national subject to imagine its own generosity in welcoming some others. The nation is hospitable as it allows those genuine ones to stay' (2015, p.46). And yet, even as it adheres to ideas of migrants who are welcome, and their inclusion, the narrative of the genuine asylum applicant functions not in opposition or as a challenge to the overarching regime of bordering and exclusion - but, rather, as an integral part of it. The insistence, always, is that genuine asylum applicants are small in number; in Fairer, Faster, Firmer, for instance, New Labour contrasted 'those who 
have fled persecution' with the 'large numbers of economic migrants [who] are abusing the system' (Home Office, 1998, p.3; see also Sales, 2005, 2002; Kushner, 2003). Thus, the border is only ever to be 'opened up very selectively' (Yuval-Davis, Anthias and Kofman, 2005, p.520), in an extremely narrow and limited way. The majority of unwanted migrants remain liars and cheats - and, therefore, the overall framework and restrictions of border control must be kept in place.

The demarcation of which limited groups of people might be understood as genuine refugees has sometimes been carved out along gendered lines. As I documented earlier, under both New Labour and the current Conservative government men have often been characterised as fraudulent claimants. Thus, as I explained, in her 2015 party conference speech Theresa May insisted that the 'young men' who made up the majority of those who had managed to reach Europe during the refugee 'crisis' were clearly not 'the most vulnerable' (The Independent, 2015). As Marco Palillo has highlighted, we see here the 'feminization ... of the refugee category', as it is only the 'passive, feminized, helpless subject' (2018, pp.28-29) who is depicted as legitimately in need of protection. The distinction between the vast majority who are abusing the system and the small number who are genuine has, importantly, also been made along racial lines and involved further racial differentiation and stratification. As I have set out, since its emergence the narrative of the abusive asylum cheat has been attached both to people who are not white and those deemed to be 'not quite white'. So, it has essentialised and pathologised these unwanted migrants as a homogenous group, whose tendency to dupe and defraud justifies their exclusion from the UK. Yet, when distinctions between good and bad asylum claimants have been made, predictably, it is often those with lighter skin who have been elevated to the position of genuine.

Schuster highlights how, for instance, during a brief period in 1999 refugees from Kosovo were 'welcomed in Europe' (2003a, p.237). She contrasts their treatment with the 
approach, a few years later, to people fleeing Zimbabwe. As she notes, then, 'in spite of discussions in the British parliament and the Commonwealth concerning the rogue government of Robert Mugabe and his persecution of the opposition group MDC', it was only following 'the fierce struggle of campaigning groups' (2003a, p.237) that the UK government agreed to temporarily suspend deportations. More recently, during the 2015 refugee 'crisis' the death of three-year-old Aylan Kurdi from Syria, whose body was washed ashore on a Turkish beach in September that year, prompted outraged coverage across the media as well as a wave of public compassion. Following this, the UK government began to refer to Syrian refugees as 'genuine' and introduced a small resettlement programme for them. Nadine El-Enany has drawn out the racial hierarchising that runs through the demarcation of people from Syria as genuine refugees. As she explains, while the image of Aylan Kurdi - which featured on the front pages of most UK national newspapers - was potent because he was so young, it was also the 'innocence evoked by the body of a lightskinned child' (2016, p.13) which prompted the sympathetic response to his death. ${ }^{8}$ In contrast, as El-Enany observes, the thousands of people who drowned in the Mediterranean before him, across 2015, received very little attention: 'The images of black African bodies washed up on the shores of Europe's Mediterranean beaches ... did not prompt an equivalent outpouring of compassion and charitable action' (2016, p.14).

Through such examples we see, therefore, how - even as the overt language of race does not appear in contemporary narratives of bordering - somatic difference nonetheless matters in their racialisation of unwanted migrants. Those who are, without fail, marked out as 'fake' asylum seekers, and thus as inherently fraudulent and deviant, are always people with darker skin. Indeed, in the more recent media mobilisations of the narrative of the

\footnotetext{
${ }^{8}$ The identification of people from Syria in this way highlights, of course, the "motility and contingency of racial categories' (Anderson, 2013, p.37). Although people from Syria are often understood - in contrast with white people in Europe, for instance - as having darker skin, in this instance, they were interpreted as having a lighter pigmentation, compared with the darker skin of people forced to flee countries in Africa.
} 
immigration cheat, during the 2015 refugee 'crisis', coverage of the 'economic migrants' and 'illegal immigrants' trying to 'sneak' into the UK was often accompanied by images of young men in the 'Jungle'9 camp at Calais, most of whom had black or brown skin (Bhatia, 2018). Although this demonising narrative has been attached to non-white and 'not quite white' migrants, then, and has essentialised and pathologised them as a homogenous group, there is, simultaneously, further racial work being done by the use of such images. As these pictures have routinely been included alongside media reports, the duping and cheating of immigration controls has, more recently, come to be strongly associated with people who have darker skin.

\section{'Gold-diggers searching for an easy life': The narrative of the parasitical scrounger}

The second narrative of bordering that I trace in this chapter very much connects to the first, as it explains why unwanted migrants come to the UK in the first place and want to secure the right to stay. Bringing the poverty of people coming from the Global South and Southern and Eastern Europe to the fore, it transforms this actual economic disadvantage into a much more stigmatising, and racialising, form. Thus, it essentialises and homogenises the unwanted migrants it targets as parasitical scroungers who make their way to the UK to grab hold of all the money and wealth 'we' have. That is, it pathologises them as inherently greedy and lazy spongers, who come here to enjoy an 'easy' life by exploiting the welfare benefits system, as well as by 'milking' other public services such as the NHS.

Whereas the dominant narrative of the immigration cheat is, as I suggested in the previous section, very much a contemporary formulation - albeit one that draws on and reworks longer-standing ideas about unwanted migrants' rule-breaking and criminal

\footnotetext{
${ }^{9}$ As Bhatia explains, although this term was initially used by the people living in the camp to highlight the 'squalid living conditions, powerlessness and limbo' there, it was subsequently co-opted by the tabloid media, which "turned the "jungle" into a powerful metaphor loaded with hyper-racist, criminalised and other negative connotations' (2018, p.190).
} 
proclivities - the narrative of the parasitical scrounger goes back a long way. I highlighted in Chapter One that, prior to the introduction of the 1962 Commonwealth Immigrants Act, nonwhite migration to the UK was repeatedly problematised by politicians and the media. In fact, one of the key charges levelled at black Commonwealth citizens in the years preceding this legislation was their supposedly workshy nature and alleged appetite for unemployment support. Solomos quotes The Times in 1958, for example, as stating that the 'causes of resentment against coloured inhabitants' include that 'they are alleged to do no work and to collect a rich sum from the Assistance Board' (2003, p.55). Similarly, Dilip Hiro points to a commonplace view during the 1950s of West Indian migrants as 'indolent blacks', living off unemployment support, and quotes a Home Office Minister during this period as saying, 'They come in by air and at once begin to draw National Assistance' (1992, p.36).

In later decades, indeed, the idea of black people as inherently lazy and needy continued to be mobilised in the UK, though now in relation to black British communities. Writing in the mid-1980s, Bryan, Dadzie and Scafe highlighted how the relationship of black British women, in particular, with the welfare state was often portrayed as 'parasitic. We are described by the media as "scroungers" and depicted as having a child-like dependence upon a benevolent caring (white) society' (1985, p.111). Thus, while the figure of the 'scrounger' has long been deployed to vilify the working class (Hall et al., 2013; Hall and O'Shea, 2013; Tyler, 2013), it is important to recognise that the idea of natural indolence, and parasitical tendencies, has a significant history as a racialising trope, as well (see also Holzberg, Kolbe and Zaborowski, 2018). In its contemporary incarnation, however, inherent laziness and freeloading greed is never assigned to migrants who are unwelcome through explicit racial reference. Rather, this deviance is attributed to them through a range of more muted, 'postracial' registers.

Since the onset of mass mobility, the narrative of unwanted migrants as parasitical scroungers has been prominently attached - like the narrative of the abusive immigration 
cheat - to people seeking asylum. In portraying them like this successive governments and the media have built on the idea, highlighted in the previous section, that the majority of those seeking protection in the UK are actually 'economic migrants' - which, as I have explained, supports the racialising claim that most asylum applicants are liars who are defrauding the system. In the narrative of the scrounger, however, 'economic migration' and the desire for a more prosperous life have been cast, in themselves, in a more stigmatising way. So, it is insisted that large numbers of asylum seekers are coming to the UK in order to take advantage of, and lazily live off, 'our' welfare benefits system. Thus, from the late 1980s onwards the Conservative government, and subsequently New Labour, repeatedly mobilised the idea of fraudulent asylum applicants coming here 'for the sake of the benefits they might enjoy' (Schuster, 2003b, p.148; see also Bloch and Schuster, 2002). The media also consistently portrayed asylum claimants like this, referring to them as 'scroungers' and 'parasites' who were 'creaming off' the benefits system (Moore, 2013; Philo, Briant and Donald, 2013; Matthews and Brown, 2012; Bloch and Schuster, 2002; Coole, 2002; Kaye, 2001).

In their analysis of media responses to the arrival in October 1997 of a relatively small number of Roma asylum seekers from the Czech Republic in the UK, Colin Clark and Elaine Campbell document some additional terms and phrases used to insist on asylum applicants' freeloading, money-grabbing propensities. These included 'gold-diggers searching for an easy life', as well as 'loose-fingered marauders' (2000, pp.32, 40; see also Guy, 2003). More recently, in response to the 2015 refugee 'crisis' the same ideas were, predictably, re-deployed. Media coverage repeatedly presented people forced to flee countries in the Global South as attempting the perilous journey to the UK solely for the sake of 'welfare handouts' and 'lavish benefits' (Berry, Garcia-Blanco and Moore, 2015, pp.40, 47).

In this iteration, then, the narrative of the parasitical scrounger racialises in exactly the same way as that of the abusive immigration cheat. That is, there is no reference to the 
physical appearance of those targeted; nor, indeed, are they problematised through appeals to 'culture' which, as I have highlighted, is a more subtle racial code that has often been used to essentialise and homogenise groups deemed as 'other' in the contemporary period. Yet, as it insists that they are coming here to enjoy an easy life and to exploit the welfare benefits system, the narrative of the scrounger portrays all people seeking asylum as inherently lazy and greedy. In this way, therefore, it 'instigates "group-ness", and ascribes characteristics' (Garner and Selod, 2015, p.14); it transforms the diverse group of people designated as 'asylum seekers' into a homogenous bloc, with negative qualities and traits. Consequently, through this race-making process, 'asylum seekers' are disparaged and pathologised en masse - and, in this way, the narrative of the parasitical scrounger works to legitimise their exclusion from the UK.

We see the same, more 'abstract' (Garner, 2013, p.504) process of race-making, or racialisation, indeed, in contemporary media depictions that refer not only to people seeking asylum but 'migrants' and 'immigrants' more broadly as collectively 'taking advantage of' or 'milking' the benefits system. In such reporting, the 'migrants' and 'immigrants' who are essentialised and homogenised in this way are almost always identified as coming from countries in the Global South and Southern and Eastern Europe (see, for instance, Dawar, 2015; Barrett and Goldhill, 2013; Doyle, 2013). Alongside this homogenising of non-white and 'not quite white' migrants, however, in some of the more recent mobilisations of this narrative the figure of the welfare scrounger has, at points, been particularly associated with those who are Eastern European. Thus, since the enlargement of the EU in 2004, there has been a recurring concern around the supposed issue of Eastern European 'benefit tourism'. Taulant Guma and Rhys Dafydd Jones (2019) point to media coverage in March 2011, for instance, on the imminent end of the Worker Registration Scheme, which meant that nationals of the 'A8' states became entitled to access welfare benefits without any restrictions. In this coverage it was insisted that there were 'New Eastern European "benefit 
tourism" fears ... because the government is being forced to scrap safeguards on receiving handouts'. In fact, the government appeared to endorse such 'fears' as the Department for Work and Pensions was quoted as saying, 'It is absolutely necessary to protect the taxpayer and the benefit system from possible abuse' (Hough and Whitehead, 2011; see also Doyle, 2011; Ford, 2011a; Hall, 2011). More recently, during the 2016 Brexit referendum campaign, which was fought overwhelmingly on the issue of immigration, media coverage repeatedly claimed that people from Eastern Europe were coming to the UK to exploit the benefits system, and often designated them specifically as 'benefit tourists' (Moore and Ramsay, 2017).

In the portrayal of people from Eastern Europe as benefit scroungers and welfare cheats, we see the mobilisation of this narrative of bordering through different racial registers. Some media depictions, for instance, have framed Eastern Europeans' supposedly parasitical tendencies specifically in terms of cultural difference (Fox, Moroşanu and Szilassy, 2012) - a register which, as I have explained, is now well-recognised as a code for race. At points, this dominant narrative has also operated through a form of racialised expression that has, perhaps, been less well documented: the language of nationality. In her research on Operation Nexus and the police's increasing involvement in immigration enforcement, which I highlighted in Chapter One, Parmar (2016a) draws attention to the use of this language by the police officers she observed, noting that they never used 'explicitly racist terminology' when talking about non-UK nationals brought into custody. Rather, she describes how the police talked about groups in 'stereotyped, homogenized ways' through their nationality. So, Parmar explains: 'I overheard "Afghans", or "Eritreans" being talked about as "likely to be genuinely seeking asylum" whereas "Albanians" were usually "caught up in something criminal".' As she puts it, therefore, 'nationality was coopted as a safe mode of expression ... This way of talking about groups - as engaged in types of behaviour through 
their nationality in a racialized way, was somehow acceptable, discussed openly and presumably not regarded as racist' (see also Parmar, 2018a).

The deployment of this 'safe mode of expression' - which, as I noted at the beginning of this chapter, Parmar also suggests might be seen as 'a continuation of raciological articulation in post-racial times' (2016a) - can be traced in some of the media coverage of Eastern Europeans as exploiters of the benefits system. At the end of 2013, for instance, as the end of transitional controls on nationals of the 'A2' states, Romania and Bulgaria, approached, a flurry of articles reported on how people from these countries were planning to come to the UK to live off benefits. In these articles, the alleged scrounging behaviour of these migrants was often presented through the apparently innocent register of nationality. On $31^{\text {st }}$ December, for example, the day before the transitional controls came to an end, The Sun's front page carried a picture of people in Romania boarding a UK-bound coach, under the headline 'Cheeky beggars'. The racialisation of these migrants through the language of nationality emerged clearly as the report went on to set out, 'The first coachload of Romanian migrants left for the UK yesterday - with some boasting of plans to beg and steal from “"generous” Brits' (Flynn, 2013, p.1). Similarly, the paper's editorial for the same day opened with alleged quotations from those travelling on the coach - "“I want to go to Britain to beg." "I don't like work." "We'll steal scrap metal and claim benefits"” - before it was then explained: 'These are Romanians on a bus from Transylvania, en route to London, free to make their lives here from midnight tonight ... These newcomers aim to fleece "rich" Brits and abuse a benefits system that has so far escaped lightly from the demands of EU migrants' (The Sun, 2013, p.6).

As well as casting them as exploiters of the benefits system, the narrative of the parasitical scrounger has also insisted that migrants who are unwanted come to the UK to greedily 'milk' other public services and resources. In recent years, there has been a clear focus on the alleged abuse of the NHS. Like the claim of benefit scrounging, this accusation 
goes back, in fact, over decades. Paul Gordon (1983a) has highlighted how, during the 1950s and 60s, non-white Commonwealth citizens were marked out by overtly racist political and media depictions as unsanitary and bringers of disease. As he explains, it was argued that as a result of this they would act as a significant 'drain' or 'burden' on the UK's health services. In contemporary portrayals a similar idea has been circulated, though, of course, in more racially coded ways. In their analysis of press coverage of the 2015 refugee 'crisis', for example, Berry, Garcia-Blanco and Moore point to an article which appeared in the Daily Mail under the headline 'Immigrants, HIV and the true cost to the NHS' (2015, p.40). The article set out that more than $60 \%$ of the 7,000 new HIV cases diagnosed in the UK each year were among people who were 'born abroad', and listed those represented within this as coming from countries including Russia, Brazil and Romania, as well as 'particularly from Africa'. It then assigned freeloading tendencies to these 'migrants' and 'asylum seekers', insisting that they were 'specifically target[ing] Britain' as 'health tourists', in order to 'guarantee themselves a lifetime of free drugs and medical care, courtesy of the NHS' (2015, p.40; see also Guma and Jones, 2019; Philo, Briant and Donald, 2013; Hayes, 2002).

Once more, therefore, as it is asserted that people from countries in the Global South and Southern and Eastern Europe are collectively taking advantage of and exploiting the UK's health services, we see the more 'abstract' process of racialisation that I have documented across this chapter playing out. Through such depictions, non-white and 'not quite white' 'asylum seekers' and 'migrants' are essentialised and pathologised as a group of naturally deviant scammers and scroungers; they are constituted through the category of race, as they are produced as 'a homogenous mass with specific characteristics' (Garner, 2017, p.213). At the same time, however, there also appears to be some hierarchising within such portrayals: it is notable, I think, that in the Daily Mail article new HIV diagnoses in the UK were identified as being among migrants 'particularly from Africa'. We see here, then, another example of how - even as they do not categorise racially through reference to 
physical appearance - phenotypic difference nonetheless matters in narratives of bordering. Some of the earlier, explicitly racist narratives to which I referred above seemed to be alluded to and evoked as people with darker skin were more clearly demarcated as the 'foreign' carriers of ill-health and disease.

Some of the features that I suggested in Chapter One make understanding dominant depictions of unwanted migrants as narratives particularly fitting are evident in the portrayal of them as parasitical scroungers. Most noticeably, perhaps, sheer invention and fabrication run through these claims. For instance, against the assertion that many people come here and make asylum claims specifically to access the benefits system, research indicates that most asylum applicants are in fact unaware of welfare support before they arrive in the UK (Refugee Council, 2010). We might also note how, since 1999, those going through the asylum process have not actually been allowed to access the mainstream welfare support system at all (Gower, 2015). Rather, they have to apply to the Home Office for financial assistance. If their application is successful, they are given $£ 37.75$ a week (Home Office, 2019a), which is under half the amount provided to those in receipt of mainstream benefits (DWP, 2019) - a far cry, then, from the 'welfare handouts' that it has been insisted fraudulent asylum applicants are accessing.

Research has also highlighted that even when asylum claimants are granted refugee status, and so technically become eligible to access the mainstream benefits system, a number of barriers make it difficult for them to do this - and, therefore, they often become homeless and destitute as a result (British Red Cross, 2018; Refugee Council, 2014). Moreover, against the recent identification of people from Eastern Europe, in particular, as 'benefit tourists', research has actually shown that the vast majority of these migrants are in work (Migration Observatory, 2014). At times, the concoction that runs through the narrative of the scrounger is accompanied by - or, perhaps, is the cause of - a complete lack of logic. Alongside the accusation that people from the Global South and Southern and Eastern Europe are coming to 
the UK to enjoy an easy life and live off 'our' benefits system, there is often the simultaneous claim, in direct contradiction of this, that they also want to steal 'our' jobs (Rzepnikowska, 2019; Moore and Ramsay, 2017; Philo, Briant and Donald, 2013; Garner, 2007a).

We might also point to the fictitious, fabricated nature of the dominant narrative of the parasitical scrounger - and, indeed, the other racialised narratives of bordering that I trace in this chapter - in one further way. Critics have noted how, since 9/11 and the beginnings of the 'War on Terror', the racialised idea of an intrinsically primitive and violent Muslim culture has frequently been mobilised to mask the social and political causes of situations and events. So, for instance, Kundnani highlights how violence and conflict in the Middle East have often been explained as the result of an inherent Muslim rage and bloodthirstiness, rather than in terms of their 'political origins' $(2014, \mathrm{p} .58)$, including the neo-imperial agenda of the United States and its allies. Similarly, Lentin and Titley (2011) have documented how 'race riots' in Europe - such as in Bradford in 2003, and in Paris in 2005 - have been framed as the actions of a naturally antagonistic Muslim youth, rather than as a response to and protest against the anti-Muslim racism that pervades Western societies. We can see a similar pattern of concealment playing out, I would suggest - a similar obfuscation of problematic societal and structural conditions by ideas of individual pathology and deficiency - through the deployment of racialised narratives of bordering.

Thus, for example, as migrants who are unwelcome are essentialised and pathologised as freeloading spongers, the significant wealth disparities that actually exist between Western and non-Western countries are pushed firmly out of view. The structural condition of poverty and economic disadvantage becomes instead a matter of intrinsic greediness and selfishness of unwanted migrants' natural badness and deviancy. Indeed, portraying people from countries that were formerly colonised by Britain, in particular, as inherently grasping and parasitical functions not only to erase the material reality of their economic disadvantage but, in fact, to cover up the historical and political reasons for this disadvantage. That is, this 
pathologising depiction works to obscure how the British Empire stripped the countries that it colonised of wealth and resources, and so how colonialism was a key cause of their now impoverished state.

As I highlighted earlier in the chapter, the idea of the innate deceitfulness of the majority of asylum claimants has been evidenced in part by the UK government by pointing to the high proportion of asylum applications that are rejected. Yet, the narrative of the inherently scheming and manipulative immigration fraudster conceals how the UK's racist immigration system itself creates and produces asylum 'cheats', as it deliberately refuses to recognise as legitimate all but a minority of claims. Similarly, the erasing and invisibilising capabilities of racialised narratives of bordering can be traced in the narratives that I to map in the final section of this chapter, too. The well-established narrative of unwanted migrants' criminality, for instance, obscures the social, economic and political conditions that contribute to their criminalisation - including the racism and wealth inequality of UK society broadly, as well as the institutionalised discrimination of the criminal justice system - and replaces these with an explanation of inherent 'otherness' and undesirability (see also Aliverti, 2018b).

Making unwanted migrants desirable through class: Opening up the border to the 'brightest and the best' and those who 'work hard and contribute to the UK'

There also exist contemporary representations that separate some unwanted migrants from the dominant narrative of the parasitical scrounger and demarcate them as acceptable to be let in. As with the depiction of the genuine asylum seeker, however, these are narratives of limited inclusion, which only permit the relaxation of the border in a very restricted way. One of the key narratives disseminated by successive governments in this area has accompanied the development of policies of 'managed migration', which I highlighted in Chapter One. Thus, it is set out in this depiction that while the vast majority of unwanted migrants want to 
come to the UK to exploit and lazily live off 'our' public services and resources, a minority actually has something to offer 'us' - and these migrants, who are 'the brightest and the best' (Anderson, 2013, p.58; see also Home Office, 2018; The Independent, 2015; The Guardian, 2011), should always be welcomed and allowed in. In this elitist formulation, then, we see a clear example of how, as Goldberg explains, for those 'forced to bear [the] load' of race 'class standing mitigates and mediates the load, to be sure' (2015, p.76). Being rich and highly skilled effectively lifts migrants who would normally be deemed as inherently deviant and thus unwanted out of race; economic and class status elevates them from the confines and exclusions of racial undesirability. ${ }^{10}$

Alongside this, successive governments have also marked out those who 'work hard', 'pay taxes' and 'contribute to the UK' (Home Office, 2011, 2005, 2002) as another group to whom the border can be opened up. In one sense, this is a straightforward inversion of the narrative of the lazy, selfish scrounger. It marks out some unwanted migrants as good and desirable by emphasising that they are the exact opposite of freeloaders and spongers; so, it frees them of these negative traits and characteristics, it de-racialises and de-stigmatises them. At the same time, however, there is something else going on here, too. Although terms such as 'hard-working' and 'tax-paying' undoubtedly encompass people who are not economically well off, a classed distinction nevertheless runs through them. Those who are identified in this way may not be rich, but they are also clearly differentiated from the group at the very bottom of the class ladder - the non-working poor, or 'underclass'. In this way, the demarcation of some unwanted migrants as acceptable because they 'work hard' and 'pay taxes' can be understood in terms of the intersection between class and race, as well. That is

\footnotetext{
${ }^{10}$ Connecting back to the discussion in Chapter One about how government and media narratives on immigration have come to shape and organise the public consciousness, research has demonstrated greater levels of public support for migrants who would normally be deemed 'unwanted' when they are highly skilled. For instance, the proportion of British respondents to the 2014 European Social Survey who agreed that 'many' unskilled labourers from India, and Poland, should be allowed into the UK was just $8 \%$ and $9 \%$ respectively. When respondents were asked about professionals from India and Poland, however, these percentages rose to $20 \%$ and $21 \%$ (Migration Observatory, 2020).
} 
just as in the narrative of 'the brightest and the best', economic and class standing is here mediating, and mitigating, racial 'otherness' and inferiority.

Some migrants' rights groups have, at points, tried to repurpose this narrative of limited inclusion in a more egalitarian and expansive manner. A poster campaign in the runup to the 2015 General Election, for instance, which featured people who had migrated to the UK alongside their job titles, emphasised that it wanted to demonstrate how 'all immigrants ... add value to this country' (JCWI and MAX, 2015). Yet, the narrative of 'hard work' and 'contribution' is, by its nature, selective and restrictive (de Noronha, 2018a). Only those who are deemed economically active and productive - who have attained a certain economic and class status - are marked out as worthy of inclusion in the UK.

\section{Narratives of immediate danger and threat: The criminal, the terrorist and the sexual predator}

In the final section of this chapter, I turn to some dominant narratives that present unwanted migrants as constituting a more immediate and overt threat. The first of the narratives that I trace in this area focuses on the idea of their particularly criminal proclivities. Like the narrative of the parasitical scrounger, this has a long history. As I explained earlier, claims of a propensity for criminality were attached to Jewish refugees coming from Eastern Europe at the beginning of the twentieth century, and to black Commonwealth citizens arriving in the UK following the Second World War. Unlike the narrative of the scrounger, however, in the present era the idea of migrants who are unwelcome as having an inherent disposition for crime has tended to feature less centrally within the government's official claims - because, I would suggest, it is now more readily recognised as a racist trope.

As I documented earlier in this chapter, 'foreign criminals' have been persistently demonised in government depictions as naturally abusive immigration cheats, who attempt to 'dodge deportation' and frustrate the border control system. In some official portrayals, they 
have been hinted at as intrinsically dangerous law-breakers, too, as they have been associated with more serious forms of offending and framed as a public protection concern (de Noronha, 2018b; Bhui, 2007). Yet, it is noticeable that in the current period the government has not really assigned criminal propensities to unwanted migrants beyond this specific group. Conversely, certain sections of the media, as well as more right-wing - though still mainstream - politicians have not only insisted on the deep-rooted deviance of 'foreign criminals': they have also repeatedly portrayed unwanted migrants more broadly as inherently inclined towards crime. As they have done this, however, they have disseminated the narrative of intrinsic criminality through some of the 'post-racial' registers already traced in this chapter. Thus, these media and political depictions have worked to subdue and obfuscate the racism of this narrative - meaning that any accusations to this effect can be more easily dismissed.

Across contemporary media depictions of unwanted migrants as inherently deviant in this way, the more abstract process of racialisation that I have documented throughout this chapter can be detected. In these depictions, then, 'asylum seekers', 'migrants' and 'immigrants' have been constructed as a 'bounded entity ... with similar pathological characteristics and behaviours' (Garner, 2013, pp.507-508); that is, they have been essentialised and homogenised as a mass of natural-born criminals. Press coverage of asylum issues during the early 2000s, for example, included headlines such as 'Asylum: Tidal wave of crime', 'Asylum gangs "are to blame for a new era of crime"' and 'Brutal crimes of the asylum seekers' (Greenslade, 2005; see also Kundnani, 2001). Such a portrayal also ran through much of the more recent reporting on the 2015 refugee 'crisis'. The 'asylum seekers', 'economic migrants' and 'illegal immigrants' living in the 'Jungle' camp in Calais, in particular, were frequently depicted as breaking the law, and were presented as especially prone to theft and violence (Berry, Garcia-Blanco and Moore, 2015). 
More broadly, media reporting on 'foreign crime' in the UK has also often suggested that 'migrants' and 'immigrants' - who are almost always marked out as coming from countries in the Global South and Southern and Eastern Europe - are a group with a propensity for behaving in this way. In the search of national newspapers that I conducted, for instance, covering the period $6^{\text {th }}$ July 2012 to $6^{\text {th }}$ July 2014, a number of articles presented them like this. On $19^{\text {th }}$ July 2012, for example, The Sun, The Telegraph and the Daily Mail ran reports under the following headlines: ' 1 -in-5 rape and murder suspects are migrants' (Parry, 2012, p.17); 'A fifth of murder and rape suspects are immigrants' (Alleyne, 2012); 'Nearly a fifth of all suspected rapists and murderers arrested last year were immigrants' (Robinson, 2012). The countries of origin for these 'rape and murder suspects' were identified as including Afghanistan, Angola, Chile, Ghana, Macedonia, ${ }^{11}$ Russia and Zimbabwe; at no point was it clarified in any of the articles that being arrested for or charged with an offence did not equate to a determination of guilt. Rather, it was insisted that the figures showed how 'serious and dangerous criminals' (Parry, 2012, p.17) were routinely being let into the country. Thus, police statistics were misleadingly deployed to insist that non-white and 'not quite white' migrants are responsible for a significant number of crimes in the UK - and, therefore, that their offending is particularly prolific, that they have a predisposition towards behaving in this way. ${ }^{12}$ We see once more, then, how, as Garner puts it, "“[r]ace” can thus be made, through racialisation, without a stable phenotypically defined object' (2013, p.507), as through such reporting on 'migrants' and 'immigrants', 'a collective with shared characteristics emerges' (2013, p.507).

\footnotetext{
${ }^{11}$ In 2019 the Republic of Macedonia officially changed its name to the Republic of North Macedonia.

${ }^{12}$ Against such depictions of inherent criminality, it is worth pointing to empirical research that refutes this claim. In the UK context, for instance, Hindpal Singh Bhui notes that 'in April 2008, the Association of Chief Police Officers ... announced that an internal study had found no evidence of higher levels of offending by migrant communities' (2009, p.158). In the US context, Ousey and Kubrin conclude that their review of studies carried out between 1994-2014 'call[s] into question those theories that advance a strong positive relationship between immigration and crime. Clearly, our findings do not support this body of theories' (2018, p.77). They also note that the studies they review offer 'some support' for the thesis that immigration may be one of the factors that has contributed to the drop in crime in the US - although, as they emphasise, 'much more research is needed to reach a definitive conclusion' $(2018, \mathrm{p} .80)$.
} 
Even as media reports have portrayed non-white and 'not quite white' 'asylum seekers' and 'migrants' as a mass of inherently criminal undesirables, however - and so have 'categorized them as an undifferentiated and racialized Other' (Hubbard, 2005, p.63) particular associations, and stratifications, simultaneously run through these depictions. I noted earlier that, in the coverage of the 2015 refugee 'crisis', articles on the camp in Calais were often accompanied by visual images of the 'asylum seekers', 'economic migrants' and 'illegal immigrants' living there, most of whom were young men with black or brown skin. As Monish Bhatia (2018) has highlighted, indeed, such images were used repeatedly in media reporting on 'clashes' between the camp's residents and French law enforcement, which typically overlooked the violence being inflicted by the police and focused instead on the allegedly criminal behaviour of the migrant men. Bhatia points, for instance, to an online article in the Daily Mail headlined 'The Battle of Calais' which, as it emphasised how 'migrants' had attacked the police with 'missiles' and 'objects', was accompanied by over 20 images of the 'battle', including numerous pictures of groups of young black men. Such images evoke, of course, the explicitly racist narratives about 'black youth', criminality and rioting that became particularly prominent during the 1970s and 80s (Connell, 2012; Gilroy, 1987). Consequently, a specific association between violent disorder and darker skin is rearticulated through this contemporary coverage, even as the reports themselves avoid obviously racial terminology and do not categorise the unwanted migrants they depict in this way. Again, therefore, it becomes clear how phenotypic difference matters in narratives of bordering - even as the overt language of race does not appear in them. ${ }^{13}$

\footnotetext{
${ }^{13}$ It is important to emphasise that fabrication and invention - which, I have suggested, make the use of the term 'narrative' for present-day portrayals of unwanted migrants particularly fitting - run through the media depiction of the Calais camp's residents' violence towards the police. As Bhatia (2018) highlights, media reports downplayed the violence being inflicted on those living in the camp by the French authorities, as police harassment and abuse was rarely reported on. Thus, as in the example of 'The Battle of Calais' article, resistance to state violence by the camp's residents comes to be presented in a quite different way; that is, as a matter of intrinsically deviant and violent migrants attacking the unsuspecting and well-meaning police. What we see in this contemporary depiction mirrors, of course, the process that played out in the earlier, explicitly racist portrayals also mentioned in my analysis, focused on 'black youth', criminality and rioting. As Gilroy has set out, during the 1970 s and 80 s the wider political context was repeatedly ignored in official and media
} 
The narrative of intrinsic criminality has also been disseminated through the register of nationality - and, in fact, some particularly clear examples of this emerged during the 2016 Brexit referendum campaign which, as I explained earlier, was fought overwhelmingly on the issue of immigration. A month before the referendum vote, for example, Vote Leave, the official campaign for leaving the EU, issued a statement which pointed to high rates of crime in Turkey. It warned that if the UK remained an EU member state and Turkey subsequently joined the EU, 'the government will not be able to exclude Turkish criminals from entering the UK' (Boffey and Helm, 2016). This was not an official government position, of course. Yet, Vote Leave was being fronted by several Conservative government ministers, including Michael Gove and Chris Grayling, as well as prominent Conservative backbench MPs such as Boris Johnson - who, in July 2019, became the British Prime Minister. Thus, the racialised claim of an apparent Turkish inclination for criminality can be understood as endorsed by a number of mainstream political figures.

A few weeks prior to this, in fact, Vote Leave had made the same suggestion in relation to people from another EU candidate country, Albania. In an article for the Daily Mail that was published under the headline 'Think the EU's bad now? Wait until Albania joins', Michael Gove implied that Albanians have a particular propensity for criminal behaviour as he pointed to their apparently disproportionate presence in 'our' prisons. He wrote: 'As Justice Secretary, I am well aware that there are around 10,000 foreign criminals in our jails - and one in 20 of those is Albanian. Of all the prisoners in our jails who come from European countries, 10 per cent come from Albania - yet Albania comprises less than half of one per cent of the overall population of Europe' (Gove, 2016). We can see here how,

explanations of 'confrontations' between black communities and the police. The focus, instead, was on 'crime rather than politics as the motivation' (1987, p.119) - and, in this way, black political organisation and protest against the institutional racism of the police was transformed into a matter of an inherent disorderliness and violence. The type of fabrication and distortion I am tracing here, then, is that which I identified as running through narratives of bordering at the end of the previous section: that is, the erasure of problematic societal and structural conditions and their replacement by ideas of individual pathology and deficiency. I trace further examples of such societal and structural erasure as I continue with this section. 
as I suggested in the previous section, the narrative of inherent criminality works to conceal the structural causes of unwanted migrants' criminalisation - and, in this instance, apparent over-representation in the criminal justice system. As the idea of an intrinsic Albanian 'otherness' and deficiency is mobilised, social, economic and political factors such as the wealth inequality and racism that structure UK society broadly, as well as the institutionalised discrimination of the criminal justice system, are pushed firmly out of view.

Racialisation through the 'safe mode of expression' (Parmar, 2016a) of nationality can also be traced in media reporting on individual 'foreign criminals'. Across the articles on individual non-citizens convicted of offences that I identified, for instance, in the search of national newspapers I conducted, the nationality of the person being reported on was often marked out in the headline, alongside the 'type' of offender they were. So, for instance: 'Romanian fraudster' (Brown, 2012); 'Iranian thug' (Young, 2013); ‘Jamaican crack dealer’ (Cooper, 2014). In this way, the person being reported on was constructed as if the offence for which they had been convicted was integral to them - and this intrinsic deviance was framed through their nationality.

The idea of certain nationalities as having proclivities for specific types of criminal behaviour also appeared to play out across the reports. Resonating with their racialisation as benefits scroungers through the language of nationality, which I examined in the previous section, articles on people from Romania, for example - which included men and women tended to concentrate on individuals convicted of money and theft-related offences, including cashpoint theft, pick-pocketing and large-scale benefit fraud (see also Fox, Moroşanu and Szilassy, 2012; Light and Young, 2009). Articles on people from Jamaica, on the other hand, which focused exclusively on men, centred on individuals convicted of drug-related crimes, as well as violent offences, including murder. This was also the case, indeed, for men from the Caribbean more broadly, as well as for those from countries in Africa. Thus, as many of these reports were accompanied by pictures of the 'foreign criminals' on whom they were 
reporting, they also evoked explicitly racist narratives about black men as drug dealers and violent offenders (Wilcox, 2005; Bowling and Phillips, 2002; Cashmore and McLaughlin, 1991). Just as with the media coverage of the refugee 'crisis' and Calais, therefore, we see again how narratives of bordering avoid overtly racial terminology and categorisation - and yet, through such accompanying images, they still manage to articulate a link between 'serious' criminality and somatic difference.

Alongside the dominant narrative of a propensity for criminality, unwanted migrants have been framed as an immediate danger in other ways. Critics have highlighted how, for instance, post 9/11, 'asylum seekers' began to be essentialised and homogenised not simply as criminals, but as terrorists, too (Back, 2007; Sales, 2005; Yuval-Davis, Anthias and Kofman, 2005). More recently, during the refugee 'crisis' in 2015, this narrative was injected with a fresh lease of life. Following the attacks in Paris in November that year, it was alleged that a Syrian passport had been found in the vicinity of the bombings at the Stade de France. It later transpired, in fact, that the passport was fake (BBC News, 2016b). Yet, by this point, a link had already been made; and 'asylum seekers' and 'migrants', often identified specifically as 'Arab' and 'Muslim', were subsequently accused by media coverage of being terrorists in disguise and conflated with the figure of the culturally backward and violent Islamic extremist (De Genova, 2018; Holmes and Castañeda, 2016).

The other narrative of overt threat that is prominent in the current era draws on the depictions of intrinsic criminality I documented above, but insists that migrants who are unwelcome are particularly prone to a specific form of criminal behaviour: sexual offending. This racialised depiction - like the idea of unwanted migrants' disposition for criminality more broadly - goes back a long way. In the overtly racist anti-immigration narratives of the past, the idea of black men as having a propensity for vice offences, for instance, was common. Paul Gilroy has highlighted how, during the 1940s and 50s, 'reports of black pimps living off the immoral earnings of white women' (1987, p.95) not only appeared in the press 
but were also disseminated by senior members of the government, including the Home Secretary. Later, notions of an abnormal black male sexuality continued to be mobilised, including in relation to black British men. As critics have noted, the media has repeatedly depicted black men as inherently sexually threatening and violent (Kalunta-Crumpton, 2000; Grover and Soothill, 1996).

In contemporary narratives of bordering, the racialised trope of innate sexual deviance has continued to be circulated - but, of course, in less overtly racist ways. Since the beginnings of mass mobility, therefore, 'asylum seekers' have been essentialised and homogenised as a group with lascivious and hypersexual tendencies, as they have often been described as 'sexual predators' and 'rape beasts' (Philo, Briant and Donald, 2013; Tyler, 2013; MRCF, 2011). This more abstract process of racialisation can be detected, too, in coverage concerned with 'migrants' and 'immigrants'. I highlighted earlier that, in the media search on 'foreign crime' that I conducted, articles on individual non-citizens convicted of offences focused almost entirely on men originally from countries in the Global South and Southern and Eastern Europe. Across this coverage, such 'migrants' and 'immigrants' were often suggested as a pathological collective with sexually violent propensities, as a number of the headlines referred to those on whom they were reporting using language such as ‘immigrant rape thug' (Spillett, 2013, p.2), 'migrant child sex gang' (Watson, 2014) and 'migrant sex beast' (Mathews, 2013). Once more, though, even as this sort of coverage homogenises non-white and 'not quite white' migrants as a mass of undesirable sexual deviants, certain associations and stratifications also run through these depictions. Thus, many of the articles on individual non-citizens convicted of sexual offences that I identified focused on men originally from countries in Africa or the Caribbean; and, alongside the written report, these articles often also included visual images of those on whom they were reporting. In this way, they evoked, and remobilised, overtly racist narratives about black 
men as inherently sexually violent. Without ever referring to race, then, they reiterated a link between darker skin and sexual offending.

Like the narrative of the terrorist, that of the sexual predator was also reinvigorated during the 2015 refugee 'crisis'. At the end of 2015, mass sexual assaults were reported to have been perpetrated by 'asylum seekers' and 'migrants' during the New Year's Eve celebrations in Cologne, Germany - a country which, compared with the rest of Western Europe at least, had taken a less restrictive approach to the refugees arriving across this period (Canning, 2017). The assaults, therefore, were presented by significant sections of the media in the UK as providing clear evidence of the dangers of unwanted immigration, as those allegedly responsible were essentialised and homogenised as a mass of inherently problematic sexual deviants. It was notable, too, that as well as attaching this racialised narrative to 'asylum seekers' and 'migrants', the alleged perpetrators were also identified specifically as 'North African', 'Arab' and 'Muslim' men - and their innate sexual pathology was presented through the language of culture, in terms of their supposedly primitive attitudes to women and 'backwards' way of life. Thus, an opinion piece in the Observer, for instance, presented what happened as the result of 'unreconstructed attitudes towards women by newly arrived young Arab men' (Hutton, 2016). A column in The Telegraph by Allison Pearson (2016) began with the headline 'Cologne assault: Cultural difference is no excuse for rape', and ended by asserting 'I fear that [this] grotesque mass attack on women ... was not an isolated incident, but the first of many battles in a clash of civilisations'. Similarly, in the Daily Mail, a piece by the far-right commentator Katie Hopkins (2016) insisted: 'These migrants are a cultural time-bomb, brought up in a different era, Islamic Bernard Mannings incompatible with modern life.'

As critics have noted, the insistence upon sexual offending by Muslim men as the result of an essentialised and backwards culture differs sharply from media explanations of sexual crimes committed by white British men, where race or culture is never mentioned 
(Tufail, 2015). Indeed, it is noticeable how, in the case of the Cologne assaults, the 'cultural' explanation offered for 'Muslim' and 'Arab' migrant men carrying out these attacks was not simply different. It also worked, in fact, to completely exculpate and exonerate Western European men - to erase and silence their participation in and infliction of sexual violence. That is, as sexual offending was presented as a deviant cultural characteristic of these migrant men - as intrinsic to, and contained solely within, the figure of the 'other' (Holzberg, Kolbe and Zaborowski, 2018) - the Cologne assaults were presented as a 'new dimension of crime' (Medien, 2016), as a type of attack that was previously unheard of in Europe. Through this example, therefore, we see, once more, the erasing and invisibilising capabilities of racialised narratives of bordering. Patriarchy and misogyny as longstanding structural features of Western European countries were, through this coverage, glossed over and concealed, and sexual violence was presented as emerging solely from the cultural deficiencies of newlyarrived migrant men.

\section{Conclusion}

In this chapter, I have mapped the narratives circulated by the UK government and media in the current era that problematise 'unwanted' migrants and legitimise their targeting by the direct activities of border enforcement; and I have demonstrated how these narratives of bordering can be most fully understood through the framework of race and racism. As I have shown, these dominant representations do not deploy the overt language of race. They do not categorise and stigmatise those they are depicting in terms of biological or somatic difference - although, as I have also drawn out, this does not mean that visible difference does not matter in present-day portrayals of migrants who are unwelcome. Yet, as narratives of bordering disparage and vilify the non-white and 'not quite white' migrants on whom they focus, they do this in a distinct way. They demean and stigmatise through the specific processes of essentialisation and homogenisation - processes which are central to the race- 
making operation, and which characterise and distinguish the inferiorising and 'othering' that we see in racially explicit forms of classification and expression. Thus, even as narratives of bordering do not use the language of race, race is nonetheless made. Through the various coded registers that I have documented across this chapter, migrants who are unwanted are constituted, specifically, as racially different and deviant.

Indeed, as narratives of bordering racialise unwanted migrants, utilising these more sanitised forms of expression, we see, perhaps, what Goldberg has identified as the 'conceptual promiscuity and lability' $(2015, \mathrm{p} .10)$ of race. That is, as race is made through a range of seemingly raceless registers, the 'elasticity' and 'lack of ... fixity' that characterises raciality becomes apparent - a lack of fixity which, as Goldberg explains, 'has served the interests of power well by enabling an agile capacity to cement people in place' $(2015, \mathrm{p} .11)$. As I now proceed, in Chapter Three, to consider the practice of the courts and the sentencing hearing, I start to think about how the racialised narratives of bordering that I have traced across this chapter might be seeping into the individual narratives delivered by legal professionals during this process. More than this, though, I also conceptualise in what way, specifically, they might be being put to work in the particular context of the sentencing hearing. So, I theorise to what end, or for what purpose, the muted racial formulations of dominant narratives of bordering might be being mobilised and used. 


\section{Chapter 3}

\section{Racialised Narratives of Bordering and the Practice of the Sentencing Hearing}

\section{Introduction}

In Chapter One of this thesis, I set out my focus on government and media-disseminated narratives of bordering and in how these might be imprinting themselves on contemporary criminal justice processes; and in Chapter Two I demonstrated the centrality of race and racialisation to the functioning of these dominant narratives. In this chapter, I introduce the final layer of my conceptual foundations. Thus, I explore the specific aspect of the criminal justice system on which my research is focused, the endpoint of the court process, the practice of the sentencing hearing; and I consider how dominant narratives of bordering might be seeping into this - as well as what, more specifically, these muted racialised depictions might be being mobilised to do.

There is a considerable literature on sentencing, comprising legal, sociological and normative perspectives on the allocation of punishment. Yet, much of this literature has focused on 'sentencing practice' in terms of the decision to impose a particular punishment on a defendant, and how magistrates and judges arrive - or should arrive - at this decision. The practice of the sentencing hearing itself, and what goes on in the courtroom during sentencing proceedings, has received very little attention (Mann, Menih and Smith, 2014; Gathings and Parrotta, 2013; Travers, 2007). Alongside this, the sentencing hearing has often been overlooked by ethnographies focused on the processes and practices of the criminal courts. While, as Jacobson, Hunter and Kirby point out, 'the large majority of defendants who appear at the Crown Court do so for sentencing only, rather than for trial', it is, as they also explain, the trial that has typically been understood as the 'central event' $(2015, \mathrm{p} .27)$ of the criminal courtroom and which has therefore commanded the most academic attention. In the first half of this chapter, then, I work to fill this gap in the literature by developing an 
understanding of the process and practice of the sentencing hearing. Specifically, I suggest that by continuing to use the framework of narrative, and conceptualising what is said by the prosecution, defence and judge during the hearing as individual narratives, we can build an understanding of sentencing accounts as more than simply factual or representational. We can start to see them, instead, as plotted and purposive versions of 'what happened', of the incident that is being dealt with by the court - each of which is concerned with what I refer to as the defendant's punishability.

In the second half of the chapter I turn my attention to what the individual narratives delivered during the sentencing hearing might look like, and how they might be working towards their particular purposes and meanings. By conceptualising narratives from a sociological point of view and approaching them as 'social acts' or 'social practices' (Ewick and Silbey, 1995, pp.197, 211), we can understand how they are always governed and shaped by certain norms and conventions. Thus, as social acts, narratives are told in line with the 'local norms' (Ewick and Silbey, 1995, p.207) of their immediate social setting - in the case of sentencing narratives, then, they are delivered in line with the rules and conventions of the criminal court and law. But they are also shaped by wider social norms and conventions; so, they 'bear the imprint of dominant cultural meanings' and reflect and reproduce hegemonic or 'master narratives' (Ewick and Silbey, 1995, pp.211-212). Understanding this, therefore, provides the link between dominant narratives of bordering and the sentencing process. It helps us to see how these ideas about 'unwanted' migrants might be making their way into the practice of the sentencing hearing - how these racialised depictions might be seeping into the individual narratives delivered by the prosecution, defence and judge. Importantly, moreover, by turning to the existing literature on gendered and racialised narratives in the trial, we can also start thinking about what narratives of bordering might be mobilised to do in the specific context of the sentencing hearing. In other words, we can begin theorising how they might be put to work in individual narratives focused on the issue of the defendant's 
punishability. Ultimately, I argue that racialised narratives of bordering are likely to be deployed in sentencing hearings to present non-white and 'not quite white' migrants as inherently deviant and problematic, and through this as punishable in themselves. That is, these narratives will be invoked to portray the defendants to whom they are attached as innately punishable people.

\section{The practice of the sentencing hearing: The story so far}

The sentencing hearing is the endpoint of the court process, taking place following a guilty verdict in a trial or, more often, after a defendant has pleaded guilty. As Jacobson, Hunter and Kirby (2015) note, there are three main elements to the hearing. The prosecution speaks first, giving the 'facts of the case', which includes an account of the offence being dealt with by the court and also involves highlighting any existing legal guidance on an appropriate sentence. The defence then speaks for the defendant, arguing for leniency through the 'plea in mitigation'. Finally, the judge ${ }^{1}$ delivers their sentencing remarks and imposes the sanction that they have decided on. Apart from confirming their name at the beginning of proceedings, the defendant is not expected to speak during the hearing. ${ }^{2}$

As I highlighted in the introduction to this chapter, relatively little research - across both the literature on sentencing, as well as that on the courts - has focused on what happens

\footnotetext{
${ }^{1}$ In the magistrates' courts, of course, it is magistrates who pass sentence on the defendant. As I conducted my observations of sentencing hearings in the Crown Court, however, in this chapter I focus on Crown Court practices - unless it is specified otherwise.

${ }^{2}$ For some hearings, a pre-sentence report by the Probation Service will also be requested; and, as the Probation Inspectorate (2017) has highlighted, the use of oral pre-sentence reports - requested on the day of plea and sentencing and delivered by a probation officer during the hearing - is increasing. In the sentencing hearings that I observed, however, reports to the court by the Probation Service were predominantly written; across all the observations that I conducted, there was just one instance when a probation officer delivered an oral presentence report during the hearing. This was partly, I think, because a significant portion of my fieldwork took place before targets on increasing the number of oral reports were introduced (HM Inspectorate of Probation, 2017). But it was also probably because I conducted observations in the Crown Court, where offences considered to be more serious are sentenced - and, while there is an overall emphasis now on the use of oral probation reports, written reports continue to be used for more serious offences. In the analysis of my empirical material in Chapters Five and Six, I draw out how extracts from written probation reports were sometimes woven into the accounts delivered by the prosecution, defence and judge during the hearings that I observed. However, as oral probation reports were not part of the vast majority of hearings that I saw during my fieldwork, I do not consider them as one of the key elements of the practice of the sentencing hearing.
} 
in the courtroom during the sentencing hearing. When the practice of the sentencing hearing has been examined, moreover, there has been a tendency to approach what is said by legal professionals during this as simply factual or representational - to understand them as delivering neutral and objective accounts. The defence's account, it should be acknowledged, has generally been identified as more of a 'creative' construction. McConville et al., for instance, describe how they observed defence solicitors trying to 'soften the harder edges' (1994, p.199) in their explanations of the incident being dealt with, in order to persuade magistrates to treat the defendant in a more lenient way (see also Gathings and Parrotta, 2013). The facts of the case, however, has been described rather more straightforwardly as 'a fair and impartial summary of the prosecution case' (Shapland, 1981, p.121; see also Wasik, 2014). Similarly, judges' remarks - which have received the most attention in the sentencing literature - have often been viewed as factual exposition or record; that is, as a representational account of how the decision to impose a particular punishment has been made.

Thus, in his observational research on sentencing hearings for young people in juvenile courts in Australia, for instance, Max Travers argues that the sentencing remarks delivered during the hearing 'often provide an insight into how the magistrate arrived at a decision; they are, after all, designed to communicate what was in the magistrate's mind to an “over-hearing” audience' (2007, p.28). In line with this, Travers goes on to argue that the repeated references to ideas of reform and rehabilitation throughout the remarks he observed demonstrate how 'welfare values' shape sentencing decision-making in the Australian juvenile courts. In a more recent study involving observations of sentencing hearings in the Portuguese context, Andreia de Castro-Rodrigues and Ana Sacau adopt a similar view to Travers, identifying the oral sentencing pronouncements by judges to defendants as likely to 'closely reflec[t] the individual process of the sentencing decision' (2014, p.382). Through their analysis of the content of these oral remarks, they argue that it can be seen how judges' 
personal values and attitudes exert significant influence on the final sanction imposed, even though in Portugal sentencing decision-making is tightly structured by specific rules and legislation.

Alongside these observational studies, research that has analysed transcripts of sentencing hearing proceedings has also tended to conceptualise judges' remarks in a similar way. In the UK context, for example, a recent study by Shona Minson and Rachel Condry focuses on transcripts of Crown Court sentencing hearings for women with dependent children who had been sent to prison, and explores the sentencing remarks in these cases as a way of 'understand[ing] the thinking of judges ... who sentenced mothers to imprisonment' (2015, p.37). Likewise, in their analysis of transcripts of judges' remarks delivered during sentencing hearings for Indigenous defendants in South Australia's higher courts, Samantha Jeffries and Christine Bond examine these judicial 'sentencing stories' in order 'to establish in what ways Indigeneity may come to exert a mitigating influence over sentencing' (2010, p.223). Though they explore what takes place during the sentencing hearing, then, such observational and transcript studies are really more closely aligned with the research highlighted in the introduction to this chapter, which has dominated the literature on sentencing - that is, research that focuses on the sentencing decision and how this decision is made. Historically, empirical research on sentencing decision-making has often been conducted using statistical methods. By approaching judges' sentencing remarks like this, therefore, scholars have worked to develop a qualitative branch to this research (Jeffries and Bond, 2010; Travers, 2007).

Some sentencing theorists, however, have challenged the idea that what judges say during the hearing offers an uncomplicated window into their decision-making process, and have suggested that we need to think about sentencing remarks in a different way. Cyrus Tata, in particular, has argued that "the view that the "reason" for a decision given in court is a simple unmediated expression of the judge's thinking is highly questionable' (2002, p.416). 
Instead, he sets out that judges' remarks should be seen in terms of the 'social production of accountability' (2002, p.417). Thus, what the judge says in a sentencing hearing does not offer a 'simple factual presentation of the linear decision process (2002, p.421). Rather, it is a 'constructed', 'mediated' and 'selective' account, shaped to present a 'defensible' (2002, pp.418-419) version of how the sentencing decision has been made. In a later article, Tata identifies judges' sentencing remarks in terms of 'reason-giving craftwork' (2007, p.440). In doing so, he clarifies that he is not suggesting such judicial accounts are 'duplicitous' (2007, p.440) or that they function to obscure the 'real' or 'true' reasons underlying sentencing decisions. Rather, Tata explains that recognising the social nature of sentencing means understanding that 'sentencing reason giving is necessarily purposive' (2007, p.440).

Tata's emphasis on the social character of judges' sentencing remarks anticipates my framing of the narratives delivered during the sentencing hearing specifically as social acts or practices, which I set out later in the chapter. As I explain, understanding prosecution, defence and judges' sentencing accounts in this way has implications for what they look like and how they unfold. By insisting on the allocation of punishment as a social process, moreover, and in particular by highlighting the significance of accountability and defensibility for judges' reason giving, Tata also brings to our attention the issue of audience in relation to sentencing. The question of audience in relation to sentencing decision-making has been examined by some scholars through a focus on the 'external' audience of the public. Thus, as Mike Hough and Julian Roberts (2017) highlight, some research has identified a link between punitive public attitudes and the sanctions that sentencers impose.

Writing in the early 2000s, for instance, Millie, Jacobson and Hough pinpointed the sharp increase in England and Wales' prison population since the early 1990s as largely the result of magistrates and judges' 'growing preparedness to use custodial sentences, and when they do so, to pass longer sentences' (2003, p.370). They argued that this 'tougher sentencing' should be understood partly as the consequence of an increasingly harsh 'climate 
of opinion' (2003, p.378), comprised of political pressure, media attention and public attitudes. Linking back to the discussion in Chapter One on the relationship between government and media narratives about 'unwanted' migrants, and hostile public views on immigration, it might be noted how the three elements of the harsh 'climate of opinion' around punishment that Millie, Jacobson and Hough identified are tightly interlinked. More recently, Carly Lightowlers and Hannah Quirk (2015) have examined the higher custody rate and increased length of prison sentences imposed for offences committed during the so-called English 'riots' of 2011. They connect this sentencing 'uplift' $(2015$, p.75) - which they also refer to as a form of 'judicial abandon' (2015, p.65) - in part to punitive public attitudes.

Other scholars have considered the relationship between the 'external' audience of the public and sentencing decision-making from a normative perspective, exploring what role, if any, public opinion should play in shaping sentencing policy and practice (Ryberg and Roberts, 2014). As Roberts $(2014,2011)$ notes, arguments for the incorporation of public views into decision-making about criminal punishment have been made on several bases. From a consequentialist perspective, for example, it has been suggested that if sentencing policy and practice fails to reflect public opinion, the perceived legitimacy of the criminal justice system will decline. This, it has been argued, could 'result in a number of adverse effects, including the prospect of people resorting to vigilantism' (Roberts, 2011, p.111).

Despite the often punitive nature of public opinion, some theorists have also advocated for public input into sentencing decision-making as a way of ensuring proportionate sanctioning, and so in terms of the sentencing principle of desert. Matt Matravers (2014), for instance, contends that 'any plausible answer' to how the seriousness and severity of an offence should be determined must be 'context sensitive': 'By “context sensitive" I mean that judgements of seriousness and severity will reflect social conditions and practices such that what is deserved will be constituted by what is popularly believed to be - or what is implicit in current social practices as - serious, severe, and so proportionate' 
(2014, pp.36-37). Roberts argues for the incorporation of public views on a similar basis, contending that 'the seriousness of an offense is determined in part by the societal reaction to the proscribed conduct' (2011, p.105). He explains, however, that the way public attitudes shape sentencing should be tightly circumscribed, and that only informed public views should be considered - that is, views which are expressed by 'people who have been given some time and information to arrive at a decision' $\left(2011\right.$, p.106). ${ }^{3}$ The limited incorporation of public opinion into sentencing decision-making for which Roberts advocates might be seen to have been adopted by the sentencing guidelines authorities in England and Wales. In the 2000s the Sentencing Advisory Panel commissioned research on public attitudes towards offences including domestic burglary, rape, and causing death by driving, to help inform sentencing guidelines on these (Ashworth, 2008; Hough et al., 2008). More recently, the Sentencing Council ${ }^{4}$ has commissioned studies into public views on guilty plea sentence reductions (Dawes et al., 2011), as well as drug offences (Jacobson, Kirby and Hough, 2011), which were drawn upon in the development of new sentencing guidelines (Sentencing Council, 2017, 2012b).

Tata's consideration of audience not in relation to sentencing decision-making, but in terms of judges' reason giving during the hearing, also identifies the external audience of the public as important - and, alongside this, he points to additional audiences for whom judges may be constructing 'defensible' sentencing accounts. This includes those who are actually in

\footnotetext{
${ }^{3}$ Empirical research on public attitudes to criminal justice has demonstrated that, where people are provided with more detailed information about the criminal justice system and how it operates, their views often become less punitive (see Hough and Roberts, 2017). Thus, the literature on public opinion and sentencing has often distinguished between 'uninformed' and 'informed' public views (Ryberg and Roberts, 2014). In relation to the discussion in Chapter One, then, about how the dominant ideas of the government and media orchestrate and shape public opinion, it might be argued that in research studies where detailed information about criminal justice is given to participants, such dominant, punitive ideas are to some extent cut through.

${ }^{4}$ The Sentencing Council, which became operational in 2010, is responsible for preparing and issuing definitive sentencing guidelines for England and Wales. Prior to its establishment, the arrangements for developing and publishing sentencing guidelines were slightly more complicated. So, during the 2000s, the Sentencing Advisory Panel drafted and consulted on guidelines, and then provided advice to the Sentencing Guidelines Council - which was responsible for the creation and publication of definitive guidance (Sentencing Council, 2021b).
} 
court for the hearing, such as the defendant, prosecution and defence representatives, and potentially the victim - as well as any media that may be present (Tata 2007, 2002). Beyond the immediate confines of the courtroom, a further audience that Tata (2020) highlights in addition to the public (who may hear about the sentencing remarks if they are reported by the media) $)^{5}$ is the more specialised audience of the Court of Appeal. As I indicate in the next section of the chapter, in relation to audiences beyond the immediate confines of the courtroom, many of the sentencing hearings I observed seemed to have quite low visibility. Often, it was only the defendant, the legal professionals involved and one or two court staff who were present, plus occasionally a few of the defendant's family or friends - so the proceedings had a private feel. Yet, there were also a couple of occasions where judges appeared to be taking particular care to adhere to the legal norms and conventions of sentencing narratives - norms and conventions which I explore later in this chapter. The judges' delivery of clearly legalistic accounts, therefore, seemed to reflect a concern with making their reason giving defensible to the 'external' audience of the Court of Appeal. I explore both these instances in Chapter Five, where I begin my examination of the empirical data that I collected during my fieldwork.

Tata's sociological critique from within the sentencing literature, then, warns us against a conception of judges' sentencing remarks as straightforwardly factual and representational accounts. Alongside this, the significant body of socio-legal research on the process that sometimes precedes the sentencing hearing, the trial, also problematises approaching judges' remarks, as well as the prosecution's facts of the case, in this way. Jo Winter (2002) has set out how, according to legal positivist ideas, the criminal trial proceeds as follows: objective 'facts' and 'evidence' about the incident in question are put forward by the prosecution and defence, the jury then retires to consider this evidence - and, through

\footnotetext{
${ }^{5}$ Criminal courts are of course a public setting, and so individual members of the public may hear sentencing remarks if they are sitting in the public gallery in court. As I proceed to explain, however, in most of the sentencing hearings that I observed during my fieldwork I was the only member of the public present.
} 
their deliberations, the 'truth' of 'what happened' is finally established. Yet, as Winter explains, socio-legal researchers have repeatedly challenged such an understanding. They have argued that, far from entailing an 'objective' and 'factual' presentation of the incident being dealt with, the trial actually involves the 'social construction of reality' (Winter, 2002, p.344) by the prosecution and defence. That is, during the trial process, 'facts' and 'evidence' about 'what happened' are, as Winter puts it, continually 'interpreted and reinterpreted, shaped and reshaped' (2002, p.344).

Thus, in her influential study Conviction, for instance, Doreen McBarnet highlights how both the prosecution and defence present what is effectively 'an edited version' of the incident being dealt with by the court - in terms of it being pared-back and simplified, but also in terms of it being told 'with vested interests in mind' (1981, p.17). She explains: 'Far from being "the truth, the whole truth and nothing but the truth" a case is a biased construct, manipulating and editing the raw material of the witnesses' perceptions of an incident into not so much an exhaustively accurate version of what happened as one which is advantageous to one side' (1981, p.17). Similarly, in his well-known ethnography of Wood Green Crown Court, Paul Rock highlights how accounts of the incident in question presented during a trial are not only simplified, constructed to ‘strip away volumes of context and history’ (1993, p.31), but are also inflected and shaped by the prosecution and defence in very different ways. He states: 'Trials supplied competing stories about the past, reconstructing all the indeterminacy and muddle of everyday life into what McConville once called "opposing distortions"' (1993, p.36). In her research on trials for drug offences, which I explore in more detail later in the chapter, Anita Kalunta-Crumpton sets out that the prosecution 'demands that a defendant be adjudged responsible for an alleged ... offence', whereas the defence 'claims that the defendant is innocent' $(1999$, p.20). As she explains, therefore, during drugrelated trials, the versions of 'what happened' put forward by prosecution and defence representatives operate to 'create or prevent the creation of a drug offence' $(1999, \mathrm{p} .57)$. 
Building on this research, Winter has argued that it is not only the prosecution and defence who offer selective, shaped versions of the incident being dealt with during the trial, slanted in favour of the defendant's guilt or innocence. As she explains, under the legal positivist conception of the trial, the judge is often understood as an 'independent arbiter performing a supervisory role, ensuring that applicable rules and conventions are followed' (2002, p.343). Yet, Winter suggests that via the practice of 'summing up' to the jury, before the jury retires to consider its verdict, judges are also able to 'step into the fray' (2002, p.346). That is, she contends that judges' summing up during the trial can function as 'a third, largely unacknowledged, limb of advocacy' (2002, p.347), as the account of the incident that the judge presents may work to encourage the defendant's conviction, or their acquittal.

Against such socio-legal investigations into the trial, then, what we might term a legal positivist conception of the sentencing hearing - namely, the idea that the prosecution's facts of the case and the judge's sentencing remarks are straightforwardly objective and representational - begins to look less plausible. With this in mind, I want to propose a specific framework for thinking about the sentencing hearing that can move us beyond notions of factual record and representation, and which can also be deployed to understand all of the accounts delivered by legal professionals during this process: narrative.

\section{Narrative: A framework for understanding the practice of the sentencing hearing}

Critics writing on the criminal courts have routinely drawn comparisons between the practice of the courtroom and the theatre (Jacobson, Hunter and Kirby, 2015; Rock, 1993; Carlen, 1976). The trial, in particular, has often been described in terms of the various 'actors' involved playing their specific parts in a well-rehearsed, and often dramatic, public performance. Such an understanding is not entirely inappropriate for the sentencing hearing. As Jacobson, Hunter and Kirby (2015) note, there can be moments of drama and tension 
during this. In particular, perhaps, the moment before the judge begins their sentencing remarks, as the defendant waits to discover how they will be sanctioned, often feels laden with suspense.

And yet, describing the criminal courts in this way can also feel rather ill-fitting. The processes and practices of the court are, sometimes, not well-rehearsed and choreographed but messy and chaotic (Jacobson, Hunter and Kirby, 2015). For lay participants, at least, they are also often slow and tedious: in her well-known study of the magistrates' courts, Pat Carlen notes how 'for the majority of the defendants, the court experience is characterised by long periods of waiting' (1976, p.27; see also Jacobson, Hunter and Kirby, 2015; Rock, 1993). Indeed, rather than being a place of high drama and suspense, the court is more often characterised by mundanity, repetition and routine (Bottoms and McClean, 1976) - an idea that I explore in more detail as this chapter continues. It is worth noting, too, that while the court is officially a public setting, and so what takes place in it might be understood in terms of a public 'performance', as I began to suggest in the previous section in practice court proceedings often have a much more private feel. This is in part because, in some cases that go through the court, the 'deeply private details of individuals' lives' (Jacobson, Hunter and Kirby, 2015, p.73) are delved into and scrutinised. But it is also because - unless the case being dealt with is high profile in some way - there is rarely anyone in court beyond those who are immediately involved in the case. Certainly, in most of the sentencing hearings that I observed during my fieldwork, the only people in the courtroom were the defendant, the prosecution, defence and judge, and the court clerk and usher - plus sometimes one or two of the defendant's family members or friends.

Less dramatic and spectacular in its connotations - and so more fitting, I would suggest, in terms of the overall demeanour of the court - the idea of narrative and storytelling also offers us, as I indicated at the end of the last section, a useful framework for conceptualising all of the accounts delivered by legal professionals during the practice of the 
sentencing hearing. Before proceeding further with this, however, it is important to highlight that, while the language of 'narrative', 'stories' and 'storytelling' has frequently been deployed in criminological writing on the courts - Rock's analysis, cited above, of the trial as supplying 'competing stories about the past' provides just one example of many - the usage of these terms in such writing has sometimes been vague and imprecise. ${ }^{6}$ Thus, in the existing literature on the courts, an idea of what stories and narratives are, or do, is not always set out clearly; and, concomitantly, what referring to courtroom accounts in this way means, or particularly draws out, is often not explored fully or examined critically. Moreover, if we unpack the assumptions which underpin the deployment of these terms in writing on the courts, it also becomes clear that they are often being used in quite different, and sometimes conflicting, ways. In this way, then, criminologists writing about stories and storytelling in the courtroom appear to bear out Mieke Bal's observation, that 'narrative' is one of those 'very common and seemingly obvious' concepts which 'has been used so often it has begun to lead a life of its own and is understood somewhat differently by every user' $(2009$, p.5).

In his ethnography of Wood Green Crown Court, for example, Rock refers to accounts delivered during the trial as 'stories' and 'narratives' in part to denote their formulaic and generic nature. So, he writes about how, as the prosecution and defence put forward their cases, 'time and again ... the same plots seemed to be exposed, plots that were familiar to the point of being a little hackneyed to insiders' (1993, p.78). Alongside this, Rock describes courtroom accounts as narratives, too, to get at how the prosecution and defence construct - from the complexity and confusion of 'what happened' - carefully organised and shaped accounts of the incident with which they are dealing. He explains, for

\footnotetext{
${ }^{6}$ As I highlighted in Chapter One there is now a rich literature within the criminological sub-field of narrative criminology, which explores 'the role the telling and sharing of stories play in committing, upholding and effecting desistance from crime and other harmful acts' (Sandberg and Ugelvik, 2016, p.129). I would like to emphasise, therefore, that in identifying vague and imprecise usage of the terms 'narrative', 'stories' and 'storytelling' within criminology, I am referring specifically to their deployment in criminological writing on the courts.
} 
instance, how during trials the prosecution and defence worked to give 'structure and plot' (1993, p.75) to the information and details supplied by witnesses, and he also writes about how, in the stories that they relayed to the court, barristers 'attempted to tie events and people plausibly together' (1993, p.78).

In his research into Crown Court trials for violent offences, on the other hand, Nigel Fielding (2006) appears to put forward a quite different understanding. At one point during his analysis he alludes to Bennett and Feldman's (1981) idea that structurally, there are good and bad stories, and that a bad or weak structure can mean a story is regarded by those listening to it as less plausible. This suggests, perhaps, a conception of narrative that is centred on notions of construction, coherence and plot. Yet, Fielding also uses the idea of narrative and storytelling to describe how victims and witnesses in a trial often want to give an account of 'what happened' that goes beyond the limits of the questions put to them by barristers. That is, he deploys the term 'narrative' to capture how these lay participants sometimes attempt to recount the incident being dealt with in a much more detailed and embellished way. Thus, what some of the legal professionals interviewed for his research described as 'go[ing] on with an unstructured response', 'rambl[ing] on' and 'blurt[ing] it all out' is identified by Fielding as victims and witnesses attempting to give their evidence in 'a narrative form' and as taking 'a narrative approach' (2006, pp.183-185). His idea of storytelling as fulsome, flowing and unstructured, then, is almost in direct opposition to that put forward by Rock, who identifies courtroom narratives as carefully organised and precisely plotted.

My conception of narrative is closer to Rock's than Fielding's; Rock's identification of narrative's 'structure and plot' is, as I now go on to argue, key. For Rock, however, who also cites Bennett and Feldman, structure and plot appear to be very much tied to the idea of a story's credibility. Thus, structure is something that can be done well or poorly, and if a story or narrative has what Bennett and Feldman refer to as 'structural ambiguities' (1981, p.79) it 
is less likely to be believed. I would suggest, on the other hand, that we should approach the plotting of stories not through the lens of goodness or badness, and in terms of supposed structural weakness or strength and associated levels of credibility. Rather, we should be concentrating on what the 'structure and plot' of a narrative is actually doing. That is, we should be thinking about what this critical ingredient of stories and storytelling is working to achieve.

In his essay 'The value of narrativity in the representation of reality', Hayden White (1987) explores what narrative as a form of writing is, and what 'narrativising' does, by looking at historical narratives alongside two types of non-narrative historical writing, annals and chronicles. As he explains, 'the annals form ... consists only of a list of events ordered in chronological sequence'; there is, in this form of writing, 'no suggestion of any necessary connection between one event and another' (1987, pp.5-6). Similarly, in the chronicle we see the 'perseverance' of 'chronology as the organizing principle'; and yet, unlike annals, there is also in chronicles a focus on 'a central subject - the life of an individual, town, or region; some great undertaking, such as a war or crusade; or some institution, such as a monarchy, episcopacy, or monastery'. In this way, then, this form of writing tends towards a 'greater narrative coherency' (1987, p.16). White notes, however, that while the chronicle 'often seems to wish to tell a story, aspires to narrativity', in the end it 'typically fails to achieve it'. This is because, he argues, 'the chronicle usually is marked by a failure to achieve narrative closure. It does not so much conclude as simply terminate. It starts out to tell a story but breaks off in media res, in the chronicler's own present; it leaves things unresolved, or rather, it leaves them unresolved in a storylike way' $(1987$, p.5).

Against the lack of closure and resolution that characterises the chronicle, then, and the chronological listing of annals - where there is no attempt to tie 'loose ends' $(1987, \mathrm{p} .8)$ together, or explain 'blank years in the annalist's account' (1987, p.11) - White argues that the distinguishing feature of the narrative form emerges. Thus, he sets out, contrasted with 
non-narrative forms of writing, 'the extent to which narrative strains for the effect of having filled in the gaps' becomes apparent; it becomes acutely clear how historical narratives work to impose on the events that they relay 'an image of continuity, coherency and meaning' (1987, p.11). Narratives, therefore, are defined by structure and plot - and, as they organise and shape 'reality', as they impose fullness and finality on the events that they recount, they convey and produce meaning. As White further explains, then: 'The historical narrative ... reveals to us a world that is putatively "finished", done with, over, and yet not dissolved, not falling apart. In this world, reality wears the mask of a meaning, the completeness and fullness of which we can only imagine, never experience' (1987, p.21; emphasis mine).

Now, for White, the plotting and shaping of the narrative form is always focused on the production of moral meaning; the purpose of narratives is always to moralise. Thus he asks, simply, 'Could we ever narrativize without moralizing?' (1987, p.25). As I indicate later in this chapter, and as we will also see in the analysis of my empirical material, moralising is undoubtedly an important aspect of the narratives delivered during the sentencing hearing. However, I would suggest that by adopting a more sociologically-inclined perspective at this point we can develop a more expansive view of the possible purposes and meanings for which narratives might be constructed and pulled together.

In their much-cited article 'Subversive stories and hegemonic tales: Towards a sociology of narrative', Patricia Ewick and Susan Silbey identify stories and narratives as 'social acts' (1995, p.197) and as 'communicative devices in human interaction' (1995, p.211).Consequently, they argue that narratives can be organised and plotted for a whole range of different effects and meanings. Thus, as they explain, narrators construct and relay their stories not simply to moralise - but, in fact, 'to entertain or persuade, to exonerate or indict, to enlighten or instruct' (1995, p.208). In a similar way, Barbara Herrnstein Smith has set out an understanding of narratives as a type of 'social transaction' (1980, p.232), and has explained that there are a 'multiplicity of functions that may be performed by narratives 
generally and by any narrative in particular' (1980, p.235). To achieve different functions, she observes, narrators craft and pull together 'what happened' in particular ways. That is, we 'preserve, omit, link, isolate, and foreground different features or sets of features' (1980, p.217) according to the specific purpose, or purposes, of our narratives.

From this perspective, therefore, we can move beyond the ideas of factual record and representation that have often been dominant in writing on the sentencing hearing, and we can understand the accounts delivered by legal professionals during this process in a quite different way. By approaching the prosecution's facts of the case, the defence's plea in mitigation and the judge's sentencing remarks as individual narratives, we can see them all as carefully plotted and shaped accounts of the incident being dealt with by the court, each of which has been organised and pulled together for its own distinct purpose or meaning. In the trial, the stories told by the different legal professionals involved can be understood as centred on the issue of guilt, and so as different versions of 'what happened' focused either on incriminating or exonerating the defendant (Kalunta-Crumpton, 1999; Rock, 1993; McBarnet, 1981). Yet, by the sentencing hearing, of course, guilt has been determined either through a jury's verdict or the entering of a guilty plea. Thus, as the focus has by this point shifted to the allocation of sanctions and punishment as a result of the guilt that has been established (Padfield, Morgan and Maguire, 2012; Tata, 2007), we might say that the narratives produced about the incident in question during the sentencing hearing are centred on the issue of the defendant's punishability. I draw out the distinct purposes of each narrative - what each one is specifically doing in relation to the overarching focus of the sentencing hearing - in Chapters Five and Six, where I explore my empirical data. At this stage, however, we might say that broadly, the different narratives produced by the different legal professionals involved in the hearing are focused on the construction, and negotiation, of the defendant's punishability. 
'Punishability', it should be acknowledged, is not a term that has often been deployed in writing on the criminal courts, either in the legally or criminologically-focused literature. I use it here, in the first place, to capture how, in the sentencing hearing, the narratives delivered by legal professionals are concerned with the defendant as someone who is punishable, whom it is legitimate to sanction or punish; and how they are also concerned with how punishable the defendant is - whether, broadly speaking, they deserve harsher or more lenient treatment. Alongside this, I would contend that the term 'punishability' has specific analytic value because it focuses our attention on what the narratives in the sentencing hearing might look like and how they are likely to unfold. That is, it teases out how, in particular, the stories delivered by the prosecution, defence and judge during sentencing proceedings are likely to work towards their distinct purposes and meanings.

Thus - when it has been deployed by scholars - 'punishability' has been utilised in a legal sense, to refer to an individual's legal liability for punishment (see, for instance, Brudner, 2009). In this way, it reflects how defendants will be constructed and negotiated as deserving of punishment in legal terms, through the conventions of the criminal law - as we will see, then, in terms of their prohibited acts and forbidden intentions. ${ }^{7}$ At the same time, however, since 'punishability' is not a narrowly legalistic term, and does not have only legally-focused connotations, it also allows for how defendants in the sentencing hearing are likely to be made punishable in a broader way. So, it encompasses how, as social acts or

\footnotetext{
${ }^{7}$ I recognise that the production of legal guilt and liability for punishment does not rest solely on prohibited acts and forbidden intentions - that is, on the core legal elements of the actus reus and mens rea. In his book Character in the Criminal Trial, Mike Redmayne has documented how the Criminal Justice Act 2003 'usher[ed] in a much more liberal admissibility regime' in relation to the use of 'bad character' evidence about a defendant during a trial, to demonstrate their alleged 'propensity to offend' (2015, pp.274-276). Redmayne also observes how factors relating more to the defendant than to the offence for which they are being sanctioned - for example, the defendant's attitude to the offence, or some of their personal circumstances - have long been considered relevant in sentencing proceedings. Across Chapters Five and Six, indeed, where I explore the empirical data that I collected during my fieldwork, I highlight instances where legally codified factors of personal mitigation (Jacobson and Hough, 2011) were referred to during sentencing hearings. Nonetheless, as I explore in the next section of this chapter, it remains the case that the actus reus and mens rea constitute the overarching framework on which the criminal law rests - and so that prohibited acts and forbidden intentions form 'the essential building blocks of a legally sustainable case' (McConville, Sanders and Leng 1991, p.65).
} 
practices, sentencing narratives are also likely to mobilise and tap into wider social meanings and hegemonic or dominant narratives. Hence, 'punishability' suggests how sentencing accounts will not simply focus on criminal acts and intentions - but, through recourse to dominant narratives about, for example, gender and race, will also be concerned with whether defendants are deserving or undeserving in themselves, with if they are good or bad people.

Indeed, I would suggest that this aspect - the role of ideas about the defendant's intrinsic nature in the production of liability for criminal punishment - is also well captured by identifying sentencing hearings as centred specifically on the construction and negotiation of the defendant's punishability. Such a framing expands our perspective beyond the criminal act committed; by referring to the defendant, and their punishability, it signals how notions of who the defendant is - and, more specifically, about their innate goodness or deviance - are also likely to be utilised by legal professionals during sentencing proceedings. ${ }^{8}$ In the sections that follow I explore the construction and negotiation of defendants' punishability in more depth, as I conceptualise how sentencing hearing narratives are likely to play out and unfold.

\section{Making defendants punishable in legal terms: Stories of prohibited acts and forbidden}

\section{intentions}

In their investigation of narrative from a sociological point of view, Ewick and Silbey highlight how, as social acts and practices, narratives are always told in particular ways, that their content is always 'governed by social norms and conventions'. As they explain, it is these norms and conventions, or 'content rules', which determine 'what constitutes an appropriate or successful narrative' (1995, p.207). In the first place, then, as Ewick and Silbey set out, narratives always adhere to the 'local norms' (1995, p.207) of their immediate social setting; so, in the case of stories delivered in the criminal courtroom, they follow and

\footnotetext{
${ }^{8}$ It is, additionally, arguable that by describing sentencing hearings as focused on the construction and negotiation of the defendant's punishability, the role of, for example, legally codified personal mitigating factors - referred to in the footnote above - are also effectively captured.
} 
are told in line with the rules and conventions of the criminal law. The existing literature on the courts, much of which, as I have highlighted, focuses on the trial, helps us to trace what this looks like in practice for narratives that are concerned with the issue of a defendant's guilt. By exploring this existing literature, therefore, I would suggest that we can also start to develop a sense of how accounts in the sentencing hearing might play out, too; that is, we can begin to understand how sentencing narratives might construct and negotiate defendants as legally punishable.

The conventions of the criminal law and how these govern the narratives that are delivered during the trial, might, perhaps, be understood in terms of what sort of information can be relied on in court and form part of the stories that are told. Thus, Jacobson, Hunter and Kirby note how, for example, under the hearsay rule, it is generally the case that 'witnesses are not allowed to relay information that has been told to them by another' $(2015, \mathrm{p} .89)$. More centrally, though, I would suggest that the construction of trial narratives in line with criminal law norms should be seen in terms of how accounts of 'what happened' are delivered in accordance with the overarching framework on which the criminal law rests. That is, they are told through the framework of the actus reus, the prohibited act, and the mens rea, the forbidden state of mind - as McConville, Sanders and Leng put it, 'the essential building blocks of a legally sustainable case' (1991, p.65; see also Norrie, 2014). It is important to note, of course, that strict liability offences, which do not require some form of mens rea, actually 'substantially outnumber offences that require a mental element in English criminal law today' (Lacey and Zedner, 2017, p.66). As Andrew Ashworth and Jeremy Horder (2013) explain, however, most strict liability crimes are summary offences and thus triable only in the magistrates' courts. Hence, although 'around half of the offences triable in the Crown Court have a strict liability element' (Ashworth and Horder 2013, p.138), this nevertheless means that many of the offences the Crown Court deals with still require proof of some form of fault or intention. 
The way in which the framework of the actus reus and mens rea shapes courtroom narratives from the very start of the criminal trial is evident from one of the trials that Fielding (2006) explores. The defendant in this case was being prosecuted for murder: he was accused of stabbing the victim, a friend of his, to death, following an argument between them in a pub earlier that day. The stabbing had been witnessed by the brother of the victim, who was also in the pub when the argument occurred. In his analysis of the prosecution's opening speech - which, coming immediately after the jury has been sworn in, marks the beginning of the trial - Fielding focuses on what he identifies as the prosecution barrister's 'businesslike approach' (2006, p.112) in relaying 'what happened' between the defendant and the victim that day. He highlights, for example, how the prosecution deployed 'abstract constructions' in their account of the incident, noting, in particular, the use of phrases such as 'the knife having been used'. He observes, too, how the prosecution only described the incident's 'ostensible key features', and how they also avoided including any 'emotive content', except when directly quoting the defendant, the victim or the victim's brother. In this way, Fielding argues, the prosecution barrister worked to give their opening account an 'authoritative air' (2006, p.112), in order to insist upon on the 'truth' of the version of events they had relayed. Indeed, Fielding also sets out how this tactic was repeated later on in the trial, in the prosecution's closing speech. The 'factual circumstances' of the incident being dealt with were once more 'emphasized and exploited', he explains, in order 'to confirm the prosecution case as measured, dispassionate and authoritative' (2006, p.113).

What we might note alongside this, however, which receives less attention in Fielding's analysis, is how the rules and conventions of the criminal law determined and shaped the prosecution's opening speech. Thus, the prosecution's narrative about 'what happened' set out that a prohibited act had been committed; that is, that following an argument in the pub between the defendant and the victim earlier that day, the victim had been stabbed and had died very shortly after this. It was also asserted that it was undoubtedly 
the defendant who was responsible for this prohibited act. As well as describing how the victim's brother had heard the victim say to the defendant, 'Are you going to use that knife on me?' shortly before he collapsed and died, the prosecution highlighted, too, that when the police arrived, 'the defendant admitted he caused the injury that killed [the victim]' (2006, p.112). Importantly, moreover, in relation to the specific charge of murder that was being pursued against the defendant, the prosecution's narrative emphasised, as well, the defendant's clear intent to kill the victim. At one point, for instance, after the prosecution had given some details of what the argument between them had been about, it was then specifically highlighted how the defendant had later been heard saying, 'I don't need him in my face, I am going to do him in' (2006, p.112; emphasis mine). By giving a version of events that clearly identified the wrongful act committed, and which also insisted on the defendant as intentionally carrying out this act, therefore, the prosecution delivered, in their opening speech, a narrative of incrimination constructed firmly in accordance with the rules and norms of the criminal law.

The assertion of guilt through legal norms and conventions can be seen to continue in the next stage of the trial, as the prosecution goes on to present its case and narrate 'what happened' by calling and questioning its witnesses. I highlighted earlier Fielding's observation that, when giving evidence in court, victims and witnesses often want and sometimes attempt to recount 'what happened' in a way that goes beyond the limits of the questions put to them by barristers. Similarly, Jacobson, Hunter and Kirby note how the victims and witnesses they interviewed for their research often said that they felt restricted by the questions they were asked by legal professionals, and 'that they could not say what they wanted to at the point at which they finally took the stand in court' $(2015$, p.88). Fielding, as I have noted, argues that what we see happening here is victims and witnesses wanting to take 'a narrative approach' - where 'narrativising' is understood as recounting the incident in question in a detailed and embellished fashion, and so delivering the 'whole story' rather than 
a more succinct version that is appropriate within the confines of the criminal trial and court. I would suggest, however, that rather than seeing lay participants' frustration solely in terms of them wanting to relay a more expansive version of events than is permitted, we might understand this 'clash' between victims and witnesses, and legal professionals, in another way.

Thus, I would argue that as they recount 'what happened', victims and witnesses are also attempting to deliver plotted, purposive accounts. The functions of the story they want to tell, however - which might include, for example, in the case of a victim, conveying how awful the experience they have been through was - do not necessarily coincide with the purposes of the prosecution, or defence's, narrative. Hence, legal professionals work to address this through their questioning; that is, they attempt to reshape the story being delivered in an appropriate way. What Fielding has characterised as barristers simply filtering out 'irrelevant details' (2006, p.185), therefore, might be better understood as the prosecution, or defence, working to reorganise and restructure lay participants' alreadyplotted accounts. In other words, legal professionals push lay participants away from the tales that they want to deliver, towards stories clearly focused on incrimination, or exoneration - the narratives that are central to the criminal trial.

As the trial moves to the evidence of the prosecution witnesses, then, the prosecution attempts to 'facilitate the development of narratives' (Ewick and Silbey, 1995, p.209) and control the story being presented to the court through their questioning (Rock, 1993; McBarnet, 1981) - ensuring, specifically, that it asserts the defendant's guilt in a legally acceptable way. We can see how this plays out by exploring one of the trials described in more detail by Rock (1993), for a man who was being prosecuted for wounding with intent, having been accused of stabbing another man in the cheek with a knife. After the prosecution's opening speech, the victim of the attack was called to give evidence - and, in Rock's words, he was 'placed under instant and continuing control' by the prosecution 
barrister, who took him through the details of the incident 'stage by stage' (1993, p.81). Thus, the prosecution's questions elicited details of the injury the victim had sustained through the attack - a scar on his cheek, which required nine stitches. In this way, it was established that a prohibited act, the causing of a wound, had taken place. The prosecution then worked to insist that it was undoubtedly the defendant who was responsible for this act. So, he prompted the victim 'to furnish a meticulous description ... of the defendant's physical appearance' (1993, p.81), and he also asked questions about the identity parade the police had organised, at which the victim explained that he had picked out the defendant.

Importantly, moreover, the prosecution's questions to the victim also addressed the issue of intent. Following the victim's explanation that the defendant had approached him while he was sitting with his girlfriend in a park, then, and that he had initially told the defendant to 'go away please', the prosecution asked him, pointedly, if the defendant had said 'anything in particular' to him before the attack. The victim responded, 'He said, 'I'm going to stab you"' (1993, p.81). Hence, through the questions that he asked, the prosecution extracted from the victim an 'appropriate' (Ewick and Silbey, 1995, p.207) narrative of incrimination. That is, the prosecution elicited a version of 'what happened' which detailed the wrongful act committed, and the defendant's clear intention in doing this - and thus which affirmed the defendant's guilt in a legally palatable way.

In the trial, therefore, we can see how prosecution narratives of incrimination, told in line with the 'local norms' of the criminal law and the courtroom, assert guilt by telling a story about the prohibited act the defendant has committed, and their clear intent in carrying this out. Conversely, as McConville et al.'s (1994) research suggests, defence narratives of exoneration often contest guilt by relaying stories that are essentially the opposite of this. So, they insist that it was not the defendant who committed the wrongful act - or, alternatively, they emphasise that while the defendant did do it, they certainly did not intend to carry it out. By tracing this pattern from the literature on the trial, then, we can, as I suggested earlier, 
begin to develop an understanding of what narratives in the sentencing hearing might look like, too. Thus, we should expect sentencing narratives to be similarly focused on prohibited acts and forbidden intentions, as they work to construct and negotiate defendants' punishability in a legally appropriate way.

In the sentencing hearing, moreover, as I have also suggested, the focus is not simply on the defendant as legitimately punishable, as someone whom it is justifiable to sanction or punish. There is a concern, too, with how punishable the defendant is, and whether they deserve harsher or more lenient treatment. Consequently, we should also expect sentencing narratives to be concerned with the specific legal elements that relate to this. Typically, these legal elements have been framed by the criminal law and sentencing theorists as combining to produce the 'offence seriousness' (Ashworth, 2015; Wasik, 2014). However, I would suggest that we might also understand them as specifying the defendant's particular level of legal punishability.

So, as sentencing accounts work to construct and negotiate just how punishable, in legal terms, the defendant is, we should expect them to concentrate not simply on the prohibited act that has been committed, but also on the particular nature of this wrongful act, on the 'harm done or risked' (Ashworth, 2015, p.157) by carrying it out. And we should expect sentencing narratives to focus, too, not only on the defendant's intention, but also on the particular degree or level of intent they had in committing the offence - what is referred to, under the criminal law, as the convicted person's culpability (Ashworth, 2015; Wasik, 2014). As we will see in the examination of my empirical data in Chapters Five and Six, during many of the sentencing hearings that I observed the harm done or risked by a criminal act, and the defendant's level of culpability, were often constructed and negotiated through reference to sentencing guidelines. While these do not exist for all criminal offences in England and Wales, since the formation of the Sentencing Council in 2010 definitive 
guidelines have been introduced for offence types including assault, burglary, drugs, fraud, theft and sexual offences (Sentencing Council, 2021c).

It is worth noting that, in contrast with some recent developments in sentencing practice, narratives in the sentencing hearing have sometimes been imagined by critics in terms of their individualised specificity and attention to detail. Thus, examining the increasing use, in the United States in particular, of numerical sentencing guidelines, Aas has set out that such quantitatively-focused technologies have been introduced into sentencing proceedings 'at the expense of richness of language and narratives' (2005, p.21). Similarly, in her research on sentencing in the Scottish courts, Jacqueline Tombs has argued that as judges have increasingly been presented with 'formulaic' information about the people they are sentencing, from 'risk-based instruments' (2008, p.102), their 'creative abilities' have been hindered and they have been prevented from telling as 'textured' (2008, p.85) stories as they used to previously. I would suggest, however, that an understanding of sentencing accounts as governed by local or institutional norms, and so as shaped by criminal law rules and conventions, should lead us to conceptualise them in a quite different way.

Specifically, as stories about the punishability of defendants are filtered through the framework of the actus reus and mens rea, I would argue that sentencing narratives have never been individually textured and nuanced. Rather, they have always been delivered in a standardised and formulaic way. The increasing prevalence of sentencing guidelines in England and Wales, which I noted above, and their specification of key factors relating to the harm risked or caused by a criminal act as well as the defendant's culpability, may of course have enhanced sentencing stories' formulaic nature. However, I would contend that the effect of these guidelines has been very much to augment a pre-existing formulism; legal professionals did not, previously, have an unrestricted discretion to recount their narratives however they wished during sentencing proceedings. Thus, the characterisation of courtroom practices that I referred to earlier in the chapter, in terms of their mundanity, repetition and 
routine, might be seen to effectively capture and reflect the nature of the stories that are told during the sentencing hearing. The regular telling of legally standardised sentencing narratives, therefore - focused on prohibited acts, and the harm risked or caused by such acts, as well as forbidden intentions, and the defendant's specific degree of intent or culpability might be understood as a central element of the criminal court's repetition and routine.

As I explained previously in this chapter, and as I will demonstrate in my analysis in Chapter Five, there were a couple of instances during my fieldwork where judges appeared to be taking particular care to deliver a clearly legalistic narrative. Such care appeared to point towards an awareness that there could be a future legal challenge to the punishment they were imposing - and so, as I have suggested, to reflect the judge's concern with ensuring that their narrative was defensible to the 'external' audience of the Court of Appeal. Yet, the content of sentencing narratives is not only governed by local or institutional norms; sentencing stories unfold not solely through reference to the conventions of the courtroom and the criminal law. As Ewick and Silbey argue, as social acts and practices narratives are shaped by the conventions and norms of the wider social context, too. Thus, the stories that we tell 'bear the imprint of dominant cultural meanings' and reflect and reproduce hegemonic or 'master narratives' (1995, pp.211-212).

As I suggested in the introduction to this chapter, understanding this provides the link between dominant narratives of bordering and the practice of the sentencing hearing. From this perspective, we can start to see how contemporary representations of unwanted migrants might be seeping into the sentencing process; we can begin to understand how these racialised depictions might be percolating into the individual narratives about 'what happened' that are delivered by the prosecution, defence and judge. Importantly, moreover, by turning again to the existing literature on the courts and, specifically, to research on gendered and racialised narratives in the trial, we can also start thinking about what dominant narratives of bordering might be mobilised to do in sentencing hearings. That is, we can 
theorise how, in particular, such hegemonic, racialised narratives might be put to work in the construction, and negotiation, of defendants' punishability. Ultimately, this literature suggests that the repetition and routine of sentencing narratives will not simply be confined to their focus on defendants' prohibited acts and forbidden intentions. Their formulaic nature will play out, too, through the construction of some defendants as problematic in themselves - and the insistence, therefore, that these defendants are inherently punishable people.

\section{Making defendants punishable through gender and race: Stories of intrinsically problematic people}

Central to the authority and legitimacy of the court is the idea of its neutrality and impartiality (Ballinger, 2012; Carlen, 1976; Sachs, 1976). In relation to the trial, this translates, in part, into the legal positivist conception of this process that I highlighted earlier. That is, that straightforward, factual accounts of the incident being dealt with are presented by the prosecution and defence to the jury, who then deliberate on the 'facts' and 'evidence' put before them in order to arrive at the 'truth' of 'what happened'. Alongside this, it translates, too, into the idea that the accounts of 'what happened' delivered during the trial are not only 'exhaustively accurate' (McBarnet, 1981, p.17) - that they relay the whole truth and nothing but the truth, and are not partial, shaped or edited in any way - but that they are also presented entirely rationally and dispassionately. Hence, the prosecution and defence, and especially the judge, who supervises proceedings, are understood to be completely free from and unencumbered by the biases and prejudices that are found in wider society. The court, therefore, is conceptualised as a space apart from society-at-large; it is understood as distinct from, and indeed superior to, 'the mundane world outside' (Jacobson, Hunter and Kirby, 2015, p.65).

The supposed neutrality and impartiality of the courtroom is alluded to and asserted during court proceedings in a number of ways. The robes and wigs worn by barristers and 
judges in the Crown Court, for instance, present them not as individual people, but impersonal representatives of the law. As Winter (2002) highlights in relation to judges in particular, moreover, the various appellations used to address them, including 'the court' and 'your honour', do something similar. She explains how referring to the judge like this, rather than using their actual name, 'not only communicates reverence, but also depersonalizes the judge, transforming her or him into the embodiment of "law and justice"" (2002, p.348). We might note, too, that while the individual names of the prosecution and defence barristers are sometimes used in court - though, of course, always in the most formal form, such as 'Ms $\mathrm{X}$ ' or ' $\mathrm{Mr} \mathrm{Y}$ ' - legal professionals also routinely refer to themselves in an abstract, depersonalised way; for instance, 'the Crown/Defence says that ... '. The court's neutrality and impartiality are also insisted upon by legal professionals through their demeanour and behaviour during proceedings. Fielding observes how judges, for instance, 'tend to preserve their aplomb in the face of accounts of the plainly discreditable if not the downright depraved, and maintain the pragmatic tone beyond the point at which embarrassment, revulsion or mirth overwhelm others' (2006, p.154; see also Mack and Roach Anleu, 2010).

As I have highlighted, however, the accounts delivered during the trial are not straightforward, unedited representations of 'what happened' but partial, shaped versions of the incident in question, told with particular goals and purposes in mind. Thus, the alleged objectivity and impartiality of the court runs into trouble in this way. Socio-legal researchers and criminologists have demonstrated, moreover, how dominant ideas about, for example, gender, as well as race, which are prevalent in society generally, are reproduced in the courtroom and run through the narratives that are delivered during the criminal trial. Such research, then, challenges the idea of the court as a type of superior, sacred space, and bears out Ewick and Silbey's assertion that narratives - including those that are told in the courts are shaped not only by the norms of their immediate setting, but by hegemonic social meanings and dominant cultural narratives, too. More than simply documenting that 
dominant narratives about gender and race can be detected in the court, however, researchers working in this area have also explored what, specifically, such narratives are doing in the trial. That is, they have analysed how these dominant narratives are utilised in the individual narratives delivered by the prosecution, defence and, indeed, the judge, to help construct, and contest, the defendant's guilt. By turning to this literature, therefore, we can begin thinking about what the racialised narratives of bordering that are pervasive in the current era might be deployed to do in the particular context of the sentencing process. So, we can start conceptualising how, specifically, these dominant depictions might be mobilised and used in sentencing hearings, to help construct, and negotiate, defendants' punishability.

As Lizzie Seal has highlighted, 'gendered stories' or 'established socio-cultural narratives' (2010, p.4) about women have routinely been drawn upon in the prosecution of female defendants. In a recent article, Sarah Singh (2017) explores how this played out in a trial that she observed at Preston Crown Court, for Natalie Critchley, who was being prosecuted for the offence of causing or allowing the death of a child - specifically, her threeyear-old daughter Lia Green. Lia died as a result of peritonitis, which was caused, according to medical experts called at Critchley's trial, by an injury that 'could not have been accidental; it would have required "great force, a violent kick or punch in the stomach or being thrown extremely violently against a hard surface"' (2017, p.517). As Singh explains, the prosecution's case was that Lia's father, Richard Green - who was being prosecuted for murder - had attacked Lia and caused the injuries that resulted in her death. While Critchley was not at home at the time of the alleged attack, she was deemed to have 'allowed' Lia's death because 'she was aware of Green's violent tendencies due to the abuse she herself suffered throughout their relationship' (2017, p.513) but had failed to protect her. The prosecution also asserted that, when she returned home, Critchley realised that Lia had been injured by Green but failed to get medical assistance straight away. Critchley's defence set out, on the other hand, that 'as far as she was aware, her daughter was never physically 
harmed by Green' (2017, p.513), and that when she realised how unwell Lia - who she thought had a stomach upset - was, she called an ambulance immediately.

Singh observes how, during the case they made against Critchley, the prosecution emphasised that she had been having an affair at the time of Lia's death. In this way, Singh notes, even though 'it was established that [Critchley] had not seen her lover in the days preceding Lia's death, her promiscuity became central to the trial' (2017, p.521). Indeed, Singh goes on to highlight how, to shore up this portrayal of her, the prosecution also 'drew the jury's attention to the fact that Critchley, for a brief period prior to Lia's death, had worked as a pole dancer' $(2017$, p.521). In the presentation of their case, then, and their account of 'what happened', the prosecution tapped into established socio-cultural narratives about acceptable and appropriate femininity and constructed Critchley not as 'chaste, appropriately feminine, and therefore innocent' (2017, p.521). Rather, through her alleged promiscuity and hypersexuality, she was framed as 'faulty' $(2017$, p.519) in her femininity and therefore guilty. Thus, in the prosecution's approach to Critchley we can see what Victoria Nagy has identified as the centrality of the 'good/bad woman dichotomy' (2014, p.214) in women's trials. Specifically, we can see how female defendants are often constituted as guilty by presenting them in terms of their unacceptably unfeminine traits and so by casting them in terms of their inherent 'badness' as women.

Winter (2002) has identified the same approach to female defendants in two rather more high-profile cases. In her analysis she explores the trial of Myra Hindley who, in 1966, was tried and convicted alongside Ian Brady for the murders of Edward Evans and Lesley Ann Downey, and 'as an accessory after the fact in the murder of John Kilbride, for whose murder Ian Brady was found guilty’ (2002, p.344). She also examines the trial of Rosemary West, who was convicted in 1995 of the murders of ten girls and young women, alleged to have been committed with her husband Fred West, who killed himself in prison before the case went to court. Winter highlights that the prosecution in Hindley's case consistently 
portrayed her as 'sexually aggressive. Throughout the main body of the trial Hindley's relationships were all sexualized by the prosecution, regardless of whether or not they were sexual in nature' (2002, p.356). Similarly, Winter points to how the prosecution in West's trial, too, constructed her in terms of her 'aggressive and promiscuous sexuality' - and how, alongside this, they also worked to present her as the "antithesis of "motherhood" (2002, p.359). In both trials, then, Winter argues, the prosecution deployed gendered 'images of deviancy' (2002, p.358) in the versions of 'what happened' that they relayed, insisting on Hindley and West's intrinsic 'badness' as women to construct them as guilty and so to urge conviction. Moreover, she highlights how in West's trial, the judge's summing up to the jury was marked by 'an almost complete acceptance of the prosecution's versions of [her] sexuality and maternity' (2002, p.358). Thus the judge, Winter explains, was also pushing the jury towards conviction - and he did this, like the prosecution, by relying heavily on 'notions of bad womanhood' (2002, p.355), by presenting West in terms of her supposedly unfeminine behaviours and thus as guilty because of her deviance as a woman.

Conversely, as critics have noted, the construction of female defendants as not guilty often relies on portraying them in terms of their adherence to acceptable and appropriate femininity, and thus by insisting on their 'goodness', normality and conformity as women (Keenan, 2000; Kennedy, 1992). We can see how this plays out through Christine Bell and Marie Fox's (1996) exploration of the 1992 trial of Susan Christie, who was accused of the murder of Penny McAllister, the wife of the man with whom she was having an affair. As Bell and Fox explain, the defence's version of 'what happened' insisted upon Christie as a 'shy virgin' and 'sexually innocent' (1996, p.476). Through this, the defence attempted not, in this instance, to assert Christie's absolute innocence in relation to McAllister's death - but to reduce her level of guilt and support the contention that she should only be convicted of manslaughter, on the basis of diminished responsibility. 
We see something similar in Donald Nicolson's (1995) analysis of the 1992 Court of Appeal judgment in the case of Kiranjit Ahluwalia, who had been convicted, a few years earlier, of murdering her abusive husband. As Nicolson demonstrates, in its judgment the Court of Appeal emphasised how Ahluwalia was a 'caring mother' and pointed as well as to her 'sense of duty as a wife' (1995, p.194), in order to insist upon her as a good, non-deviant woman, and thus to help justify allowing her appeal. Nicolson contrasts the judgment in Ahluwalia's case with the way the Court of Appeal portrayed Sara Thornton, who had also been convicted of murdering her abusive husband - but whose first appeal, heard in 1991, was refused. As Nicolson notes, the judgment in Thornton's case focused not only on details of 'what happened' that appeared to illustrate her premeditation and intent to kill. It also constructed her as at the 'opposite end of the scale of appropriate femininity' (1995, p.190) to Ahluwalia. Thus it was suggested that Thornton was promiscuous, that she had 'rejected a woman's allotted domestic role' (1995, p.192) and that she was 'uppity, rebellious and aggressive' (1995, p.196) - in order to present her as a bad and deviant woman, and so to help justify rejecting her appeal.

Nicolson's examination of the different presentations of Ahluwalia and Thornton in the Court of Appeal judgments on their cases does not focus attention on the intersection between dominant narratives about gender and race. Yet, it is important to recognise how the idea of Ahluwalia not simply as a caring mother and dutiful wife but, moreover, as a stereotypically passive and submissive South Asian woman, was also mobilised to assert her lesser guilt. Julia Sudbury has explained, for example: 'While early stories in the local ... press described Kiranjit as a dangerous killer, the national media soon picked up on the image of a submissive woman facing constant oppression within a traditional South Asian community’ (2006, p.15). Thus, Ahluwalia was constructed as deserving of sympathy not only as a good and non-deviant woman - but also specifically as a downtrodden and vulnerable minority ethnic woman, who needed the civilised protection of (white) British law 
to rescue her from 'brutal South Asian patriarchy' (Sudbury, 2006, p.16). As Nicolson’s analysis of Ahluwalia's case indicates, the literature on the trial has not always paid full attention to the coalescence and overlap between the various socially constructed differentiations and divisions such as race, gender, and class. As I explain in more detail towards the end of this chapter, however, in my analysis of the sentencing hearings that I observed, in Chapters Five and Six, I attempt to ensure an intersectional approach (Parmar, 2017).

From the existing literature on the trial, therefore, we can see how the individual narratives delivered during women's trials tap into dominant narratives about appropriate womanhood and femininity, and portray defendants in opposition to this to insist on them as bad, suspect, and deviant in themselves, in order to help construct them as guilty. Conversely, by depicting them as in line with these narratives and so as possessors of stereotypically feminine traits, legal professionals insist on female defendants as innately good, desirable, and conformist women - and present them, through this, as not guilty, or at least as less guilty than has been argued by the prosecution. There is, as I now proceed to explore, less research examining how dominant narratives about race are mobilised during the trial. From the literature that does exist, however, we can identify a very similar process playing out in court proceedings against racially minoritised defendants.

In her important but neglected study Race and Drug Trials: The Social Construction of Guilt and Innocence, Kalunta-Crumpton (1999) draws out the very different way that black male defendants are treated during Crown Court trials for drug-related offences, compared with their white counterparts. As she explains, 'racially imbued knowledge, stereotypes and ideologies permeate the discourses of drug trials' $(1999$, p.22), and dominant narratives about 'blackness' are routinely drawn upon in the prosecution of black male defendants. Thus, Kalunta-Crumpton notes how in the trials that she observed for black men charged with possession of drugs with intent to supply, the prosecution often focused on how the defendant 
was unemployed - whereas lack of a job was 'not made a crucial issue in the prosecution of cases involving unemployed white defendants' (1999, p.92). She also explains that black defendants were frequently questioned about any cash they had on them at the time of their arrest, including very trivial amounts - in one case, a man was asked to account for $£ 14.50$ and that they were also asked about how they had been able to afford any other material possessions they had, such as clothes, jewellery and cars. By contrast, she notes, questioning about material possessions in white defendants' cases was 'minimal' (1999, p.92). In this way, then, Kalunta-Crumpton argues, the prosecution worked to secure a conviction for possession with intent to supply in black defendants' cases by tapping into dominant ideas of 'black people, deprivation, crime and drug trafficking' and by appealing to 'the widely acknowledged image of the black community as socio-economically deprived and consequently criminally minded' $(1999$, p.88). In other words, prosecution barristers invoked dominant narratives about entrenched black poverty and an associated black propensity for crime - that is, about people who are black as inherently criminal and undesirable - in order to persuade the jury to convict these defendants.

Kalunta-Crumpton also highlights how prosecution barristers invoked other images of black deviance during drug trials to help secure a conviction. Thus, she notes how in one case that she observed the defendant was asked a series of questions about his intimate relationships after he had explained that some of the money that he had on him at the time of his arrest had been given to him by his girlfriend. The prosecution started by asking the defendant if it was correct that 'you have many girlfriends'. Following this, the prosecution then asked him whether any of his girlfriends ever gave him money - and, more specifically, whether he had ever been given money by his girlfriends 'after gratifying them sexually'. Eventually, the prosecution barrister put his insinuation to the defendant more explicitly: 'You prostitute for money. Am I right?' (1999, p.121). We can see here, therefore, as Kalunta-Crumpton explains, how the prosecution appealed to the 'myth of black sexuality' - 
the longstanding racist narrative about black men's promiscuous and hypersexual tendencies, which I highlighted in Chapter Two - in order to 'prejudice the mind of the judge and the jury against the defendant' (1999, p.120).

Alongside this, Kalunta-Crumpton notes how in some of the cases for black defendants that she observed accusations of violence were 'lifted into visibility by the prosecution', even though 'such alleged actions were not incorporated into the official reason/s for prosecuting [these] defendants' (1999, p.125). In this way, she argues, wellknown racist ideas about black men as aggressive and violent were tapped into, and so these defendants were portrayed as 'typifying a danger and disruption to society' (1999, p.125). That is, as Kalunta-Crumpton explains in an earlier journal article on her research, black male defendants were presented through the appeal to such racist ideas in terms of their 'deviation from conventional societal norms' and through the lens of 'black incompatibility with normality' (1998, pp.581-582). What we see unfolding here, then, as prosecution barristers framed black defendants through dominant narratives about race, is the construction of these defendants as recognisably and inherently deviant, the essentialising of them as suspect and undesirable in themselves - and, through this, the insistence that they must be guilty.

A similar pattern has been traced, indeed, by Patrick Williams and Becky Clarke (2018a, 2018b, 2016) in their more recent research on Joint Enterprise trials. As they explain, over the past couple of decades the racialised narrative of the gang, which frames young black men as naturally deviant and links them with 'violent criminal and problematic behaviours' (2016, p.5), has become increasingly prominent, reaching its 'apex' (2018b) following the so-called English 'riots' in 2011. Williams and Clarke document how this now hegemonic racialised narrative is frequently mobilised as a 'prosecution resource' (2016, p.15) during Joint Enterprise trials for Black, Asian and minority ethnic defendants, to help secure multiple convictions for serious offences - often murder - beyond the person who actually carried out the criminal act. Thus, Williams and Clarke highlight how, according to a 
survey that they conducted of just under 250 prisoners convicted under the Joint Enterprise doctrine, " $79 \%$ of minority ethnic respondents reported that "gang talk" was evoked in the prosecution of their court case against $39 \%$ of white respondents' (2018b; see also Williams and Clarke, 2018a, 2016).

As Williams and Clarke explain, by appealing to the racialised narrative of the gang prosecution barristers work to establish the legal necessities for conviction under Joint Enterprise. So, they aim to establish 'common purpose' amongst the various individuals on trial, meaning that these individuals are held to 'have planned to commit crime(s) together' (2018b). Following on from this, the narrative of the gang also functions to insist that defendants who were present for the offence but played secondary roles, as well as defendants who were not physically present, nonetheless had 'foresight' as to what the person who carried out the criminal act might do. ${ }^{9}$ More broadly, as Williams and Clarke observe, through the invocation of the hegemonic racialised narrative of the gang, 'prosecution teams signal ... to juries the public consciousness of minority ethnic people as the criminal Other' (2018b). That is, as they are framed through this well-known racist narrative, black and other racially minoritised defendants are portrayed as intrinsically problematic, as naturally 'violent and crime prone' (2018a, p.329). They are presented as guilty, therefore, because of their undesirable nature and pathological traits - regardless of their (lack of) actions or whether they were even present for the offence. Williams and Clarke argue, then, that the racialised narrative of the gang allows for and ensures 'collective punishment' (2018a, 2018b, 2016).

\footnotetext{
${ }^{9}$ In February 2016 the Supreme Court ruled that the common law had 'take[n] a wrong turning' in its establishment of 'foresight' as central to proving criminal liability for someone who had not actually carried out the criminal act. It determined, instead: 'The correct rule is that foresight is simply evidence (albeit sometimes strong evidence) of intent to assist or encourage, which is the proper mental element for establishing secondary liability' (Supreme Court, 2016; emphasis mine). The Supreme Court went on to explain, however, that 'This necessary correction to the wrong turning taken by the law does not mean that every person convicted in the past as a secondary party ... will have suffered an unsafe conviction ... It is for [the Court of Appeal] to enquire whether substantial injustice would occur in any particular case, but it is not the law that that is shown simply because the rules which then prevailed have now been declared to have contained a flaw' (Supreme Court, 2016). In 2019, it was reported that there had been only one successful Joint Enterprise appeal since the February 2016 ruling (Robins, 2019).
} 
This is because it 'drives the hypercriminalisation of black, mixed, Asian, and other minority ethnic (BAME) communities' and 'facilitate[s] the arrest, charging and prosecution of countless numbers of BAME people for offences they did not commit' (2018b).

Through the literature on the trial, therefore, we can see how the production, and contestation, of guilt is not simply a legal process, achieved through narratives focused on prohibited acts and forbidden intentions. It is a social process, too: that is, guilt is also constructed and challenged through wider social classifications and categorisations such as gender and race, and notions of goodness and badness, normality and deviance, that are inherent to these. We might expect, then, that something similar is happening in the sentencing hearing. So, we might anticipate that liability for criminal punishment is likely to be produced and negotiated in the same way: affirmed through ideas of the defendant's intrinsic badness and undesirability, and lessened through ideas of their natural goodness and non-deviance. And this is how, I would suggest, we might see the problematising, racialising narratives of bordering that are prevalent in the current era being put to work by the prosecution, defence and judge in the practice of the sentencing hearing.

Thus, we might expect that these dominant, racialised narratives will be appealed to and invoked during proceedings for non-white and 'not quite white' migrants, not in order to justify their exclusion from the UK - but, in the specific context of the sentencing process, to constitute a defendant as inherently problematic and deviant, and through this as punishable. And, conversely, these racialised narratives might be negotiated, and negated, to insist that a defendant is not intrinsically undesirable and deviant but, in fact, is a good and deserving migrant - and consequently that they are less punishable than has been suggested, that they can be treated with some leniency. We might anticipate, too, that some of the narratives of limited inclusion that I documented in Chapter Two will also be deployed during sentencing hearings, as another way of insisting on the innate goodness and desirability of non-white and 'not quite white' migrants and so asserting that they can be punished less severely. Hence, as 
I suggested earlier, from the literature on the trial it seems likely that the repetition and routine of sentencing narratives will play out not only through their concern with the actus reus and mens rea of defendants, as well as the level of harm caused or risked by a defendant's wrongful act and their specific degree of culpability. It will probably unfold, too, through a focus on some defendants as bad and problematic, or good and desirable, in themselves - and, therefore, through the construction and contestation of these defendants as inherently punishable people.

I noted earlier that the existing literature on the trial has not always been attentive to the coalescence and overlap between dominant narratives on, for instance, gender and race. Indeed, I am conscious that, in the way I have surveyed and presented the literature on gendered and racialised narratives in the trial in this chapter - by looking at gender first, and then race - I might appear to be intimating a separation between these narratives. As I demonstrated in Chapter Two, however, the racialisation of unwanted migrants in contemporary narratives of bordering operates, at points, through interactions with other socially constructed differentiations and divisions - so, with dominant ideas about gender, as well as class. As I analyse the mobilisation of these narratives of bordering during sentencing hearings in my empirical chapters, therefore, I work to tease out such instances of interaction and overlap. In this way, I attempt to ensure a more 'multi-dimensional' (Parmar, 2017, p.35) and thus intersectional approach.

One final issue arises from the existing literature on the trial. According to Ewick and Silbey's analysis, we might expect racialised narratives of bordering simply to run through sentencing hearings for non-white and 'not quite white' migrants; understanding legal professionals' narratives as social acts and practices means that dominant or hegemonic narratives might seep into these at any point. Yet, in her analysis of the trials of Myra Hindley and Rosemary West, Winter shows how images of gendered deviancy did not, in fact, permeate these trials equally. Rather, she demonstrates how - while the judges in both 
cases urged the juries towards conviction - in Hindley's trial the judge did not repeat 'the powerful construction of deviant sexuality offered by the prosecution' (2002, p.357).

Conversely, as I have highlighted already, in West's trial the judge's summing up reiterated the prosecution's insistence on her problematic sexuality and maternity.

Winter attributes this disparity in the judges' approaches to the 'differing levels of evidential strength' (2002, p.362) in the two trials. Thus, she explains that the evidence presented by the prosecution during Hindley's trial was 'strong' (2002, p.344); it included, for instance, the testimony of David Smith, Hindley's brother-in-law, who reported Ian Brady and Hindley to the police after witnessing the murder of Edward Evans. In West's case, however, 'there was no evidence to link her with the bodies, or even some of the victims' (2002, p.345) - and, in fact, throughout the police investigation Fred West had insisted on his sole responsibility. Winter argues, therefore, that the judge in West's trial invoked dominant ideas about appropriate femininity and rendered her in terms of her 'badness' as a woman to make up for the lack of evidence against her - in order, as Winter puts it, to 'bridge the evidential gap' (2002, p.355). I would suggest, then, that what Winter identifies in her analysis should prompt us to be concerned not simply with how narratives of bordering might be put to work in the specific context of the sentencing hearing - but with when they might be deployed, too. That is, it will be important to explore if these dominant narratives are simply running through hearings, or if in fact their mobilisation seems more context-driven and specific - to determine whether there are particular circumstances that seem to especially prompt the utilisation of racialised narratives of bordering by legal professionals.

\section{Conclusion}

In this chapter, I have analysed and conceptualised the practice of the sentencing hearing, and I have considered how dominant narratives of bordering might be seeping into this process and to what end, more specifically, these racialised depictions might be being mobilised and 
used. Thus, in the first half of the chapter I used the framework of narrative to think through the accounts delivered by legal professionals during the sentencing hearing. By approaching the prosecution's facts of the case, the defence's plea in mitigation and the judge's sentencing remarks as individual narratives, I argued that we can see how these are not straightforwardly factual or representational. Rather, we can understand them as plotted and purposive versions of the incident being dealt with by the court - each of which is concerned with constructing, or negotiating, the defendant's punishability.

In the second half of the chapter, I turned my attention to what the narratives delivered during the sentencing hearing might look like and how they might be working towards their specific purposes and meanings. I explained, then, that a sociological understanding of narratives as social acts or practices helps us to see how they are governed by the rules and conventions of their immediate social setting. In the case of sentencing narratives, therefore, they are told in line with the framework of the actus reus and mens rea - the two core elements of the criminal law. But as social acts and practices individual narratives are also shaped by the norms of the wider social context; thus, they reflect hegemonic social meanings and reproduce dominant or 'master' narratives. In this way, we can see how dominant narratives of bordering might be permeating the practice of the sentencing hearing. Moreover, by exploring the existing literature on gendered and racialised narratives in the trial, we can also start to understand what these racialised depictions might be deployed to do in this particular context. That is, we can theorise how they might be put to work in the construction, and negotiation, of defendants' punishability. So, I argued that racialised narratives of bordering are likely to be appealed to and invoked in sentencing hearings for non-white and 'not quite white' migrants, in order to constitute defendants as inherently bad and deviant - and, through this, to produce them as punishable. And, conversely, these racialised narratives are likely to be negotiated, and negated - and, as I also suggested, narratives of limited inclusion are likely to be deployed - in order to insist that 
defendants are actually good and desirable in themselves. Through this, they will be presented as less punishable than has been suggested, and so as worthy of the court's leniency.

Sentencing proceedings for 'unwanted' migrant defendants, therefore, will be marked by the repetition and routine that characterises the criminal courts broadly. The narratives delivered during these hearings will, of course, repeatedly focus on defendants' prohibited acts and forbidden intentions, in order to construct and negotiate them as punishable in legal terms. Alongside this, there is likely to be a consistent concern with ideas of these defendants' intrinsic deviance, or worthiness, too - that is, with whether they are innately punishable, or less punishable, people. Having set out the conceptual foundations for my research across the past three chapters, then, I now turn to my empirical data. Thus, in the second part of the thesis I explore the sentencing hearings for migrants that I observed, in three Crown Courts in London across a two-year period. 


\section{Part II:}

Sentencing Hearings 


\section{Chapter 4}

\section{Research Methods and Ethics: Observing Sentencing Hearings}

\section{Introduction}

In this thesis, I am concerned with how dominant, racialised narratives of bordering - which are disseminated by the UK government and media to problematise 'unwanted' migrants and justify their targeting by the direct practices of immigration enforcement - might be seeping into sentencing proceedings, to help construct and negotiate defendants' punishability. Over the next three chapters of the thesis I turn from the conceptual foundations for my research to my empirical data, the sentencing hearings that I observed in Crown Courts across a two-year period - and I begin, in this chapter, by giving an account of how I conducted my observations. On the face of it, observing court hearings may seem like a relatively straightforward form of criminological fieldwork. As John Baldwin notes, since the criminal courts are a public setting and anyone can enter them, 'conducting research [there] need involve no more than turning up with a notebook, finding a convenient vantage point, and watching whatever takes place' (2008, p.375). And yet, inevitably perhaps, in practice the research process was actually much more complicated than this. In this chapter, therefore, I explore the methodological, epistemological and ethical issues relevant to my fieldwork some of which I had anticipated and considered before I started going to court, but others which emerged as I was carrying out my observations.

\section{Starting the research process (I): Why court observations?}

It seems important to begin the account of my fieldwork by explaining why I decided to conduct my empirical research via observations of sentencing hearings. To some extent, given the focus of my research on the narratives that are delivered by legal professionals during sentencing proceedings, the choice of court observations may seem like an obvious 
one. Yet, there are other methods that I could have used: as I noted in Chapter Three, for example, some studies of sentencing hearings have relied on court transcripts to carry out their research. Thus, it is worth stating explicitly why I felt that attending court and observing sentencing hearings myself was the most useful way of investigating their possible permeation by dominant, racialised narratives of bordering.

A key limitation of court observations that has been identified in the criminal justice research methods literature has been summarised by Baldwin in the following way: '[O]pen court proceedings present only the public face of justice. Researchers who sit in court commonly realize, with a sense of unease, that the really important decisions in most cases are being taken elsewhere' (2008, p.383; see also Paik and Harris, 2015). As I set out in the previous chapter, however, whereas much sentencing research has been preoccupied with sentencing decision-making, and so with how magistrates and judges arrive at the decision to impose a specific punishment, my focus is on sentencing proceedings and how these unfold. As such, I am primarily concerned with what Baldwin refers to as 'the public face of justice'; that is, I am interested in what goes on in the courtroom during sentencing hearings, and how legal professionals construct and negotiate the punishability of the defendant. For this reason, then, court observations seemed an appropriate choice. I also emphasised in Chapter Three my theorisation of sentencing proceedings not only as a legal process but a social process, too. I explained, therefore, that despite the myth of the criminal courts' impartiality and neutrality, liability for punishment is likely to be negotiated and produced during sentencing hearings not simply through criminal law norms and conventions - but by tapping into wider social categorisations such as gender and race, as well. Leslie Paik and Alexes Harris note that a strength of observational court research is its ability to reveal 'the disjuncture between the official "law on the books" and what happens in the courtroom, or "law in action"” (2015, p.287), including legal professionals' reliance on ideas about race, gender and class. Hence, from this perspective, carrying out court observations seemed a particularly useful approach 
for investigating and uncovering the penetration of sentencing hearings by dominant, racialised narratives of bordering.

There are, undoubtedly, disadvantages to observational research in the courts. Baldwin highlights that, in fact, 'few criminologists have engaged in prolonged and systematic court observation', and notes that one reason for this is the 'lengthy periods of unrelenting tedium' (2008, p.382) to which the criminals courts are subject. In particular, as he explains - and as I also indicated in Chapter Three - 'There are frequent periods in any court where little seems to be happening. Delays and adjournments dog the work of the courts, and the consequent administrative inertia can sap the energy and enthusiasm of even the most committed researcher' (2008, p.382). Indeed, across the two years that I conducted observations, I watched 102 hours of court proceedings. Yet, just under a third of this time, 33 hours, was spent observing sentencing hearings - and just under a fifth, 17.5 hours, was spent watching sentencing hearings immediately relevant to my research, for people who had migrated to the UK. A central reason for this was the difficulty in identifying whether a hearing was relevant to my research prior to it taking place; I explain this issue in more depth below. But it was also a result of the messy and often delayed processes of the courts. On a number of occasions I turned up to a particular courtroom, expecting a sentencing hearing to take place - but it was hours before the hearing actually started. In some instances this did, as Baldwin suggests, affect my energy and enthusiasm for the research. More pressingly, however, as a doctoral student I am required to complete and submit my research within a specified period of time. Thus, the time-consuming nature of observational court research was challenging from a practical perspective.

Despite this, I felt that conducting court observations was preferable to relying on transcripts of sentencing proceedings. In the first place, there would have been clear practical difficulties attached to the latter approach. For reasons which I explain in the next section of this chapter, in my research I decided to concentrate solely on Crown Court sentencing 
hearings. Although, unlike in the magistrates' courts, all Crown Court hearings are recorded, transcripts of these are not publicly available. Thus, to access a transcript of an individual sentencing hearing, a formal request has to be submitted to the relevant Crown Court (HM Courts and Tribunals Service). Just as with court observations, I would have encountered problems identifying hearings relevant to my research, for which I wanted to request the transcript; as I have said, I explain this issue in more depth below. Added to this, however, it is generally the case that Crown Courts charge for each transcript requested. As I document later in this chapter, in order to identify 25 sentencing hearings where it was clear that the defendant had migrated to the UK, I had to observe over 50 sentencing hearings in total. Requesting transcripts for hearings that I thought might be relevant to my research, therefore, as a way of finding some that definitely were, could have been a costly enterprise. As a selffunded doctoral student, this posed a significant barrier. Moreover, it is also the case that Crown Courts can refuse to provide all or part of the transcript for a hearing (HM Courts and Tribunals Service), which presented a further potential difficulty.

More important than the practical drawbacks to relying on transcripts, there are also clear limitations to what such records can tell us about court proceedings. Thus, as Paik and Harris explain, there are many important aspects of court hearings 'that do not make the official "court record"” (2015, p.288). The official transcript tells us nothing, for instance, about the quasi- or non-verbal communications and reactions of the legal professionals involved in a specific hearing, including the judge. As Kalunta-Crumpton (1999) notes in her research on the mobilisation of dominant racist narratives during trials for drug offences, such communications and reactions can be critical to an analysis of court proceedings. Indeed, as I document in Chapter Five, during one hearing that I observed the judge's appeal to a racialised narrative of bordering to demean the defendant was partly effected through his quasi-verbal reactions to the mitigating plea, as well as the sarcastic tone with which he questioned the defence barrister (Hearing 22, Isleworth, 2016; see the table of observations 
conducted, below). By relying on transcripts, therefore, rather than conducting my own observations, I felt that I might miss important pieces of evidence that would aid my understanding of sentencing hearings for 'unwanted' migrants and how these unfold.

As I explore in more detail in a subsequent section of this chapter, the difficulties that I faced in identifying sentencing hearings relevant to my research meant that, ultimately, the 25 hearings for people who had migrated to the UK that I observed during my fieldwork constituted a convenience sample (Bryman, 2008). Clearly, then, the findings of my research are not generalisable beyond their immediate context. Yet, I would contend that observing a non-representative sample of sentencing hearings for non-white and 'not quite white' migrant defendants nonetheless enabled to me to address and answer my research questions. As I have explained, my research is focused on how dominant, racialised narratives of bordering might be put to work in sentencing proceedings. I also noted in the previous chapter that some of the literature on gendered and racialised narratives in the trial prompts a concern with when narratives of bordering might appear, too, and if there are specific circumstances that seem to especially result in their mobilisation in a hearing. Thus, the 'more interpretive and investigative logic' (Mason, 2012, p.29) that my research adopted, of examining 25 hearings for people who had migrated to the UK in depth, allowed me to address these questions by paying attention to the 'richness, complexity and detail' (Mason, 2012, p.29) of the sentencing proceedings that I observed. Through a 'deep exploration' of this sample of hearings, I was able to develop a detailed understanding and so 'build an explanation' (Mason, 2012, p.29) of the routine practice of sentencing - and, crucially, of the functioning of dominant, racialised narratives of bordering within this. 
Starting the research process (II): Accessing the courts, identifying research sites, and 'finding foreigners'

I began observing sentencing hearings in August 2014, and finished just over two years later, in September 2016. During the course of my fieldwork, I observed hearings at three Crown Courts in London: Isleworth, Southwark, and Wood Green. I say more about my choice of these particular courts, and how I went about identifying sentencing hearings potentially relevant to my research to observe, below. At this stage, though, it is worth emphasising that, while observing in courts in London was partly a consequence of me living, working and studying here, it was also an obvious choice for a research project focused on the sentencing of 'unwanted' migrants. London has the highest proportion of inhabitants of any city in England and Wales who were born outside the UK: in 2018, 36\% of London's population had been born abroad (ONS, 2019). Additionally, many of its foreign-born residents come originally from countries in the Global South, or Southern and Eastern Europe. According to the 2018 figures, the ten most common countries of birth for London residents born outside the UK were, in this order: India, Bangladesh, Poland, Romania, Italy, Pakistan, Ireland, Nigeria, Sri Lanka and Jamaica (Mayor of London, 2018). Thus it seemed probable that, by conducting my research in the criminal courts in London, I would be able to observe sentencing hearings for non-white and 'not quite white' migrants, whom government and media narratives of bordering have typically problematised and racialised and who are the focus of my research.

Before beginning my fieldwork, I spent some time considering whether I should apply to the Courts and Tribunals Service for formal research access to the courts in which I was planning to observe. In the end, I decided against doing this, for several reasons. First of all, as I highlighted in the introduction to this chapter, the criminal courts are a public setting and anyone can enter them; thus, there was no real need to obtain formal permission in order to carry out observations. Secondly - while it seemed likely that by observing in courts in 
London, I would come across cases relevant to my research - formal access would not necessarily have helped to me to establish, prior to a specific hearing, if it was for someone originally from a country in the Global South or Southern and Eastern Europe. I explain the difficulties with identifying relevant sentencing hearings, and how I dealt with this during my fieldwork, in detail below.

Thirdly, I was concerned that my application to the Courts and Tribunals Service might be refused. This was partly because of my status as a doctoral student, rather than a more senior academic researcher. But it was also because of the nature of my research. Racism in the courts can be perceived by legal professionals and, perhaps, by judges in particular, as a very contentious issue. During the course of my research, in fact, Peter Herbert, one of the few black Crown Court judges, was found to be guilty of judicial misconduct for stating during a speech that 'racism is alive and well ... in the judiciary' (Taylor, 2017a). The public nature of the courts means that, even if I had been refused formal access for my research, I could have conducted observations anyway. However, I was worried that such a refusal could have an impact on my fieldwork - that it might mean, for instance, that I would be subject to particular scrutiny while carrying out my observations.

Prior to starting my observations, therefore, my decision not to apply to the Courts and Tribunals Service was really shaped by practical considerations. As I began attending court, however, and I started to observe sentencing hearings where narratives of bordering were being mobilised, this began to feel like the right approach for other reasons. In particular, as I observed hearings where the defendant was being framed through a racialised narrative of bordering by the prosecution, or by the judge, in order to help produce them as punishable, maintaining a clear distance from the institution demeaning and disparaging them like this began to feel ethically important. I fully recognise, though, that while I was able to carry out my research without applying for formal access, for many other criminal justice research projects - including, although not limited to, those investigating more closed 
institutions and settings - not obtaining official permission would simply mean that the research does not get done.

While planning my fieldwork, I had considered observing at magistrates' courts as well. A researcher to whom I spoke, however, who had previously carried out extensive court observations, suggested that given my focus on narrative it might be more fruitful to concentrate solely on the Crown Court, since the more minor matters that go through the lower courts tend to be dealt with very quickly. This resonated with some of the existing research on the courts that I had read. Kalunta-Crumpton, for instance, who conducted her research on the mobilisation of racist narratives during trials for drug offences in both courts, explained that she nonetheless prioritised Crown Court trials 'for the principal reason that [they] provided more detailed and descriptive information useful to the analysis of social construction and claims-making' (1999, p.67). I chose the specific Crown Courts at which I observed for a mixture of reasons. I began my observations at Wood Green, mainly because it has a reputation for being quite open towards researchers. Once I felt more confident, and that I had a better understanding of the workings of the court, I also started observing at Isleworth. I chose this court partly because it covers a port of entry, Heathrow, and so deals with a significant number of immigration offences (Aliverti, 2013a). Although I wanted to see sentencing hearings for a range of different offences, I also wanted to ensure that I observed some that were specifically border-related - so, that were concerned with the class of criminal infractions for which it is migrants who are overwhelmingly prosecuted and punished. In this way, then, although the hearings that I observed during my fieldwork ultimately constituted, as I have noted, a convenience sample, there was nonetheless purposiveness (Bryman, 2008) within my approach.

I had planned to focus on just Wood Green and Isleworth; but, about ten months into my research, I decided to start observing at Southwark as well. I added this court partly for practical reasons: as I was carrying out the research part-time, alongside a job, I felt that I 
needed to be able to observe hearings at a court closer to where I live. In line with the element of purposiveness within my sampling approach identified above, however, I also added Southwark because it tends to deal with more serious, and sometimes more highprofile, cases. I thought, therefore, that observing sentencing hearings there would provide an interesting contrast with the other two courts. Indeed, the only sentencing hearing that I observed during my research where the public gallery was packed took place at Southwark. As I indicated in Chapter Three, in most of the other hearings that I saw there was only a handful of people, if that, watching the proceedings, and the 'public' setting of the court actually felt very private - something I touch on again later on in this chapter. During the two-year period that I was conducting observations I tried to go to court regularly, and at least once a fortnight. There were, however, times when my job and other pressures made it difficult to do this, and on a couple of occasions I did not observe any hearings at all for a period of a few months.

I highlighted above that one of the reasons that I decided not to apply for formal access to the courts to conduct observations was that this would not necessarily have helped to me to establish, prior to a specific sentencing hearing, if it was relevant to my research or not. This is because, during the period that I was conducting my observations, the criminal courts were not routinely identifying and recording defendants' nationalities (Aliverti, 2016). The requirement for defendants to state their nationality during court proceedings was, as I highlighted in Chapter One, legislated for by the Policing and Crime Act 2017; thus, this requirement was introduced after I had carried out my final court observation, in September 2016. As I got further into my observations it did become clear that - although defendants' nationalities were not being identified and recorded routinely during the period of my fieldwork - by the the sentencing hearing there was sometimes information in the court papers that identified the defendant as a migrant, and which also indicated which country they had migrated from. Thus, applying for official permission and gaining access to court 
files may have made it easier for me to identify, in advance of hearings, if they were for someone originally from a country in the Global South or Southern and Eastern Europe. By the time that this had become clear to me, however, I had already got underway with my observations. Moreover, as I have also explained, there were other reasons that I did not apply to the Courts and Tribunal Service for formal research access, including the nature of my research.

As such, I developed other methods to ensure that I observed sentencing hearings relevant to my project. So, on several occasions when I first started my fieldwork, I took the following approach. The day before my visit, I looked through the next day's listings for the Crown Court at which I was planning to observe: these include defendants' names, a broad time slot for each hearing, whether an interpreter is required - and, importantly, the type of hearing that is taking place is. In this way, I could identify all the sentencing hearings happening in a particular court on the day that I was visiting - and I would then attempt to observe all of these. Through this method, I thought I would undoubtedly come across sentencing hearings for people who had migrated to the UK from countries in the Global South or Southern and Eastern Europe. Moreover, such a method meant that I would be able to find these cases without, for instance, selecting certain hearings on the basis that the defendant's name 'sounded foreign', or by assuming that hearings where an interpreter was being used must be for someone who had not been born in the UK. Thus, I hoped that this approach would allow me to identify hearings relevant to my research without resorting to racialised conceptions of belonging, which criminal justice institutions have typically relied upon in their efforts to 'find foreigners' (Kaufman, 2012, p.701; see also Parmar, 2019, 2018a).

This approach did work to some extent: on the occasions that I attended court and adopted this method, I observed some relevant hearings. However, there were also problems with it. Firstly, sentencing hearings that are listed for the same day are also sometimes 
scheduled to take place at the same time as each other, in different courtrooms; so, a choice has to be made between hearings. Even if hearings are listed for different times, moreover, as I noted earlier in the chapter court proceedings often do not go ahead when they are supposed to. Further clashes between sentencing hearings, therefore, can happen as a result of this.

Secondly, at times it felt like attempting to observe multiple sentencing hearings in one day was not necessarily conducive to careful, detailed research. After each hearing I always tried to spend some time going over the notes that I had taken, to make sure I could read and understand them; I often had to write very quickly while observing, in order to keep up with the proceedings. Alongside this, I also tried to spend time after each hearing reflecting on what I had seen, and writing up any further impressions and observations - so I would record, for instance, anything I might have noticed during the hearing that felt interesting or important, that I did not have time to write down while I was in court (see Johnson, 2011). When I observed several hearings in one day, however, I sometimes felt that the quality of my reflections was affected. In particular, if I moved straight from one hearing to another, I often would not have time to think over and write further about the hearing that I had just seen until later on in the day. I worried, therefore, that there were aspects or features of these hearings that I simply forgot about, and did not document when I reflected on them later.

Thirdly, by conducting my research in this way, I also started to accumulate a sizeable amount of material on non-migrant hearings. This was undoubtedly helpful: observing a significant number of hearings for non-migrants and migrants alike in the earlier stages of my research enabled me to develop quite quickly an understanding of the practice of the sentencing hearing - to grasp what the individual narratives delivered by the different legal professionals involved were working to achieve. Additionally, although mine is not a comparative research project, observing hearings for non-migrants helped to me identify a specific approach to pressing for leniency in the sentencing proceedings for non-white and 
'not quite white' migrants that I saw. That is, it helped me to see that a particular formulation deployed by defence barristers during 'unwanted' migrant hearings was similar to, but nonetheless distinct from, an approach often used in pleas in mitigation for people who had been born in the UK. I explore this in the chapter that follows. I felt, however, that if I continued with this approach for the duration of my fieldwork, I would end up gathering a vast amount of material that was not immediately relevant to my research - and that I simply was not going to be able to comprehend and analyse in depth.

Finally, as the first few months of my fieldwork passed, it became clear that I had managed to observe a relatively small number of sentencing hearings for migrants by using this method. Thus, I realised that I needed to find a way of seeing more hearings relevant to my research more quickly, in order to be able to observe 'enough' - I say more about what this means later on - and complete my fieldwork in a reasonable period of time. In the end, therefore, I did resort to the problematic approach that I detailed above. So, I began trying to identify sentencing hearings relevant to my research by looking at defendants' names on court listings, as well as whether an interpreter was required for the proceedings. Even as I felt I was able to maintain an important ethical distance from the courts by not applying for formal research access, then, I simultaneously brought myself closer to them, as I relied on stereotypical assumptions and conceptions in order to 'find foreigners' (see also Aliverti, 2018a).

Across the two years of my fieldwork, I observed 53 sentencing hearings - for both migrants and non-migrants - in total. In 25 of these hearings, it was clear from what was said during the proceedings that the person being sentenced had been born abroad and had subsequently migrated to the UK. All of these 25 sentencing hearings for migrants, moreover, were for people originally from countries in the Global South or Southern and Eastern Europe. Thus, they were all for non-white or 'not quite white' migrants, whom the UK government and media have repeatedly stigmatised and racialised through narratives of 
bordering and who are the focus of my research. It is possible, of course, that in some of the sentencing hearings that I observed where there was no reference during the proceedings to the defendant having migrated to the UK, they nonetheless were a migrant. It is important to emphasise, then, that in stating that I observed 25 hearings relevant to my research during my fieldwork, this means that I observed 25 sentencing hearings where the defendant was explicitly identified as a migrant. In the table overleaf, I provide a breakdown of all the sentencing hearings for people who had migrated to the UK that I observed during my fieldwork. For each hearing, I set out details including the country of origin of the defendant, the court where I observed the hearing, the offence(s) for which the defendant was being sentenced and the sanction that the judge imposed. 
Table 1: Sentencing hearings for people who had migrated to the UK observed during fieldwork

\begin{tabular}{|c|c|c|c|c|c|c|c|}
\hline $\begin{array}{c}\text { Hearing } \\
\text { number }\end{array}$ & Court & $\begin{array}{c}\text { Date of } \\
\text { hearing }\end{array}$ & $\begin{array}{c}\text { Number of } \\
\text { defendants }\end{array}$ & $\begin{array}{c}\text { Country of origin } \\
\text { of defendant(s) }\end{array}$ & $\begin{array}{c}\text { Gender of } \\
\text { defendant(s) }\end{array}$ & $\begin{array}{c}\text { Offence(s) being } \\
\text { sentenced for }{ }^{2}\end{array}$ & Exposure \\
\hline 1 & Wood Green & 2014 & 1 & Poland & Man & 6 months' prison \\
\hline 2 & Wood Green & 2014 & 1 & China & Man & $\begin{array}{c}\text { Possession of an } \\
\text { unauthorised medicinal } \\
\text { product }\end{array}$ & 2 months' prison \\
\hline 3 & Wood Green & 2014 & 1 & Poland & Man & $\begin{array}{c}\text { Assault occasioning actual } \\
\text { bodily harm }\end{array}$ & $\begin{array}{c}1 \text { year and } 2 \text { months' } \\
\text { prison, suspended for 12 } \\
\text { months }\end{array}$ \\
\hline 4 & Wood Green & 2015 & 1 & Pakistan & Man & Common assault ${ }^{4}$ & Community order \\
\hline
\end{tabular}

${ }^{1}$ I have listed only the year of each hearing, in order to help preserve defendants' anonymity.

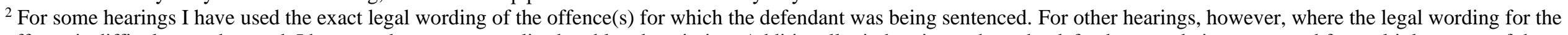

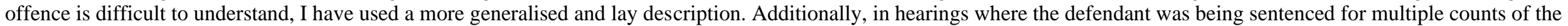
same offence (e.g. multiple thefts) I have not indicated this in the table. I do, however, specify this in my discussion of individual hearings in Chapters Five and Six.

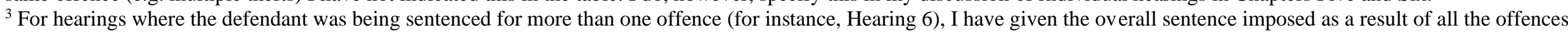
committed. In cases where the sanction imposed was a suspended sentence or a community order, I have only detailed this; I have not listed any specific requirements imposed as part of this (such as unpaid work).

${ }^{4}$ Common assault is a summary offence, so it is normally only dealt with and sentenced in the magistrates' courts. The hearing in this case, however, was technically an appeal against the defendant's conviction and sentence - hence why it was heard in the Crown Court. As the defendant's conviction was upheld, though, and the court then re-sentenced him, I consider it as a sentencing hearing. 


\begin{tabular}{|c|c|c|c|c|c|c|c|}
\hline $\begin{array}{l}\text { Hearing } \\
\text { number }\end{array}$ & Court & $\begin{array}{l}\text { Date of } \\
\text { hearing }\end{array}$ & $\begin{array}{l}\text { Number of } \\
\text { defendants }\end{array}$ & $\begin{array}{l}\text { Country of origin } \\
\text { of defendant }(\mathrm{s})\end{array}$ & $\begin{array}{c}\text { Gender of } \\
\text { defendant(s) }\end{array}$ & $\begin{array}{l}\text { Offence(s) being } \\
\text { sentenced for }\end{array}$ & Sentence imposed \\
\hline 5 & Wood Green & 2015 & 1 & Romania & Man & Non-domestic burglary & Community order \\
\hline 6 & Wood Green & 2015 & 1 & $\begin{array}{c}\text { Democratic } \\
\text { Republic of Congo }\end{array}$ & Man & $\begin{array}{c}\text { Rape, attempted rape and } \\
\text { sexual assault }\end{array}$ & $\begin{array}{c}\text { Extended Determinate } \\
\text { Sentence of } 23 \text { years; } \\
\text { custodial term of } 18 \\
\text { years }^{5}\end{array}$ \\
\hline 7 & Isleworth & 2015 & 1 & Sri Lanka & Man & $\begin{array}{l}\text { Related to being drunk and } \\
\text { disruptive on a flight }\end{array}$ & $\begin{array}{l}6 \text { months' prison, } \\
\text { suspended for } 12 \text { months }\end{array}$ \\
\hline 8 & Isleworth & 2015 & 1 & Poland & Man & $\begin{array}{l}\text { Importation of drugs } \\
\text { (Class A) }\end{array}$ & $\begin{array}{l}3 \text { years and } 6 \text { months' } \\
\text { prison }\end{array}$ \\
\hline 9 & Wood Green & 2015 & 1 & Romania & Man & $\begin{array}{l}\text { Assault occasioning actual } \\
\text { bodily harm }\end{array}$ & $\begin{array}{l}8 \text { months' prison, } \\
\text { suspended for } 12 \text { months }\end{array}$ \\
\hline
\end{tabular}

${ }^{5}$ The Extended Determinate Sentence (EDS) was introduced in 2012, following the abolition of the Imprisonment for Public Protection (IPP) sentence. The EDS consists of a custodial term (in this instance 18 years) followed by an extended period on licence. There are also specific release arrangements for this type of sentence. Whereas, with normal or determinate prison sentences, release usually happens automatically at the halfway point of the custodial term, for most people now subject to an EDS it is only possible to apply to the Parole Board for release once two-thirds of the custodial term has been completed - and this will only go ahead, of course, if the Parole Board approves it (Inside Time, 2016).

${ }^{6}$ The exact offence for which the defendant had been convicted was not specified during the sentencing hearing. 


\begin{tabular}{|c|c|c|c|c|c|c|c|}
\hline $\begin{array}{l}\text { Hearing } \\
\text { number }\end{array}$ & Court & $\begin{array}{l}\text { Date of } \\
\text { hearing }\end{array}$ & $\begin{array}{l}\text { Number of } \\
\text { defendants }\end{array}$ & $\begin{array}{l}\text { Country of origin } \\
\text { of defendant(s) }\end{array}$ & $\begin{array}{c}\text { Gender of } \\
\text { defendant(s) }\end{array}$ & $\begin{array}{l}\text { Offence(s) being } \\
\text { sentenced for }\end{array}$ & Sentence imposed \\
\hline 10 & Southwark & 2015 & 7 & $\begin{array}{l}5 \text { from Poland; } 1 \\
\text { from Albania; } 1 \\
\text { from UK }\end{array}$ & All men & $\begin{array}{l}\text { Drug-related offences, } \\
\text { ranging from possession } \\
\text { with intent to supply to } \\
\text { importation (Class A and } \\
\text { B) }\end{array}$ & $\begin{array}{l}\text { Ranging from } 6 \text { years to } \\
20 \text { years' prison }\end{array}$ \\
\hline 11 & Isleworth & 2015 & 1 & $\begin{array}{l}\text { Not specified, but } \\
\text { probably a country } \\
\text { in Northwest or } \\
\text { Central Africa }^{7}\end{array}$ & Woman & $\begin{array}{l}\text { Benefit fraud, by failing to } \\
\text { notify a change in } \\
\text { circumstances }\end{array}$ & Conditional discharge \\
\hline 12 & Isleworth & 2015 & 1 & Poland & Man & $\begin{array}{l}\text { Theft, racially-aggravated } \\
\text { actual bodily harm and } \\
\text { common assault }\end{array}$ & Community order \\
\hline 13 & Southwark & 2015 & 3 & All from Lithuania & All men & Handling stolen vehicles & $\begin{array}{l}\text { Ranging from } 12 \text { to } 15 \\
\text { months' prison, } \\
\text { suspended for } 12 \text { months }\end{array}$ \\
\hline 14 & Isleworth & 2016 & 1 & Nigeria & Man & $\begin{array}{l}\text { Causing grievous bodily } \\
\text { harm with intent }\end{array}$ & 8 years' prison \\
\hline 15 & Isleworth & 2016 & 1 & Pakistan & Man & $\begin{array}{c}\text { Breach of a restraining } \\
\text { order }\end{array}$ & $\begin{array}{l}6 \text { months' prison, } \\
\text { suspended for } 18 \text { months }\end{array}$ \\
\hline
\end{tabular}

${ }^{7}$ As I explain in Chapter Five, when I explore this hearing, the defendant's country of origin was not specified during the proceedings. However, for a number of reasons it seemed likely that she was originally from a country in Northwest or Central Africa - I set out what these reasons were in Chapter Five. 


\begin{tabular}{|c|c|c|c|c|c|c|c|}
\hline $\begin{array}{l}\text { Hearing } \\
\text { number }\end{array}$ & Court & $\begin{array}{l}\text { Date of } \\
\text { hearing }\end{array}$ & $\begin{array}{l}\text { Number of } \\
\text { defendants }\end{array}$ & $\begin{array}{l}\text { Country of origin } \\
\text { of defendant(s) }\end{array}$ & $\begin{array}{c}\text { Gender of } \\
\text { defendant(s) }\end{array}$ & $\begin{array}{l}\text { Offence(s) being } \\
\text { sentenced for }\end{array}$ & Sentence imposed \\
\hline 16 & Isleworth & 2016 & 1 & $\begin{array}{c}\text { Democratic } \\
\text { Republic of Congo }\end{array}$ & Man & Theft & $\begin{array}{l}6 \text { months' prison, } \\
\text { suspended for } 2 \text { years }\end{array}$ \\
\hline 17 & Isleworth & 2016 & 1 & Albania & Woman & $\begin{array}{l}\text { Seeking to obtain leave to } \\
\text { enter or remain by } \\
\text { deception }\end{array}$ & $\begin{array}{l}8 \text { months' prison, } \\
\text { suspended for } 2 \text { years }\end{array}$ \\
\hline 18 & Isleworth & 2016 & 1 & Lithuania & Man & $\begin{array}{l}\text { Importation of drugs } \\
\text { (Class C) }\end{array}$ & 6 months' prison \\
\hline 19 & Isleworth & 2016 & 1 & Somalia & Woman & $\begin{array}{l}\text { Importation of drugs } \\
\text { (Class C })\end{array}$ & $\begin{array}{l}14 \text { weeks' prison, } \\
\text { suspended for } 12 \text { months }\end{array}$ \\
\hline 20 & Southwark & 2016 & 1 & Peru & Man & $\begin{array}{l}\text { Possession of a false } \\
\text { identity document }\end{array}$ & 7 months' prison \\
\hline 21 & Southwark & 2016 & 1 & Poland & Man & $\begin{array}{l}\text { Possession of drugs with } \\
\text { intent to supply } \\
\text { (Class A) }\end{array}$ & $\begin{array}{l}3 \text { years and } 6 \text { months' } \\
\text { prison }\end{array}$ \\
\hline 22 & Isleworth & 2016 & 1 & Uganda & Man & $\begin{array}{l}\text { Fraud, possession of } \\
\text { articles for use in fraud and } \\
\text { possession of a false } \\
\text { identity document }\end{array}$ & $\begin{array}{l}1 \text { year and } 8 \text { months' } \\
\text { prison }\end{array}$ \\
\hline
\end{tabular}




\begin{tabular}{|c|c|c|c|c|c|c|c|}
\hline $\begin{array}{l}\text { Hearing } \\
\text { number }\end{array}$ & Court & $\begin{array}{l}\text { Date of } \\
\text { hearing }\end{array}$ & $\begin{array}{l}\text { Number of } \\
\text { defendants }\end{array}$ & $\begin{array}{l}\text { Country of origin } \\
\text { of defendant(s) }\end{array}$ & $\begin{array}{c}\text { Gender of } \\
\text { defendant(s) }\end{array}$ & $\begin{array}{l}\text { Offence(s) being } \\
\text { sentenced for }\end{array}$ & Sentence imposed \\
\hline 23 & Isleworth & 2016 & 1 & Algeria & Man & Theft & $\begin{array}{l}4 \text { years and } 8 \text { months' } \\
\text { prison }\end{array}$ \\
\hline 24 & Isleworth & 2016 & 1 & Palestine & Man & $\begin{array}{l}\text { Possession of articles for } \\
\text { use in fraud and possession } \\
\text { of a false identity document }\end{array}$ & $\begin{array}{l}1 \text { year and } 6 \text { months' } \\
\text { prison }\end{array}$ \\
\hline 25 & Southwark & 2016 & 1 & Romania & Woman & $\begin{array}{c}\text { Non-domestic burglary and } \\
\text { theft }\end{array}$ & $\begin{array}{l}1 \text { year prison, suspended } \\
\text { for } 2 \text { years }\end{array}$ \\
\hline
\end{tabular}


As I explained earlier, during my fieldwork I observed a total of 102 hours of court proceedings - with 33 of these hours spent observing sentencing hearings, and 17.5 hours spent observing sentencing hearings immediately relevant to my research, for people who had migrated to the UK. The length of the individual sentencing hearings for migrants that I observed varied significantly. The shortest hearing that I watched, for a man originally from Romania who had pleaded guilty to assault occasioning actual bodily harm (Hearing 9, Wood Green, 2015), was just 10 minutes long. The longest hearing, for seven men - five from Poland, one from Albania, and one from the UK - being sentenced for drug-related offences ranging from possession with intent to supply to importation (Hearing 10, Southwark, 2015), lasted for over two hours. The longest hearing for an individual defendant that I observed lasted for almost one and a half hours: this was for a woman originally from Romania, who had been convicted of a series of non-domestic burglaries and thefts (Hearing 25, Southwark, 2016). In total, nine of the hearings for migrants that I observed were under 30 minutes long; 10 lasted for between 30 minutes and under an hour; and six continued for an hour or more.

The difficulties that I faced in identifying hearings relevant to my research meant that, as previously stated, the 25 sentencing hearings for migrants that I observed during my fieldwork constituted a convenience sample. That is, I included within my research sample any sentencing hearing for a defendant who had migrated to the UK that I came across during the two-year period that I was conducting observations; I watched this group of 25 hearings because, quite simply, they were available to me (Bryman, 2008). Nonetheless, it is important to highlight that, although it was a convenience sample, there was range and variety amongst the sentencing hearings for migrants that I observed. Thus, I saw hearings for a mixture of offence types: this included border-related offences - for which, as I have noted, it is predominantly migrants who are prosecuted and punished - as well as offences such as assault, burglary, and theft, which are common amongst all defendants in the Crown Court. The hearings also varied in terms of offence severity. So, I saw hearings for relatively minor 
offences, such as common assault, and possession of an unauthorised medicinal product, as well as for those that are more serious, such as rape. In line with this range in offence seriousness, moreover, I observed sentencing hearings where less punitive sanctions - such as a conditional discharge - were imposed, as well as those where lengthy prison sentences were handed down.

There was variation within the sample, too, in terms of the defendants. For example, some defendants had migrated to the UK relatively recently, within the past few years, but a number had been in the country for over a decade. Some did not have valid immigration status, and so were undocumented, whereas others had leave to remain - and in some hearings it was made clear that the defendant had acquired legal citizenship and so had 'naturalised' as a British citizen. Additionally, I watched sentencing hearings for both men and women - although reflecting the low proportion of women who are processed through the criminal justice system (Prison Reform Trust, 2019), out of a total of 33 defendants across the 25 relevant hearings that I observed, just four defendants were women. Through the sample of hearings that I saw, therefore, I was not only able to engage in a 'deep exploration' of the practice of the sentencing hearing overall; I was also able to investigate some of the variations that might differentially inflect and shape proceedings (Mason, 2012). In the first hearing I examine in Chapter Five, for instance, for a woman originally from Albania who had pleaded guilty to an immigration-related offence (Hearing 17, Isleworth, 2016), I document how at one point her defence barrister portrayed her through a narrative of limited inclusion, in a specifically gendered way.

It is, however, a limitation of my research that, while I observed sentencing hearings both for people originally from countries in the Global South, and those from Southern and Eastern Europe, the 25 hearings for 'unwanted' migrants that I saw were quite heavily dominated by 'not quite white' defendants. As can be seen from the table of the observations that I conducted, out of the 33 defendants across the 25 relevant hearings that I saw, 19 
defendants were originally from countries in Southern or Eastern Europe. Yet, despite this, I still managed to capture some of the nuances of narratives of bordering through the sentencing hearings that I observed. In Chapter Two, I documented how non-white and 'not quite white' migrants are often racialised by narratives of bordering in the same way - that they are collectively essentialised and pathologised as inherently abusive immigration cheats and parasitical scroungers, as well as natural-born criminals and sexual predators. At the same time, though, as I also noted, there is racial stratification within these narratives.

Thus, I drew out how, for example, when small groups of unwanted migrants have been elevated to the position of 'genuine' asylum seekers, it is often people who are ostensibly white - such as, for example, refugees from Kosovo during the late 1990s - who have been demarcated like this. I documented, too, how media reporting has frequently used visual images to insist on a strong and particular link between black migrant men and certain forms of criminality. As I explained, then, coverage of 'clashes' between the French police and those living in the 'Jungle' camp in Calais during the 2015 refugee 'crisis' carried numerous pictures of groups of young black men, who were blamed for the disorder and violence. Similarly, 'foreign criminal' media reports have worked to evoke and remobilise older, overtly racist narratives about sexual violence and black men, by repeatedly publishing pictures of men originally from countries in Africa and the Caribbean who have been convicted of sexual offences. As we will see in the analysis of my empirical material, such stratification on the basis of phenotypic difference is detectable within the data that I collected. In Chapter Six, therefore, I explore a hearing for a man originally from Democratic Republic of Congo, who had been convicted of rape, attempted rape and sexual assault (Hearing 6, Wood Green, 2015). In this hearing, the judge portrayed the defendant through the racialised narrative of bordering of the sexual predator - and the defendant's skin colour seemed to particularly facilitate the judge's depiction of him as intrinsically sexually violent. 
Data collection and analysis: Capturing 'what happens' in court and the impact of my social positioning, observing 'enough' sentencing hearings, and my analytic approach As I indicated earlier, when I highlighted that it was often quite difficult to keep up with proceedings, my approach to conducting observations and collecting data was, essentially, to try to record as much of each sentencing hearing as possible. During each hearing, then, I used speedwriting in order to be able to create, afterwards, effectively a transcript of the proceedings (Smith and Skinner, 2017). I also tried to document other aspects of the hearing - for instance, the way that the defendant was behaving or the judge's non-verbal reactions, including facial expressions. As Singh (2017) has noted, due to the pace of proceedings it is often quite difficult to do this - that is, to keep a verbatim record of what is being said and also to document other things that are going on in court. However, although I started my fieldwork with a fairly clear idea of what I was researching, I also wanted to be able to capture aspects that I had not thought about or identified as important prior to starting my observations. I felt it was important, therefore, to take this relatively freeform approach. As I explained earlier, I always tried to spend time immediately after each hearing going over my notes, to make sure that I could read and understand what I had written and also to add any further details of or reflections on the proceedings that I had just observed. I also typed up my notes as soon as possible after the hearings - either on the same day, or the day afterwards. In this way, I hope I have been able to produce accurate and reliable accounts (Johnson, 2011).

It is important, though, to acknowledge the limitations of my records. As I spent a lot of time in court looking down and writing, to try to produce a verbatim record of proceedings, there will, of course, be things that happened that I simply did not notice. My records of the verbal transactions in court are also sometimes incomplete. Like Aliverti (2013a), I found there were times where it was difficult to follow the technical language being used, or where legal professionals were speaking very quickly - or where I simply could not hear what was being said. Additionally, it is important to acknowledge my bias as a 
researcher who is interested in and focused upon a specific topic, and the potential effects of this. As Toni Johnson explains: 'Undoubtedly I view events through a particular lens of inquiry and this ultimately shapes the way in which my perception of events unfold. I write about what I perceive as significant and that which substantiates my own hypothesis' (2011, p.64). While I hope my more freeform approach to recording court proceedings will have helped to counter the effects of this bias, it is likely, nevertheless, that there were 'missed moments ... outside the scope of my vision or interest' (Johnson, 2011, p.65).

The reliability and accuracy of my observations, and subsequent analysis and interpretation of them, must also be considered in relation to my social position: specifically, my position as a white, British researcher, who has never been racially minoritised or experienced racist discrimination, investigating racism in the courts against migrants who are deemed unwelcome. I raise this here not to engage, I hope, in what Claire Alexander has referred to as 'reflexivity by rote ... a necessary genuflection at the altars of power and difference' (2004, p.138). Rather, I aim to actually contend with the impact of my positioning on the research that I have produced (Parmar, 2018b; Lal, 1996) - to take seriously the effects of my privileged racial identity on my work (Duneier, 2004). At various points during my research, indeed, I received important reminders about the effects of my privileged positioning on my investigations and analysis - about the blind spots and limitations of my perspective and the partiality of my view (Haraway, 1988).

During a workshop when I presented a paper on some of my early findings, for instance, my 'implicitly white perspective' was 'exposed' (Phillips and Earle, 2010, p.367) to me as it was pointed out that I had not said anything about defendants' presence and visibility in the courtroom in my analysis. Thus, it was highlighted that I had not explored the effects of visual and somatic difference on the way that non-white migrants were narrated and racialised. I hope, in my analysis across the forthcoming empirical chapters, that I have now gone some way to address this. Even as I draw out the similarities in the way that non-white 
and 'not quite white' migrants were racialised, then, as they were framed through the essentialising, homogenising narratives of bordering that I mapped in Chapter Two, I have also worked to document the differences in their treatment. Such differences include the racial stratification within narratives of bordering that I referred to in the previous section, and the way that this appeared to unfold in one particular hearing - as well as other instances where it seemed that the defendant's phenotypic difference was shaping legal professionals' articulations and reactions. By thinking about how my social position influences what I see and how I interpret it, and by attempting to address limitations to my research when these have been pointed out to me, therefore, I have aimed to approach reflexivity as more than mere 'confessional or testimonial exhortation' (Phillips and Earle, 2010, p.362). Instead, I have attempted to engage with it as, in Phillips and Earle's formulation (2010), an ongoing practice in the collection, analysis and writing up of my data.

In fact, a further instance where I was alerted to something that I had not seen - or, at least, to which I had not paid sufficient attention - led to me making changes to my overall project design. During a presentation of my research at a conference, I was asked about resistance to narratives of bordering: one question enquired whether I had ever seen defence barristers do anything more than just negotiate these narratives, and another asked what I had observed in terms of defendants' reactions and resistance to being characterised in this way. In my responses, I gave examples of behaviour by defence barristers and defendants that had seemed to me to be more subversive. However, I think I also downplayed these as I recounted what had happened, concentrating more in my replies on the highly regulated nature of the courtroom and the difficulties, particularly for defendants, of doing anything that might be seen as stepping out of line.

This, indeed, was how I was planning to frame these moments in the writing of my thesis. At this point, I was not intending to do more than briefly explore them, within my overarching analysis of how racialised narratives of bordering were being deployed. As I 
thought about this further following the conference, however, and as I began to write up these instances, it became apparent to me that by approaching and portraying such moments of resistance in this way I was presenting a view of migrants who are deemed unwanted as only ever stigmatised and abjectified. That is, through my depiction of 'what happens' in the sentencing process, and the lack of attention that I was paying to defence barristers and defendants' practices of contestation and subversion, I was actually reproducing and reinscribing the logics of 'othering' (Clarke, Chadwick and Williams, 2017).

There is, of course, a risk of going too far the other way - of portraying agency and resistance 'beyond what really exists' (Clarke, Chadwick and Williams, 2017, p.273; see also Scraton, 2016). Yet, in reshaping my project, to include, as I have done now, a specific chapter on practices of resistance, I have not suggested that these moments were more transgressive than they actually were; I do not deny that the courtroom is a tightly controlled environment, where disruptions are only ever momentarily destabilising, never revolutionary (Johnson, 2011). Rather, through the inclusion of this chapter, I have worked to more fully explore defence barristers and defendants' challenges and contestations during sentencing hearings, and to devote sufficient attention to their attempts - however constricted or limited - to subvert and resist. I have attempted to 'write against othering', therefore, by, as Michelle Fine puts it, 'allow[ing] us to hear the uppity voices ... who speak against structures, representations, and practices of domination' (1994, p.78).

Earlier, I mentioned the issue of observing 'enough' sentencing hearings relevant to my research during my fieldwork. This was something that I thought about a great deal during the period that I was conducting observations: specifically, what does 'enough' mean, and how many sentencing hearings for non-white and 'not quite white' migrants do I need to see in order to be able make knowledge claims? Thus, the question of 'how many hearings?' is, in part, an epistemological matter. As I suggested previously, however, there is a practical dimension to it, as well. In particular, the need to complete and submit my doctoral research 
within a specified time period meant that I could not just carry on with my fieldwork indefinitely. As Uwe Flick (2012) has emphasised, then - and, indeed, as my earlier discussion on some of the reasons for choosing court observations over transcripts of proceedings indicated - qualitative research is shaped not only by 'internal' factors, such as how you think you can best investigate your topic. It is often heavily influenced by 'outside' determinants, too, such as financial budgets and time constraints (see also Wincup, 2017).

In thinking about 'how many hearings?', moreover, it was also important for me to consider the amount of data with which I could realistically deal. This was because, after observing the first few sentencing hearings, I knew that I wanted to examine the transcripts of proceedings I was producing using manual analysis. There were a number of reasons for this: most importantly, perhaps, it became clear to me after observing several hearings that, in order to understand what is happening during the process of sanctioning a defendant, you need to read through and view their sentencing hearing as a whole. Having a huge number of hearings to deal with, therefore, would have made manual analysis very difficult. If I had collected a large number of sentencing transcripts, good quality and nuanced analysis of my data would have been hard to achieve. I give a more detailed explanation of how I actually conducted the manual analysis of the data that I collected later in this section.

In a short essay responding to the age-old qualitative research question 'How many interviews is enough?', Jensen makes the following suggestion: 'Rather than asking the question "how many interviews should I do", my advice would be to ask instead: why do I feel like [the interviews completed already] are not enough?' (2012, p.39). In order to determine if I had observed 'enough' sentencing hearings, I ultimately took a quite similar approach. Thus, by the end of September 2016, I had observed 25 hearings for people who had migrated to the UK from countries in the Global South or Southern and Eastern Europe. At this point, I decided to take a break from observations, to give myself time to read through and properly analyse the data that I had so far collected. My plan, at this stage, was that I 
would start attending court again at some point in the near future, to carry out some further observations. Yet, as I examined the transcripts of proceedings that I had already gathered, it started to become less clear to me why I thought I needed to do this. That is, responding to Jensen's suggested question, it was not immediately obvious to me why I felt that the observations I had carried out so far were not enough.

I did not reach the qualitative research ideal of theoretical saturation (Baker and Edwards, 2012; Bryman, 2008) through the data I collected; I am sure that, had I gone back to court and observed further hearings, I would have discovered something new. Nonetheless, I did arrive at what Emma Wincup has referred to as 'a "good enough" understanding' of my research topic through the observations I conducted, so that 'what was once strange ha[d] become familiar' (2017, p.78). Or, to put it another way, the data that I gathered allowed me to identify and comprehend clear patterns, as well as nuances (Paik and Harris, 2015), in the mobilisation of dominant, racialised narratives of bordering during sentencing hearings for 'unwanted' migrants. Thus, across the 25 sentencing hearings for non-white and 'not quite white' migrant defendants that I observed, I traced racialised narratives of bordering in 16 hearings. The permeation of the sentencing hearings that I watched by these racialised narratives was not pervasive, then - but, as I detected them in just under two-thirds of the proceedings I saw, it is evident that their appearance was far from anomalous or a one-off. Moreover, from the hearings that I observed, I was able to identify a clear pattern as to how these dominant, racialised narratives were being deployed in the specific context of sentencing proceedings. That is, it was possible to see how racialised narratives of bordering were being put to work - or, what they were being mobilised to do - in the construction, and negotiation, of non-white and 'not quite white' migrant defendants' punishability.

Alongside this overarching routine, I was also able to draw out smaller patterns and routines across the sentencing hearings that I saw. So, it was possible to see how racialised narratives of bordering were sometimes invoked, or negotiated, by legal professionals in 
similar ways, using common formulations or turns of phrase. Additionally, I traced patterns in terms of when these dominant narratives tended to appear during hearings. Thus, as I document in the next chapter, racialised narratives of bordering seeped into the individual narratives delivered by prosecution barristers, and judges, unevenly, and when they were appealed to there often seemed to be specific, contextual reasons for this. The sentencing hearings where dominant narratives of bordering were not traceable in prosecution and judges' narratives, indeed, generally tied in with this pattern. In contrast to the specificity and context underpinning the mobilisation of narratives of bordering in prosecution and judges' narratives, however, I also saw a series of hearings where defence barristers countered the idea of their client as an inherently parasitical scrounger for no obvious reason. In these hearings, then, the spectre of the scrounger appeared to just run through mitigating pleas and, therefore, a quite different pattern underlying when or in what circumstances racialised narratives of bordering permeated sentencing hearings seemed to unfold.

Consequently, after reviewing the data that I had collected I felt I had developed a 'rich understanding' (Paik and Harris, 2015, p.284) of sentencing proceedings for 'unwanted' migrants through the patterns I had traced. I decided, then, that I had reached a point in my fieldwork where I had seen 'enough' hearings, and that it was now possible for me to make credible knowledge claims. As I emphasised earlier I recognise, of course, that what I have identified across the 25 sentencing hearings for non-white and 'not quite white' migrants that I observed is not generalisable. I have traced the permeation of sentencing proceedings by dominant narratives of bordering, and patterns in terms of how these racialised narratives are deployed, as well as when or in what circumstances they tend to appear, within a convenience sample of hearings that took place in specific Crown Courts. But I would suggest, nonetheless, that what I have detected within this convenience sample offers us an insight into the practice of sentencing hearings for 'unwanted' migrant defendants in England and 
Wales. To borrow Johnson's words, therefore, I would argue that my research can be treated as 'reliably observed data, with instances which may be of importance' (2011, p.63).

I noted above that I used manual analysis to examine the data that I collected from my observations of sentencing hearings. I would describe this manual analysis as a gradual and ongoing process. Thus, it started with the transcription of my written notes from sentencing hearings; as I explained previously, I did this as soon as I could following observations either on the same or the following day. Wincup explains that transcribing one's own notes enables researchers 'to become steeped in the nuances' (2017, p.137) of the data they have collected. As she states, then: 'The transcription process offers the opportunity for reflection on the data and attention to emerging themes and should be seen as an integral part of the analytic process' (2017, p.137). Through transcription, therefore, I began the process of familiarising myself with, and comprehending, my data.

The approach I subsequently took to analyse the hearings that I had observed, once transcription of my written notes was complete, was more structured. Thus, in the first instance I used what Paik and Harris refer to as 'focused coding' (2015, p.291), to identify whether the key racialised narratives of bordering that I documented in Chapter Two could be detected in the sentencing proceedings I had watched. So, I analysed the transcripts of hearings that I had produced specifically to see if the dominant narratives of the abusive immigration cheat, the parasitical scrounger, the criminal, the terrorist or the sexual predator could be detected. It could be argued, perhaps, that by taking such a focused approach, I ran the risk of 'over-reading' hearings; that is, by looking specifically for these racialised narratives, it seems likely that I would find them. As explained above, however, the manual analysis I conducted was an ongoing process - and, therefore, I spent time reflecting on and re-reading my data, which included interrogating identifications I had previously made of racialised narratives of bordering in hearings. Through this process, indeed, I ultimately decided that in four hearings where I had initially identified defence barristers as countering 
their clients as parasitical scroungers, they were not, in fact, engaging with this racialised narrative; I explain why I came to this conclusion in more detail in Chapter Five. Originally, then, I identified dominant narratives of bordering as permeating 20 out of the 25 hearings for 'unwanted' migrants that I observed - but, upon further reflection and scrutiny of my data, I excluded these four hearings and so the overall number reduced to 16 .

Alongside this focused approach, I also engaged in more 'open-ended' (Paik and Harris, 2015, p.291) analysis. So - as well as examining the hearings through the predetermined categories, or codes, of key narratives of bordering - I attempted to let 'salient themes' and 'common concepts, events, processes' (Paik and Harris, 2015, p.291) emerge from the data itself through reading and re-reading of the transcripts. This approach helped me to identify the specific patterns that seemed to be playing out in terms of when, or in what sort of circumstances, racialised narratives of bordering tended to appear. Thus, having initially become alert to these patterns through a few hearings, I was able to pinpoint them as potential 'common processes' and subsequently find further examples. Taking a more openended approach also helped me to detect ideas about 'unwanted' migrants that were mobilised by legal professionals during hearings that fell outside the scope of the key racialised narratives of bordering. In Chapter Five, for example, I note how length of residence in the UK was appealed to in some hearings by defence barristers, to portray their client as belonging to the country and so as a good and desirable person who could be afforded leniency by the court.

Although observations of sentencing hearings were the main source of data for my research, I also gathered information about the courts and sentencing proceedings in other ways. During my fieldwork, then, I had some conversations with those working in the courts in which I was observing: most often court ushers and clerks, and prosecution and defence barristers, but also, on two separate occasions, judges. I did not actively seek out these conversations, but I also never passed up the opportunity to speak to someone who 
approached me. Like Lisa Flower (2018), I felt that these informal conversations might offer additional information that could be useful to further understanding my research topic.

When those who approached me discovered that I was a researcher, their next question, understandably, was usually 'What are you researching?' Typically, I kept my response quite simple, telling them that I was looking at the sentencing of people who had migrated to the UK - or, on several occasions where the person I was speaking to seemed a bit confused by my initial reply, explaining that I was interested in the sentencing of foreign nationals. It was noticeable how my social positioning, and specifically my racial identity, seemed to affect some responses to this information. Thus, during a conversation that I had with a judge quite early on in my observations, his immediate response to the brief explanation I gave of my research was to suggest that I should read Roger Hood's 1992 study Race and Sentencing. In this way, then, the judge appeared very alert to the possibility of racist discrimination in the sanctioning of migrants. And yet, shortly after this, he insisted that there are now around a quarter of a million asylum applications made in the UK every year - a gross exaggeration, as the UK in fact deals with about 25,000 to 30,000 asylum claims annually (Home Office, 2019d). He then told me, 'We have a system that can't cope with this abuse'.

The judge repeated claims about fraudulent asylum seekers duping the UK's immigration system, therefore, without any apparent worry that as a result of this I might view him as racist. His seeming lack of concern must, of course, in part be seen in terms of the coded nature of this racism. As we will see in the chapters that follow, as I trace the permeation of narratives of bordering through sentencing proceedings, such racialised formulations were often deployed in open court - so judges, and indeed other legal professionals, did not seem worried about saying such things in an officially 'public' setting. Yet, I also felt that the fact that I am white and British contributed to the judge's response. That is, my racial identity meant that the judge appeared to feel entirely comfortable 
articulating such views to me, and talking unguardedly about people seeking asylum as 'abusers' of the UK's immigration system.

As can be inferred, perhaps, from the fact that some of those working in the courts where I conducted observations approached me and asked what I was doing, there was often a curiosity about my presence (see also Aliverti, 2018a, 2013a).I In many instances, those who approached me ultimately seemed quite unconcerned about me being there, and were relaxed about talking and answering questions. At other points, however, I was treated with some suspicion. On several occasions, for example, I was told by court ushers that I could not write anything down during hearings. They only seemed to be persuaded that making notes was, in fact, permitted if I told them that I had observed at the same court just a few weeks previously and had been allowed to do this. On another occasion a judge asked me, in open court, who I was and what I was doing. I explore this incident more fully, and what it appeared to reveal about the sentencing hearing that I had just observed, in Chapter Six.

During another visit, I was invited to speak with a judge whom I had been observing during a break in the proceedings. This might, of course, be interpreted as a display of openness and welcome towards research in the courts, rather than as an indicator of wariness and suspicion. Yet, as I moved from the public gallery in the courtroom to a seat in the judge's chambers, my relationship to the judge noticeably changed. In the courtroom, I had been researching him - but in his chambers, the conversation was very much led by the judge and I increasingly felt like the object of scrutiny. The invitation to speak with him in his chambers felt, therefore, to some extent as if it was an attempt to restore the usual dynamics of power in the courtroom - that is, as if it functioned to demonstrate and reassert the judge's authority over me (Lal, 1996).

Overall, however, it is important to emphasise that while I was occasionally treated with suspicion, I generally moved around and observed in the courts that I visited with relative ease. Again, this should be understood in terms of my social positioning, and 
specifically my racial identity. My whiteness meant that, on some occasions when I visited court, I simply was not asked to account for what I was doing or to explain who I was. My whiteness also noticeably informed the assumptions that some court staff made about me. At various points during my research I was asked, upon entering a courtroom, if I was the police officer in the case, or the interpreter for the hearing. At no point, however, was I asked if I was the defendant.

\section{The ethics of observing sentencing proceedings}

As I highlighted at the beginning of this chapter, the court is officially a public setting, which anyone can enter to observe what is going on. As a result, then, there is no formal ethics approval procedure that researchers have to go through if they are conducting court observations - and, indeed, criminological studies that have involved observing court proceedings have not often reflected on the ethics of carrying out this type of research. Yet, as I attended court and observed sentencing hearings, I felt that there were undoubtedly ethical issues to navigate. Most prominently, perhaps, I was concerned about the possible harm that my research might cause defendants.

In their research on the Crown Court Jacobson, Hunter and Kirby (2015) highlight how some of the defendants to whom they spoke found it upsetting that the court is a public space, which anyone can enter - and so that anyone, effectively, might hear details of their case. Alongside this, going through the criminal justice system is, in itself, a distressing experience (Feeley, 1979). This was immediately evident in a number of the sentencing hearings that I saw, where the defendant was visibly anxious and upset. During such hearings, in particular, a sense of my own voyeurism - similar, perhaps, to what Phillips (2012) describes feeling during her research within prisons - was especially acute, and I had concerns about the potential further harm that my presence in court might be causing. That is, I was concerned that being watched by an unknown observer, as they were going through the 
process of being sanctioned, might be increasing and exacerbating the defendant's anxiety and distress.

I attempted to mitigate this possible impact in different ways. Thus, like Olivia Smith and Tina Skinner (2017), I tried to maintain a low profile in court and be discreet in my notetaking. Sometimes, I would find myself sitting alongside family and friends of the defendant in the public gallery - and, if I was ever asked who I was and what I was doing, I would clearly explain my research. I also emphasised that the anonymity of everyone involved in the hearing, including the defendant, would be preserved when I wrote up my research. Thus, across Chapters Five and Six, I have used pseudonyms for all the defendants in the hearings that I explore, and I have also changed any other potentially identifying details, such as dates of birth. From another perspective, however, it might be argued that while there are ethical risks to carrying out court observations, if this sort of research is not conducted then what happens in the courts will remain largely invisible. The criminal court, as I have emphasised throughout this chapter, is formally a public setting and in theory anyone can enter and watch what is taking place. In practice, however, as I have also explained, this rarely happens - and so court proceedings are often essentially private in nature, as the only people who are present for a hearing are those with an immediate involvement in the case being heard.

The need to address the privacy and invisibility of what happens in court feels particularly pressing in relation to what I document in the empirical chapters that follow. Essentially, then, I uncover the processes of racialisation and 'othering' that people from the Global South and Southern and Eastern Europe are subjected to during sentencing proceedings - the harsh and racist ways in which these defendants are constructed and negotiated as punishable. My research might, therefore, be viewed in terms of what Clarke, Chadwick and Williams (2017) have identified as critical social research as a site of resistance. That is, it might be understood in terms of the important role that researchers have 
to play in 'bearing witness' (2017, p.262) to, and communicating knowledge about, processes of power, marginalisation and injustice.

It would be disingenuous to suggest that, as a $\mathrm{PhD}$ student, my research does not have other aims, as well (Phillips and Bowling, 2003). By pursuing this project I am, of course, hoping to attain a specific academic qualification, and potentially begin an academic career. At the core of my research, however, is an explicitly political commitment, and 'decidedly interventionist' (Hillyard et al., 2004, cited by Clarke, Chadwick and Williams, 2017, p.264) aims. In choosing this topic, I have taken as my departure point 'the interests of those out of power' (Mathiesen, 2004, cited by Clarke, Chadwick and Williams, 2017, p.266), and I have worked to critically examine the practice of their criminal sanctioning - to scrutinise, and denaturalise, the sentencing proceedings to which 'unwanted' migrants are subjected. Through investigating and interrogating this process, and uncovering the racism that runs through it, therefore, I believe that - despite the potential risks of carrying out court observations - my research is ethically justified.

\section{Writing up sentencing hearings and presenting my findings}

It is, finally, important to briefly explain how I have chosen to write up my empirical research and present my findings. As I noted earlier, I traced dominant, racialised narratives of bordering in 16 of the 25 sentencing hearings for non-white and 'not quite white' migrant defendants that I observed. Over the subsequent two chapters of the thesis I examine all 16 of these hearings - and I divide them in the following way. In the next chapter, Chapter Five, I explore 13 sentencing hearings where the narrative of the abusive immigration cheat, and/or that of the parasitical scrounger, came through. I draw out how these dominant, racialised narratives were being put to work in the construction, and negotiation, of 'unwanted' migrants' punishability - and I also uncover specific patterns in terms of when, or in what sort of circumstances, they tended to emerge. I refer, too, to some of the hearings where 
dominant narratives of bordering did not come through in this chapter, and I consider the non-presence of racialised narratives in these hearings in relation to the specific patterns identified around when narratives of bordering typically appeared.

In Chapter Six, I consider the remaining three sentencing hearings where dominant narratives of bordering could be traced. As I explain, in these hearings the same patterns that are documented in Chapter Five, as to how and when narratives of bordering were tapped into by legal professionals, could be detected. Significantly, however, it was also possible to see defence barristers, as well as defendants, behave in more subversive ways in these proceedings. I draw out, therefore, how in these three hearings the characterisation of the defendant through racialised narratives of bordering was not simply negotiated - but, in fact, resisted. In my second empirical chapter, then, I focus on defence barristers and defendants' practices of resistance to racialised narratives about 'unwanted' migrants.

Throughout Chapters Five and Six, I attempt to follow individual sentencing hearings all the way through in my analysis, rather than jumping back and forth across different hearings. This is important, first of all, because the narratives delivered by the prosecution, defence and judge during a sentencing hearing are not discrete or isolated stories, but interact with and speak to each other. Thus, following sentencing hearings all the way through helps to capture and reflect this. Related to this, keeping hearings together is also important in terms of tracing racialised narratives of bordering and the way that these are mobilised across sentencing hearings. As we will see in the chapters that follow, sometimes the formulation of a defendant through a narrative of bordering in a hearing was very clear. At other times, however, the appeal to these racialised narratives was subtle - and, in fact, sometimes it was not easily evident without the context of what had gone before, without seeing it in terms of the rest of the hearing. By keeping sentencing hearings together, therefore, and following them all the way through, I have worked to trace and uncover the full extent of their permeation by racialised narratives of bordering. 


\section{Chapter 5}

\section{Racialised Narratives of Bordering, and the Construction and Negotiation of Punishability}

\section{Introduction}

Across the first three chapters of this thesis, I theorised the mobilisation of dominant, racialised narratives of bordering during sentencing proceedings. I argued, then, that these racialised narratives - which are circulated by the UK government and media to problematise non-white and 'not quite white' migrants and justify their targeting by border enforcement might be tapped into in the specific context of the sentencing hearing, to help construct, and negotiate, defendants' punishability. In this first empirical chapter, I explore 13 of the sentencing hearings for migrants from the Global South and Southern and Eastern Europe that I observed during my fieldwork in Crown Courts, in which racialised narratives of bordering could be detected. As I show, what I conceptualised across the first part of the thesis, about the deployment of these narratives in sentencing proceedings, was in fact happening.

Thus, I uncover in this chapter the overarching pattern of how dominant, racialised narratives of bordering were being put to work in the construction and negotiation of nonwhite and 'not quite white' migrant defendants' punishability. As I demonstrate, two of the narratives of bordering I traced in Chapter Two, the narrative of the abusive immigration cheat, and that of the parasitical scrounger, could be detected across the 13 hearings that I explore. These racialised narratives were appealed to in the individual narratives delivered by legal professionals during sentencing, in order to construct defendants as inherently problematic, and to essentialise them as undesirable in themselves - and, through this, to help produce them as punishable. Conversely, the narratives of the immigration cheat and the parasitical scrounger were also negotiated and negated in these hearings in various ways, to 
insist that defendants were not intrinsically suspect or deviant but, in fact, were naturally good and deserving migrants. Through this, defendants were constructed as less punishable than had been suggested - and so were portrayed as worthy of the court's leniency. I demonstrate, too, how the narratives of limited inclusion that I documented in Chapter Two were invoked in the hearings I saw as well, as another way of constituting defendants as deserving of less punitive treatment. In particular, the narrative of migrants who 'work hard', 'pay taxes' and 'contribute to the UK' - which, as I noted, separates some migrants who are usually deemed 'unwanted' from the figure of the inherently parasitical scrounger - was mobilised during several of the hearings I observed. This functioned to depict defendants as desirable in themselves, and thus to insist that it was not necessary to sanction them so severely.

As well as drawing out this overarching pattern, I also document some smaller patterns and routines across the 13 sentencing hearings that I examine in this chapter. I show how, for instance, legal professionals sometimes invoked, or negotiated, racialised narratives of bordering in similar ways, utilising common formulations and turns of phrase.

Additionally, I trace specific patterns in terms of when, or in what sort of circumstances, these racialised narratives tended to appear. I highlighted in Chapter Three how, in her analysis of the trials of Myra Hindley and Rosemary West, Winter (2002) shows that images of gendered deviancy did not permeate these trials equally. Rather, the judge in West's trial relied much more heavily on ideas of her problematic sexuality and maternity in his summing up to the jury because, Winter argues, the evidence against her for the murders she was being prosecuted for was weak. Ideas about West's intrinsic abnormality and badness were deployed by the judge, therefore, to help 'bridge the evidential gap' (2002, p.355). Something similar was detectable in the sentencing hearings that I observed. Thus, racialised narratives of bordering seeped into the individual narratives delivered by prosecution barristers, and judges, unevenly, and when they were appealed to it often appeared to be for specific, 
contextual reasons. The sentencing hearings where dominant narratives of bordering were not traceable in prosecution and judges' narratives, indeed - including those hearings where these racialised narratives could not be detected at all during the proceedings - generally tied in with this pattern. In other words, the specific, contextual factors that seemed to especially prompt the mobilisation of racialised narratives of bordering by prosecution barristers, or judges, were largely not present in these hearings.

In contrast to the specificity and context that apparently underpinned the appeal to dominant narratives of bordering in prosecution and judges' narratives, however, I also saw a series of sentencing hearings where the spectre of the parasitical scrounger seemed to just run through defence narratives. So, defence barristers countered this racialised narrative even though there had been no suggestion that the defendant might be viewed like this - and it was not the nature of the offence, either, that appeared to motivate the defence's insistence that their client was not problematic in this way. There was no obvious reason or prompt for defence representatives' negation of this dominant narrative, then; and, therefore, a quite different routine as to when or in what circumstances racialised narratives of bordering permeated sentencing proceedings seemed to unfold in these hearings. As I explain, it seemed, from them, that distancing the defendant from the figure of the scrounger might be emerging as a standard feature of defence practice in non-white and 'not quite white' migrant sentencing proceedings. That is, it appeared from these hearings that framing the defendant as someone who would never take advantage of and 'sponge off' the UK was developing as a routine defence approach to asserting their client's good and desirable nature - and so to constructing 'unwanted' migrant defendants as less punishable. 


\section{The narrative of the abusive immigration cheat in immigration offence hearings: Agnesa}

and Tomás

I begin my analysis in this chapter by exploring the two sentencing hearings I observed during my fieldwork that were concerned with immigration-related offences. In these hearings the border touched and marked the court overtly, in the way that has been documented by critics within border criminology, because the defendants were being prosecuted for violating the immigration system. The injection of the direct practices of immigration enforcement into court proceedings was visible, too, in one of the hearings as it was mentioned by the defendant's barrister during the plea in mitigation that, after serving the sentence imposed for the offence, his client was going to be removed from the UK. Alongside this, though, border control also permeated these sentencing proceedings in a more covert and subtle manner. As we will see, therefore, the racialised narrative of the abusive immigration cheat was tapped into, as well as countered and negated, by the legal professionals involved in these hearings, as part of the sentencing hearing practice of constructing and negotiating the defendant's punishability.

The first immigration offence hearing that I examine in this section was for a woman, originally from Albania, whom I will call Agnesa, who had pleaded guilty to seeking to obtain leave to enter or remain by deception, by giving false details on an asylum claim (Hearing 17, Isleworth, 2016). While, as we will see, the prosecution attempted to present 'what happened' as fairly straightforward, it transpired during the hearing that the circumstances of Agnesa's arrest and prosecution were actually quite complicated. Thus, although the sentencing hearing took place in 2016, the offence itself had actually been committed many years earlier, in 2002, when Agnesa first arrived in the UK. The immigration authorities found out about what she had done a few years later, in 2005. Yet, Agnesa was not prosecuted at this point but was simply told to leave the country, because the 
asylum claim which had included the false details had been rejected and so she was in the UK without leave to remain.

So, Agnesa left the country - and, as she was by now married to a British citizen, she then made an application to re-enter the UK as the spouse of a citizen, which was approved. A few years later, in 2009, she applied for British citizenship, which was also approved. It was only when someone linked to her offence was later investigated and prosecuted that criminal proceedings were subsequently started against her, around a decade after the authorities first became aware of what she had done. This context - that the offence was not prosecuted when it initially came to light, and that Agnesa was only brought to court many years later - is critical, I would suggest, for understanding how the hearing unfolded. As I argue, the very specific circumstances of Agnesa's case help to explain why, in the prosecution and judge's accounts, the racialised narrative of the inherently abusive immigration cheat was mobilised.

Opening the hearing with the facts of the case, the prosecution set out 'what happened' in the following way:

\section{Prosecution:}

She arrived in the UK in 2002, in the back of a lorry, and immediately claimed asylum. The date of birth she put on her application was $6^{\text {th }}$ November 1984 , but it is really $25^{\text {th }}$ April 1982. This was one of the false details on the paperwork in her asylum claim.

Judge:

So, the false date would have put her as a minor? 


\section{Prosecution:}

Yes. The second false detail was in relation to her parents. She claimed in her asylum application that her parents were deceased, so she was an orphaned minor. She said that her mother had died in 1995 of natural causes. After this, she said she continued to live with her father, who was an army officer, and her brother, but then on $16^{\text {th }}$ March 1997 a group of ex-army officers went to the base where her father worked and killed him. This was untrue. Neither of her parents were deceased, and after she gained leave to remain in this country, her parents applied for visitor visas to come and see her.

I said in Chapter Three that I would draw out the distinct purpose of each sentencing narrative - what each account is specifically doing in the construction, and negotiation, of the defendant's punishability - in the analysis of my empirical material. To begin with this, then, we can see here, I think, how in the facts of the case the prosecution delivers an opening version of events that insists it is right for the defendant to be before the court. That is, at the very outset of the hearing, 'what happened' is narrated in such a way to confirm that the defendant is legitimately punishable. There was, potentially much more information that could have been included in this opening account. As was typical across many of the sentencing hearings that I observed during my fieldwork, however, the prosecution barrister relayed a sparse and truncated narrative, in which only certain 'facts' were included. Thus, the prosecution account of 'what happened' delivered at the start of Agnesa's hearing amounted, essentially, to: 'The defendant came to the UK in 2002, she made a claim for asylum, and she put details that she knew were false on her claim.' In doing so, the prosecution set out a version of events that focused on the prohibited conduct in which Agnesa had engaged, and her clear intent in doing this. 'What happened' was narrated in terms of the actus reus and mens rea, therefore, 'the essential building blocks of a legally 
sustainable case' (McConville, Sanders and Leng, 1991, p.65) - in order to present Agnesa as punishable in legal terms, to produce her as sanctionable through the norms of the criminal law.

But we can also start to see here how rendering the defendant punishable in the facts of the case is not only a legal exercise. Through the inclusion of a couple of additional 'facts', the prosecution barrister appeared to be making Agnesa sanctionable in another way. It was noticeable, for instance, that it was specifically highlighted how Agnesa had entered the UK that, when she arrived in 2002, it was 'in the back of a lorry'. And it was also interesting that, after explaining Agnesa was not, as she had initially claimed, an orphaned minor, the prosecution then drew attention to how, once she had secured leave to remain in the UK, 'her parents applied for visitor visas to come and see her'. Both of these details, I would argue, were doing more than helping to set out the legal case against Agnesa.

In the first place, Agnesa's mode of arrival in the UK was, ultimately, legally irrelevant to the offence for which she was being sentenced. In the other hearing for an immigration offence that I observed, which I explore later in this section, how the defendant had entered the UK was also discussed briefly by the prosecution and judge at the beginning of the proceedings. Yet, in this instance this information was, in fact, legally significant, as had there been proof that the defendant had used the false passports in his possession to enter the country then - according to guidance from the Court of Appeal - this should have aggravated his punishment. Given that Agnesa's was an immigration offence it might, of course, be countered that even though how she had got into the country was not legally important, the inclusion of this information during her sentencing hearing should hardly be considered unusual. I recognise this - but I also think that, within the sparse and truncated narrative that is the 'facts of the case', the decision to include a specific piece of information is significant. Moreover, the particular phrasing used by the prosecution to describe how Agnesa had entered the UK, 'in the back of a lorry', is worth our attention. As Philo, Briant, 
and Donald (2013) have highlighted, stories about unwanted migrants 'sneaking' into the UK 'in the backs of lorries' appear often in the media and are presented as evidence of the determination of 'bogus asylum seekers' and 'illegal immigrants' to abuse and defraud the UK's immigration system. I would suggest, therefore, that by drawing attention to Agnesa's stereotypically clandestine entry, and by describing it in this specific way, the prosecution was beginning to insinuate her as an archetypally deceptive immigration cheat.

The second detail that the prosecution included, about Agnesa's parents' application for visitor visas after she had gained leave to remain in the UK, added to this portrayal. At first sight, it seemed that this information was relevant to making the legal case against Agnesa, because it evidenced that her parents were, in fact, alive; so, it appeared to be demonstrating that one of the details included in her asylum claim, about being an orphan, was false. And yet, this was not actually how the immigration authorities found out about this aspect of Agnesa's case. As became clear later in the hearing, Agnesa herself told immigration that her parents were still alive, before she secured leave to remain in the UK and they applied for visas in order to visit her. By including this legally superfluous information, then, about how the parents whom Agnesa had previously said were dead had later applied to visit her, the prosecution appeared to be emphasising the scale of the deception that Agnesa had committed - the brazenness of her violation of the UK's immigration system. Through the highlighting of this 'fact', therefore, as well as the information about how she had got into the country, the prosecution seemed to be appealing to the dominant narrative of the abusive immigration cheat, mobilising these additional details to tap into and frame Agnesa through this racialised narrative. In this way, Agnesa was suggested as recognisably and inherently bad and deviant - in order to help produce her as punishable.

Portraying Agnesa in this way might be understood as the prosecution simply emphasising her punishability, by highlighting not only the legal basis for her sanctioning, 
but insisting on her as an intrinsically undesirable person, too. And yet, there also appeared to be specific, contextual reasons why the idea of Agnesa as an archetypal asylum fraudster was deployed in this opening narrative. Firstly, invoking the racialised narrative of the abusive immigration cheat appeared to support the prosecution's subsequent contention about how punishable Agnesa was - about her particular degree of punishability. As happened in most of the other sentencing hearings that I observed, after setting out an account of 'what happened' the prosecution then suggested a suitable sanction for the offence, noting, in this instance: 'There are no sentencing guidelines, but these are familiar cases ... they almost always result in a custodial sentence.' Thus, the suggestion of Agnesa's scheming and manipulative nature - that she had not simply done something problematic, but was problematic in herself - seemed to present her not merely as punishable but as particularly punishable, to justify the call for her imprisonment.

As I suggested earlier, moreover, I also think that the very specific circumstances of her prosecution underpinned the appeal to this racialised narrative here. The fact that Agnesa was not arrested when the offence was first discovered, and that it had, in fact, been known about for years before any action was taken meant that simply setting out her criminal act and intent was not enough to justify bringing her, now, before a court, and punishing her. The prosecution, therefore, implied that Agnesa was an asylum scammer, a natural liar and a cheat, as a way of navigating this. So, she was presented as inherently deviant, and thus as punishable in herself, to help legitimise the pursuit of sanctions against her at all. I should be clear that, by exploring the specific circumstances and reasons that appeared to prompt the mobilisation of racialised narratives of bordering by prosecution barristers and, as we will also see, by judges, I do not mean to present racism in court as an occasional or exceptional occurrence. Rather, as I set out in the introduction to this chapter, I am trying to understand why these racialised ideas permeated the sentencing proceedings that I observed unevenly. As we will see, while the dominant narrative of the immigration cheat ran through the 
individual narratives delivered by the prosecution, defence and judge in Agnesa's hearing, in the other immigration offence hearing that I observed it was traceable only in the defence's account.

In the plea in mitigation, defence barristers generally re-told the story of "what happened' to present their client as less punishable than the prosecution had suggested - and, as Agnesa's barrister did this, he appeared attuned to how she had been portrayed in the facts of the case and seemed to be countering this framing. So, after acknowledging 'it is accepted that age 20 she came to the UK in the back of a lorry, she was discovered at the port', he explained, however, that it was not Agnesa who had come up with the false details she had put on her asylum claim. Rather, 'Her story would have been prepared in advance by the people assisting her - a false story that she was an unaccompanied minor.' In this way, the defence attempted to make Agnesa less punishable in legal terms, by insisting that her degree of intent in committing the offence - which, as I noted in Chapter Three, is known under the criminal law as her culpability - was minimal. At the same time, though, by insisting that the deception did not actually originate with Agnesa, he was also undoing the prosecution's depiction of her as an inherently problematic asylum cheat. The defence built on this as he then described how Agnesa's offence had come to the attention of the immigration authorities in the first place, introducing information that, notably, had been excluded from the prosecution's account. After explaining that, soon after arriving in the UK, Agnesa had met and married her husband, the defence went on:

She told her husband about her true date of birth and her position. It was her husband and her who decided to go to immigration in Croydon ${ }^{1}$ and seek advice. They told her she was here illegally, and that if she remained here she would be

\footnotetext{
${ }^{1}$ The Home Office's immigration headquarters, Lunar House, is in Croydon.
} 
doing so illegally. They told her she could return to Albania and make a fresh application. That is what she did. She wasn't expelled, she wasn't arrested, even though she told them what she had done.

Part of what the defence was doing here was pointing out that at the time the immigration authorities found out about Agnesa's offence, in 2005, it was not deemed worth prosecuting. Alongside this, though, he was also negotiating, and negating, the portrayal of his client as an inherently deviant fraudster, trying to dupe and exploit the system, by carefully relaying examples of Agnesa's compliance and honesty in her dealings with immigration. Thus, he highlighted that not only was it Agnesa who brought her own offence to immigration's attention - but, in fact, that once she had been told she was in the UK illegally and that she had to leave and make a fresh application to re-enter, that is precisely what she did. The defence inverted the racialised narrative of the abusive immigration cheat, therefore, insisting that far from having a propensity to defraud and deceive Agnesa was a good person who had made a one-off mistake - and, consequently, that she could be treated leniently. As the defence then explained, 'She accepts what she did was wrong, wrong in the English language, and in the Albanian language', he appeared to insist once again that Agnesa was not, in herself, bad. Through this formulation, however, he did not seem to be specifically addressing, and countering, the narrative of the immigration cheat. Rather, he seemed to be anticipating the possible perception of an innate Albanian criminality and immorality - to be engaging with the potential idea of Agnesa's natural deviance, expressed this time through the coded racial register of nationality. He attempted to head off this possible perception, therefore, by insisting that Agnesa fully understood the problem with her actions and was entirely able to differentiate between right and wrong.

In the closing section of his plea the defence emphasised that since returning to the UK Agnesa had become a British citizen, and added that 'her children are British passport 
holders, her husband is too'. As I highlighted in Chapter One, immigration status has no formal relevance for sentencing. Yet, as I also explained, Aliverti's (2013b) research has shown how people convicted of immigration offences, who have insecure immigration status and so are removable from the UK, are often given custodial sentences as a way of facilitating their ejection from the country. Thus, we might see the defence's insistence upon Agnesa's British citizenship here as aimed at forestalling this possibility. We might also understand the defence's emphasis not only on Agnesa's, but also her family's citizenship status, as drawing attention to their legal belonging to the UK - and, therefore, as a way of insisting on Agnesa's deservingness because of this. In some of the other hearings for nonwhite and 'not quite white' migrants that I saw, length of residence was similarly mobilised as a marker of belonging by the defence, to portray the defendant as good and desirable and so as worthy of less punitive treatment (see also Aliverti, 2016). Alongside this, though, I also think that pointing to how, upon her return to the UK, Agnesa had acquired British citizenship worked to underline once more her overall compliance and honesty with the immigration system. That is, through this the defence reiterated that Agnesa's breach of the UK's immigration controls when she first arrived was an anomaly, a one-off violation; she subsequently followed, and indeed was accepted through, all the proper channels and processes following this unfortunate incident. Once more, therefore, the defence negated and inverted the racialised narrative of the abusive immigration cheat - in order to portray his client as desirable and deserving in herself, and so to insist that she could be afforded some leniency.

After affirming Agnesa's goodness in gendered terms, depicting her as a dutiful wife and mother as he explained, 'Her husband works extremely hard and she looks after their four children, in a traditional family picture painted for the court', the defence then ended his narrative in the following way: 
When she was in her 20s, she did something very wrong ... She committed an offence; I try not to brush this aside. But it is possible to focus on the positives with her because of her good character, her plea, and the fact that she has brought up a thriving family and is contributing well to our society. If a custodial sentence must be imposed, it can be suspended.

Here, the defence highlighted legal factors reducing Agnesa's punishability, including her 'good character' or lack of previous convictions, and the fact that she had entered a guilty plea (Ashworth, 2015; Wasik, 2014). But he also worked, at this point, to distance her, too, from the narrative of the parasitical scrounger, as he emphasised that since returning to the UK, 'she has brought up a thriving family and is contributing well to our society'. Thus, the defence framed Agnesa, in a specifically gendered way, through the related narrative of limited inclusion that I documented in Chapter Two: that of migrants who are acceptable because - instead of freeloading and taking advantage - they 'work hard' and 'contribute to the UK'. Through this formulation, the defence reinforced his portrayal of Agnesa as an intrinsically good and desirable migrant, who had simply made a terrible mistake. In this way, therefore, he supported his contention that an immediate custodial sentence was not necessary - that, in spite of what the prosecution had said about the usual sanction imposed for this type of offence, Agnesa did not actually have to be punished with such severity.

The plea in mitigation in the other hearing I observed that was for an immigrationrelated offence played out in a very similar way. This hearing was for Tomás, originally from Peru, who had pleaded guilty to the possession of two false passports (Hearing 20, Southwark, 2016). Although the prosecution did not obviously cast him as a stereotypically abusive immigration cheat in the facts of the case, the defence nonetheless seemed very concerned to dispel any idea of his client like this. The nature of the offence, I would suggest, prompted his concern that Tomás might be viewed in this way. Throughout the defence's 
version of 'what happened', then, he worked to insist that Tomás was not inherently fraudulent or abusive but that he was, rather, a good migrant who had simply made an unfortunate mistake. Notably, the defence did this in ways that paralleled the tactics utilised by the defence barrister in Agnesa's hearing. Thus, he highlighted at one point that, while Tomás had entered the UK unlawfully, he only agreed to do this after he was 'approached by a third party'. As in Agnesa's hearing, therefore, it was asserted that Tomás' deception did not originate with him - that it was someone else who had suggested he should behave in this way. Likewise, the defence in Tomás' hearing also emphasised that, while his client had breached the immigration system by committing the offence, since its discovery he had been entirely honest and cooperative in his dealings with the authorities. So, the defence pointed first of all to Tomás' 'very open-handed' behaviour during the court process, explaining, 'At his very first appearance in the magistrates' court he gave his real name.' He then set out how Tomás was also complying fully with immigration. Noting that Tomás was aware he was going to be removed from the UK following the completion of his criminal sentence, the defence added: 'He has already signed the appropriate paperwork, and is happy to be deported.'

Highlighting this could, perhaps, be seen in terms of something Aliverti (2016) identifies in her research on foreign nationals before the courts: that defence representatives sometimes explained their client was going to be deported anyway, in an attempt to secure a less lengthy prison sentence. Thus, she documents one instance where a judge was told: 'He will be whisked off by the immigration authorities ... This is not to say he will get off scot free, but he will be out of the country quite soon' (2016, p.78). At the same time, though, I would suggest that the formulation deployed by the defence in Tomás' hearing was doing something else, as well. By drawing attention to how Tomás was actively - enthusiastically, even - cooperating with his own expulsion, the defence appeared to be inverting one of the formulations that I pointed to in Chapter Two, about how 'foreign criminals' routinely 
attempt to 'dodge deportation' and 'cheat the system'. By distancing Tomás from such behaviour, then, the defence worked to separate him from the racialised narrative of the immigration cheat, and to insist that his client's violation of the UK's immigration controls had been a one-off, isolated incident - that it was not reflective of an undesirable nature. Just as in Agnesa's hearing, therefore, it was asserted that Tomás was, in himself, a good and deserving person - and that he could, consequently, be punished less severely.

Unlike Agnesa, Tomás had not, ultimately, been able to regularise his immigration status in the UK - and, therefore, his barrister could not point to how his client was now in the country legally. Similar to Agnesa's hearing, however, Tomás' barrister did emphasise how his client's family members were in the UK with official permission. So, he highlighted that one of Tomás' sisters 'is married to a British citizen, and is here on a spouse visa', while the other 'has been in the UK for 26 years, and is a British national'. In one sense, as in Agnesa's hearing, this was about insisting on Tomás' sisters' legal belonging in the UK - in order, in this instance, to imbue Tomás with an associated worthiness, to help make him less punishable. At the same time, though - just as drawing attention to Agnesa's acquisition of British citizenship had - emphasising Tomás’ sisters’ legality and identifying their specific immigration statuses was also about underlining their compliance with and observance of the UK's immigration processes. In this way, therefore, the defence appeared to be suggesting that, by extension, Tomás should not be understood as an archetypal immigration cheat - to be insisting, once more, that his violation was an unfortunate anomaly, a regrettable one-off.

Finally, resonating with Agnesa's hearing again, the defence consolidated his portrayal of Tomás as a good and deserving migrant by distancing him, too, from the figure of the scrounger. So, at one point, the defence explained: 'He has been working in a hospital - albeit on a false ID - as a storehouse worker, paying his taxes, for the past six years. The money he earned went on rent and daily living arrangements, but he also spent money each month on medication for his mother and sister, who are in Peru.' Here, then - just like the 
defence in Agnesa's hearing - Tomás' barrister insisted that his client was not a freeloading parasite by framing him through the related narrative of limited inclusion of 'hard work' and 'contribution'. In this instance, however, the class-inflected dimensions of this narrative, which I pointed to in Chapter Two, were more immediately apparent. In Agnesa's hearing, as I have highlighted, her 'contribution' to the country was presented in a specifically gendered manner, in terms of the family that she was raising. In Tomás' hearing, the defence followed the dominant depiction that has been circulated by successive governments more closely, as he emphasised his client's economic input and how Tomás had been 'paying his taxes, for the past six years' in the UK.

Alongside this, it is also possible to detect a slightly different formulation coming through in Tomás' hearing - to trace how his barrister was simultaneously working to counter the racialised narrative of the parasitical scrounger in another way. As we have seen, in his mitigating plea the defence drew attention to what Tomás had been doing with his earnings, highlighting that - while some had gone on living expenses - he had also been paying for medication for his mother and sister, who were in Peru. Through this, the defence appeared to depict Tomás as the exact opposite of the stereotypical migrant freeloader, who grabs hold of money in order to selfishly enjoy an 'easy' life in the UK. Rather, it was emphasised that Tomás had used much of the money that he had earned to generously and selflessly support his family. The defence inverted the dominant narrative, therefore, working to insist that Tomás was not tainted by such negative traits and characteristics - and, thus, to de-racialise and de-stigmatise him through this depiction. The same formulation was, in fact, deployed by defence barristers across a number of the other sentencing hearings for non-white and 'not quite white' migrants that I observed during the course of my fieldwork. I explore this in detail in the final section of this chapter.

There also appeared to be a moment, at the beginning of Tomás' hearing, when Tomás himself worked to emphasise that he was a good and desirable migrant. While a 
Spanish-speaking interpreter had been booked for and was present at the hearing, before the facts of the case got underway the defence explained to the judge: 'The defendant is actually now content for the proceedings to be in English.' After insisting that what he was about to say should be interpreted into Spanish for Tomás, the judge responded: 'It is important that he knows the interpreter is here, and that if he doesn't understand anything it can be interpreted - he just needs to raise his hand.' At this point, Tomás replied to the judge, in English: 'I understand.' In their analysis of the role of interpreters in criminal courts in England and Wales, Aliverti and Seoighe observe how 'the significance of English language proficiency in Britain goes beyond a mere matter of communication' (2017, p.133). Rather, as it has been linked by successive governments to 'social cohesion' and 'integration', it has become a marker of migrants' commitment to culturally assimilating into a supposedly homogenous (and therefore implicitly white) 'British way of life'. Thus, as Tomás insisted, through his barrister, that he did not need an interpreter for the hearing - and as he also demonstrated this himself by responding to the judge in English - he appeared to separate himself from unintegrated and so undesirable cultural 'others'. He presented himself, conversely, as having mastered the English language and accordingly assimilated into British society - and, therefore, as a worthy and deserving migrant, who could be punished less severely.

In Agnesa's hearing, the construction and negotiation of her as an asylum fraudster by the prosecution and defence was undoubtedly traceable - but it was also, as I have drawn out, quite subtle. As the judge delivered his sentencing remarks, however, his mobilisation of the racialised narrative of the abusive immigration cheat was very clear. He opened his narrative like this:

[Full name of defendant], remain seated while I tell you the reasons for your sentence. I don't think it is a very attractive argument to say the authorities should 
have arrested you in 2005. The fact of the matter is you deliberately disobeyed the limitations on entering this country and applying for asylum. You told the probation officer you came illegally from Albania in the back of a lorry to seek a better life - so you are an economic migrant, as it is sometimes termed. You said you were informed in Belgium that if you were a minor and your parents were dead, you were likely to be allowed to remain in the country. You said you couldn't speak English, you were unaware of the rules and regulations, so you followed their advice. But you are an intelligent person: you gave a false date of birth and said your parents were dead to be given more favourable treatment than you were entitled to. This has a knock-on effect on all people who don't lie and claim asylum.

In one sense, the judge delivered here a final, authoritative version of 'what happened' that affirmed Agnesa as punishable in legal terms. Thus, he specified her prohibited conduct and forbidden intent as he asserted towards the beginning of his narrative, 'you deliberately disobeyed the limitations on entering this country and applying for asylum'. Agnesa's legal punishability, and in particular her mens rea, was emphasised later, too, as the judge went on to insist that she was 'an intelligent person', who was fully aware that putting false details on her asylum claim would result in her receiving 'more favourable treatment'. At the same time, however, the judge was also rendering Agnesa punishable by essentialising her as 'bogus' and a cheat. He began to frame her in this way as he repeated the detail from the facts of the case about how she had entered the UK clandestinely, 'in the back of a lorry'. He then built on this suggestion as he identified Agnesa, specifically, as an 'economic migrant'. 'Economic migrant' is not, as I noted in Chapter Two, simply a technical description. Rather, as it has been associated repeatedly with the alleged abuse and exploitation of the UK's asylum system, it has also come to be - as Anderson has put it in relation to the term 'asylum 
seeker' - 'value laden and negative' (2013, p.4). As I argued in Chapter Two, in fact, as terms such as 'economic migrant' - as well as 'illegal immigrant' and 'foreign criminal' have been persistently tied to negative traits and inherent deviance, they might even be seen as connoting, on their own, racial undesirability and 'otherness'.

Indeed, the judge's deployment of 'economic migrant' in this way - not merely as a technical description, but also a moral judgement of Agnesa, to help convey her suspect nature - became clearer with what followed. As he proceeded to roundly dismiss Agnesa's professed lack of knowledge about the asylum system and to insist that she lied entirely knowingly, in order to secure an unfair advantage, he was partly, as I explained above, emphasising her legal punishability and in particular her mens rea. But the judge's description here also resonated with political and media depictions of asylum 'cheats' who arrive in the UK already knowing exactly how to dupe and 'play' the immigration system (Philo, Briant and Donald, 2013). By framing Agnesa like this, then, the judge suggested her as a skilled scammer, a natural and savvy manipulator of the asylum system - and, as he did this, the more 'value laden and negative', and indeed essentialising and racialising connotations of her as an 'economic migrant', seemed to come through. The judge's portrayal of Agnesa as a stereotypical fraudster was, finally, reinforced as he insisted that her actions in putting false details on her claim would have a 'knock-on effect on all people who don't lie and claim asylum'. In doing so, he reproduced a longstanding government assertion about the effects of asylum 'abuse' by fake claimants on 'genuine' applicants (Philo, Briant and Donald, 2013; Bloch and Schuster, 2002; Home Office, 1998). Consequently, Agnesa was depicted squarely and unambiguously through the dominant, racialised narrative of the abusive immigration cheat.

Now, in fact, the judge ultimately imposed the more lenient sanction that the defence had requested - a suspended prison sentence. We might ask why, therefore, did the judge present Agnesa as intrinsically problematic in this way? Once again, the answer lies, I would 
suggest, in the particular circumstances of her case. Although, at the start of his remarks, the judge dismissed the idea that Agnesa's presence in court was based on questionable charges, his depiction of her as deceptive and manipulative points to a recognition that her prosecution, so long after the discovery of the offence, was not entirely justified. As the judge delivered his narrative, then, he appeared to be working quite hard to justify the allocation of sanctions on her: his portrayal of Agnesa as inherently deviant and undesirable in herself seemed to be an attempt to insist that she was definitely legitimately punishable.

Conversely, in Tomás' hearing, the judge delivered a very brief and legally-focused final account which did not appeal to the racialised narrative of the abusive immigration cheat at all. After explaining that, according to previous cases in the Court of Appeal, the usual sentence for this type of offence, with a guilty plea, was six months' prison, the judge then set out that Tomás' possession of two false passports necessitated 'some uplift' - and, accordingly, he imposed a sentence of seven months' custody. The very different approach by the judge in this instance might, perhaps, be understood in terms of factors present in Tomás' hearing, but not Agnesa's, that protected against Tomás being framed in a racialised way. Notably, as I highlighted earlier, Tomás had worked to portray himself as a good migrant by insisting that he did not need an interpreter and by speaking English at the start of the proceedings; this was in clear contrast with Agnesa, who relied on an Albanian-speaking interpreter throughout her hearing. It seems possible, therefore, that Tomás' presentation of himself as culturally 'integrated', and not 'other' in terms of language proficiency, insulated him against a racialised depiction - that it influenced the judge's construction of Tomás during his sentencing remarks.

And yet, there were also potentially protective factors present in Agnesa's hearing that were absent from Tomás' sentencing. In particular, there was a clear difference in terms of their appearance. While both Agnesa and Tomás had lighter skin - I say more about the impact of visual and somatic difference on legal professionals' responses to defendants in the 
following section - Agnesa was smartly dressed, wearing a suit, whereas Tomás, who 'appeared' in court via videolink from prison, was more casually attired. Thus, he was wearing a fleece-type top over a worn-looking T-shirt. I highlighted in Chapter Two how, as Goldberg (2015) puts it, class standing mitigates and mediates the load of race. We might, therefore, have expected Agnesa's more polished appearance to have shielded her from a racialised portrayal, and Tomás' dishevelment, on the other hand, to have facilitated his stigmatisation as an undesirable 'other'. Yet, as we have seen, what happened, in fact, was the reverse of this.

I would suggest, then, that why Agnesa was depicted in a racialised way, and Tomás was not, might be better understood in terms of what the judge in each hearing was working to justify. As I have set out, in Agnesa's hearing there were real questions about why she was in court in the first place. The judge, therefore, rendered her as intrinsically problematic and deviant in herself to help navigate this - in order to insist that it was legitimate for her to be sanctioned. In Tomás' hearing, by contrast, no such questions about his prosecution were raised; and the judge also imposed what appeared to be a fairly uncontroversial sentence, in line with the guidance provided by previous cases heard in the Court of Appeal. Thus, there was no need, in this instance, to go beyond legal justification - and, as a result, the judge delivered a very different narrative in this hearing.

The evidence for the pattern that I am beginning to trace here, about when, in particular, racialised narratives of bordering tended to appear, and what sort of circumstances seemed to prompt their mobilisation by the prosecution, or the judge, in a hearing, becomes stronger as this chapter develops. As we will see, these racialised dominant depictions, and thus ideas of a defendant's inherent badness, were also appealed to during proceedings where a severe sanction was being pushed for by the prosecution or imposed by the judge. Resonating with Agnesa's hearing, therefore, they tended to be deployed in situations where it seemed that additional justification for the punishment was needed. In other words, they 
appeared to be mobilised in instances where legal legitimation, on its own, did not seem to be enough.

\section{Constructing and negotiating the defendant as an abusive immigration cheat in non-} immigration offence hearings: Joseph, Farid and Gloria

It is, perhaps, not that surprising that the narrative of the abusive immigration cheat came through in immigration offence hearings; or, at least, we might expect it to happen in these hearings more than in proceedings for non-immigration offences. But, in fact, I also saw this racialised narrative mobilised in hearings where the offence for which the defendant was being sanctioned had nothing to do with the border or enforcing immigration controls. In this section, therefore, I look at three further sentencing hearings: two for fraud offences and the other for a series of thefts. In these hearings, the defendant's involvement with the immigration system, and the idea of them as a fraudulent, cheating migrant or, conversely, as cooperative and non-violating, was 'lifted into visibility' (Kalunta-Crumpton, 1999, p.125) as part of the process of constructing and negotiating their punishability.

The first hearing I examine was for Joseph, originally from Uganda, who had pleaded guilty to fraud and some additional fraud-related offences: two counts of possession of articles for use in fraud and possession of a false identity document (Hearing 22, Isleworth, 2016). In this hearing, it did not actually become clear until later in the proceedings that Joseph had migrated to the UK. During the plea in mitigation, then, the defence barrister explained that Joseph had come here in 2004, to seek asylum, in order - unsuccessfully, as we will see - to secure some sympathy for him. Prior to this, however, the judge did not appear to be aware that Joseph was a migrant. This information may have been in the papers before him. As I explained in Chapter Four, it seemed from the observations I conducted that, by the sentencing hearing, there was sometimes information in the court papers that identified the defendant as a migrant, and which sometimes indicated which country they had migrated 
from, as well. From his preliminary exchanges with the prosecution, however, it seemed that the judge had not looked at these papers before the start of the hearing. Thus, just after the hearing got underway, the prosecution began to explain that Joseph had pleaded guilty in a plea and case management hearing a week earlier. At this point the judge, who was staring at his computer, exclaimed: 'In front of whom? I can't get access to this case!'2

It is worth noting, too, that no interpreter was used during this hearing. Aliverti and Seoighe explain that, during their research on the role of interpreters in the criminal courts, 'judges, probation officers, defense lawyers, and prosecutors pointed to the presence of interpreters as one of the strongest indications that the case involves a foreign national' (2017, p.135). Yet, although the judge did not find out about Joseph's migration history until later in the proceedings, it is important to recognise that, in contrast to the hearings explored above - which, as I highlighted, both involved defendants with lighter skin - as a black man Joseph was marked out racially from the start of the hearing. Indeed, throughout the first half of the hearing, before the information about him having come to the UK to seek asylum was introduced, Joseph's visible difference and physical embodiment of race through his skin colour appeared to be very much shaping the judge's reaction to him.

The prosecution opened the hearing with what appeared to be a very legally-focused facts of the case. Thus, he set out the prohibited conduct Joseph had engaged in, explaining that he had attempted to buy a designer watch from a shop in West London using a false bank card. When the shop supervisor became suspicious about the card and asked Joseph to return with identification, he did so the next day. This time, Joseph presented another false bank card and a fake French passport - at which point the police were called and he was arrested. The prosecution also pointed to Joseph's intent in committing the offence. So - after noting how, in his police interview, Joseph had explained that the plan to buy the watch had been

\footnotetext{
${ }^{2}$ Since the introduction of the Crown Court Digital Case System (DCS) most court papers are now accessed digitally. Two of the Crown Courts I observed in, Isleworth and Southwark, were 'early adopters' of this new system, from 2015; national rollout of the DCS took place from April 2016 (Legal Aid Agency, 2015).
} 
devised by someone else and he was simply carrying it out - the prosecution also emphasised that in the same interview, Joseph had admitted he knew what he was doing was wrong. The prosecution confirmed, therefore, that Joseph was punishable in legal terms; and, following this, he then asserted how punishable Joseph was.

Following the sentencing guideline for fraud offences (Sentencing Council, 2014) ${ }^{3}$ closely, the prosecution set out, first of all, Joseph's degree of intent in attempting to buy the watch - insisting that, as there was 'clearly some planning involved', Joseph's culpability should be placed at the highest level specified by the guideline, Level A. He subsequently moved onto the other element which determines how punishable, legally speaking, a defendant is, which I also highlighted in Chapter Three: the harm done or risked by the prohibited conduct. In the fraud guideline, harm is categorised in terms of 'the actual, intended or risked loss as may arise from the offence' (Sentencing Council, 2014, p.7). As the watch Joseph had attempted to buy was said to be worth $£ 5,400$, the prosecution placed Joseph's conduct in Category 4, which covers 'loss caused or intended' (Sentencing Council, 2014, p.7) of $£ 5,000$ to $£ 20,000$. However, the prosecution also acknowledged that the value of the watch meant that the offence only just qualified as Category 4. Thus, he indicated that, as a result, Joseph should probably be sentenced at the lower end of the range of possible sentences - which the guideline set out as between 26 weeks and three years' custody.

It was noticeable, therefore, that at this point, the judge interjected and insisted 'But he attempted to carry it through not once, but twice' - referring here, apparently, to how, after the first visit to the shop, Joseph had returned the following day and attempted to purchase the watch once again. In this way, against the prosecution's apparent suggestion that a prison sentence of a matter of months was appropriate, the judge seemed to be asserting that Joseph

\footnotetext{
${ }^{3}$ From $8^{\text {th }}$ November 2018 all of the Sentencing Council's Crown Court guidelines were made available in an online format, and the printed definitive guidelines were withdrawn (Sentencing Council, 2018). However, at the time that I was conducting my observations the printed guidelines were still in use - and, therefore, it is these that I reference.
} 
should be punished more severely. Earlier on during the prosecution's narrative, in fact, the judge had also challenged another comment which suggested that Joseph's offence might be treated as less serious. Noting that the passport Joseph had used during the second visit to the shop was definitely false, the prosecution added, 'though it wasn't particularly sophisticated'. The judge responded to this: 'Well, it was sophisticated enough for him to try to use it.'

These interjections by the judge continued as the defence barrister started to deliver his narrative. Thus, the defence began by picking up on the prosecution's assertion that there had been 'some planning involved' in the attempt to buy the watch, and by challenging the idea that this automatically meant Joseph's level of culpability was high. The defence insisted, instead, that any planning that had taken place had been carried out by the other person involved in the offence, to whom Joseph had referred during his police interview. The judge, however, resisted this attempt to minimise Joseph's involvement. He countered, therefore: 'But how many times did he go to the shop?'

Seemingly undeterred, the defence continued to set out that Joseph's culpability should not be viewed as high, as he then described exactly what the role of the other person who, it transpired during the hearing, was going to stand trial for his involvement at a later date - was. So, the defence explained that this other person had been responsible for 'all the planning and logistics' of the offence. He added, moreover, that following the first, unsuccessful attempt to buy the watch, Joseph had not wanted to go back to the shop and try again - but the other person, and some acquaintances of his, went to Joseph's home and 'pressured him into doing it. He didn't fear for his safety, but he knows of them and he felt under some pressure'. The defence noted, too, that Joseph had carried out his part in the attempted fraud 'for a relatively small payment, not the full $£ 5,400$ '. At this point, the judge made it clear that he had had enough of the attempts to reduce Joseph's culpability. He responded to the defence, in a dismissive tone of voice: 'This has been well thought out: you have the first card, then another card, and the false passport with a picture - it's been well 
organised'. The judge then added, 'You'll be interested to know your client is nodding in agreement.' $^{4}$

The judge's apparent hostility towards Joseph from the very beginning of the hearing might, of course, be explained in a number of ways. One explanation was offered by the defence barrister immediately following the hearing. Speaking to the prosecution, outside the courtroom, I heard him say, 'He's a harsh sentencer' - so, the defence appeared to be locating the judge's response to Joseph in terms of a general 'toughness' and to be suggesting that he always behaved like this. And yet, in a sentencing hearing immediately prior to Joseph's, for a white British ${ }^{5}$ man who had pleaded guilty to domestic burglary, the same judge had, at one point, actually behaved in quite a compassionate manner. During this hearing, the defendant kept putting up his hand as his barrister delivered the plea in mitigation. Eventually, the judge said to the defence, 'I think your client wants to give instructions.' At this point, the defendant explained, 'No, I don't; can I just say something, judge?' - and, in fact, the judge agreed, allowing the defendant to say a few words about his involvement in the offence before proceeding to sentence him.

This was in direct contrast with something that happened at the end of Joseph's hearing. Towards the end of the plea in mitigation, Joseph also attempted to get the attention of the court, by tapping on the glass screen of the dock several times. He was ignored by everyone, however, including the judge. Then, at the end of the judge's sentencing remarks, Joseph stood up and raised his hand - and, at this point, the judge acknowledged what he was

\footnotetext{
${ }^{4}$ I looked up at this point in the hearing, to see if what the judge was describing was happening. Joseph did not appear to be nodding - but, of course, he may have been doing so in the moments before I looked up at him. It is important to note, however, that even if Joseph did start nodding as the judge made his point, this does not necessarily mean that he was agreeing with what the judge was saying about his high level of culpability in committing the offence. It could have been, for instance, that he was agreeing that the attempt to buy the watch had been highly planned and well thought out - not by him, but by the other man involved in the offence, whom Joseph had told the police about and who was going to stand trial for his involvement. Whatever actually happened at this point, it is interesting to note the attention that the judge paid to Joseph here, when his reaction appeared to support what the judge was saying - and to contrast this with how Joseph was ignored and dismissed by the judge later in the hearing, as my analysis also documents.

${ }^{5} \mathrm{It}$ is, of course, only my assumption that he was British - because nothing was said about him having migrated to the UK during the hearing, and because he had a British (London, specifically) accent when he spoke.
} 
doing, but dismissed him immediately, saying: 'You can speak to your solicitor in the cells.'

Given the more sympathetic way that he treated the other, white defendant, I would suggest, then, that - rather than him simply being generally tough and a 'harsh sentencer' - there might be a different explanation for the judge's hostility towards Joseph. I would argue, therefore, that the antipathy the judge displayed towards Joseph during both the prosecution and defence's narratives, and his repeated insistence that Joseph should be punished more severely than either of them set out, should almost certainly be seen as shaped by racism. Thus, the judge's reaction to Joseph during the first half of the hearing clearly illustrates how - even as, as I documented in Chapter Two, contemporary articulations of race have become increasingly coded, and explicitly racist expression has become socially unacceptablesomatic difference remains central to racist discrimination and treatment.

The judge's racism during the first half of Joseph's hearing was not articulated openly, then, and his hostility was expressed solely in legal terms. As soon as the defence introduced the information about Joseph's migration history, however, and explained that Joseph had come to the UK to seek asylum, this immediately changed. As I suggested earlier, the defence mentioned this in an apparent attempt to secure some sympathy for his client. Somewhat predictably, though - given the judge's clearly unsympathetic response up to this point - it did not have the desired effect. Rather, as soon as this information was introduced, the judge reacted negatively to it. He started to disparage Joseph, therefore, and to portray him in a racialised way, as he began to insinuate that Joseph must be an abusive asylum cheat.

Thus, as the defence explained 'He is an asylum seeker', the judge instantly jumped in and demanded: 'From where?' The defence responded, 'He is originally from Uganda' - at which point the judge asked, incredulously: 'Why is he seeking asylum from Uganda? I've just been there.' The defence explained that Joseph's asylum claim was on the basis of his sexuality, adding 'his family has ostracised him completely because of it'. He then set out 
that Joseph had come to the UK and made his asylum claim back in 2004, but that he was still waiting for a decision from the Home Office and that because of his immigration status he could not work. So, the defence seemed to be trying to explain why Joseph had become involved with the offence. As the defence then highlighted, 'He is the sole carer for his brother, who has disabilities, the primary of which is arthritis', he worked to make Joseph less punishable in legal terms. Like all Sentencing Council guidelines, the fraud guideline specifies that being the 'sole or primary carer for dependent relatives' $(2014$, p.10) can reduce the sanction imposed. We see here, then, an example of a legally-codified mitigating factor that is not about the criminal act or the degree of culpability in carrying this out - but, rather, the defendant's personal circumstances and the possible impact of imprisonment on them and their family (Jacobson and Hough, 2011). The judge, however, completely ignored the point that the defence was trying to make. Instead, he continued with his insistence that Joseph, and indeed his family, must be fraudulent and abusive immigration cheats.

Responding to the defence's mention of Joseph's brother, therefore, the judge asked sceptically: 'His brother is from Uganda as well, he's also an asylum seeker?' The defence replied, 'He is from Uganda, I'm not sure if he's an asylum seeker'. He then attempted to get the plea in mitigation back on track by introducing information that evidenced Joseph's brother's disabilities and the fact that Joseph was his primary carer. So, the defence explained that Joseph's brother was in receipt of a disability-related benefit and that he was living with Joseph. The judge's reaction to this information, however, was obviously dismissive, as he simply responded, 'Uh huh'. The defence persisted with this legal factor one last time, as he then further explained, 'There is no other family member who could take care of his brother. His sister is in Birmingham ...'. Once more, though, the judge paid no attention to the point that the defence was trying to make. Rather, as soon as the defence mentioned Joseph's sister, the judge interrupted him to ask, sarcastically: 'She's also from Uganda, claiming political asylum?' 
What we see unfolding here, quite straightforwardly, is the racialised narrative of the abusive immigration cheat shaping the judge's reaction to Joseph. Thus, from the moment that the defence mentioned that Joseph was an asylum seeker, the judge's response was one of suspicion and disbelief. From this point on, moreover, the judge repeatedly suggested through the questions he asked and his tone of voice in asking them, as well his quasi-verbal utterances - that not only Joseph, but Joseph's brother and sister as well, must be deviant asylum fraudsters, duping and exploiting the UK's immigration system. Indeed, as the judge proceeded to his sentencing remarks, he continued to mobilise the idea of Joseph as an immigration fraudster in the narrative that he delivered. Initially, the judge began his version of 'what happened' in a legally-focused way, as he referred twice to the 'planning' and 'premeditation' involved in the attempt to buy the watch. In doing so, he rendered Joseph not simply as punishable in legal terms, but as particularly punishable, as he insisted - as he had throughout his earlier interactions with the prosecution and defence - on Joseph's high level of culpability. After this legally-oriented start to his narrative, however, the judge then appeared to construct Joseph as punishable in another way. Thus, after setting out the range of possible sentences specified by the fraud sentencing guideline, he added: 'The defendant, apparently, comes from Uganda. He has been in the country waiting for a determination of his nationality, and whether he can remain.'

The judge went on, entirely correctly, to dismiss this information as legally irrelevant, as he noted immediately after saying it, 'I needn't concern myself with that'. Yet, it is nonetheless the case that he introduced this information into his narrative. It is notable, too, that what the judge said about Joseph's immigration case was, in fact, completely inaccurate: it was clear from the plea in mitigation that there was no question about Joseph's country of origin or nationality at all. It seemed, therefore, that by drawing attention to Joseph's ongoing involvement with the immigration system, and by suggesting that Joseph's asserted nationality was in some way dubious, and yet to be confirmed by the authorities, the 
judge was intimating him as untrustworthy and a fraud. He appeared to be framing Joseph through the racialised narrative of the abusive immigration cheat, then, suggesting him as having a suspect and undesirable nature - in order to help produce him as punishable.

In my analysis of Agnesa's hearing, in the previous section, I suggested that she was constructed by the judge as an inherently duplicitous immigration cheat because there were questions about why she was in court at all. I argued, therefore, that more than legal legitimation was needed in order to justify imposing any sanctions on her. In Joseph's hearing, there also appeared to be specific reasons for the judge's mobilisation of this racialised narrative. Rather than reaching beyond legal legitimation and portraying Joseph as problematic in himself to validate punishing him in the first place, however, the judge seemed to be framing Joseph in this way to help authorise a severe sentence. As I highlighted earlier, the prosecution had indicated during the facts of the case that a prison sentence of just over 26 weeks would be appropriate for the offences to which Joseph had pleaded guilty. It is also worth noting that, during the mitigating plea, the defence pointed out that the written presentence report prepared by probation for Joseph's hearing had recommended a suspended prison sentence. Thus, as the judge sent Joseph to prison for one year and eight months, he appeared to be imposing an especially harsh sanction on him. This assessment, indeed, seems to be borne out by a subsequent judgment from the Court of Appeal. A few months later, Joseph's prison sentence was reduced by five months. ${ }^{6}$

The deployment of the narrative of the immigration cheat in Joseph's hearing, then, adds to the pattern that I began to trace in Agnesa's hearing, about the specificity and context that seemed to underpin the appeal to dominant, racialised narratives of bordering by prosecution barristers and judges. In a further five hearings that I examine across this chapter and the next, I provide additional evidence that these racialised narratives typically seemed to

\footnotetext{
${ }^{6}$ I do not include a reference for the Court of Appeal judgment here, in order to help preserve Joseph's anonymity.
} 
be mobilised by the prosecution, and/or the judge, when more justification, beyond legal reasons, appeared to be needed for the punishment pressed for or imposed. Alongside this, I also think that the way Joseph's hearing unfolded is significant because it particularly brings to our attention the coded nature of the racism of dominant narratives of bordering. Thus, the fact that there was no racial reference during the first half of Joseph's hearing, but then, upon learning that he had come to the UK to seek asylum, the judge openly stigmatised him as a fraudulent immigration cheat, reminds us of their sanitised and in fact 'post-racial' quality. The judge was entirely comfortable essentialising and pathologising Joseph in this way, I would suggest, because the narrative that he mobilised to do this is devoid of overtly racist expression - it does not bear 'the stain of the racial' (Goldberg, 2015, p.55).

What I saw in this hearing, indeed, appears to resonate with what Parmar (2018a, 2016a) witnessed during her research on the police and Operation Nexus. As I highlighted in Chapter Two, Parmar often heard police officers talking about groups of foreign nationals in essentialised and homogenised ways through the language of nationality. As she explains, they did this openly, without any apparent concern that they might be perceived as racist. By contrast, she notes that the police officers she observed demonstrated more restraint when speaking explicitly in terms of race. The judge's avoidance of any racial terminology in the first half of Joseph's hearing, therefore, but then enthusiastic disparaging of him as an asylum seeker when this possibility became available, appeared to parallel this.

Information about the defendant's involvement with the immigration system, and a portrayal of them as an abusive cheat or, conversely, as compliant and cooperating, came through in a further two non-immigration offence hearings that I saw. One of these was for Farid, originally from Algeria, who had pleaded guilty to 12 thefts, predominantly bags and laptops taken from people in public places (Hearing 23, Isleworth, 2016). In this hearing, Farid's immigration history was brought into view from the very start of the proceedings, by the prosecution. Thus, the prosecution barrister opened the facts of the case by saying: 'The 
defendant has a long history of offending for similar matters. He was eventually removed from the country, but he returned illegally, and committed this series of theft matters. He was committing the offences for a long period of time - from August 2014 to May 2016.'

Farid's immigration history was, in part, referred to here to help explain that he had a longer history of theft offences beyond those for which he was being sentenced during this hearing. Sentencing legislation sets out that recent and relevant convictions are an aggravating factor, which should result in defendants being sentenced more severely (Ashworth, 2015; Roberts, 2008) - and, later on, the prosecution specified exactly how many previous convictions for theft Farid had. At the same time, though, the inclusion of this immigration-related information was also doing more than this. By emphasising how Farid had previously been ejected from the UK, but had then 'returned illegally', without official permission, it seemed that the prosecution was tapping into the racialised narrative of the immigration cheat and insinuating Farid as an inherently problematic immigration 'abuser'. The prosecution not only specified Farid's criminal conduct in his opening narrative, therefore, but also appeared to be essentialising Farid as suspect in himself - in order, it seemed, to help justify the assertion made later in the facts of the case, that a fairly lengthy prison sentence was appropriate.

The defence, indeed, appeared to recognise and respond directly to the prosecution's depiction of his client as problematic in this way. So, at one point during the plea in mitigation the defence emphasised that, although Farid had returned to the UK illegally, he now 'actively wants to be deported back to Algeria, this is going to happen'. Using almost exactly the same formulation that Tomás' defence barrister deployed, then, the defence here distanced Farid from the prosecution's racialised framing of him as an exploitative immigration cheat - insisting that, despite his earlier infraction, he was now cooperating fully with immigration and assisting enthusiastically with his own expulsion. Thus, the defence asserted that Farid was not an intrinsically bad and manipulative immigration abuser, but that 
he had simply made some unfortunate mistakes - and, as a consequence, that it was possible to afford him some leniency.

As the judge delivered his sentencing remarks, he opened his version of 'what happened' not by giving an account of Farid's criminal conduct, the series of thefts to which he had pleaded guilty. Rather, the judge began his narrative by repeating the detail from the facts of the case, about how Farid had carried out these offences after returning illegally to the UK. Thus, he stated: 'Had you obeyed the orders that were made, you would not have come back to this country. You came back illegally, whether an order was made or not.' Here, then - just as the prosecution had - the judge appeared to be insinuating Farid as a stereotypical immigration abuser. As he drew attention to how Farid had re-entered the country without official permission, and in spite of his earlier expulsion, the judge seemed to be framing Farid through the racialised narrative of the immigration cheat - in order to depict him as suspect and undesirable in himself.This portrayal of Farid as inherently problematic appeared to emerge for a reason similar to that in Joseph's hearing, where, as I noted, the dominant narrative of the immigration cheat seemed to be tapped into by the judge to help justify the severe punishment that he imposed. As I have explained, then, in the facts of the case the prosecution had suggested that a fairly lengthy custodial term was appropriate for Farid. Specifically, the prosecution stated that the sentencing guideline for theft offences (Sentencing Council, 2015) pointed towards a prison sentence of between one and three and a half years The judge, however, passed a sentence well in excess of this range. Thus, he sent Farid to prison for four years and eight months. ${ }^{7}$

\footnotetext{
7 The severity of Farid's punishment becomes particularly apparent when it is considered that four years and eight months was the prison sentence imposed following a discount of a third for Farid's early guilty plea. The judge set out during his sentencing remarks that his starting point had actually been seven years in prison which is double the maximum sentence recommended by the theft sentencing guideline for Level A culpability, Category 2 harm offences, which during the hearing Farid's thefts had been agreed to be. It is important to acknowledge that the guideline also sets out that the sentence lengths it proposes are based on cases involving single thefts - and, of course, Farid was being sentenced for twelve offences. And yet, Farid's offending had been placed in Category 2 harm based on the estimated value of all the items he stole across the twelve separate offences; so, the fact that he had committed multiple thefts appeared already to have been taken into account in that way.
} 
Towards the end of his remarks, as he explicitly acknowledged that the sentence he was imposing was more punitive than what the guideline recommended, the judge actually referred to Farid's immigration history again. It was noticeable, however, that this time the judge did not appear to be deploying this information to stigmatise and racialise Farid. Rather, he attempted to utilise it in a quite different way. After explaining 'I am going to depart considerably from the guidelines', therefore, the judge referred to Farid's previous convictions as one factor justifying this. He also emphasised how Farid's offences were 'committed over a sustained period of time'; this is another aggravating factor listed by the theft guideline. Then, following this, the judge said: 'If I am right in saying an order was made preventing you from coming back - was it? I think it was, I hope it was - then you failed to comply with a court order from this country.'

Under the theft guideline - and, indeed, all guidelines issued by the Sentencing Council - 'failure to comply with current court orders' (Sentencing Council, 2015, p.7) is also specified as an aggravating factor. And yet, this refers to orders made by the criminal courts; the only 'order' that could have been made preventing Farid from returning to the UK would have been a deportation order, which is imposed by the Home Office. ${ }^{8}$ The judge, however, must have been aware of the possibility of an appeal against Farid's sentence, because the punishment that he imposed was much more severe than what the theft guideline recommended. ${ }^{9}$ Hence, at the point that he specifically listed the factors that he said justified the sanction he was passing, the judge attempted to turn his reference to Farid's immigration history into a legally relevant factor - that is, he tried to make it legally defensible. This was one of the instances, therefore, that I referred to in Chapter Three, where it seemed that -

\footnotetext{
${ }^{8}$ As I highlighted in Chapter One, the imposition of a deportation order means that the person concerned is banned from returning to the UK while the order is in force. As I also explained, the revocation of a deportation order is entirely at the discretion of the Home Office - and, therefore, such an order effectively constitutes an indefinite ban on re-entering the UK.

${ }^{9}$ I have conducted several online searches since this hearing to see if an appeal against Farid's sentence was ever lodged; I have not been able to find any evidence that one was.
} 
certainly towards the end of his narrative - the judge was particularly attuned to the 'external' audience of the Court of Appeal. I consider the other instance where this appeared to be the case towards the end of this section.

Farid was not actually present in court for his sentencing hearing, but appeared - just as Tomás had - via videolink from prison: the use of videolink for remanded defendants' appearances in court is increasingly common and happens at every stage, excluding trials, of proceedings (Gibbs, 2017). Research on the use of videolink for defendants' appearances in court has raised concerns about how it affects their already limited participation in proceedings, marginalising and disenfranchising them still further. I touch on this issue in more detail in the next chapter, as I consider defence barristers and defendants' practices of resistance. At this point, however, we might think about how the appearance of the defendant in court via a screen potentially links to their portrayal by legal professionals in a disparaging and racialised way. That is, it is worth considering how the use of videolink might enable the sort of narrative delivered by the prosecution, and the judge, in Farid's hearing, both of whom made him punishable in part by essentialising and stigmatising him as an abusive and exploitative immigration cheat. In her research on Operation Nexus, Parmar notes how, in police custody, the use of CCTV to monitor detainees in cells resulted in a 'sense of distance and disconnection between suspects and the police', and she describes how, at times, 'this allowed stereotypes and everyday racism to circulate' (2019, p.949). I would suggest that, in the context of the courts, the use of videolink might have a similar effect. In other words, the appearance of some defendants via videolink during court proceedings might contribute to their racialised representation by legal professionals - including the mobilisation of racialised narratives of bordering to aid the construction of 'unwanted' migrant defendants as punishable.

It is important to note, of course, that in some of the sentencing hearings I observed where the defendant was portrayed through a racialised narrative of bordering - Agnesa's, for 
instance, and also Joseph's - they were actually physically present in court. Conversely, as I have explained, Tomás had his hearing by videolink - and yet, as I set out in my earlier analysis, he was not depicted in a racialised manner by the prosecution or the judge during their narratives. My argument is not, however, that the use of videolink will automatically result in the problematisation and dehumanisation of the defendant. As I have drawn out, there are other factors at work: specifically, what the prosecution or the judge is working to justify in a hearing - whether more than legal legitimation is needed to validate, for example, the defendant's presence in court, or the imposition of a harsh sanction on them. What I am suggesting, rather, is that the use of videolink might facilitate racialisation. That is, in sentencing hearings for migrants originally from countries in the Global South or Southern and Eastern Europe, their appearance in court via a screen might encourage the appeal to racialised narratives of bordering; it might lubricate the cogs of legal professionals rendering them punishable in this way.

The final hearing that I look at in this section, for Gloria, who was originally from a country in Northwest or Central Africa, ${ }^{10}$ provides an interesting counterpoint to Joseph and Farid's hearings. Gloria had been convicted following a trial of a benefit fraud offence: namely, failing to notify a change in circumstances which affected her entitlement to Jobseeker's Allowance (Hearing 11, Isleworth, 2015). Given the nature of her offence, it might be assumed that the narrative of the parasitical scrounger, who takes advantage of the welfare benefits system and 'sponges off' the UK, was mobilised during this hearing. In fact, however, the judge, who seemed to have presided over Gloria's trial, as well, appeared very sympathetic towards her during the proceedings and imposed a lenient sentence - and he justified this by portraying Gloria in a positive way. Specifically, in his sentencing remarks he took the opposite approach to the judges in Joseph and Farid's hearings. While Joseph and

\footnotetext{
${ }^{10}$ Gloria's country of birth was not specified during the hearing. However, she was black and the judge went on to specify that she had been granted asylum in the UK. She also had a French-speaking interpreter for the hearing. Thus, it seems likely that she was originally from a country in Northwest or Central Africa.
} 
Farid had their harsh sanctions legitimated by emphasising their non-compliance with the immigration system, then, and insisting on them as abusive cheats, Gloria was constructed as relatively unpunishable by highlighting her positive immigration history and framing her through the narrative of limited inclusion of the 'genuine' refugee.

In his narrative, the judge placed Gloria's culpability for the offence of which she had been convicted as medium - so, what the fraud sentencing guideline (2014) refers to as Level B. The harm caused by the offence was deemed to be in the lowest category, Category 6 , because under $£ 2,500$ had been obtained: the amount that Gloria had been convicted of receiving by failing to notify her change in circumstances was a little over $£ 1,600$.

Consequently, the range of possible sentences specified by the guideline went from a Band A fine $^{11}$ to a 'medium level' (2014, p.29) community order - with a suggested starting point of a 'low level' community order for an offence where $£ 1,000$ had been obtained. Yet, the judge departed from the guideline and passed a more lenient sentence than was recommended.

Thus, Gloria was given one of the least punitive criminal sanctions available: a conditional discharge.

The judge justified this, in part, by emphasising Gloria's goodness in gendered terms. Similar to the defence in Agnesa's hearing, then, at one point the judge praised Gloria's apparent feminine conformity as he stated, 'You are an exceptionally good mother, and have provided exceptionally good leadership and guidance for your sons.' Before presenting her in this way, however, the judge also constructed Gloria as less punishable in herself by bringing her compliance with the UK's immigration system into view. Nothing had been said about Gloria's migration history by the prosecution or defence during their narratives. As I noted above, though, the judge appeared to have presided over Gloria's trial - so, it seems possible that the information he deployed may have surfaced during these earlier proceedings.

\footnotetext{
${ }^{11}$ Sentencing Council guidelines refer to three levels of fines: Bands A, B and C. Band A is the lowest level of fine: according to Sentencing Council (2021a) guidance, a Band A fine can range from $25 \%$ to $75 \%$ of a defendant's 'relevant weekly income', with a starting point of 50\%.
} 
Towards the beginning of his sentencing remarks, therefore, the judge stated: 'You came to this country 15 years ago with two young children, as an asylum seeker. You were granted asylum and became a British citizen, as are your sons.'

In one sense, the judge here appeared to be constructing Gloria as desirable, and thus less punishable, by adopting a strategy that, as we saw, was also deployed by the defence barrister in Agnesa's hearing. As he drew attention to how Gloria's asylum application had been successful, then, and how following this she had 'naturalised' as a British citizen, the judge was emphasising that, in legal terms, Gloria now belonged. At the same time, though, by highlighting, in particular, that Gloria had come to the UK 'as an asylum seeker', and by noting that her claim for protection had subsequently been approved by the immigration authorities, the judge also appeared to be doing something slightly different. Thus, he seemed to be mobilising the narrative of limited inclusion that I documented in Chapter Two which relates specifically to the narrative of the abusive immigration cheat: that of the 'genuine' refugee. As I explained in Chapter Two, against the allegedly widespread abuse of the immigration system by false asylum claimants, 'genuine' refugees are said to be conveniently small in number - and the UK, it is often asserted, has a 'proud history' of offering sanctuary to such desirable migrants (Kushner, 2003). By framing Gloria through this narrative of limited inclusion, therefore, the judge presented her as an intrinsically good and deserving person who, in committing her offence, had simply made a terrible mistake. Consequently, she was portrayed as worthy of the court's significant leniency.

As I have suggested, Gloria's hearing offers an interesting contrast to Joseph and Farid - and, indeed, Agnesa's - hearings, because the judge constructed her in the opposite way: not as an inherently bad and deviant migrant, then, but as naturally good and deserving. Yet, it is important to emphasise that what unfolded in Gloria's hearing nonetheless fits with and consolidates the pattern I have been tracing across this chapter, about when or in what sort of circumstances dominant ideas about 'unwanted' migrants tended to be deployed by 
the prosecution and/or the judge. As I have argued, racialised narratives of bordering seemed to be appealed to during proceedings when additional justification, beyond legal reasons, was needed to validate the punishment being pressed for or imposed. In Agnesa's hearing, therefore, as we have seen, the extra-legal justification of her as an abusive immigration cheat was mobilised to help overcome the questions about her prosecution in the first place, and whether she should be subject to criminal sanctioning so long after the commission of her offence. In Joseph and Farid's hearings, ideas about their inherently duplicitous natures were utilised alongside descriptions of their criminal conduct to help justify the especially harsh sentences that the judges handed down.

In Gloria's hearing, conversely, the judge reached beyond legal reasons and tapped into ideas about what sort of migrant she was not to help justify her prosecution, or authorise a harsh sanction - but, rather, to help validate a much more moderate punishment than the sentencing guideline recommended. Thus, the extra-legal justification of Gloria as a 'genuine' refugee was mobilised to help navigate the fact that, although she had been convicted of the offence, and the legal features of this pointed towards a certain range of sanctions, the judge deemed such punishments inappropriate for her case. It might be said, therefore, that in Agnesa, Joseph and Farid's hearings, racialised narratives of bordering were mobilised to add to and supplement the defendants' legal punishability. In Gloria's hearing, on the other hand, a narrative of limited inclusion was deployed to mitigate, and even counter, how legally punishable she was.

Across the final section of this chapter and in Chapter Six, I examine three further sentencing hearings where racialised narratives of bordering were tapped into by judges because it seemed that additional justification, beyond legal reasons, were needed for the punishments that they imposed. In two of these hearings, ideas of the defendant's intrinsic badness appeared to be mobilised for reasons similar to that in Joseph and Farid's hearings not to validate an especially harsh sentence, then, but to authorise sanctions that were 
nonetheless severe. In the other hearing, the judge seemed to be framing the defendant as inherently deviant for the same reason that Agnesa was - because there appeared to be questions about why the defendant was in court and being punished at all. Alongside this, though, there were also many hearings for 'unwanted' migrants that I observed during my fieldwork where racialised narratives of bordering were not tapped into by the prosecution or the judge. So, there were hearings such as Tomás', as well as most of the hearings that I explore in the final section of this chapter, where the defence countered narratives of bordering in their mitigating plea - but such narratives did not appear in the facts of the case or sentencing remarks. As I explained in Chapter Four, moreover, there were also nine hearings that I saw during my observations in which racialised narratives of bordering could not be detected during the proceedings at all.

As I suggested in the introduction to this chapter, however, it was generally the case that hearings where narratives of bordering were not detectable in the prosecution or judges' narratives tied in with the pattern I have traced, about the specific factors that seemed to prompt these racialised narratives' mobilisation. In most of these hearings, then, such specific factors were not present; that is, there appeared to be no real reason in these proceedings for the prosecution, or the judge, to reach beyond legal legitimation to help justify the punishment being pressed for or imposed. Thus, in all but three of these hearings, the sanctions pushed for and handed to the defendant were at the less severe end of the criminal punishment spectrum: non-custodial sanctions such as community orders and suspended sentence orders, therefore, as well as, on a few occasions, shorter prison sentences. ${ }^{12}$ Moreover, in all of the hearings where racialised narratives of bordering could not be detected in the facts of the case or the sentencing remarks, there was nothing obviously controversial or unusual about the punishment that the prosecution urged, or the judge

\footnotetext{
${ }^{12}$ I do not mean to suggest, of course, that these sanctions are not punitive; I fully recognise that community orders, suspended sentence orders and shorter prison sentences inflict pain on those who are subjected to them.
} 
passed. There were no hearings, for example, like Agnesa's, where there appeared to be doubts about whether the defendant should be in court and subject to criminal sanctions. Nor were there any hearings like Joseph and Farid's, where the judge appeared to impose an excessive sentence - or, indeed, like Gloria's, where the punishment handed down was much more lenient than recommended.

I noted above that in all but three of the hearings where racialised narratives of bordering could not be detected in the prosecution or judges' narratives, the sentences pushed for or imposed were at the less severe end of the criminal punishment spectrum. There were three hearings, then, where - although the sentence handed to the defendant was not obviously controversial or unusual - it was nonetheless more punitive than in the other proceedings. Thus, in these three hearings the defendants were given significant custodial terms. It might have been expected, therefore, that the judges would tap into racialised narratives of bordering during their sentencing remarks in these proceedings - in order to construct the defendants as inherently bad and deviant and so to help justify sanctioning them in a harsh way. Indeed, as I have indicated, I saw hearings where this did happen: where racialised ideas about 'unwanted' migrants were deployed by the judge not to help authorise a clearly excessive sentence, but to aid the legitimation of a punishment that was nonetheless severe. I explore the hearings where this unfolded in the final section of this chapter and in Chapter Six.

Hence, it might be argued that the three hearings I observed where a long prison sentence was passed, but no narrative of bordering was mobilised to help justify this sanction, disrupt the pattern of the specific circumstances in which the prosecution or judge tended to appeal to these racialised narratives. Yet, at the same time, it also appeared that in two of these hearings, there might be an explanation for the ostensibly anomalous way that they played out. That is, in these hearings, there seemed to be factors militating against the judges utilising ideas of the defendants' intrinsic badness, alongside legal reasons, to help validate 
the severe punishments that they imposed. One of these hearings, then, was for seven men five from Poland, one from Albania and one from the UK - who were being sentenced for drug-related offences, ranging from possession with intent to supply to importation (Hearing 10, Southwark, 2015). As I noted in Chapter Four, this was the longest sentencing hearing that I observed during my fieldwork, as it lasted for over two hours. This was also the hearing that I referred to in the same chapter, which was unusual compared with most of my observations, because the public gallery in the courtroom was packed. As such, it had a far less 'private' feel than most of the sentencing hearings that I watched.

The judge certainly seemed to be sensitive to the hearing's higher-than-normal degree of visibility - including its potential visibility to the 'external' audience of the Court of Appeal. Thus, unusually amongst the hearings that I observed, the judge left court following the prosecution and defence narratives, in order to prepare her sentencing remarks. During this break in proceedings, in fact, I heard one of the defence barristers tell a defendant's family member that the judge was taking this step, and writing her remarks down, because of the likelihood of appeal. When the judge returned to court, she sentenced the seven defendants to prison terms ranging from six to 20 years - and, as she did this, she appeared to be taking particular care to deliver an explicitly legalistic narrative, which relied heavily on the sentencing guideline for drug offences (Sentencing Council, 2012b). One explanation for the judge not tapping into narratives of bordering during her sentencing remarks, therefore, even though she imposed severe punishments on the defendants, was the hearing's possible visibility beyond the confines of the courtroom, and so the judge's apparent concern with ensuring that her narrative was legally defensible.

In the other hearing where a long prison sentence was passed, but no narrative of bordering was deployed to help justify this punishment, there seemed to be a different possible explanation as to why the judge did not reach beyond legal reasons and portray the defendant in a racialised way. This hearing was for Jakub, originally from Poland, who had 
been convicted of possession with intent to supply of Class A drugs (Hearing 21, Southwark, 2016). The judge imposed a custodial term of three and a half years on Jakub, which is of course a considerable sanction. Yet, as his culpability had been judged as 'significant', and the harm of his offence had been deemed to be Category 3, because he was apparently involved in 'street dealing' (Sentencing Council, 2012b, p.11), this was also the lowest possible sentence set out by the drugs sentencing guideline. The judge, indeed, seemed at pains to emphasise this in his sentencing remarks. At one point, therefore, he stated, 'This is the least sentence I can impose', before later adding, 'This, in all the circumstances, is the best that I can do'. The 'official' leniency of the long prison sentence that the judge passed, then - and his insistence, moreover, that it should be viewed like this - meant that there appeared to be little reason for him to construct Jakub as intrinsically bad, in order to add to or supplement his legal punishability.

I recognise, of course, that the explanations I have offered for why racialised narratives of bordering did not appear in these two hearings cannot be considered definitive. As I have also indicated, in fact, there was a third hearing where a severe punishment was imposed, but no narrative of bordering was mobilised by the judge. This hearing was for Olufemi, originally from Nigeria, who had been convicted of grievous bodily harm with intent and was sentenced to eight years in prison (Hearing 14, Isleworth, 2016). There did not appear to be any specific factors militating against the judge appealing to a racialised narrative of bordering in his sentencing remarks to help justify this long sentence. As such, Olufemi's hearing appeared to be an anomaly, and out of kilter with the overarching pattern that I have traced. Yet, despite this, it does seem significant that the majority of the hearings where narratives of bordering were not mobilised by the prosecution or the judge appeared to fit with the general pattern of these racialised narratives typically being tapped into for specific, contextual reasons. Thus, in most of the sentencing hearings where racialised ideas about 'unwanted' migrants did not surface in the facts of the case or the sentencing remarks, 
there did not seem to be a clear need for the prosecution or the judge to reach beyond legal legitimation in their narratives.

\section{The narrative of the parasitical scrounger in non-white and 'not quite white' migrant} sentencing hearings: Marek, and many others

In the final section of this chapter, I explore a series of sentencing hearings where the narrative of the parasitical scrounger came through. I have, of course, already looked at two hearings, Agnesa and Tomás', in which the defence barristers not only insisted that their clients were not immigration cheats, but emphasised they were not scroungers, too, to aid the portrayal of them as good, less punishable people. As we will see, the formulations that they deployed to do this played out across a number of other hearings; defence barristers, then, often countered their clients as inherently lazy freeloaders in very similar ways. In the first hearing I look at in this section, moreover, the pattern that I have documented across this chapter, of racialised narratives of bordering typically being deployed by prosecution barristers, or judges, for specific, contextual reasons, can also be traced. In this hearing, the judge appeared to essentialise the defendant as a deviant scrounger to help legitimise the imposition of a long prison sentence on him. Just as in Agnesa, Joseph and Farid's hearings, therefore, this seemed to be another instance where ideas of the defendant's intrinsic badness were mobilised in order to supplement his legal punishability - and so because justifying the significant punishment passed solely in legal terms did not appear to be doing enough.

And yet, alongside this, I also draw out a very different pattern as to when or in what sort of circumstances racialised narratives of bordering typically emerged in sentencing hearings for 'unwanted' migrants in this final section. Across a number of hearings that I saw, defence barristers distanced their client from the figure of the parasitical scrounger during the plea in mitigation - even though there was no obvious reason or prompt for their countering of this dominant narrative. Thus, there had been no suggestion during the hearing 
that the defendant might be seen like this, nor did the nature of the offence appear to motivate the defence's concern that their client might be viewed as problematic in this way. Against the pattern of narratives of bordering being mobilised by the prosecution, and/or the judge, for specific reasons, then, a very different routine came to light across these hearings. Contesting their clients as inherently parasitical scroungers seemed to simply run through these defence narratives - and so appeared to be emerging as a standard defence approach to constructing non-white and 'not quite white' migrant defendants as less punishable.

The first hearing that I look at was for Marek, originally from Poland, who had pleaded guilty to importing a Class A drug, specifically cocaine, into the UK (Hearing 8, Isleworth, 2015). As I indicated above, this hearing went on to resonate with some of the previous hearings that I have examined, as the judge seemed to frame Marek through a racialised narrative of bordering in his sentencing remarks to help justify a long prison sentence. At the beginning of the proceedings, however, Marek's hearing actually played out quite distinctly. The prosecution started his version of events in a very legally-oriented manner, firstly specifying Marek's prohibited conduct, that he had brought cocaine back to the UK from Peru, and then setting out the alleged harm of this conduct. According to the drugs sentencing guideline (Sentencing Council, 2012b), therefore, the weight of drugs that Marek had imported, 216g, placed his offence in a lower category of harm, Category 3. Following this, the prosecution moved onto Marek's degree of intent in committing the offence At this point, though, the prosecution did not refer to any of the factors listed in the sentencing guideline to support his contention that Marek's culpability should be seen as 'significant'. Rather, diverging from his earlier legal focus, he constructed Marek's elevated intent in another way. Thus, the prosecution told the judge: 'It's not as if he is from some third world country, and he's not aware of the rules. He is an EU national. He is aware of our laws and also the danger of going to Peru.' 
On the face of it, the prosecution's argument here was about Marek's assumed familiarity with UK law as an EU national; that is, that he must have been fully aware that what he was doing was illegal, and so should be assigned a significant level of culpability. But there was also a racialised element to the prosecution's assertion. As he emphasised, specifically, 'It's not as if he is from some third world country', the derogatory term that he deployed suggested an essentialised ignorance and backwardness to people from the Global South, against Marek's supposedly more advanced understanding as a European. In contrast with some of the previous hearings that I have looked at, then, the prosecution did not mobilise a racialised dominant depiction to demean and disparage Marek, and render him punishable in this way. Instead, in this instance, what happened was the exact opposite. Marek was positioned as superior to racial 'others' in order to argue for his obvious awareness of what he was doing in importing the drugs - and thus to insist that he should be treated with some severity. We see a clear example here, therefore, of how 'not quite white' migrants from Southern and Eastern Europe, though often racialised and stigmatised, can also be depicted quite differently. In other words, we see here how, as I explained in Chapter One, these migrants can at points be lifted out of their supposed racial undesirability, and elevated into whiteness (Anderson, 2013; Fox, Moroşanu and Szilassy, 2012).

Marek was not demeaned and racialised in the facts of the case, then. Yet, as the defence delivered the plea in mitigation, he seemed keen to emphasise that his client was not an intrinsically lazy freeloader, who had imported the drugs as a way of making money without having to do any 'real' work. Similar to Tomás' hearing, it appeared to be the nature of the offence that prompted the defence's concern that his client might be seen as deviant like this - specifically, the fact that, as was explained later on, Marek had been paid for bringing the drugs into the UK. Thus, as the defence began his mitigating narrative, he seemed to insist first of all that hard work ran through Marek's family, as he noted 'His mother is a librarian, his father is working'. The defence then drew attention to Marek's own 
industrious nature. He set out, therefore, that since arriving in the UK, Marek had been employed in construction - before explaining that, however, in recent months work had been quiet, and as a result Marek had fallen into debt.

At this point the judge asked 'How long has he been in the country?' The defence replied 'Three years' - and he then repeated the information about Marek's employment that he had just given, though this time with a slightly different inflection. So, he explained: 'He has worked for the bulk of his time here, paying taxes, but he is now desperate for money, there's not much work about.' Here, then - just as had also happened in Agnesa and Tomás' hearings - the defence framed Marek explicitly through the narrative of limited inclusion of 'hard work' and 'contribution'. Thus, in this way, he worked to emphasise that his client was not a naturally lazy sponger, who had turned to crime because he just could not be bothered to get a job. Rather, the defence insisted that Marek was a good and hard-working migrant, who had fallen on hard times and so who had been forced into behaving like this. - and, consequently, that he was worthy of the court's leniency.

Similar to Joseph's hearing, the judge in this hearing was quite vocal prior to delivering his sentencing remarks. In particular, as soon as the defence set out that Marek had committed the offence because work had become scarce and he was 'desperate for money', the judge began to ask a series of questions about this. As he did this, it became apparent that he simply did not believe that poverty was the real reason Marek had turned to importing drugs. Thus, the judge asked initially, 'Why wasn't he claiming benefits? Does he have a National Insurance number?' The defence responded, somewhat uncertainly, 'I think he didn't want to claim benefits' - before then trying to move on from this as he began to point to some of the legal factors reducing Marek's punishability. The judge, however, persisted with his line of enquiry, insisting that the defence should take instructions 'on why the defendant thought it was preferable to smuggle drugs rather than claim benefits'. After speaking with Marek, then, the defence returned to his position in court and explained to the 
judge, 'He says he wasn't really aware of how the benefits system works' - to which the judge replied, 'I find that difficult to accept, he's been here for three years.'

The defence did not really offer any response to this. Instead, he simply trailed off 'Yes ...', before turning, once more, to legal factors as a way of making Marek less punishable, emphasising that he had pleaded guilty at the earliest opportunity and that he had no previous convictions for this type of offence. Following this, the judge proceeded to sentence Marek. At this point, the idea that had been lurking behind his questions and interjections - that Marek had not smuggled the drugs because he was facing financial difficulties but, rather, because he was naturally grasping and greedy - was explicitly mobilised in his sentencing remarks, to help affirm Marek's punishability. Initially, the judge constructed Marek as sanctionable in legal terms, emphasising his intent and thus culpability as he asserted 'you left to collect the drugs with your eyes open'. Following this, however, the judge portrayed him in a more racialised way. Thus, he appeared to assign deviant golddigging tendencies to Marek as he said: 'I am told you were desperate for money, but having worked here for three years - you weren't aware of benefits? I don't accept this. The allure of drug smuggling money was more attractive to you than benefits.'

In Joseph and Farid's hearings, I suggested that the judges invoked racialised narratives of bordering, and thus appealed to ideas of the defendant's inherent badness, to help justify sanctions that were much harsher than the relevant sentencing guidelines recommended. This did not appear to be what was happening here. After setting out that Marek's culpability was between 'lesser' and 'significant', and confirming that the amount of cocaine involved placed the harm of his conduct, as the prosecution had suggested, in Category 3, the judge passed a sentence broadly in keeping with what the drug offences guideline advised. Yet - as I noted in my consideration of Jakub's case, in the previous section, in which the same length of custodial sentence was passed - the punishment imposed 
on Marek, of three and a half years' prison, ${ }^{13}$ was nonetheless considerable. The introduction of the drug offences guideline by the Sentencing Council, in 2012, saw a significant reduction in sentences for so-called drug 'mules' - those who are pressured or coerced into bringing drugs into the country (Sentencing Council, 2012a). For those who are not recognised as having been exploited, however, it is still the case that drug importation is punished more severely than many other criminal offences (Ashworth, 2015). The judge's invocation of the racialised narrative of the parasitical scrounger, therefore, seemed to reflect this. That is, as he rejected the idea of Marek as actually impoverished and framed him, instead, in terms of his money-grabbing propensities - as he insisted that Marek was, in fact, simply inherently grasping and greedy - the judge appeared to be working to justify the significant prison sentence that he imposed.

It also seemed that the judge's mobilisation of the racialised narrative of the parasitical scrounger might be doing something else in Marek's hearing. As we have seen, the direct practices of border enforcement were visible in some of the sentencing hearings for 'unwanted' migrants that I observed. Both Agnesa and Tomás, of course, were being sanctioned for immigration offences; in Tomás' hearing, moreover, it was highlighted by the defence that following his prison sentence Tomás would be removed from the UK - and, indeed, in Farid's hearing the defence emphasised this about his client as well. Yet, it was simultaneously the case that I saw very few hearings in which it was specified by the judge as they sentenced the defendant that, as a consequence of the criminal sanction they were imposing, deportation proceedings would be initiated. In both Joseph and Farid's hearings, then, the prison sentences passed meant that the threshold for automatic deportation was actually crossed - yet neither of the judges mentioned this in their sentencing remarks. In Marek's hearing, conversely, the judge did explicitly state that, because of the sentence he

\footnotetext{
${ }^{13}$ The judge's starting point for the sentence was, in fact, five years and three months, but this was reduced by a third because of Marek's early guilty plea.
} 
was handing out, the automatic deportation provision had been triggered - and so that Marek was facing expulsion from the UK.

After explaining this, the judge immediately added that any immigration action was, ultimately, a decision for the Home Office. This, then, was the hearing to which I referred in Chapter One, where the judge asserted, 'The sentence I have passed means that you are subject to the deportation provision of the UK Borders Act, but what actually happens is a matter for you and the immigration authorities ${ }^{14}$. And yet, in spite of the judge's insistence on the strict separation between criminal punishment and border enforcement, we might, nevertheless, understand his appeal to a racialised narrative of bordering in his sentencing remarks as working to depict Marek not simply as punishable - but also as deportable. That is, by portraying Marek as inherently undesirable and deviant, it might be seen that the judge was not only working to legitimise the imposition of a long prison sentence on him. The judge might also, in fact, be understood as tapping into ideas of Marek's suspect nature as a way of constructing him as deserving of permanent exclusion from the UK.

The insistence by Marek's barrister that his client was not an intrinsically lazy scrounger but, rather, that he was a good and hard-working migrant, was something that played out across a number of other hearings I observed. One of these was the hearing to which I referred to in the previous section, for seven men - five from Poland, one from Albania, and one from the UK - who were being sentenced for a range of drug-related offences, including, like Marek, importation (Hearing 10, Southwark, 2015). The importation aspect had allegedly involved some of the men hiding heroin, cocaine and cannabis in the spare tyres of lorries coming to the UK from Europe. In this hearing, the defence barrister for

\footnotetext{
${ }^{14}$ As I explained in Chapter One, EEA nationals are not actually subject to automatic deportation - so, what the judge stated in Marek's hearing was technically incorrect. Despite this inaccuracy, however, he was right to say that Marek was facing deportation as a result of the sentence imposed on him. As I also set out in Chapter One, from April 2009 Home Office policy was to consider deportation where an EEA national received one year or more in prison for a sexual, violent or drug-related offence, and in January 2014 this one-year threshold was broadened out and applied to all convictions. Thus, the sentence of three years and six months' prison that Marek received meant that he comfortably crossed the deportation threshold.
} 
one of the men, Lukasz, originally from Poland, appeared to be countering the narrative of the scrounger for the same reason as the defence in Marek's hearing; so, because of the nature of the offence. Resonating with Marek's hearing, therefore, Lukasz's barrister emphasised during his plea in mitigation that while his client had become involved with the operation as a way of making money, he was not a workshy gold-digger who had smuggled drugs because he could not be bothered to get a job. Rather, the defence insisted that Lukasz was an industrious and deserving migrant, who had fallen into financial difficulties and so had been forced into behaving in this way:

He has been in this country for eight to nine years, all along he has been working hard and diligently in a warehouse in Heathrow. But the costs of living in Slough were high, so he moved to Dover. Then he became unemployed and fell into hardship, and was having difficulty providing for his family, so he got involved with [name of another defendant, alleged organiser of the operation].

Alongside this, though, I also saw something different in this hearing. So, during the mitigating plea he delivered, the defence barrister for another of the defendants, Pawel, also from Poland, similarly emphasised that his client was not a lazy scrounger but, rather, was good and hard-working. Unlike Marek or Lukasz's barristers, however, he did not appear to be asserting this as a result of the nature of the offence committed; that is, because Pawel had also made money through his involvement with the operation. Rather, Pawel's barrister seemed to be raising it completely independently of this, simply to portray his client as a desirable and deserving migrant who, instead of sponging and taking advantage, had worked hard during the time he had been in the UK. Thus, he said of Pawel at one point: 'He came to the UK in 2005, he found work in the Crewe area, and he returned to Poland in 2008, having earned money and assisted with his parents' renovation of their property.' Here, the defence 
distanced Pawel from the spectre of the parasitical scrounger not only by emphasising his industrious nature, but by deploying, too, one of the formulations that we saw in Tomás' hearing. Thus, like Tomás' barrister, he drew attention to what Pawel had done with the money he earned in this country - emphasising how, rather than spending it all on himself to enjoy an 'easy' life, he had used it more altruistically and helped his family. In this way, Pawel's barrister depicted his client as the exact opposite of a selfish parasite, inverting the dominant narrative of the scrounger in order to de-stigmatise and de-racialise him.

The approach taken by Pawel's barrister in this hearing, of distancing his client from the figure of the parasitical scrounger not because of the offence for which he was being sentenced, but quite independently of this, simply as a matter of course, played out, in fact, across six more hearings. In four of these, defence barristers insisted that their client was not an inherently lazy freeloader in the same way as in the mitigating plea for Pawel. So, they emphasised not only that their client had been working hard in the UK, but also that they had been using their earnings entirely selflessly, to take care of their families. Thus, in a hearing for a man originally from Romania, Nicolae, who had pleaded guilty to non-domestic burglary - specifically, stealing some tools from a garden shed - the defence set out: 'He has been using his time here well, working and earning money. His parents in Romania are both blind, and he regularly sends money to them' (Hearing 5, Wood Green, 2015). Likewise, in the hearing for Suntaraj, originally from Sri Lanka, who had been convicted of an offence related to being drunk and disruptive on a flight back to the $\mathrm{UK},{ }^{15}$ the defence explained: 'His partner and unborn child are in Sri Lanka. He works five days a week to support them and sends them money, $£ 500$ per month’ (Hearing 7, Isleworth, 2015).

In a hearing I touched on briefly at the end of the previous section, for Olufemi, originally from Nigeria, who had been convicted of grievous bodily harm with intent, the

\footnotetext{
15 The exact offence for which Suntaraj had been convicted was not specified during this hearing. However, during the facts of the case the prosecution specified that he had been drunk during the flight, and had behaved in a 'disorderly' way, so it seems likely that the offence was in the area I have suggested.
} 
defence explained that prior to being remanded in prison he was 'someone who was very hard-working, working very long hours'. Moreover, it was highlighted, too, that Olufemi had been 'sending money back to Nigeria. He has an extended family there, and has been paying for their education. He was supporting seven family members' (Hearing 14, Isleworth, 2016). The fourth hearing in which this formulation was detectable was for a group of men originally from Lithuania, who had been convicted of handling stolen cars. In this hearing, two of the three defendants were portrayed by their barristers in this way. Thus, the defence for one of the men, Evaldas, said: 'He came to this country in 2010, he has worked almost all the time he has been here. His family is in Lithuania, he has essentially been supporting them.' Echoing this in the mitigating plea that he delivered, the barrister for another of the defendants, Gintaras, explained: 'He has been working in a variety of professions, earning $£ 200$ to $£ 300$ per week ... He has been striving to do better for himself while in this country, and for the family he is supporting in Lithuania, his daughter and granddaughter' (Hearing 13, Southwark, 2015).

Additionally, in two further hearings, defence barristers worked to distance their clients from the spectre of the scrounger as a matter of course via a slightly different approach: not by inverting this racialised narrative, then, but by mobilising related narratives of limited inclusion. So, in the hearing for Maryam, originally from Somalia, who had pleaded guilty to importing khat ${ }^{16}$ into the UK (Hearing 19, Isleworth, 2016), the defence insisted on her as a good and deserving migrant initially by drawing attention to how 'she has been resident in the country for the last twelve years'. As the defence then added, 'and she works as a carer', she appeared to allude subtly to the narrative of 'hard work' and 'contribution', too - an allusion the judge seemed to recognise as, imposing a suspended prison sentence, she noted during her sentencing remarks 'You perform a very valuable job'.

\footnotetext{
${ }^{16}$ Khat was banned and classified as an illegal Class C drug on $24^{\text {th }}$ June 2014 - just a few weeks before I began my court observations.
} 
In another hearing, for Asif, originally from Pakistan, who had been convicted of common assault $^{17}$ (Hearing 4, Wood Green, 2015), the other, even more selective narrative of limited inclusion that I documented in Chapter Two, that of 'the brightest and the best', was deployed to render him less punishable. So, after highlighting, as in Maryam's hearing, Asif's long residence in the UK, explaining 'He has an 18-year history in this country', the defence then added: 'He is not only law abiding, but a productive wealth creator.' Here, the classed dimensions of this narrative came through clearly. As Asif's barrister insisted on his client as a 'wealth creator', Asif's superior economic status was mobilised to lift him out of any perceived racial undesirability.

In the case of Maryam's and - even more clearly perhaps - Asif's hearings, the phrasing deployed by their barristers made it apparent that they were appealing to narratives of limited inclusion, in order to distance their clients from the figure of the parasitical scrounger. In the other hearings, however, where the formulation I have identified focused on the defendant as working hard in the UK and using the money that they earned to help their family members, the interpretation I have offered might, potentially, be questioned. Thus, it could be asked: is this formulation necessarily about inverting, and distancing the defendant from, the racialised narrative of the selfish migrant freeloader? Might it be possible to understand what the defence barristers were doing in these hearings in a different way? I highlighted in the previous chapter that, because there was no clear way of ascertaining prior to a hearing if it was relevant to my research, I ended up observing many sentencing hearings where it seemed that the defendant had not migrated to the UK. And, in fact, across these non-migrant hearings, I saw a number of pleas in mitigation where defence barristers

\footnotetext{
${ }^{17}$ As I highlighted in a footnote in Chapter Four, common assault is a summary offence and so is normally only dealt with and sentenced in the magistrates' courts. Technically, however, Asif's hearing was an appeal against his conviction and sentence - and, consequently, it was being heard in the Crown Court. Following the appeal section of the hearing, Asif's conviction was upheld and he was then re-sentenced. Thus, I consider this part of the proceedings as a sentencing hearing.
} 
constructed their clients as less punishable through formulations that seemed quite similar to what I observed in proceedings for non-white and 'not quite white' migrants.

Thus, I saw several non-migrant mitigating pleas where it was emphasised by the defence that their client was currently working. In one hearing, for example, the defence said, 'He went straight into work after leaving school', and in another, it was stated 'He is a man of some promise, he has continued working'. In a further hearing, the defence explained: 'He is working in a local shop, earning $£ 80$ per week ... He is a productive member of society.' I also saw non-migrant hearings where the defence drew attention to how their client was financially supporting, or trying to support, their family. In one hearing, for instance, the defence highlighted: 'He is a hard-working, family man ... If he passes the qualification he is currently undertaking, he will have a permanent job which he can utilise to support his girlfriend and daughters.' In these hearings, defence barristers' emphasis on their clients' working status seemed to be about portraying them as economically productive citizens, and thus about making them desirable and deserving in terms of class. Alongside this, references to how male defendants, in particular, were supporting their family members - about how they were acting as reliable providers and caretakers - worked to make them good in gendered terms (see also Gathings and Parrotta, 2013). We might ask, therefore: is it not the case that what I have documented in non-white and 'not quite white' migrant hearings was simply the same as this? That is, by emphasising that their clients were working hard in the UK and that they were using the money they earned to help their families, were not defence barristers in these hearings simply constructing defendants as good, and thus less punishable, through classed and gendered norms?

Indeed, I explained in Chapter Four that in four hearings for 'unwanted' migrants that I observed where I initially traced the narrative of the parasitical scrounger being countered by defence barristers, I ultimately decided that this was not the case. In three of these hearings, this was because it became clear that the defence's emphasis on how their client 
was earning money in the UK and using this to support family members was not being mobilised, primarily, to negate them as inherently deviant - but, rather, for more practical reasons. So, this information was deployed to persuade the judge not to send the defendant to prison, because it would mean he could not continue supporting his parents (Hearing 2, Wood Green, 2014); to argue for lower costs than had been requested by the prosecution (Hearing 9, Wood Green, 2015); and to explain how much the defendant could pay in compensation (Hearing 12, Isleworth, 2015). In the fourth hearing, however, although the defence undoubtedly highlighted that her client was employed and supporting his family financially to insist that he was not an undesirable person, I eventually concluded that the way she presented this information was not obviously different to the formulations I traced in nonmigrant hearings. The defence barrister stated of her client, then, who was originally from Poland: 'He has worked all his life as a painter and decorator. He wants to carry on supporting his daughter' (Hearing 3, Wood Green, 2014). This could, perhaps, be understood as an attempt to head off the racialised narrative of the lazy and selfish migrant freeloader. Yet, after several readings I felt less convinced, and it seemed more accurate to interpret it as the defendant being framed as an economically productive worker and reliable father - so, as deserving of leniency because of his classed and gendered conformity.

Ideas of classed and gendered conformity certainly ran through the formulation deployed by defence barristers in the mitigating pleas for Pawel, Nicolae, Suntaraj, Olufemi, Evaldas, Gintaras and, of course, Tomás, as it was emphasised that they had been working hard in the UK and using their earnings to support their family. And yet, in these hearings, the presentation of this information also had particular inflections and nuances, which indicated that the defence was specifically engaging with, and countering, the racialised figure of the lazy, selfish scrounger. In the first place, then, it was noticeable in these hearings that when defence barristers set out that their client had been working while they had been living in the UK, they rarely just stated this. Rather, they sometimes emphasised how their 
client had been working for most of their time since arriving in the country - for instance, 'He came to this country in 2010, he has worked almost all the time he has been here.' Or they explained how much their client had been working in the UK: 'He works five days a week', '[He was] working very long hours'. Or they introduced additional detail, and insisted on their client's particularly productive nature, in some other way - for example, 'He has been using his time here well', 'He has been striving to do better for himself while in this country'. Through these specific inflections and additions, therefore, defence barristers were directly addressing and dispelling the racist trope of their clients as inherently lazy and indolent. They presented them not simply as working, but in terms of an ongoing, relentless even, industriousness and activity - in order to insist that they were anything but naturally parasitical and dependent.

Alongside this, it was striking in these hearings that it was highlighted not only how male defendants were providing financial support to partners and children. It was foregrounded, too, when they were using their earnings to help their parents, for instance, and indeed other members of their family. In part, of course, the inclusion of this information simply reflected the realities of these defendants' lives, and the fact that many people - often men - who migrate to the UK from less economically well-off countries provide financial help to family members who have remained in their country of origin. And yet, the decision to specifically draw attention to this, to 'lif[t] into visibility' (Kalunta-Crumpton, 1999, p.125) how defendants were providing financial support to family members including those who are often not considered to be immediate dependants, is important. The focus on this by defence barristers was very much about insisting that their clients were not greedy, selfish parasites, who were only concerned with looking after themselves and enjoying an 'easy' life. The emphasis on the generous and altruistic way in which defendants were using their earnings, therefore, worked to invert, and so directly counter, this racist stereotype. 
Overall, the practice of defence barristers countering their clients as parasitical scroungers - either by inverting this racialised narrative, or by mobilising a related narrative of limited inclusion - unfolded across 11 of the sentencing hearings for 'unwanted' migrants that I saw, and could be traced in relation to 13 defendants. In seven of these hearings, and for eight defendants, there was no obvious prompt or reason for the defence insisting that their client should not be viewed as an inherently lazy freeloader. From this series of seven hearings, then, a consistent pattern of defence barristers working to distance their clients from the figure of the scrounger simply as a matter of course seemed to emerge. Thus, it appeared that adopting such an approach might be developing as a standard element of defence practice in non-white and 'not quite white' migrant sentencing hearings. That is, it seemed that heading off this racialised narrative might be becoming a staple, and specific way, of presenting 'unwanted' migrant defendants as intrinsically good people, who had simply made a mistake - and of insisting, therefore, that they could be punished less severely.

\section{Conclusion}

In this chapter, I have shown how two of the dominant, racialised narratives of bordering that I traced in Chapter Two, the narrative of the abusive immigration cheat, and that of the parasitical scrounger, could be detected in some of the sentencing hearings for 'unwanted' migrants that I observed. As I have demonstrated, these racialised narratives were being put to work in the specific context of sentencing proceedings to help construct, and negotiate, non-white and 'not quite white' migrant defendants' punishability. Thus, I have uncovered how these racialised narratives were mobilised and tapped into in order to constitute defendants as intrinsically undesirable and deviant, to portray them not simply as having done something problematic but as problematic in themselves - and, therefore, to help produce them as punishable. Conversely, I have also shown how these narratives were negotiated and negated in various ways, in order to contest defendants as inherently bad and deviant and 
depict them, in fact, as naturally good and deserving migrants - and, through this, to insist that they were worthy of the court's leniency. I have documented, too, how, at points, the narratives of limited inclusion I identified in Chapter Two were tapped into as well, as another way of rendering defendants as desirable in themselves, and so of portraying them as deserving of less punitive treatment.

Alongside the overarching pattern of how narratives of bordering were being put to work in sentencing hearings, moreover, I have documented some of the smaller patterns and routines that could be detected - including when, or in what sort of circumstances, these racialised narratives tended to be deployed. So, I have shown how racialised ideas about 'unwanted' migrants were often appealed to by the prosecution, or the judge, in specific contexts: for example, when a defendant's presence in court seemed to be based on questionable charges, or when a severe sanction was being pushed for or imposed. Thus, ideas of inherent deviance often seemed to be tapped into by the prosecution or judge on occasions when more than legal legitimation was needed - when a solely legal justification for criminal punishment did not appear to be enough. As I have explained, indeed, the hearings where dominant narratives of bordering were not traceable in prosecution and judges' narratives - including those hearings where these racialised narratives could not be detected at all during the proceedings - generally tied in with this pattern. In other words, the specific factors that seemed to especially prompt the mobilisation of racialised narratives of bordering by prosecution barristers, or judges, were largely not present in these hearings.

At the same time, however, as I have also documented, against the pattern of narratives of bordering being mobilised by the prosecution or judge in specific contexts, distancing the defendant from the figure of the parasitical scrounger seemed to simply run through some defence narratives. From the seven hearings where I observed this unfolding, therefore, a quite different pattern as to when or in what sort of circumstances racialised ideas about 'unwanted' migrants permeated sentencing proceedings seemed to emerge. In this 
series of hearings, the lack of an obvious prompt or reason for defence barristers heading off the narrative of the scrounger appeared to suggest that such an approach might be emerging as a standard feature of pleas in mitigation in non-white and 'not quite white' migrant sentencing proceedings. That is, it seemed from these hearings that insisting that the defendant is not an inherently lazy freeloader might be developing as a regular way of making 'unwanted' migrant defendants less punishable, and so pressing for them to be treated less severely.

It is important to emphasise, though, that even as defence barristers countered and contested the idea of their individual clients as inherently undesirable and deviant migrants, they did not work to question or challenge the framework of racialised narratives of bordering overall. Rather, the formulations that they deployed actually inadvertently reinforced this framework. So, as defence barristers framed their particular clients as good and deserving migrants, they implicitly upheld the 'problem' of intrinsically bad and undeserving migrants as legitimate - and insisted, therefore, that while the defendants they were representing should not be seen like this, abusive immigration cheats and freeloading scroungers undoubtedly exist. In identifying defence representatives' adherence to this racist framework, it is important to recognise that their reluctance to narrate outside of it and render their clients as less punishable in more resistant ways is, in part, a consequence of the institutional context within which they are operating. I explore this issue further in the chapter that follows. And yet, as I also explain in Chapter Six, during my fieldwork I did, in fact, observe a small number of sentencing hearings in which more disruptive behaviour was traceable. Thus, I saw three hearings where defence barristers, as well as defendants themselves, contested the mobilisation of racialised narratives of bordering through the use of more subversive and oppositional formulations. In my second empirical chapter, therefore, I turn my attention to the more radical tactics of these hearings, and focus on defence barristers and defendants' practices of resistance. 


\section{Chapter 6}

\section{Challenging Racialised Narratives of Bordering: Defence Barristers and Defendants' Practices of Resistance}

\section{Introduction}

In Chapter Five I documented how, as defence barristers contested the framing of defendants as abusive immigration cheats or parasitical scroungers, they typically did this by negating or inverting these racialised narratives, or by mobilising narratives of limited inclusion. Through this, they insisted that their clients were in fact good and deserving migrants - and so that they could be punished less severely. In doing so, as I argued in the chapter's conclusion, defence representatives implicitly upheld the legitimacy of the 'problem' of inherently bad and deviant migrants, and rearticulated the idea that - while their individual clients should not be seen in this way - immigration fraudsters and freeloading spongers definitely exist. Thus, through the formulations that they deployed, defence barristers adhered to and actually inadvertently reinforced the racist framework of narratives of bordering.

In this chapter, however, I trace something different. So, I highlight moments in three sentencing hearings that I observed where defence barristers, as well as defendants themselves, appeared to challenge the mobilisation of racialised narratives of bordering in more resistant ways. I recognise, as I set out in Chapter Four, the danger of over-reading and romanticising these moments, of over-assigning the possibilities for disruption in the courtroom, which is a highly regulated environment. As I explore them, then, it is very much within this context; I document how such practices of resistance transgressed, ultimately, in a limited way. Yet, despite this, it is still important to analyse them fully. Paying these moments of contestation proper attention is, as I also explained in Chapter Four, critical to a research practice of 'writing against othering' (Fine, 1994, p.75). That is, it is crucial to ensuring that I do not ignore and silence the 'uppity voices' (Fine, 1994, p.78) that emerged 
at points during sentencing hearings - and so, in the version of 'what happened' that I put forward, that I do not portray 'unwanted' migrant defendants as only ever stigmatised and abjectified.

In the first section of this chapter, I look at defence barristers' practices of resistance. In the existing literature, the practice of defence lawyers and barristers has usually been explored in terms of their adherence to courtroom norms and conventions. As I have indicated, indeed, my research bears this focus out, as the defence barristers I observed generally appeared to deliver their mitigating narratives in conformist and conventional ways. In two of the sentencing hearings that I saw, however, the defence barristers seemed at points to be taking a more oppositional approach, as they challenged the construction of their client through a racialised narrative of bordering more radically and subversively than I witnessed during other proceedings. As I explore these two hearings, then, I analyse how the defence's contestation of their client as inherently bad and deviant was more resistant, and I also draw out what effects their more questioning approach had on the proceedings. I consider, too, why such resistance might have emerged.

In the second section, I turn to defendants' resistance. As critics writing on the criminal courts have noted, though formally central to proceedings, defendants are practically marginalised throughout the court process: the most obvious marker of this during the sentencing hearing is that they are not allowed any opportunity to speak. In some of the hearings that I observed defendants did, despite this, attempt to say something and to insert themselves into the proceedings in this way, although they were typically silenced very quickly. Yet, there were other, more subtle forms of 'communicative expression' (Johnson, 2011, p.59) also deployed by defendants during hearings; sometimes, these seemed to convey resignation and acceptance - but at other points, they appeared to express resistance. By focusing on one hearing I saw, therefore, I show how the defendant, through his reactions and behaviour during the proceedings, almost seemed to be challenging legal professionals' 
portrayal of him through a racialised narrative of bordering. I demonstrate, moreover, how he appeared to be articulating that he was not an inherently deviant migrant in a more resistant manner; that is, how his reactions and behaviour during the hearing seemed to be invoking a much more complicated, and thus subversive, version of events.

\section{Telling subversive stories and refusing to accept racialised depictions: Defence barristers'}

\section{practices of resistance}

As I suggested above, research on the practice of defence lawyers and barristers has typically drawn out how they follow courtroom convention; the question of their possible resistance has, in fact, rarely been raised. Often, the conformist behaviour of defence representatives has been explained in terms of a straightforwardly positive view of them and their work. Thus, some studies emphasise how they operate tactically, within the range of practices that are deemed appropriate in court, simply in order to secure the best possible outcome for their client (Flower, 2018; Gathings and Parrotta, 2013). For other critics, however, the conventional practices of defence representatives are also generated in other ways. In their study of defence lawyers, McConville et al. argue that we also need to understand defence practices of mitigation in terms of, for example, their dependence on legal aid. So, there is a 'need to generate volume business and to turn cases around quickly so that other cases can be handled in the interests of achieving economic viability' (1994, p.201). Sticking to 'acceptable behaviour', then, might be seen as having a more practical aspect to it - as 'going through the motions' in order to get through as many cases as quickly as possible. McConville et al. highlight, too, that since defence representatives appear regularly in court, they also 'need to retain credibility with the court itself in order to continue as effective workers in the daily business of processing defendants' (1994, p.201). Behaving as expected, and not 'rocking the boat', therefore, might also be seen as a matter of professional survival and career prospects. 
My research, to a significant extent, bears out the emphasis on defence representatives' conformity in the existing literature. And yet, in a couple of the hearings that I observed, I did witness some more subversive behaviour by defence barristers, as they challenged the depiction of their clients through racialised narratives of bordering. In the first hearing that I look at, the defence negotiated the idea of his client as an inherently lazy and selfish scrounger in all the usual ways that we saw in the previous chapter. Alongside this, though, at one point the defence also contested this racialised depiction of his client not simply by constructing him, conversely, as hard-working and deserving - but, in fact, by going outside the framework of the good/bad migrant altogether and by looking beyond ideas of individual deficiency or desirability. In the second hearing that I explore, the defence countered the depiction of his client through a racialised narrative of bordering in conventional terms, by inverting it. Yet he also did this forcefully and repeatedly, pushing back against the judge's insistence that his client was intrinsically deviant in a way that I simply did not see in other hearings. As a result, his approach felt very different to the negotiations by defence barristers that I documented in the previous chapter. The type of resistance displayed by the defence representatives in each of these hearings was different, therefore - yet both approaches, as we will see, had the clear effect of destabilising the process of punishing the defendants.

\section{Narrating outside the framework of racialised narratives of bordering: Tamir's hearing}

The first hearing that I explore was for Tamir, originally from Palestine (Hearing 24, Isleworth, 2016). Similar to Joseph, whose case I explored in the previous chapter, Tamir had pleaded guilty to possession of articles for use in fraud - specifically, 13 false bank cards in someone else's name - and possession of a false identity document. Unlike Joseph, however, Tamir had not also been charged with actually attempting fraud with these items. Opening the hearing with the facts of the case, the prosecution barrister delivered a typically concise 
version of events that rendered Tamir punishable, of course, in legal terms. The prosecution's narrative about 'what happened' unfolded in the following way:

Prosecution:

The circumstances are that the defendant was seen at Next in Westfield Shopping Centre. He was recognised by a member of staff as someone who had frequented the store previously and used fraudulent cards to make purchases.

\section{Judge:}

But there were no charges, so I mustn't take this into account?

\section{Prosecution:}

No, there were no charges. The police were called, the officers spoke to him and asked him if he had anything that he shouldn't have. He told the police he had fake cards, he was searched and found in possession of the bank cards, and also a Belgian ID card. He has pleaded guilty to all of these matters today.

He was interviewed by the police, he admitted the ID card was fake and that he had made it because he had no other form of ID. In terms of the bank cards, he said someone gave them to him, he said he was aware of their illegality but he needed the money. He referred to a man he had met in a coffee shop, Ali; he said he would buy things on Ali's behalf and would be given around $£ 150$ to $£ 200$ for these purchases. He accepts that what he has done is wrong.

We can see here how the prosecution specified Tamir's prohibited conduct as she explained that the police had searched him and found the bank cards and fake ID on him. She 
pointed to his clear intent, too, as she described how during his police interview Tamir had confirmed that he was 'aware of [the] illegality' of the bank cards, and had acknowledged that what he had done was wrong. On the face of it, then, the prosecution's account appeared to be straightforwardly legalistic. Yet, it was noticeable that the prosecution also included some additional details, that did not appear to be strictly relevant to the specific offences for which Tamir was being sentenced. Thus, the prosecution highlighted at the start of her narrative that the police had been called to the shopping centre by a shop worker there, who had recognised Tamir 'as someone who had frequented the store previously and used fraudulent cards to make purchases'. This partly functioned to explain why Tamir had been approached and searched by the police in the first place. But it also brought into view how Tamir had apparently been using the fake bank cards in his possession to actually commit fraud - despite the fact, as I explained above, that he was not being sentenced for this. As the prosecution then included the detail from Tamir's police interview about the man, Ali, he said he had met, for whom he would buy items in return for cash, it was not only re-asserted that Tamir had been committing fraud with the cards. It was also implied, in fact, that Tamir had been making fraudulent purchases regularly, over a sustained period of time. Alongside this, it was interesting, moreover, that the prosecution included a further detail from Tamir's police interview, his explanation that he got hold of the fake bank cards in the first place because 'he needed the money'. Yet, having asserted this, the prosecution did not then go on to say anything more about this, or elaborate on why Tamir had said that this was the case.

What I am tracing here is less tangible than, for instance, what I documented in Agnesa's hearing, in the previous chapter, where the prosecution barrister mobilised legally irrelevant details in his opening account to frame Agnesa through the racialised narrative of the abusive immigration cheat. And yet, as the prosecution in Tamir's hearing portrayed Tamir as repeatedly using the fake bank cards found on him to commit fraud, apparently in order to generate an income, there nonetheless seemed to be a suggestion of a racialised 
narrative of bordering. Specifically, the prosecution appeared to be hinting at Tamir as a lazy foreign scrounger, who had turned to crime as an 'easy' way of making money. The defence certainly seemed to be worried that his client might be perceived like this. He may, then, have been picking up on the prosecution's insinuations - although it seems possible too that, as in Marek's hearing, which I also explored in Chapter Five, the money-related nature of the offence prompted the defence's concern. As the defence began the plea in mitigation, therefore, he immediately worked to emphasise that Tamir was not a workshy freeloader, who used false bank cards because he just could not be bothered to get a job. Rather, the defence insisted that his client was actually a good and hard-working migrant, who had been forced into behaving in this way. The defence began his version of 'what happened' like this:

This type of offence is often committed by a man in his current situation. He is Palestinian, he was living in Lebanon; he came to the UK in the hope of a new life, potentially via some sort of asylum application. He met and married a Czech national, they have been married for three years; he does have a work permit ${ }^{1}$ but, by some sort of lacuna, he doesn't have a National Insurance number, this is to do with restricting access to benefits - quite reasonably, of course, for people new to the country. This is the background to how he is in this predicament. His mother is in Lebanon, she suffers from significant ill health and has significant medical bills. He tries to help her pay, and this drew him into criminality.

\footnotetext{
${ }^{1}$ Citizens of the Czech Republic are EEA nationals - and, therefore, by marrying a Czech national Tamir would have acquired rights of residence in the UK. He would have also acquired the right to work, as the defence barrister indicated - although it is not the case, as the barrister suggested, that a specific 'work permit' would have been issued. Rather, as the family member of an EEA national Tamir would have been issued with a residence permit, on which it would have been indicated that he had permission to work in the UK (Home Office, 2015a).
} 
In one sense, the defence was working here to make Tamir less punishable in legal terms. Thus, as he documented the broader circumstances of Tamir's life, he seemed to be pointing to his client's reduced level of choice, and so lesser intent, in committing the offence. The defence attempted to reduce Tamir's culpability through this, though, in a careful way, without violating the norms of the criminal law. So, as he referred to the impossible situation in which Tamir had found himself as, somewhat understatedly, 'the background to how he is in this predicament', the defence avoided the suggestion that his client did not have any choice in how he had behaved. In other words, the defence worked to ensure that the judge did not think he was suggesting Tamir was not ultimately individually responsible or accountable for his wrongful actions. I saw this type of approach in several of the non-migrant sentencing hearings that I observed, as well. Defence barristers, then, sometimes alluded to the social disadvantage defendants had experienced, to help explain the limited choices before them and so to point towards a reduced level of mens rea. Yet, they typically introduced this information very cautiously, presenting factors such as poverty, for instance, as the 'background' or 'context' to the offences for which their clients were being sentenced, in order to avoid the suggestion that the defendant did not have any choice at all. ${ }^{2}$

At the same time, however, as Tamir's barrister narrated 'what happened' in this way, he was also making Tamir less punishable by insisting that he was not an inherently lazy scrounger, using tactics similar to those deployed by defence representatives in the hearings that I explored in the previous chapter. Hence, the defence set out first of all that, while Tamir had the right to work in the UK, he had been prevented from actually doing this by an administrative loophole, related to restricting access to the welfare benefits system for newly-

\footnotetext{
${ }^{2}$ In one of the non-migrant hearings that I observed the defence barrister did not introduce information about the social disadvantage and hardship that her client had faced in this more careful way. Rather, she presented it very clearly as having significantly constrained the choices available to him; thus, her presentation was more in line with Barbara Hudson's (1999) idea of a 'hardship defence'. The judge, predictably perhaps, reacted badly to this. In her sentencing remarks, she dismissed the attempt to minimise the defendant's culpability in this way as the defence putting forward 'a pathetic excuse'.
} 
arrived migrants. Similar to in Marek's hearing, then, the defence emphasised that Tamir's lack of employment - which had resulted in him using the fake bank cards - was not his own fault. As the defence relayed this information, moreover, it was noticeable how he quickly added that, despite the adverse impact of the loophole in Tamir's case, he was not suggesting that immigration-related restrictions on benefits should not be in place. He made it clear to the judge, therefore, that neither he nor his client were saying that migrants should be able to come to the UK and instantly claim any benefit they want. Thus, the defence continued to emphasise Tamir as a hard-working migrant, who would never take advantage in this way.

As he also drew attention to what Tamir had been doing with any cash he made from using the bank cards, the defence deployed a formulation that we saw in a number of the hearings in the previous chapter. He highlighted, then that - rather than spending it all on himself, in order to enjoy an 'easy' life - Tamir had been sending any money that he had obtained to his mother in Lebanon, to help her pay her medical bills. Through this detail, the defence depicted his client as the exact opposite of an inherently greedy and selfish sponger. He reinforced his 'good migrant' portrayal, therefore - and, consequently, Tamir was presented as less punishable than the prosecution had suggested, and as a deserving recipient of the court's leniency.

The defence continued to insist that his client was not a scamming scrounger as he then emphasised Tamir's 'sheer transparency' in his dealings with the police. He evidenced this 'transparency' by explaining that, when the police approached Tamir initially and asked if he was in possession of anything illegal, 'he said the bank cards were in his pocket and the false ID was on him'. At this point, however, the judge - who was, in fact, the same judge who had presided over Farid's hearing - interjected, and started to push back against how Tamir was being portrayed. Thus the judge insisted, first of all, against the defence's assertion of Tamir's 'sheer transparency' by telling the police about the items he had on him: 'I don't want to sound curmudgeonly, but he had to tell them, didn't he? Otherwise he would 
have been searched and they would have been discovered anyway.' The defence did not reply to this directly, but instead continued to emphasise Tamir's honesty, setting out how he had also made 'full admissions' in his subsequent interview with the police. The judge then interjected again, noting that Tamir did not have any previous convictions, and also stating that he would get 'full credit for his guilty pleas' - before adding, 'though it is a mercy he pleaded guilty given the state of the evidence'. Once more, therefore, the judge appeared to be contesting the defence's assertion of Tamir's non-fraudulence and honesty, as he insinuated that entering a guilty plea was, in fact, the only option that was realistically available to him.

The defence immediately responded: 'But it is right to mention his concern about sending money home and his frustration at not earning money in one of the most affluent countries in the world.' As he emphasised again that Tamir had been using the money that he had obtained from the use of the bank cards to help his mother, the defence re-asserted him as the direct opposite of a selfish, greedy gold-digger. Against the judge's insinuations, then, the defence insisted that his client was a good and deserving person - that Tamir's wrongdoing was not reflective of a deviant or undesirable nature, but simply a terrible mistake. Following this, however, the defence started to do something quite different. As he highlighted Tamir's 'frustration at not earning money in one of the most affluent countries in the world', he appeared to move beyond the framework of inherently deviant parasites versus hard-working migrants altogether - so, beyond ideas of individual deficiency and desirability. Instead, the defence seemed to be to pointing towards the unjust structural conditions that had resulted in his client's current situation.

Thus, through this intervention, the defence gestured again to the immigration-related restrictions that had stopped Tamir from accessing employment. Yet, this time, he did not downplay them by insisting that such measures are, in fact, perfectly reasonable. Rather, he alluded more clearly to their problematic nature as he noted Tamir's 'frustration' at being 
prevented from earning money in the UK. As the defence also emphasised the UK's status as 'one of the most affluent countries in the world', he drew attention, moreover, to the vast wealth disparity between the Global North and South. Consequently, he signalled towards the very real poverty and economic inequity from which Tamir had migrated - an economic inequity which, as I explained in Chapter Two, the racialised narrative of 'unwanted' migrants as innately greedy and grasping serves to obscure. In this way, therefore, the defence seemed to underline the injustice of his client's situation still further. That is, as he pointed towards Tamir's clear economic disadvantage, he appeared to more obviously question the immigration-related restrictions to which Tamir had been subjected since arriving in the UK.

Hence, as the defence foregrounded the political and economic conditions that had forced his client into criminal activity, he started to shift away from a narrative that was accepting of Tamir as sanctionable, himself, for the offence, and which was working simply to make his punishment less severe. Rather, the defence seemed to be moving towards an account that was disrupting and unsettling Tamir's individual responsibility for 'what happened' - and so which appeared to be questioning the fairness and legitimacy of his criminalisation, and subjection to punishment, at all. The approach by the defence at this point, therefore, clearly underlines the dependence of the criminal justice system on the doctrine of individual responsibility and accountability. This doctrine is enshrined in the criminal process, of course, through the 'essential building block' (McConville, Sanders and Leng, 1991, p.65) of mens rea and so the focus on defendants' autonomous choice and intention $-\mathrm{a}$ focus that Alan Norrie identifies as the criminal law's 'repressive individualism ... which obscures the social realities beneath the legal appearances' (2014, p.29). As we have seen throughout this thesis, moreover, individual responsibility is also insisted upon via social categorisations such as gender and race - and, in the sentencing hearings that I have explored, through racialised ideas about 'unwanted' migrants which characterise defendants 
as innately, and so individually, either good or bad. Tamir's barrister reached outside of this simplified framework, then, and uncovered problematic social conditions that racialised narratives of bordering function to conceal and silence. In doing so, he delivered a more complex and multi-dimensional version of events - which started to destabilise and undercut the practice of his client's punishment.

This intervention by Tamir's barrister was the most radical display of resistance by a defence representative that I saw across the hearings for non-white and 'not quite white' migrant defendants observed during my fieldwork. I did not see any other defence barristers narrate beyond the idea of individually good and bad migrants, and visibilise and problematise structural conditions, in this way. The defence appeared to continue with this more resistant approach, indeed, as he then highlighted to the judge that - apart from a short conversation immediately prior to the hearing - Tamir had not spoken with his legal representatives at all during the two months he had been remanded in prison. This, apparently, had been because of problems with booking an interpreter to assist with a legal visit. Consequently, the uneasy space that had already opened up in the hearing, as a result of the defence's questioning of Tamir's individual responsibility for his offence, seemed to extend a little wider. That is, the process of punishing Tamir started to move even less assuredly, as the defence unsettled not only the legitimacy of his client's presence in court in the first place - but also drew attention to the distinct lack of due process that he had experienced following his arrest.

The judge certainly seemed to sense the destabilisation of the hearing at this point, and acted quickly to minimise this disruption. Unsurprisingly, perhaps, he did not respond directly to the defence's point about Tamir's 'frustration at not earning money in one of the most affluent countries in the world'. He did, however, address the fact that Tamir had not received any legal advice prior to the hearing. Thus, he initially expressed concern by saying 'That is unsettling, I have real sympathy for him' - before then working to step past this and 
keep the process of punishment moving as he told the defence, 'but your care today will have compensated for this'. The judge's efforts seemed to be effective. So, following this response, the defence did not persist any further with the issues that he had just raised, but instead turned to the sentencing guideline for fraud and began to suggest where Tamir's offence should be placed in relation to this. The defence dropped his more resistant stance at this point, therefore, and returned to the conventional defence practice of negotiating and lessening his client's punishability.

Following this, the judge moved straight into his sentencing remarks, justifying the 18-month prison term he imposed on Tamir with a brief and entirely legally-focused account. An optimistic reading of this narrative might be that the defence's insistence that his client was not an inherently deviant scrounger had made an impression on the judge. That is, the judge delivered a version of events that did not portray Tamir in a racialised way because of what the defence had said previously - including, perhaps, the attention the defence had drawn to the structural conditions that had forced Tamir into criminal activity. Yet, it also seems possible that the judge did not go beyond legal justification because this simply was not needed. The sanction that the judge imposed, then, was broadly in line with what the sentencing guideline recommended - and, moreover, while 18 months is by no means an insignificant prison term, it is perhaps short enough to be seen as not that severe, either. Hence, in keeping with the pattern that I traced across Chapter Five, as to when racialised narratives of bordering were typically mobilised by judges, it seems possible that the sentence passed meant there was no pressing reason to construct Tamir as inherently deviant - and so to supplement his legal punishability.

The more subversive behaviour by Tamir's barrister in this hearing, therefore, seemed only to cause a momentary disruption - a minor destabilisation that the judge was able to smooth over and move past quickly. And yet, it is interesting to note something that happened shortly after the judge had finished delivering his sentencing remarks, which might 
be read as indicating that the defence's resistance actually had a more significant effect. Just as Tamir's hearing came to an end, and the barristers involved in the next hearing started to move into place, the judge looked at me and said: 'There is a lady in the public gallery taking notes. Can you tell us who you are?' I explained that I was a PhD student, researching sentencing hearings; the judge responded by checking that I would be ensuring the anonymity of everyone involved in the hearings I observed when I wrote up my research. I confirmed that I would. The judge then said: 'There is no prohibition on taking notes in court, as you know, but I like to know who is in court.' He asked me one further question, what institution I was studying at, before then moving onto the business of presiding over the next hearing.

I explained in Chapter Four that, although I generally moved around the courts in which I conducted observations with relative ease, I was at points treated with suspicion by some court staff. Within the range of suspicious responses directed towards me, however, being asked who I was, in open court, by the judge, was unusual: this was the only time that this happened to me during my two-year period of observations. It is worth emphasising, too, that I had actually observed this judge previously, on two separate occasions - and yet he did not ask me on either of these occasions who I was. It could be, of course, that Tamir's hearing was the first time that he had noticed me and saw that I was taking notes. On one of the previous occasions that I had observed this judge, though, I had specifically written in my fieldnotes how visible I had felt during the hearings I watched. This was because the courtroom that he worked in was quite small, and there had only been two other people sat alongside me in the public gallery, which was close to the judge's bench. It seems unlikely, therefore, that the judge would not have noticed me, and what I was doing, on this occasion. Why, then, did he only ask me who I was following Tamir's hearing?

I highlighted earlier that the judge who sentenced Tamir had also presided over Farid's hearing; in fact, Tamir was sentenced on the same day, immediately after Farid. Thus, it seems possible that it was the harsh sentence imposed in Farid's hearing - as I explained in 
the previous chapter, it was well outside what the sentencing guideline recommended - that prompted the judge's concern about who I was and why I was taking notes in court. But it also seems possible that the more resistant approach adopted by Tamir's barrister actually had a more significant effect than it first appeared from the relatively effortless way that the judge seemed to move past the issues raised by the defence during the proceedings. In other words, during the hearing, the judge ignored the suggestion that Tamir's criminalisation was questionable, and also glossed over the lack of due process that he had experienced following his arrest. Yet, the defence's problematisation of Tamir's treatment was nonetheless the reason for the judge's anxiety following the end of the proceedings about who was observing from the public gallery - because he was worried about potentially negative perceptions of the case.

\section{Refusing to accept a judge's racialised depiction: Daniela's hearing}

The other hearing that I explore in this section, for Daniela, originally from Romania (Hearing 25, Southwark, 2016), also involved a defence barrister whose more resistant approach to a narrative of bordering opened up an uneasy space in the proceedings, where it started to become unclear why the defendant was being punished. As we will see, however, the way the defence resisted the racialised narrative mobilised in this hearing, and unsettled Daniela's punishment, was different to the defence's approach in Tamir's hearing. Moreover, as well as opening up this uneasy space, the defence's subversive behaviour in Daniela's hearing also seemed to have another, more tangible effect. As he contested the depiction of Daniela through a racialised narrative of bordering, the defence appeared to make it impossible for the judge to impose as harsh a sentence as he seemed to be considering at the beginning of the hearing. Thus, through his more challenging approach, the defence seemed to push the judge, reluctantly, to punish Daniela less severely. 
Daniela was being sentenced for three non-domestic burglaries and seven thefts. She had been convicted of two burglaries and six thefts following a trial in the magistrates' courts three months previously, and had been sent to the Crown Court to be sentenced for these offences, along with the 'other matters' of a further burglary and a theft. It was not clear from the hearing whether these 'other matters' had been adjudicated through a trial or guilty pleas. Despite being classified in different ways, most of the offences were actually very similar in nature: they had apparently involved taking mobile phones, and sometimes cash, from staff and customers in various shops. In three of the offences, however, 'staff only' areas of shops had been entered in order to take the items - and, therefore, they had been prosecuted as nondomestic burglary. During the hearing it emerged that all of the offences had been committed around two and a half years previously, while Daniela was 16 , and thus legally a child. By the time of her trial and sentencing, though, she was 19 - and so she was dealt with by the courts as an adult. It transpired during the hearing, too, that another defendant had also been convicted of committing these offences, along with Daniela. This other defendant was two years younger than Daniela, however. Therefore - although this was not stated explicitly during the proceedings - the fact that the other defendant was still under 18 probably meant that she was being sentenced in the youth court.

As highlighted above, Daniela was originally from Romania; this information seemed to be contained in the court papers, which the judge appeared to have looked at prior to the hearing. Thus, at the start of the facts of the case, he told the prosecution that he had been working on an Excel spreadsheet of Daniela's offences, to try to 'put them in order'. Presumably, therefore, the judge was aware of Daniela's nationality from the outset of the hearing. It is worth noting, too, that Daniela had a Romanian-speaking interpreter for the proceedings; so, even if the judge had not picked up on her nationality from reading the court papers, he may have assumed it as a consequence of this (Aliverti and Seoighe, 2017). It is, additionally, important to draw attention to Daniela's physical appearance: specifically, that 
she was wearing what appeared to be traditional Roma dress, including a long skirt and a headscarf. It was striking, then, that while the prosecution opened the hearing with a very legally-focused facts of the case, the judge interrupted this narrative a couple of times, apparently to portray Daniela in a more racialised way. Specifically, the judge seemed determined that Daniela should be depicted as an inherently criminal Romanian or Roma thief. After the prosecution had finished specifying what items Daniela had stolen, therefore, as well as, for the three non-domestic burglaries, which 'staff only' areas of the shop she had entered to take them, he then began to consider a further legal factor affecting how punishable she was, her previous convictions. At this point, the judge interrupted as follows:

\section{Prosecution:}

Moving on to her antecedents, she has 15 convictions for 25 offences, 19 of which were theft.

Judge:

She had her first findings of guilt when she was 14, she was offending at a phenomenal rate then - she was still 15 at the time of offence six. They're all theft from the person and shoplifting?

Prosecution:

Yes.

I highlighted in Chapter Two that, when operating through the register of nationality, the narrative of bordering of intrinsic criminality has often set out a particular association between people from Romania and theft-related offences, including cashpoint theft and pickpocketing (Light and Young, 2009; see also Aliverti, 2018a). It is important to highlight, too, 
how Roma from Eastern European countries have often been depicted, like Romanians, as having an innate propensity for theft-related crime; usually, this racialised characteristic has been presented in cultural terms (Yuval-Davis et al., 2017; Guy, 2003; Clark and Campbell, 2000). Thus, as the judge drew attention to how Daniela had first been convicted of an offence when she was 14 and emphasised that, even at this age, 'she was offending at a phenomenal rate', he seemed to be framing her through these dominant depictions. That is, he seemed to be insisting that Daniela was an archetypal Romanian or Roma thief, with a natural disposition for behaving in this way - an insistence which strengthened as he also specifically checked with the prosecution that all Daniela's previous convictions were for theft from the person and shoplifting.

A few moments later, in fact, the judge appeared to bolster his portrayal of Daniela through this racialised frame, as the prosecution started to situate her offences in relation to the relevant sentencing guidelines. As the prosecution set out that Daniela's culpability should be seen as high because she committed the offences with another person, and thus 'she was part of a group', the judge commented: 'They've got a little system going, and it's very simple for them to do because they're practised at it.' Albeit more subtly than in the earlier interruption, the judge nonetheless appeared to be insisting on a racialised conception of Daniela here. So, as he emphasised the allegedly organised and skilful way that Daniela and the other defendant had carried out their offences, he seemed to be portraying them both as natural-born Romanian thieves.

While the prosecution did not present Daniela in a racialised way during the opening version of 'what happened', then, the judge, through his interjections, did. As the defence began his mitigating narrative, he appeared to be alert to this and responding directly to it. Thus, the defence started his version of events as follows: 'She was 16 at the time the offences were committed, this is a very important consideration. I say that because Your Honour will see in the main pre-sentence report it is stated that the police, probation and 
children's services believe she is a trafficked child, brought specifically to the UK to commit crime.' In one sense, as the defence barrister drew attention to this information, he was working to make Daniela less punishable in legal terms. The sentencing guidelines for theft and burglary offences both set out that involvement through exploitation or coercion reduces a defendant's culpability (Sentencing Council, 2015, 2011). ${ }^{3}$ At the same time, however, the defence was also countering the judge's presentation of Daniela as an inherently problematic Romanian thief. So, by foregrounding the opinion of a number of agencies that 'she is a trafficked child, brought specifically to the UK to commit crime', the defence immediately worked to insist that Daniela was not a deviant criminal but, in fact, the opposite of this: a vulnerable young person, who had been targeted and exploited by undesirable criminals.

This aspect of the defence's depiction became even clearer just a few moments later, as he explained: 'These are young people, being used like something from the nineteenth century, in Charles Dickens' stories, being couriered from one place to another.' As he referred to Daniela as 'being used like something from the nineteenth century' by the people who had brought her to this country - who, he explained later, were older members of her family - the defence's portrayal resonated with media stories about how 'barbaric' Romanian mafias and gangsters operating in the UK ruthlessly exploit women and children (Light and Young, 2009). His depiction of Daniela's exploitation resonated, too, with the 'focus on victimhood' (Tonkiss, 2018, p.127) that has been identified in the messaging of some migrants' rights organisations. That is, it chimed with the way that some advocacy groups have attempted to mark out particular groups of migrants as acceptable and deserving by

\footnotetext{
${ }^{3}$ Following the introduction of the 2015 Modern Slavery Act, there is now a legal defence for people who commit offences as a direct result of being a victim of trafficking. This defence could not have been used in Daniela's case, however, as it only applies to offences committed after $31^{\text {st }}$ July 2015 , when the legislation was brought in; Daniela's offences were carried out in 2013-14. Crown Prosecution Service guidance (2019) sets out that, in cases where it appears that the defendant may have been trafficked but a defence under the Modern Slavery Act is not possible, prosecutors should still consider if there is a defence of duress - and, if not, if it is in the public interest to prosecute. It was not clear from Daniela's sentencing hearing, however, whether the opinion that she had been trafficked had been raised before, and if this information had been put forward by her defence representative during her trial.
} 
emphasising their suffering and vulnerability (see also de Noronha, 2015; Anderson, 2008). By mobilising the information about her trafficking from the pre-sentence report, therefore, and by foregrounding her 'victim' status, the defence contested the portrayal of Daniela through a racialised narrative of bordering in a conventional way. He distanced her from the stigmatising representation insisted upon by the judge through straightforward inversion: by asserting that, rather than innately bad and criminal, Daniela was in fact suffering and exploited - and, consequently, she could be afforded leniency. ${ }^{4}$

Even as the defence challenged the judge's portrayal of Daniela through a standard approach, however, he simultaneously behaved more subversively. As soon as the defence introduced the information about how Daniela had been trafficked to the UK, then, the judge actually rejected it - and yet, the defence refused to accept this. Thus, after the defence initially referred to the pre-sentence report and explained how the police, probation and children's services believed that Daniela had been 'brought specifically to the UK to commit crime', the judge interrupted him, saying, 'She doesn't accept this.' The defence immediately pushed back against this, responding 'But being realistic ...' - at which point the judge cut him off again, demanding: 'What are your instructions?' The defence did not answer this question directly. Rather, he pointed to the young age of Daniela and the other defendant at the time of committing the offences, and explained how this indicated that they were trafficked children - to which the judge replied: 'Are these her instructions?' The defence said that Daniela had not told him herself that she had been trafficked, to which the judge responded, 'You should advance her instructions.' The defence persisted, however, directing the judge's attention towards 'the mechanics of how the offences were committed. You have

\footnotetext{
${ }^{4}$ It is important to emphasise that, in drawing out the approach that the defence barrister took to render Daniela less punishable, I am not suggesting that she had not been exploited and victimised by those who had forced her into criminal activity. My point, rather, is that by focusing on this information, and framing Daniela solely through the lens of vulnerability and victimhood, the defence was working to present her in a particular way.
} 
a 16-year-old child in an area of London that she wouldn't normally frequent' - before the judge interrupted him again, insisting once more: 'You need instructions.'

Yet, the defence still did not relent. Rather, he returned to the pre-sentence report, highlighting again that agencies including the police and children's services believed that Daniela had been trafficked - before then asking the judge directly: 'If you are asking a 16year-old, "Were you coerced or forced by older relations", what answer do you expect her to give? She was probably told in advance to say "no comment".' Yet again, the judge dismissed the narrative that the defence was trying to deliver, responding, 'Including to her barrister, her lawyers? I'm a bit old fashioned, I don't simply not take instructions.' The defence replied by insisting on his version of events one more time, asserting that the 'inference' that Daniela had been trafficked 'has been drawn by authorities far more experienced than me'. Thus, during this exchange, the defence repeatedly resisted the judge's attempts to silence the version of 'what happened' that he was attempting to relay. Indeed, the defence went on to insist at two later points that Daniela had been trafficked to the UK and forced into committing the offences - despite the fact that the judge had made it very clear that he simply did not accept what had been written in the pre-sentence report.

While I certainly observed defence representatives pushing back against judges during some of the other hearings that I observed, I did not see any of them challenge in the way that Daniela's barrister did. Usually, when judges made it clear that they were not sympathetic to the point being raised, defence barristers backed down fairly quickly. So, for instance, in one of the non-migrant hearings that I observed, for a man who had pleaded guilty to actual bodily harm, the defence tried to persuade the judge that the offence was less serious, according to the sentencing guideline, than the prosecution had suggested. The judge, however, challenged this - at which point the defence repeated the justification he had just delivered, but then added 'I don't seek to labour the point. If you are not with me, I won't try to persuade you.' Something similar happened in one of the hearings that I referred to in 
Chapter Five, in which I initially detected the defence countering his client as a parasitical scrounger - but subsequently decided that details about the defendant earning money and supporting his family were being mobilised for more practical reasons. This hearing was for a man originally from Romania, who had also pleaded guilty to actual bodily harm (Hearing 9, Wood Green, 2015). During the mitigating plea, the defence attempted to place his client's offence in a less serious sentencing guideline category than had been suggested by the prosecution. The judge rejected this, however - at which point the defence backed down quickly, responding simply, 'I'm not going to persuade you'.

In another hearing, for a man originally from Poland, who had pleaded guilty to exposure (Hearing 1, Wood Green, 2014), the judge interjected during the facts of the case to say that he thought the offence was more serious than the prosecution had set out. He explained that this was because of the vulnerability of the women to whom the defendant had exposed himself. During the mitigating plea there was then an exchange between the judge and the defence about this issue - and the defence pushed back against the judge's assessment of the women's vulnerability twice. When the judge insisted for a third time, however, that the women involved should be viewed as particularly vulnerable, the defence stopped pressing on this point and moved on. Although Daniela's barrister was not radical in terms of the actual narrative he was delivering, then, he nonetheless challenged the judge's depiction of Daniela as intrinsically problematic and deviant in a way that was firmly against the conventions of the court. Compared with the approach taken by defence representatives in the other hearings that I saw, he displayed a resistance to judicial authority that was unusual.

Indeed, as Daniela's barrister refused to be silenced on the issue of her trafficking and exploitation, his narrative seemed to move past a straightforward plea for leniency. Rather, as he repeatedly drew attention to his client's victimisation and vulnerability, it started to appear questionable that Daniela was in court, and being punished, at all. As in Tamir's hearing, the judge seemed to sense, and respond to, the disruption effected by the defence's more resistant 
approach. As he proceeded to deliver his sentencing remarks, the judge opened his account of 'what happened' as follows:

Can you stand up, please. You fall to be sentenced for seven thefts and two sorry, three - burglaries. These are two series of offences albeit closely related. One of the offences was shoplifting, otherwise what you have done is with someone else, I understand a member of your family, gone into shops, places where people are working, people who have jobs and are earning money honestly, and very skilfully distracted them and taken the opportunity to steal their property - often phones, sometimes money from their handbags.

As the judge drew attention to how Daniela had 'very skilfully distracted' the people from whom she had stolen, he once again portrayed her as an inherently criminal Romanian thief, for whom it came naturally to behave like this. He seemed to hint at her as a lazy migrant freeloader, too, as he contrasted her behaviour with that of her victims, depicting the shop workers from whom she had stolen as 'people who have jobs and are earning money honestly'. In particular, his phrasing here resonated with the media reports that I highlighted in Chapter Two, about how - following the end of transitional controls in 2013 - Romanian scroungers and beggars were planning to come to the UK to abuse the benefits system and to 'fleece' 'rich' and 'generous' British people (Flynn, 2013; The Sun, 2013). Notably, however, although the judge constructed Daniela as innately bad and deviant in this way, he actually went on to impose a lighter sanction than the relevant sentencing guidelines seemed to recommend: a suspended prison sentence, rather than an immediate custodial term of several years. His appeal to these racialised dominant narratives in his remarks, therefore, appeared to be functioning in a similar manner to the judge's invocation of the narrative of the abusive immigration cheat in Agnesa's hearing, which I explored in the previous chapter. 
That is, the judge essentialised and pathologised Daniela as a freeloader and a thief not to validate a severe sanction but, rather, to insist that she definitely was punishable - to justify her presence in court at all.

As I have suggested, the defence's repeated insistence that Daniela had been trafficked to the UK and forced to carry out her offences meant that serious questions about the legitimacy of sanctioning her had been raised. Consequently, the judge depicted Daniela as intrinsically undesirable in order to address this - to quell this disruption, and get on with the business of punishing her. Daniela's hearing, then, seemed to fit with the pattern traced across the previous chapter and this one, about the specific circumstances in which narratives of bordering tended to be appealed to by judges. Thus, it appeared that in his sentencing remarks the judge portrayed Daniela through this racialised frame because - as a result of the defence barrister's interventions - legal reasons for punishing her, on their own, were not enough.

At the beginning of this section I explained that, alongside destabilising, momentarily, the process of sanctioning Daniela, the defence's more resistant approach in this hearing also appeared to have another, slightly more tangible effect. As highlighted above, the judge ultimately imposed what seemed to be a more lenient sentence than the relevant sentencing guidelines recommended - despite the fact that he had exhibited clear hostility towards Daniela throughout the hearing. It is worth noting, too, that at the beginning of the proceedings the judge had actually indicated that he was going to pass a much more severe sentence. In the facts of the case, then, the prosecution barrister had specified that the recommended sentence range for the burglaries was, according to the category in which he had placed Daniela's offences, a prison term of between one and five years. He subsequently moved onto the thefts, placing Daniela's offences in a category for which the sentence range was a low-level community order to 36 weeks' custody. The judge, however, challenged this, stating that the thefts Daniela had committed should, in fact, be placed in a higher category. 
He justified this assertion by trying to turn his depiction of her as an inherently deviant thief into a legally relevant factor.

Thus, picking up on the point he had made earlier about how Daniela and the other defendant had 'a little system going, and it's very simple for them to do because they're practised at it', the judge said: 'If it is simple for them to commit offences, with the routine all worked out, it could lead you to say that it is sophisticated.' Here, the judge was alluding to a factor in the theft guideline, 'Sophisticated nature of offence/significant planning' (Sentencing Council, 2015, p.4), which is listed as indicating a higher level of culpability. He insisted, therefore, that the sentence range for Daniela's theft offences was actually 26 weeks to two years' custody. Hence, it seemed at this point that the judge very much had a custodial sentence in mind.

It is worth asking why, then, against this earlier indication, the judge finally passed a much more lenient sentence: 12 months' custody, suspended for two years. He justified doing this in his sentencing remarks in the following way: 'The question is, should it be suspended or not? With some regret, I am driven to conclude that it should. I do not think it is really what you deserve, but I do have to bear in the mind the age you were when the offences were committed.' The fact that Daniela was legally a child at the time of carrying out the offences may well, of course, have had an effect on the judge's decision. Alongside this, though, I would also suggest that the defence's repeated emphasis on her victimisation and exploitation during the hearing contributed to the judge ultimately passing a lesser sanction. That is, the defence's refusal to be silenced on the issue of Daniela's trafficking, and the questions that accordingly arose about why she was in court at all, made it impossible for the judge to be as punitive as he initially indicated he was planning. Therefore, the judge suspended the prison sentence that he imposed. Consequently, it appeared that the defence's more oppositional approach resulted not only in a sense of disruption, an uneasy few moments during Daniela's sentencing hearing. It also seemed to effect a much more concrete outcome: through his 
interventions, the defence appeared to ensure that the judge was not able to sanction his client in a more severe way.

Understanding the emergence of resistance to narratives of bordering in sentencing hearings As I suggested in the introduction to this chapter, it is important not to overplay the disruptions that were traceable in Tamir and Daniela's hearings. Ultimately, the resistance effected by their defence barristers was limited. As I have highlighted, there were moments during both sets of proceedings where the punishment of the defendants started to seem questionable, and in Daniela's hearing it also appeared that the judge was forced to pass a less severe sentence than he had originally wanted. Yet, both defendants were, in the end, sanctioned; thus, despite the defence barristers' interventions, at no point did the process of punishing the defendants stop. As I have also emphasised, however, the more subversive behaviour displayed by the defence representatives in these hearings was unusual. It is worth considering, then, why resistance to racialised narratives of bordering emerged during these proceedings, and to explore what might underpin defence barristers behaving in this more resistant way.

I suggested earlier in the chapter that defence barristers might not resist, and instead adhere to the conventional practices of the courtroom, for a number of reasons. So, it might be that they are operating tactically, within the range of practices deemed acceptable in court, in order to secure the best possible outcome for their client. Additionally, though, we might also understand defence barristers' conformist behaviour in terms of the need to get through cases as quickly as possible, in order to earn a living. It is worth considering, too, how the need to 'retain credibility with the court' (McConville et al., 1994, p.201) discourages a more subversive approach, as defence representatives are concerned with acquiring and maintaining professional respect. One factor I did not consider, however, is how adherence to the framework of racialised narratives of bordering, in particular, and the failure of most 
defence barristers to narrate outside of this and constitute their clients as less punishable in more resistant ways, might be a consequence of not recognising it as racist. That is - even as they are keen to insist that their clients should not be viewed as 'bad' migrants - most defence representatives do not recognise ideas about, for instance, abusive immigration cheats and parasitical scroungers specifically as racist depictions. They are, therefore, comfortable operating within this overarching framework, and do not feel the need to question or challenge it at all.

The non-recognition of narratives of bordering as racist by defence barristers is, of course, partly a result of their coded and muted nature. But it should also be understood in terms of the continuing whiteness of the legal profession. While the representation of people from racially minoritised groups amongst barristers in England and Wales has increased in recent years, the Bar remains very white-dominated. Statistics from the Bar Standards Board (2019) highlight that, currently, around $80 \%$ of practising barristers are white - and just under $75 \%$ identify themselves as having a white British background. These figures were borne out by the sentencing hearings that I saw. The vast majority of defence barristers whom I observed - as well as prosecution barristers and, of course, judges ${ }^{5}$ - were white, with British accents. $^{6}$

In their exploration of narrative, Ewick and Silbey highlight that while hegemonic representations are often adhered to and reproduced in individual narratives, more ‘subversive stories' (1995, p.217), which undercut or challenge dominant depictions, can be told. As they explain, however, these more resistant tales are more likely to be delivered by people in socially marginalised positions - because their social positioning means that they

\footnotetext{
${ }^{5}$ The judiciary is even more white-dominated than the Bar. In 2019, just 3.6\% of Circuit Judges (who are fulltime judges) and $7 \%$ of Recorders (practising barristers or solicitors who sit part-time as judges) were from black, Asian or minority ethnic backgrounds (Courts and Tribunals Judiciary, 2019; see also Lammy, 2017). ${ }^{6}$ I recognise, of course, that someone with a British accent may have acquired this after migrating to the UK and, therefore, that amongst the white defence barristers I saw it is possible that some may have come originally from countries in Southern or Eastern Europe.
} 
are more able to recognise the misrepresentations and falsifications of hegemonic narratives. It is unsurprising, then, that the framework of narratives of bordering was adhered to by defence barristers in most of the hearings that I saw, and that more oppositional ways of making defendants less punishable were, generally, not deployed. Those who have experience of being targeted and vilified by racist depictions - who, as a result, are more likely to recognise the distortion and pathologising of dominant narratives about 'unwanted' migrants, and so perhaps question or challenge them - constitute a minority of the legal professionals working in the criminal courts.

Ewick and Silbey's analysis points us, therefore, towards another factor that aids an understanding of the non-resistance of defence barristers. At the same time, it also helps us to see why subversion and opposition might emerge in a sentencing hearing. That is, it suggests that defence representatives might be more resistant to the mobilisation of narratives of bordering because of their own experience of social marginalisation - and, specifically, their own experience of racism. In Tamir's hearing, it was not obvious that this might underpin the defence barrister's more questioning approach; Tamir's legal representative was a white man, who spoke with a middle-class British accent. In the case of Daniela's hearing, however, Ewick and Silbey's identification of why, in particular, resistance to dominant depictions might appear seemed to offer a compelling way to understand the defence barrister's behaviour during these proceedings. As I have highlighted, the defence barrister in Daniela's hearing did not actually challenge the framework of narratives of bordering. Rather, he insisted that his client was not inherently criminal by portraying her, conversely, as a criminally exploited victim of trafficking; thus, he inverted the judge's racialised depiction of her and rendered her less punishable in conventional terms. Yet, as I have also explained, he fought very hard to get his own portrayal recognised, and to dislodge the judge's presentation of Daniela as an intrinsically undesirable Romanian thief. He contested the racialising and 'othering' of her, then, in a way that I simply did not see in any other hearing. 
Daniela's barrister was a black British man, who I would guess was probably in his

50s. He approached me before the start of Daniela's hearing, outside the courtroom, and asked me what I was doing - and the conversation that we subsequently had might be seen as offering an insight into why his approach was so different. After I gave a brief explanation of my research, we began discussing racism in the courts, and during this conversation he talked about the racist treatment he had experienced when he had first started working as a barrister in the mid-1980s. So, he told me that when he first started appearing in court, 'ushers would check if you were the defendant when you came in, and judges would just stare at you, and would look surprised when you spoke English'. He then added, half-jokingly, 'and then when you'd left, they'd probably call the Bar Council!' He said that he thought the way he was treated now was different, and that he did not feel he was subjected to racism in court anymore. However, he was also very clear about the continuing institutional racism of the criminal justice system towards those going through it as defendants.

I would suggest, therefore, that we might connect his earlier experiences of racism within the courts to his particular resistance against this on behalf of his client - that it helps us to understand the robust way that he contested the judge's characterisation of Daniela as an intrinsically deviant Romanian thief. It was notable, indeed, that during a second conversation I had with him, very briefly at the end of Daniela's hearing, he did not explicitly describe the judge's treatment of Daniela as racist - and yet he nonetheless implied that what had just unfolded in court might be seen like this. Thus, following the hearing I told him that for much of the proceedings I had thought the judge was going sentence Daniela more severely than he eventually did. Daniela's barrister responded that, following the Brexit referendum and the anti-immigration sentiments that had been mobilised during this, he felt that defendants from Eastern Europe were getting 'hammered' in the way they were punished by judges. 


\section{'The mute always speak': The communication of resistance by defendants during sentencing proceedings}

Research on the criminal courts has often drawn attention to how, although they are formally central to proceedings, defendants are practically marginalised during the court process. As critics have noted, this happens in a number of ways. The legal and technical language used during proceedings, for instance, can make it difficult for defendants to follow what is happening (Jacobson, Hunter and Kirby, 2015). Unlike in other jurisdictions, moreover, defendants in England and Wales are physically separated from their legal representative during court hearings, through the use of the dock. This can further impede defendants' ability to understand and indeed participate in what is going on around them (Mulcahy, 2013). The use of 'secure docks' - found now in most courts in England and Wales - might also be seen as having increased the difficulties faced by defendants in engaging with proceedings. As the law reform organisation Justice has put it, 'the secure dock resembles a large glass box, with high walls made of glass panels' (2015, p.1). A legal challenge heard in the mid-1990s by the European Court of Human Rights found that 'only minimal loss of sound was caused by the presence of the glass screens used in English docks' (Mulcahy, 2013, p.1145). Yet, during one hearing I observed, where I sat immediately behind the dock, I found it almost impossible to hear what was being said. I imagine that the defendant's experience could only have been marginally better. Research has identified, too, the problems caused for defendants by the increasing use of videolink during proceedings. The sound quality on videolinks has often been found to be poor, and - even more starkly than the use of the dock - appearing in court remotely effects a physical separation between defendants and their legal representative, making communication during a hearing very difficult (Gibbs, 2017; Plotnikoff and Woolfson, 2000).

Research has also pointed to specific, additional ways that people who have migrated to the UK may be sidelined and rendered passive during court hearings. In her research on 
immigration-related offences, Aliverti (2013a) notes how the particular strangeness of court proceedings for people who have only recently arrived in the country can affect understanding and participation. Language can act as significant barrier, as well. Defendants who do not speak English as their first language can request an interpreter for court hearings. Yet, in their research on the use of interpreters in criminal proceedings, Aliverti and Seoighe observe that 'court participants such as lawyers and probation staff frequently seemed to forget the presence of the interpreter in the courtroom and failed to allow sufficient pause in their contributions to allow for interpretation' (2017, pp.145-146).

Aliverti and Seoighe note, too, how - particularly since the restructuring of court interpretation services in 2012, and the provision now of interpreters via a contract with a single private company - non-attendance of interpreters at court hearings has become a significant problem. As they explain, sometimes the interpreter's non-attendance means that the hearing is adjourned. But it can also result in the hearing going ahead using an interpreter who speaks a different language; they document, for instance, a case involving a defendant who required a Hindi interpreter, where in the end a Panjabi-speaking interpreter was used. It can even mean proceeding with no interpreter at all, with magistrates and judges taking a 'let's see how we get on' approach. Aliverti and Seoighe's research also documents concerns about the quality of court interpretation under the post-2012 arrangements, as pay for interpreters reduced under the single provider contract. Many qualified and experienced interpreters, therefore, have now stopped working in the courts.

Perhaps the most obvious way in which defendants are marginalised, even excluded, during the sentencing hearing, however, which applies to all defendants, is that they are not given any opportunity to speak. Unlike in the trial, where they are allowed to give evidence in their defence, during sentencing defendants are not permitted to speak at all, apart from confirming their name at the beginning of proceedings. Thus, Carlen's memorable characterisation of the defendant as the inert 'dummy player' $(1976, \mathrm{p} .81)$ in the court 
process might seem to particularly play out in the sentencing hearing. Across many of the hearings that I observed, indeed, defendants often seemed to be, as Aliverti puts it, 'spectators in their own case' (2013a, p.101). Yet, this was not always so: on a couple of occasions I saw defendants behave in a more resistant way, to attempt to speak up and insert themselves into the proceedings.

During one of the hearings that I touched on in the final section of Chapter Five, for example, for the three men originally from Lithuania who had been convicted of handling stolen vehicles, the judge asked one of them, Gintaras, 'Do you understand?' after imposing a suspended sentence on him. Gintaras responded in Lithuanian with what was obviously more than a simple 'Yes' or 'No'. Although the interpreter did not interpret what he was saying thus providing an interesting example of how they can attempt to police defendants' behaviour - Gintaras kept speaking for some time. Eventually, the judge cut him off by beginning to sentence one of his co-defendants. I highlighted too in the previous chapter how, during the mitigating plea in his hearing, Joseph tapped on the glass screen of the dock several times to try to get the court's attention. Thus - although he was ignored by everyone and so did not get to say anything - he nonetheless attempted to insert himself into the proceedings in this way. Indeed, as I also noted, he tried once again later on in the hearing: as the judge finished his sentencing remarks, Joseph stood up in the dock and raised his hand. This time the judge verbally dismissed him, telling him that he could talk to his solicitor after the hearing. Even though Joseph was not actually able to speak in court, however, he nevertheless challenged the silence expected of him in this way.

Alongside the overt tactics through which Gintaras and Joseph tried to make themselves heard, it is important to think as well about the more subtle ways that defendants might express themselves during proceedings. In her exploration of asylum appeal hearings, Johnson reads what she identifies as the 'restive silence' (2011, p.58) of the claimants she observed - their impatient, animated quietness during proceedings - as an alternate form of 
communication, and articulation of resistance to the formalism and formulism of the asylum court. Her analysis demonstrates, therefore, that by decentralising what is spoken, and paying attention to other modes of communication 'such as body language and gestures' (2011, p.59), people who are apparently saying nothing become far more expressive than they initially appeared. Nthabiseng Motsemme, whom Johnson cites, puts this idea clearly: '[W]hen we reject dominant western oppositional hierarchies of silence and speech, and instead adopt frameworks where words, silence, dreams, gestures, tears all exist interdependently and within the same interpretive field, we find that the mute always speak' (2004, p.910).

In some of the hearings that I observed, defendants' bodily articulations and gestures seemed to be unambiguously conveying passivity and abjection. Tamir, for instance - who was not physically present for his hearing, but appeared via videolink from prison - sat for most of the proceedings with his head bowed downwards, holding it in his hands. At the end of the hearing, as the judge finished his sentencing remarks, he spoke directly to Tamir, via the interpreter, asking him to get the prison officer who was in the room with him (but who was not visible on the videolink) so that he could give him some instructions. Tamir did as he was asked - but, at the point that the judge spoke to him and Tamir looked up into the videolink, he had a bewildered look on his face, as if he was not really sure what had just happened to him. Sometimes, however, defendants' non-verbal expressions seemed to have a more resistant quality to them. In one hearing in particular I was struck by the defendant's tears. Tears and crying might, of course, be understood as communicating resignation and abjection - and, as I will to document, I certainly saw hearings where this appeared to be the case. Yet, in this hearing, the defendant's loud sobbing seemed distinct; it had a more unsettling nature to it. Indeed, as he cried without restraint at two separate points during the proceedings, he almost seemed to be challenging the portrayal of him through a racialised narrative of bordering. Moreover, the defendant appeared to be doing this in a more 
oppositional manner, as his tears seemed to allude to and animate a much more complicated, and thus subversive, version of events.

The hearing was for Fabrice, originally from Democratic Republic of Congo (Hearing 6, Wood Green, 2015). He had been convicted of rape, attempted rape and sexual assault. Because his case had been adjudicated through a trial, and the judge sentencing him had also presided over these earlier proceedings, the prosecution did not provide an initial account of Fabrice's offences in the facts of the case. Rather, the prosecution went straight to the sentencing guideline for sexual offences (Sentencing Council, 2013) - and, as he set out how punishable Fabrice was in legal terms, it transpired that Fabrice had been convicted of attacking two women, on separate occasions. In his narrative, the prosecution pointed to factors in the guideline that he said increased the harm of Fabrice's offences, specifically the use of abduction and threats of violence. The prosecution then insisted that Fabrice's culpability was at the highest level, although he did not give any reason for this. It was later described, however, how the rape of one of the women, and the attempted rape and sexual assault of the other, had taken place in both instances after Fabrice had pretended to be a taxi driver and had offered to drive them home, following a night out with their friends. It seemed possible, therefore, that the prosecution was asserting Fabrice's higher culpability on the basis that a '[s]ignificant degree of planning' (Sentencing Council, 2013, p.10) might be said to have been involved in the commission of the offences.

After the prosecution had pointed to some additional aggravating factors specified by the guideline, including the location and timing of the offences, the judge interjected to explain that she was considering passing an Extended Determinate Sentence. ${ }^{7}$ At this point, a

\footnotetext{
${ }^{7}$ The Extended Determinate Sentence (EDS) was introduced in 2012, following the abolition of the Imprisonment for Public Protection (IPP) sentence. The EDS consists of a custodial term and an extended period on licence. There are also specific release arrangements for this type of sentence. So, whereas release usually happens automatically at the halfway point with a normal or determinate prison sentence, for most people now subject to an EDS it is only possible to apply to the Parole Board for release once two-thirds of the custodial term has been completed - and this will only go ahead, of course, if the Parole Board approves it (Inside Time, 2016). As I go on to highlight, for an EDS to be imposed there are certain conditions that must be met. These include that the defendant has been convicted of a specified offence (i.e. a sexual or violent offence listed in
} 
more racialised element to the narration of 'what happened' appeared to come through. One of the conditions for the imposition of this type of sentence is that there is deemed to be 'significant risk to members of the public of serious harm occasioned by the commission by the offender of a further specified offence'8 (Legal Aid, Sentencing and Punishment of Offenders Act 2012, s.124). As the judge noted that probation's pre-sentence report had identified Fabrice as 'dangerous', she set out that this condition was fulfilled. The defence, however, immediately responded to the judge on this, clarifying that the pre-sentence report actually showed that the OASys risk assessment ${ }^{9}$ had determined Fabrice as posing 'a medium risk of sexual offending'. But, as the defence explained, the probation officer who had completed the pre-sentence report had questioned this, on the basis that Fabrice had threatened one of the women he had attacked with a gun. Consequently, the OASys risk classification had been overridden - and the probation officer had replaced it with their own assessment that Fabrice was in fact dangerous.

Yet, as the defence then set out, there was actually no evidence that Fabrice had made threats with a gun. Rather, during his trial one of the women had said that she thought he had one, because during the attack she had noticed him looking at the glovebox in his car. So, the defence explained, it was the woman's 'intuition' that Fabrice might threaten her in this way - but not something that had actually happened. I would suggest, therefore, that in the portrayal of Fabrice in the pre-sentence report, we see the framing of him through a racist dominant depiction. That is, as the probation officer inaccurately deployed the evidence that had been given during his trial and insisted that he had used a gun to threaten one of the

Schedule 15 of the Criminal Justice Act 2003), and that the court considers that the defendant presents a significant risk of causing serious harm by committing a further specified offence (Legal Aid, Sentencing and Punishment of Offenders Act 2012, s.124).

${ }^{8}$ As highlighted in Footnote 7, above, a specified offence is a sexual or violent offence that is listed in Schedule 15 of the Criminal Justice Act 2003.

${ }^{9}$ The Offender Assessment System, or OASys, is a risk assessment and management tool that has been used by the Probation and Prison Services since 2001 (HM Prison and Probation Service, 2019). 
women, Fabrice appeared to be constituted through longstanding racist ideas about intrinsically violent and dangerous black men (Connell, 2012; Wilcox, 2005; Gilroy, 1987).

Fabrice was suggested in a racialised way by the pre-sentence report, then, although he was not framed specifically through a narrative of bordering. As the defence began to deliver her plea in mitigation, however, she nonetheless seemed to be working to counter the idea of her client as an inherently bad and deviant migrant. Thus - after emphasising again that the information in the pre-sentence report did not support the conclusion that Fabrice was 'dangerous', but also telling the judge that she acknowledged his offences constituted 'some of the worst of their kind' - the defence then continued her version of 'what happened' as follows:

He has a tragic and disturbing history. He came to the UK aged 16 or 17, from Democratic Republic of Congo. He lived with his father, mother and sister in DRC, and had his education there.

His father was a politician and university teacher. During the 1997 uprising, his father as a politician was a target and his family was a target, too. His life changed when his family was targeted. He was forced to behead his father in front of his mother and sister. He was then forced to join the army and fight for them. He eventually escaped and ended up in the UK - a family friend helped with this. His mother and sister were still in DRC. His mother became ill, and later died, his sister had cholera and also died.

He has been diagnosed with post-traumatic stress disorder. A psychiatrist gave evidence at his trial and said that he is depressive. He is on medication, and has 
been receiving treatment in prison. They are looking at whether he should be in hospital.

As the defence relayed the horrific experiences of Fabrice and his family during the civil war in Democratic Republic of Congo, the structural conditions of political violence, which might be seen to widen our understanding of the violence that Fabrice later inflicted on the women he attacked, came into view. And yet, even as the defence alluded to these conditions, she did not mobilise them in this way. So, she did not deploy details about the broader context of Fabrice's life for the same purpose that the defence in Tamir's hearing had pointed towards problematic political and economic conditions - in order to trouble the idea of the defendant as solely and individually responsible for 'what happened'. Rather, Fabrice's barrister referred to his experiences before he came to the UK in order to present him as individually suffering and traumatised - and so to assert that, while he was undoubtedly accountable, himself, for the offences, and should be punished for them, he could be afforded some leniency. It was noticeable, therefore, that the defence initially introduced what Fabrice had experienced in his country of origin through a firmly individualised lens, explaining 'He has a tragic and disturbing history.' After describing what Fabrice and his family had been subjected to during the civil war, moreover, the defence then framed the significance of this solely in terms of Fabrice's status now as a traumatised and mentally unwell individual. Thus, she explained that Fabrice had been diagnosed with both post-traumatic stress disorder and depression, and that he had been prescribed medication and was receiving treatment for these conditions.

By presenting him as individually vulnerable and disordered, the defence was in part making Fabrice less punishable in legal terms. Like all the guidelines published by the Sentencing Council, the guideline on sexual offences includes 'mental disorder' (2013, p.11) as a personal mitigating factor: that is, even where mental ill health is not seen to reduce the 
defendant's culpability, it can be taken into account in terms of their personal welfare (see also Ashworth, 2015; Jacobson and Hough, 2011). At the same time, though, the defence was also working to head off any idea of Fabrice as an intrinsically criminal and deviant migrant by presenting him, instead, as the opposite of this. So, by referring to Fabrice's previous experiences and framing them like this, the defence mobilised - similar to the defence in Daniela's hearing - images of migrant suffering and victimhood, in order to insist that while Fabrice had done something terrible he was not terrible in himself, and consequently could be treated less punitively. The defence invoked Fabrice's previous experiences in her mitigating narrative, therefore, in order to portray him as less punishable in wholly conventional terms.

At the points that I looked up from writing during the delivery of the facts of the case, and the plea in mitigation, Fabrice - who was physically present in court - was sat in the dock silently, with his head bowed downwards, staring at the ground. When the defence described how he had been forced to kill his father, however, Fabrice began to cry, and in fact he then sobbed loudly for what seemed like a number of seconds. Tears might, of course, be understood as communicating passivity and abjection; and, indeed, in most of the hearings that I observed where defendants cried, this appeared to be what was happening. Gloria, for instance, whose hearing I explored in Chapter Five, sat with her head bowed for much of the proceedings, and at points seemed to be crying quietly: she made slight noises, as if she was trying to hold in her tears, and occasionally dabbed her face with a tissue. Daniela, who stared at the floor as the judge sentenced her, also appeared to have been crying silently during her hearing. As she looked up at the end of the judge's sentencing remarks, her quiet distress became visible as she used her hand to wipe tears away from her face. In the hearing for the three men from Lithuania convicted of handling stolen vehicles, one of the defendants, Evaldas, stared straight ahead and displayed little obvious emotion as he was being sentenced. Yet, as soon as the judge finished his remarks, Evaldas sat down dejectedly and began to rub his eyes, before then bowing his head and holding it in his hands. 
Fabrice's tears seemed different, however. As with Gloria, Daniela and Evaldas, his crying undoubtedly conveyed pain and distress. Yet, unlike these defendants, he did not appear to be trying to quieten his sobbing at all or to suppress his tears in any way. Even as Fabrice's sobs expressed his suffering, then, they also felt resistant; as he cried audibly and without inhibition, he seemed to refuse to regulate himself according to the norms of emotional expression deemed acceptable within the court (Roach Anleu, Bergman Blix and Mack, 2015). Moreover, as the defence explained what had happened to Fabrice's father, and at this point Fabrice began to release his tears unrestrainedly, his crying appeared to express something about what he had lived through before he arrived in the UK. The wrenching, almost guttural nature of Fabrice's sobs seemed to communicate the violence and brutality to which he had been subjected. That is, they appeared to evoke and animate the horror and terror of violent conflict and civil war.

Thus, although in one sense Fabrice's crying might be seen as upholding the defence's depiction of him in terms of individual trauma and abject migrant victimhood, at the same time it seemed to go beyond the conventional framework of vulnerable versus deviant migrants, and deliver a more subversive story. As Fabrice sobbed loudly for those several seconds, the structural conditions of political violence, which the defence's individually-focused narrative had sidelined and understated, appeared to materialise within the courtroom more prominently. Consequently, a more complicated version of 'what happened' seemed to emerge, in which the harm that Fabrice had inflicted on the women he had attacked was not simply reducible solely to him. Instead - similar to the mitigating plea in Tamir's hearing, where the defence barrister uncovered problematic social conditions to offer a more multi-dimensional account of his client's offence - Fabrice's loud and anguished tears appeared to situate what he had done within a longer history, and larger context, of violence. 
I recognise, however, that even as I put forward such an interpretation of Fabrice's crying during the hearing, the partiality of my view and limitations of my perspective, which I emphasised in Chapter Four, must be considered. Taking seriously the effects of my social positioning on the research I have produced (Duneier, 2004), then, means recognising that as a white, middle-class British woman, who has never experienced violence and trauma like that to which Fabrice was subjected, my understanding of his tears may be very far from his own. It might be argued, indeed, that my particular perspective means not simply a lack of understanding of what Fabrice was communicating during the proceedings. The way that I may have 'distort[ed] and 'misrepresent[ed]' (Phillips and Earle, 2010, p.374) 'what happened' as a result of my social position, and in particular my whiteness, extends to how I may, in fact, have constructed a version of events that feels more palatable to me. In other words, it is arguable that by interpreting Fabrice's tears through the lens of resistance and subversion, I have been able to mitigate my feelings of discomfort at what I witnessed during this hearing: the criminal justice system's denunciation, and punishment, of an acutely traumatised black man. In drawing attention to how race and positionality matters (Parmar, $2018 b$ ) to the analysis I engage in here, I do not attempt to 'solve' the problem of my partial perspective. Rather, I aim to accept and embed it as an ongoing possibility: by making the potential effects of my social position explicit, and also through the tentative language utilised in the interpretation I offer, which acknowledges that this is how the hearing seemed or appeared to unfold to me.

As the judge began to deliver her sentencing remarks, following the end of the defence's mitigating narrative, the larger context to Fabrice's violence, which had seemed to emerge through his loud sobs, was predictably relegated to the background once more. Thus, the judge narrated a version of events which clearly demonstrated the centrality of individual responsibility to the criminal justice process - and its concomitant inability to recognise and deal with problematic structural conditions and 'bitter social realities' (Norrie, 2014, p.27). In 
the first place, then, although the judge did allude to Fabrice's experiences in his country of origin in her sentencing narrative, she minimised - trivialised, even - what Fabrice had actually been subjected to. So, she described being forced to kill his father, and then being used as a child soldier, as 'your life experience' and 'all the problems that you have faced'. The judge insisted on these experiences as barely relevant, moreover, as she also stated: 'I take [them] into account insofar as I can'.

Alongside this, the political conditions of the civil war that Fabrice had been subjected to were also erased as the judge presented the violence that he had inflicted on the two women he attacked as coming solely from within him. She depicted him, therefore, through a racialised narrative of bordering - and, specifically, as an intrinsically sexually aggressive migrant man. Hence, at the point in her sentencing remarks where she described 'what happened' in the rape offence, the judge said: 'You saw her at a bus stop. You pretended to be a friendly taxi driver offering a lift, but you were no such thing. As the evidence shows, you are a predator.' Later, narrating the attempted rape and sexual assault of the other woman, the judge set out how, just a few months after the first attack, 'you were on the prowl again'. Then, after giving further details of how Fabrice had assaulted this woman, the judge reiterated 'you are a dangerous sex predator' (emphases mine).

It might be argued, of course, that by portraying Fabrice in this way, the judge was simply demonising him as a deviant sex offender. Terms such as 'predator', for example, are often used in media coverage to vilify people who are suspected or have been convicted of sexual offences (Soothill and Walby, 1991). I would suggest, however, that as the judge continued with her narrative, the racialised nature of her portrayal became clearer. Thus, as the judge referred to Fabrice specifically as being 'on the prowl', her description resonated, in the first place, with longstanding depictions of the 'bestial' (Grover and Soothill, 1996, p.567) sexuality of black men. We see here how, though, in the 'post-raciality' of the contemporary era, such animalised imagery is stripped of any explicitly racial reference or 
terminology - meaning that its racist articulation becomes deniable (Goldberg, 2015; see also Parmar, 2019). Simultaneously, deploying this animalised turn of phrase, and then insisting on Fabrice as a 'dangerous sex predator', also evoked some of the media representations that I documented in Chapter Two, in which unwanted 'migrants' and 'immigrants' have been repeatedly essentialised and homogenised as 'sex predators', 'rape thugs' and 'sex beasts'. That is, the judge's depiction also seemed to tap into this racialised narrative of bordering, which has constituted non-white and 'not quite white' migrant men as an undifferentiated and pathological collective with hypersexual tendencies.

It is important to emphasise, however, that - even as present-day media depictions have homogenised non-white and 'not quite white' migrant men in this way - the contemporary narrative of the migrant sexual predator has also intimated a clear and specific association between sexual offending and black migrant men. As I highlighted in Chapter Two, in the press reporting on individual 'foreign criminals' that I examined, articles on men originally from countries in Africa or the Caribbean who had been convicted of sexual offences frequently carried visual images of those on whom they were reporting. The use of such accompanying images accomplishes particular racial work; thus, even as race was never referred to in any of the articles, the overtly racist narrative about black men as inherently sexually violent was nonetheless alluded to and remobilised. It seemed, therefore, in this hearing, that Fabrice's somatic difference especially facilitated the judge's portrayal of him through the dominant narrative of the sexual predator and so the insinuation of him as a naturally sexually violent migrant. We see here, then, I would suggest, an example of the racial stratification within narratives of bordering that I documented in Chapter Two unfolding in a sentencing hearing. That is, the way that the judge portrayed Fabrice during her remarks appeared to reflect how - even as they never utilise the language of race physical appearance matters in dominant narratives about 'unwanted' migrants. 
By presenting Fabrice through this racialised frame, and so by insisting on him as intrinsically undesirable and deviant, the judge worked to justify the significant punishment that she imposed: an Extended Determinate Sentence of 23 years, with an 18-year custodial term. ${ }^{10}$ Hence, Fabrice's hearing provides yet another instance of a judge appealing to a racialised narrative of bordering in order to help legitimise a severe sanction. Yet, even as the judge obscured the structural conditions that might be seen to help explain Fabrice's actions even as she insisted that Fabrice, himself, was the problem, and downplayed his previous experiences of violent conflict and civil war - the more complicated version of "what happened' seemed to surface again. As I highlighted previously, Fabrice's loud sobbing, which had started as the defence barrister had explained during her mitigating plea what had happened to his father, continued at this point for a number of seconds. After this, however, Fabrice's crying became less audible - and, by the time that the defence's narrative was over, and the judge began to deliver her sentencing remarks, the court was almost silent. Yet, soon after the judge started her narrative, Fabrice began to cry loudly again. This time, moreover, his sobbing continued for much longer. Although, at some points, it became slightly quieter, Fabrice could be heard for the entire time that the judge was sentencing him.

I would suggest, once more, that Fabrice's loud, constant sobbing articulated a version of events that reached beyond the idea of him as an intrinsically deviant and sexually predatory migrant. That is, as Fabrice communicated his pain like this, the horror of the political violence to which he had been subjected was animated to some extent in the courtroom - and, therefore, the structural conditions that the judge's narrative was working to

\footnotetext{
${ }^{10}$ As highlighted earlier, there are specific release arrangements for Extended Determinate Sentences. In contrast to those sentenced to normal or determinate prison sentences, then, who are usually automatically released at the halfway point of their custodial term, Fabrice will only be able to apply for release to the Parole Board once he has reached the two-thirds point of his sentence. It is possible, therefore, that he will serve the full custodial term, 18 years, in prison; the Parole Board is only required to authorise someone's release if they consider that any identified risks can be safely managed in the community. The scale of the punishment imposed on Fabrice becomes clearer still, moreover, when it is considered that even if he serves the full 18-year custodial term, he will then be on licence in the community (and thus subject to potential recall to prison) for a further five years - this is the 'extended licence' element of the EDS.
} 
conceal and silence nonetheless seemed to be expressed. As Fabrice continued to cry, then, an uneasy space - similar to that effected by the defence barrister in Tamir's hearing appeared to open up in the proceedings. As the wider context of the extreme violence that Fabrice had experienced seemed to impress itself more firmly upon the hearing, his sole and individual accountability for his actions felt undermined - and so the punishment being imposed upon him started to appear questionable.

In identifying this, I should be clear that I do not mean to question or trivialise the harms that Fabrice inflicted on the women he attacked. I recognise, of course, that within England and Wales' criminal justice system and indeed British society more broadly, there exists a long history of minimising sexual and other forms of gendered violence (Jordan, 2012; Stern, 2010). I also recognise that the harms of Fabrice's actions were far more severe than those of Tamir's. As a result, it may, to some, seem more problematic to interrogate Fabrice's sole responsibility for 'what happened', and his deservingness for punishment, in this way. In uncovering how Fabrice's sobs seemed to articulate a wider and less individualised history to the violence that he inflicted, however, I am not working to deny the impact of his actions. Rather I am seeking to illustrate how this more multi-dimensional version of events unsettled the adequacy, and apparent inevitability, of individually criminalising and punishing him as a response. Fabrice's unrestrained tears, then, appeared to disrupt the judge's narrative about his individual badness and pathology, and - in a similar way to the more radical narrative delivered at one point by the defence barrister in Tamir's hearing - seemed to destabilise, momentarily, the process of his punishment.

\section{Conclusion}

In this chapter, I have documented and analysed defence barristers and defendants' practices of resistance to racialised narratives of bordering. As I have explained, it is important not to over-read or romanticise these practices of resistance - to overplay the possibilities for 
disruption in the courtroom, which is a tightly controlled environment. At the same time, however, it can be seen from the sentencing hearings that I have explored that - even within the highly regulated setting of the courtroom - defence barristers and defendants do sometimes question and assert themselves against racialised representations of unwanted migrants. So, they do contest these pathologising and 'othering' depictions in more radical and subversive ways. In taking a more resistant approach, as I have explained, they open up moments in the sentencing hearing where the process of punishment seems to move less easily and assuredly. That is, as a consequence of such interventions, the imposition of sanctions on defendants appears less inevitable and justified. Resistance to these racialised dominant narratives, moreover - the challenge to their reproduction and re-articulation during the practice of punishing non-white and 'not quite white' migrants - might also be seen as having wider consequences and effects, to have a significance beyond the confines of the courtroom and the sentencing hearing. As I now proceed to the conclusion of the thesis, this is one of the issues that I consider. 


\section{Conclusion}

In this thesis I have investigated how dominant, racialised narratives of bordering, which are disseminated by the UK government and media to problematise non-white and 'not quite white' migrants and justify their targeting by actual immigration enforcement, are being put to work in the specific context of the sentencing hearing. Specifically, I have theorised and demonstrated how these racialised narratives are being tapped into and mobilised, as well as navigated and negated by legal professionals, in order to help construct and negotiate 'unwanted' migrant defendants' punishability. In this Conclusion, as I bring my research project to a close, I ask the question: what is the significance of what I have conceptualised and traced across the past six chapters? Or, to put it another way: what are the implications of racialised narratives of bordering being mobilised during sentencing proceedings for nonwhite and 'not quite white' migrants? More simply still, perhaps, the question that this concluding section poses, and seeks to answer, might be summarised as follows: what do the findings of my research actually mean?

I begin by returning to some of the developments that have been traced by border criminologists thus far, which I documented in Chapter One, and I examine what I have identified across this thesis in relation to these. I suggest, then, first of all, that Turnbull and Hasselberg's analysis of 'double punishment' (2017, p.143) offers us a useful starting point from which to think through the mobilisation of racist dominant depictions of 'unwanted' migrants during sentencing proceedings. As I explained in Chapter One, Turnbull and Hasselberg demonstrate how, as direct activities of immigration enforcement have been inserted into the criminal justice system, and so have coalesced with criminal penalties, a harsher form of sanctioning - which they define as 'double punishment' - has emerged. Understanding the aggravation and exacerbation of criminal sanctioning that results from its melding with border control practices can, I contend, help us to further unpack the effects of 
racialised narratives of bordering seeping into sentencing hearings. That is, it focuses our attention on how the deployment of harsh and exclusionary ideas about unwanted migrants, in order to help construct defendants as punishable, might be seen as adding to and intensifying the pain and distress inflicted on defendants by an already punitive sentencing process. Thus, the use of these racist dominant depictions during sentencing proceedings might be understood as a further, and more subtle example, of how bordering practices can aggravate and heighten criminal punishment.

At the same time, I suggest that we might also connect the mobilisation of racialised narratives of bordering during sentencing proceedings to the other key development that has been identified by border criminologists in the current period: the increasing shift of criminal justice agencies and institutions towards immigration control. As I set out in Chapter Five, I saw several hearings during my fieldwork where the direct activities of immigration enforcement were visible - and so where criminal justice's overt shift towards regulating the border, which has been documented by the literature on border criminology, could be detected. Yet, I also saw many hearings for migrants and non-citizens where literal border control practices did not appear at all. Even in hearings where direct practices of border enforcement were not detectable, however, it might be argued that legal professionals' appeal to racialised ideas about unwanted migrants meant that criminal justice's growing focus on managing the border could still be traced. As I have explained, these racist depictions were tapped into in order to help construct defendants as punishable. Simultaneously, though, the appeal to narratives of bordering also functioned to undermine the belonging and inclusion of non-white and 'not quite white' migrant defendants. So, it demarcated them as out of place and excludable from the UK. By uncovering the presence of these exclusionary narratives in sentencing hearings, therefore, I can be seen to have put forward a textured account of criminal justice's increasing preoccupation with border control, as my research has 
documented not simply the overt but also the covert means through which this preoccupation unfolds.

Hence, in terms of the literature on border criminology, I suggest that my research contributes to our understanding of the ways in which the present-day fixation with immigration enforcement is marking and permeating England and Wales' criminal justice system. Following this, I move on to suggest that my research might be situated in relation to another strand of criminological literature, which I have touched on at points during this thesis: the literature on racism and the criminal justice system - and, specifically, on racist discrimination in the courts and sentencing. As I explain, although criminology has often marginalised race and racism, some empirical research into racism in sentencing has been carried out - primarily quantitative analyses of judges' decision-making. The mixed nature of the available statistical evidence in this area has led some to conclude that compelling 'objective' evidence of racism in sentencing does not exist.

My research, however, might be seen as moving beyond an understanding of racism in sentencing as solely detectable through its quantitative measurement in final outcomes. That is, through critical qualitative enquiry (Phillips and Webster, 2014), and a focus on sentencing proceedings, I have explored and uncovered the presence of racism in sentencing in a different way. I recognise, of course, that the permeation of the sentencing hearings that I observed during my fieldwork by racialised narratives of bordering was not pervasive. Thus, it might be argued that across the hearings for non-white and 'not quite white' migrant defendants that I watched, racism played a fairly understated role. Yet, as I explain, my research also demonstrates that in the hearings where these racialised narratives were detectable, they were tapped into, and countered, in order to help facilitate the proceedings. In this way, therefore, racist depictions of 'unwanted' migrants might be understood as having a significant function in the sentencing hearings where they could be traced. 
In the final section of the Conclusion, I consider how the mobilisation of racialised narratives of bordering during sentencing hearings has consequences beyond the criminal justice system, and why what I have traced in my research is significant more broadly. As I explain, as narratives of bordering are deployed during sentencing proceedings, what is unfolding is more than simply the court's reproduction and repetition of these racialised ideas. Rather, through this the court has become part of 'the constitution of its own context' (Ewick and Silbey, 1995, p.211). That is, criminal courts can be understood as sites where notions of the racial difference and inferiority of non-white and 'not quite white' migrants are being produced and sustained - and, therefore, courts can be seen as participating in the wider normalisation and naturalisation of the racist border. Yet, as I have also explained, resistance to racialised ideas about unwanted migrants can sometimes be detected in sentencing proceedings. It is here, then, I suggest - that is, in relation to the broader consequences of what I have traced - that we see the real importance of these moments of resistance. As defence barristers and defendants challenge narratives of bordering, they do not simply disrupt the practice of the sentencing hearing. They also dispute the reality of racially different 'unwanted' migrants, and refuse the inevitability of the racist border. In doing so, they point towards the possibility of a world in which such oppression and exclusion does not exist.

\section{The significance of my findings to border criminology}

I began this thesis, in Chapter One, by surveying the literature produced by scholars within border criminology thus far on the changing contours of the established criminal justice system in England and Wales under conditions of mass migration and its control. As I explained, two broad developments have been traced. In the first place, it has been documented how, as the overt practices of immigration control have been injected into the traditional criminal justice system, the police, courts and prisons have increasingly shifted 
away from conventional imperatives in their dealings with non-British citizens and been geared instead towards border enforcement. Thus, they have increasingly begun to look like agencies and institutions concerned with immigration regulation.

At the same time, however, it has also been emphasised by some scholars how - even as immigration measures have made their way into the contemporary criminal justice system - the traditional functions of criminal justice still apply to non-citizens. In the case of the prison, in particular, Turnbull and Hasselberg (2017) have explained how - even as imprisonment works now to facilitate the ejection of foreign nationals - the punishment of these prisoners nonetheless continues; non-citizens continue to serve the sentences handed to them by the courts. Importantly, though, as Turnbull and Hasselberg also explain, as immigration practices have been inserted into the prison, the sanctioning inflicted on noncitizens has started to look very different. Specifically, as measures such as post-sentence detention and deportation have coalesced and merged with the criminal penalty, a harsher, aggravated form of sanctioning, which they identify as 'double punishment' (2017, p.143), has been produced.

I would suggest that what I have documented across this thesis might be examined in relation to both of the trends described above. Firstly, then, I would contend that Turnbull and Hasselberg's uncovering of the aggravation and exacerbation of criminal sanctioning as a result of its melding with border control practices provides a useful frame for understanding the permeation of sentencing proceedings by racialised narratives of bordering. Criminologists have highlighted the punitive effects upon defendants not only of actual criminal penalties, such as imprisonment - but also the criminal justice process, in itself. Most well-known, perhaps, is Malcolm Feeley's examination of this in The Process is the Punishment, which emphasises the 'costly' $(1979$, p.15) impact on defendants of pre-trial processes such as detention and bail, and repeated court appearances - as well as the painful and distressing effects of going through a trial. Feeley explains, therefore, that many people 
plead guilty not simply to secure a reduction in the sentence that is finally imposed on them, but also to avoid the humiliation and anxiety that trial proceedings can cause.

In a similar way, David Tait has underlined how, in sentencing hearings, 'punishment' is not simply something that is handed down by the judge - but is in fact inflicted, to some extent, by the proceedings themselves. Thus, as he conceptualises this stage of the criminal process as 'the violence-invoking performance, the official ritual of denunciation or forgiveness' (2002, p.470; emphasis mine), he suggests the potential humiliation and degradation of defendants as they are adjudicated and designated as deserving of a criminal penalty in court. Indeed, I gestured towards this in Chapters Four and Five, as I noted how some of the defendants whom I observed appeared distressed during their hearings. The visible upset of some defendants might be seen as one, although not the only indicator, of the punitive nature of sentencing proceedings.

Hence, from this perspective - of sentencing proceedings as punitive in themselves it might be argued that, as racialised narratives of bordering are tapped into by legal professionals, the discomfort and distress inflicted on defendants by an already painful criminal process are being added to and intensified. The mobilisation of racist depictions of unwanted migrants during sentencing hearings means that some defendants are being rendered punishable in an especially harsh and exclusionary way. In the hearings for Agnesa, Joseph, Farid, Marek, Daniela and Fabrice, then, these defendants were designated as deserving of punishment by pathologising them, by essentialising them as inherently problematic and deviant - by demeaning and disparaging them as racially undesirable 'others'. As I explained in Chapter One, Turnbull and Hasselberg's analysis of 'double punishment' notes that immigration control practices such as post-sentence detention and deportation are not 'official penal sanctions' (2017, p.147). Yet, they are experienced as punitive by those who are subjected to them; so, as these bordering practices meld with the criminal penalty, a particularly severe form of sanctioning nonetheless emerges. This helps us 
to understand, therefore, how - although not formally criminal punishment themselves - the unforgiving narratives about unwanted migrants that were occasionally deployed by prosecution barristers, and more often by judges, during sentencing hearings, might nevertheless be seen to aggravate the punitive character of this stage of the criminal process.

Thus, building on Turnbull and Hasselberg's analysis, it might be argued that the use of racialised depictions of non-white and 'not quite white' migrants during sentencing proceedings provides a further example of how bordering practices can heighten and intensify criminal punishment. In framing what I have documented in this way I recognise, however, that there are significant differences between the type of aggravated criminal sanctioning that Turnbull and Hasselberg identify, and the harsh process of sentencing that I have uncovered. In their analysis of 'double punishment', Turnbull and Hasselberg point to the 'serious and life-shattering' (2017, p.136) consequences that result as post-sentence detention and deportation blend and merge with non-UK nationals' prison sentences. They document, therefore, the intensely painful effects of lengthy, seemingly indefinite periods of imprisonment and confinement on the men to whom they spoke for their research. They also highlight the acute distress caused to their interviewees by the threat of ejection from the country - which would mean, effectively, permanent separation from their family and friends, and exile from the lives they had established in the UK.

The 'life-shattering' consequences when 'double punishment' through deportation is actually enacted, indeed, received some media attention in February 2020, as the Home Office scheduled a charter flight to deport around 50 men who had been convicted of criminal offences to Jamaica. The anticipated publication of the Windrush Lessons Learned Review $^{1}$ in the period leading up to this charter flight meant that it received much more press

\footnotetext{
${ }^{1}$ In late 2017, reports started to emerge in the media about the Home Office's treatment of the 'Windrush generation' - people who had come to the UK between 1948 and 1973, from Caribbean countries. Under the Immigration Act 1971 people from the Windrush generation had the right of abode in the UK and thus were in the country legally. Yet, as they were never provided with official documentation to prove their status, nor did the Home Office consistently keep records confirming this, many were subsequently targeted by the 'hostile
} 
coverage than previous mass expulsions. As part of this coverage, some - primarily leftleaning - publications conducted interviews with men who had already been deported to Jamaica from the UK. In one of these interviews, published in the Guardian, 23-year-old Chevon Brown described the effects of his double punishment as follows: 'What has happened has caused me grave pain and depression; I feel like I have been ripped apart from my family’ (Gentleman, 2020).

What I have traced unfolding in the sentencing hearing, then, is clearly different to this. Being rendered punishable in a harsh and exclusionary way is less obviously violent, and painful, than being locked up in prison indefinitely and then 'ripped apart' from everything that you know. Yet, the more subtly harmful nature of the aggravated process of sanctioning that I have identified, as racialised narratives of bordering are mobilised during sentencing proceedings, does not equate to an absence of harm. Acknowledging that the literal practices of border control are undoubtedly more violent, and have a more punitive effect, does not mean that the pain caused by these stigmatising, pathologising narratives should be ignored. In terms of understanding the nature of this pain, it is, certainly, a limitation of my research that I did not speak to any of the defendants whose sentencing hearings I observed - that I did not seek to explore their experience of being constructed as punishable in this severe way. Other research on the experience of racism in the criminal justice system, however, might be seen as offering an insight into the harms effected by the racist and exclusionary sentencing process that I have documented.

In The Multicultural Prison, Phillips (2012) documents the spectrum of racist practices that minority ethnic prisoners experience from prison officers, ranging from violent

environment' measures that I documented in Chapter One - with some eventually detained and deported from the UK. The Windrush Lessons Learned Review, commissioned in July 2018, was published in March 2020. It stopped short of identifying the Home Office as institutionally racist, but argued that the 'failings' that the review had identified 'demonstrate an institutional ignorance and thoughtlessness towards the issue of race and the history of the Windrush generation within the department, which are consistent with some elements of the definition of institutional racism' (Williams, 2020, p.7). 
attacks to racist comments. Drawing on Fanon's work on the psychological effects of colonialism, she explores the impact of being subjected to such practices and identifies how the experience of racism in prison - including verbal articulations of racist hostility - can be 'painful, humiliating, and a diminution of the self' (2012, p.169). The effects of being targeted by racist expression come out particularly through her interview with one man, Manu, originally from a country in Central Africa, who "talked of being called a "monkey" in the prison he was held in before'. As Phillips explains, Manu 'emotionally recalled it "getting to him", the being "treated as an animal"' (2012, p.185). Her exploration evidences, therefore, the very real harms for prisoners of being subjected to verbal articulations and expressions of racism. Thus, Phillips' research points towards a similar 'hurt and humiliation' (2012, p.185) for defendants who are racially 'othered' and demeaned as they are processed and rendered punishable by the courts.

Alongside viewing the mobilisation of racialised narratives about unwanted migrants during sentencing hearings as providing a further, more subtle example of how bordering practices can aggravate criminal punishment, we might also examine it in terms of the other trend to which border criminologists have pointed. So, we might understand what I have documented as connecting to the increasing concern of criminal justice agencies and institutions with immigration enforcement, and their growing shift towards regulating and upholding the border. As I highlighted in the exploration of my empirical data, the literal practices of immigration control were visible in a number of the sentencing hearings that I observed. Tomás, then, had been prosecuted for and had pleaded guilty to an immigrationrelated offence, the possession of two false passports. It was also stated by his barrister during the proceedings that - as Tomás was in the UK without leave to remain - he was going to be removed from the country following the completion of his prison sentence. In Farid's hearing, the defence barrister made a very similar statement. In Marek's hearing, the judge explained during his sentencing remarks that, as a result of the length of the prison 
sentence he had passed, it was likely that Marek's deportation would be pursued. In these hearings, therefore, criminal justice's overt shift towards enforcing the border, which has been documented by the literature on border criminology, could be detected.

Yet, I also saw many hearings for migrants and non-citizens where direct border enforcement activities did not appear during the proceedings - so, where the actual practices of immigration control, which border criminologists have concentrated on in their examination of the changing contours of established criminal justice, did not come through. Sometimes, the non-appearance of literal border control measures in a hearing seemed to be the result of a lack of knowledge and awareness amongst the legal professionals involved about relevant immigration provisions. As I explained in Chapter Five, then, in Joseph's hearing, for instance, the sentence imposed by the judge crossed the threshold for automatic deportation - but this simply was not mentioned by the judge during his sentencing remarks. This also happened in Tamir's hearing, which I explored in Chapter Six. The 18-month prison sentence passed by the judge meant that the automatic deportation provision would have been triggered - but the judge did not specify this as he sentenced Tamir.

In several hearings, however, the absence of direct practices of immigration enforcement was not the consequence of a lack of knowledge - but, rather, because borderfocused policies and legislation did not apply. Thus, as the table included in Chapter Four demonstrates, in many of the hearings that I observed short prison sentences, or community or suspended sentence orders, were imposed - meaning that the sanction passed by the judge was not severe enough for deportation to be an issue. In other hearings, immigration action against the defendant was not possible because, although they had migrated to the UK, they had subsequently become a British citizen. Agnesa, for example, had been prosecuted for and pleaded guilty to an immigration-related offence, seeking to obtain leave to enter or remain by deception - and thus the literal activities of border control were present in her hearing in this way. Yet, the possibility of any further immigration enforcement action against her 
disappeared during the course of the hearing as it became clear that, following the commission of the offence, she had applied for and been granted British citizenship. So, there was no possibility of removing or deporting Agnesa from the country, even if she had been given a custodial sentence of a year or more.

Even in hearings where direct practices of immigration enforcement were not present, however - or, as in Agnesa's, where they surfaced initially but then disappeared - it might be argued that the mobilisation of racialised narratives of bordering during proceedings meant that criminal justice's increasing concern with border control was nonetheless detectable. As I have explained, these racist representations were tapped into in the specific context of sentencing hearings to help construct defendants as deserving of punishment. At the same time, though, the appeal to these harsh and exclusionary narratives by prosecution barristers, and more often by judges, also functioned to undermine the belonging of non-white and 'not quite white' migrant defendants. That is, as defendants were framed like this, they were simultaneously presented as excludable from the UK. The effect of these dominant depictions in materialising the border during sentencing proceedings, even when the direct practices of immigration control were not detectable, can, perhaps, be most clearly illustrated through Agnesa's hearing. As I noted above, actual border enforcement was initially visible in this hearing because Agnesa was being prosecuted for an immigration offence. Yet, later it became clear that no further immigration action could be taken against her, because following her commission of the offence Agnesa had naturalised as a British citizen.

Even as the border faded from view in this way, though, it nevertheless remained present, as Agnesa was portrayed throughout the hearing as an inherently duplicitous and manipulative immigration cheat. As I explained in Chapter Five, the prosecution barrister, and then the judge, seemed to depict Agnesa as deviant like this because her presence in court appeared to be based on questionable criminal charges - so, more than legal reasons seemed to be needed to help authorise her punishment. Simultaneously, however, portraying Agnesa 
through a racialised narrative of bordering, and pathologising her as intrinsically suspect and undesirable, demarcated her as unwanted and not belonging to the UK. Her formal legal inclusion through her British citizenship, therefore, and so her apparent non-susceptibility to bordering practices, were undercut and unsettled as she was framed through this racist and exclusionary dominant narrative.

The materialisation of border control during sentencing proceedings, despite the nonpresence of actual immigration enforcement activities, can also be traced clearly by looking at Daniela's hearing. As I explained in my analysis of this hearing in Chapter Six, although the judge appeared to want to pass a more severe sentence at the beginning of the proceedings, ultimately he imposed a suspended sentence order on Daniela. Consequently, the punishment that the judge passed was not severe enough for the possibility of deportation to be raised. ${ }^{2}$ Yet, as the judge insisted on Daniela as a natural-born Romanian and Roma thief, and as he also later hinted at her as an inherently lazy migrant scrounger, he not only constituted her as punishable. So, he not only justified the allocation of sanctions on her, in spite of her barrister's insistence that she had been forced to commit her offences. The judge's portrayal simultaneously worked to circumscribe the border around Daniela. That is, as he tapped into these racist and pathologising depictions, and presented her as an intrinsic thief and scrounger, he also demarcated Daniela as out of place and excludable from the UK.

I would suggest, therefore, that by uncovering the presence of racialised narratives of bordering in sentencing hearings, I can be seen to have put forward a textured account of criminal justice's increasing preoccupation with immigration control. In other words, as well as pointing to the overt means through which the concern with border enforcement surfaces

\footnotetext{
${ }^{2}$ In fact, by the time of Daniela's hearing Home Office policy was that all EEA nationals convicted of a criminal offence - whether they received an immediate custodial sentence or not - should be referred for consideration of deportation (see Footnote 3 in Chapter One). However, none of the legal professionals involved in the hearing appeared to be aware of this, and so the possibility of deportation was not mentioned during the proceedings.
} 
in this stage of the criminal justice process, I have also drawn attention to the more covert and subtle ways in which it materialises.

\section{The significance of my findings to research on racism in the criminal justice system}

Thus far, I have situated my thesis primarily in relation to border criminology: so, as starting from, and contributing to, this relatively recently established and rapidly expanding criminological sub-field. Yet, research on the deployment of racialised narratives of bordering during sentencing hearings might also be viewed in terms of another strand of criminological literature. Specifically, it might be examined in relation to the literature on racism in the criminal justice system - and, in particular, to research on racist discrimination in the courts and sentencing.

As I highlighted at the very start of this thesis, criminology as a discipline has marginalised and neglected race and racism. There is a body of literature, however, on the racist discrimination of criminal justice agencies and institutions - including some empirical research that has explored this at the stage of sentencing. Most of the studies in this area have been quantitative analyses of sentencing decision-making. Typically, then, they have compared sentencing outcomes for people who are racially minoritised with those for their white counterparts, to ascertain if the former are subject to harsher criminal penalties. PinaSánchez, Roberts and Sferopoulos note that, while 'hundreds of such studies have been conducted in the United States', in the UK context statistical research into racism in sentencing decision-making has been more 'intermittent' (2019, pp.718-719). Moreover, it remains the case that, as Kalunta-Crumpton observed just over twenty years ago, the findings of UK-based quantitative studies have been 'mixed' (1999, p.16).

A series of investigations conducted during the 1980s, for example, found 'no evidence of direct, systematic bias on racial lines in sentencing in the crown court' (McConville and Baldwin, 1982, p.658; see also Moxon, 1988; Crow and Cove, 1984). 
Hood's 'landmark study' (Bowling and Phillips, 2002, p.183) Race and Sentencing (1992), however, which employed the technique of regression modelling - which is generally recognised as methodologically sophisticated, since legally relevant sentencing factors are controlled for to determine if disparities in outcomes can be attributed to these - challenged the findings of this earlier research. Thus, Hood's examination of sentencing outcomes for defendants appearing in Crown Courts in the West Midlands identified that there was 'a 5 per cent greater probability of a male black defendant being sentenced to custody than a white male' (1992, p.198). He also found that 'the average length of the prison sentences imposed on Asians who pleaded not guilty was 9 months longer, and for blacks 3.4 months longer, than for whites who pleaded not guilty' (1992, p.202).

A Home Office study of sentencing in the magistrates' courts and the Crown Court, which was published in the late 1990s, found that Asian men were 'significantly more likely to be sentenced to custody than would have been expected on the basis of their offence and other factors.' However, it also found that in the Crown Court, 'ethnic minority males were not significantly more likely to receive a custodial sentence than white males when other factors were taken into account' (Flood-Page and Mackie, 1998, cited by Shute, Hood and Seemungal, 2005, p.9). More recently, Pina-Sánchez, Roberts and Sferopoulos have investigated possible discrimination in Crown Court sentencing decision-making against people with 'traditional Muslim names' (2019, p.718). Their analysis found that defendants who are 'Muslim-named ... received on average sentences 9.8 per cent longer than other offenders' - but that once legally relevant factors were controlled for, the 'Muslim-name effect' (2019, p.726) disappeared. They conclude, therefore, that their research identified 'no evidence of discrimination' in sentencing outcomes- although they are also careful to emphasise that their findings 'should not be taken as conclusive proof of a lack of discrimination' (2019, p.729). 
Citing Shallice and Gordon (1990), Phillips and Bowling have underlined 'the disjuncture between empirical research findings on sentencing practices which show no "race effect" and "the large numbers of people who readily assert the opposite, largely (though not unimportantly) on the basis of anecdotal, personal and collective experience"" (2003, p.270). This 'disjuncture' has prompted some to make the argument that, although the available statistical findings are mixed and so compelling 'objective' evidence of racism in sentencing does not exist, racially minoritised defendants' perceptions of racism should nonetheless be a focus of concern (Shute, Hood and Seemungal, 2005; see also Pina-Sánchez, Roberts and Sferopoulos, 2019). Such a response might almost be seen as having a 'post-racial' quality to it, manifesting what Goldberg identifies as post-raciality's 'assertive deniability' (2015, p.38), as it seemingly downplays the issue of actual racism in the courts. An alternative approach might be not to shift to a primary focus on defendants' perceptions of racism - but, rather, to stop thinking about racism in sentencing as solely detectable through its quantitative measurement in final outcomes. That is, by moving beyond an understanding of racist discrimination as only 'objectively' evident in sentencing when it can be identified in judges' decision-making, and 'pinned down using sophisticated statistical techniques' (Phillips et al., 2019, p.6), it might be possible to uncover racism at this stage of the criminal process in other ways.

My research might be understood as adopting such an alternative approach. In other words, through critical qualitative enquiry (Phillips and Webster, 2014), and a focus on sentencing proceedings, I have explored and revealed the presence of racism in sentencing from a different angle. It might be argued, however, that while dominant, racist depictions of unwanted migrants could certainly be detected in the sentencing hearings that I observed during my fieldwork, the findings of my research nevertheless point towards them playing a relatively understated role. As I set out in Chapter Four, the mobilisation and navigation of narratives of bordering by legal professionals, to help construct and negotiate defendants' 
punishability, was not pervasive across the hearings that I saw. Thus, these racialised narratives were tapped into, and countered, in 16 of the 25 sentencing hearings for non-white and 'not quite white' migrant defendants that I watched. Moreover, as I explained in Chapters Five and Six, it was also the case that racist representations of unwanted migrants tended to surface in prosecution and judges' accounts only in specific circumstances. As I demonstrated, then, these pathologising depictions were typically only appealed to in the facts of the case, and more often in the sentencing remarks, when it seemed that legal reasons for the punishment being pressed for or imposed were not doing enough.

I recognise why, therefore, my research might be interpreted as demonstrating a fairly limited function for narratives of bordering in sentencing proceedings. Yet, at the same time, I would emphasise, again, that since I traced these racialised narratives in just under twothirds of the hearings for 'unwanted' migrant defendants that I observed, their appearance though not pervasive - was very far from atypical or anomalous. Additionally, in uncovering the presence of these racist depictions, it is important to attend not only to the number of sentencing hearings in which they could be detected. It is crucial to consider, as well, how they were being put to work and utilised in the hearings where they could be identified. I would argue, then, that through a critical qualitative approach, my research has revealed how when narratives of bordering were tapped into, they played a significant role in the facilitation of sentencing proceedings. As I have shown, in hearings where these racialised narratives were detectable, they were being mobilised, and navigated, in order to help construct and negotiate non-white and 'not quite white' migrant defendants' punishability. Thus, it can be seen that racial demarcation, and racist expression, were being deployed by legal professionals to facilitate and enable the practice of these sentencing hearings. Or, to put it another way, depictions of racial undesirability and 'otherness' 'lubricate[d] the cogs of the system' (Bosworth, Parmar and Vázquez, 2018, p.8), and worked to keep the proceedings 
moving, in hearings where narratives of bordering were appealed to and countered by the prosecution, defence, and/or the judge.

In highlighting the important role that racist depictions of unwanted migrants played in the sentencing hearings where they were tapped into, my thesis might be seen to link to critiques which have identified the criminal justice system as 'inherently unjust' (Moore, 2016, p.51). J.M. Moore, for instance, has put forward an alternative genealogy for criminal justice, challenging histories that have traced the emergence of policing and the prison to 'modernity and the rise of capitalism' (2016, p.39) and arguing instead that Western systems of punishment have their origins in slavery and colonialism. He sets out, therefore, that the tendency of contemporary criminal justice "to reinforce inequality and oppress the "other" which can be seen, as he explains, through its disproportionate targeting of racially minoritised groups - should be understood not as 'an aberration' but rather 'a natural consequence of its genealogy' (2016, p.38). I would argue that what I have traced in this thesis, and the functioning of racialised narratives of bordering in lubricating and facilitating sentencing proceedings, might also be seen as in line with this genealogy. The mobilisation of these racialised narratives, then, to help construct defendants as punishable, and the recourse to this exclusionary framework, too, in attempts to make defendants less punishable, resonates with Moore's account of the criminal justice system as 'built for inequality ... an instrument designed for oppression rather than liberation' (2016, pp.50-51).

Importantly, recognising the oppressive dispositions of criminal justice and the way that in some sentencing hearings racist depictions of unwanted migrants were used to keep the proceedings moving has consequences for imagining and proposing 'solutions' to what I have identified. As I explained in Chapter Four, although it would be disingenuous to downplay my academic aspirations, I also embarked upon this research project with an explicitly political commitment and 'decidedly interventionist' (Hillyard et al., 2004, cited by Clarke, Chadwick and Williams, 2017, p.264) aims. The identification of racism in 
sentencing has, indeed, previously prompted the introduction of measures aimed at tackling this issue. Following the publication of Hood's 1992 study, for instance, which identified racist discrimination as influencing judges' decision-making, a compulsory programme of 'ethnic awareness training' was implemented for members of the judiciary. The Judicial Studies Board also published the Handbook on Ethnic Minority Issues, 'designed specifically to guide judges in their handling of cases involving minority ethnic persons' (Shute, Hood and Seemungal, 2005, p.8).

Yet, such reformist interventions emerge from an understanding of racism as an anomalous intrusion into sentencing. That is, the attempt to excise and eliminate racist discrimination through guidance and training rests on the identification of racism in sentencing as an uncharacteristic 'weakness' or 'failure' in the process - an unfortunate flaw which is compromising and tarnishing an otherwise equitable and just system. Understanding how racialised narratives of bordering were functioning in sentencing proceedings, then, would appear to compel a different approach. So, recognising that these racist depictions were deployed in some hearings to keep the proceedings moving, and thus were part of ensuring that this stage of the criminal justice system worked, should shift us away from corrective or reformist measures, aimed at improving the system and making it 'better'. Rather, as Moore (2016) argues, an understanding of criminal justice's racist and oppressive dispositions should point us towards more radical and transformative interventions and solutions.

\section{The significance of my findings more broadly}

I would argue, finally, that the deployment of racialised narratives of bordering during sentencing hearings, and their mobilisation as part of the construction, and negotiation, of non-white and 'not quite white' migrant defendants' punishability, has consequences beyond the confines of the contemporary criminal justice system. In Chapters Three and Four, I 
explained how the vast majority of the sentencing hearings that I observed felt very private, as it was often only the legal professionals involved and the defendant - as well as possibly a couple of the defendant's family members or friends - who were present. Yet, despite the private feel of these proceedings, and the absence of members of the wider public as they took place, it is important to remember that the court nonetheless remains a social space. That is, the court is located within, and makes up part of, society (Kalunta-Crumpton, 1999; Eaton, 1986).

As we have seen, the significance of this, in part, is that the narratives delivered in the courtroom are permeated and shaped by hegemonic social meanings - they 'bear the imprint' (Ewick and Silbey, 1995, p.211) of dominant cultural narratives. But, as Ewick and Silbey explain, it also means that the stories relayed during courtroom proceedings become 'part of the constitution of their own context' $(1995, \mathrm{p} .211)$. Thus, to put this another way, it is not simply the case that narratives delivered during legal proceedings are 'reflective of or determined by ... dominant meanings and power relations' (Ewick and Silbey, 1995, p.211). Rather, through their telling courtroom narratives become constitutive of these - they become 'implicated in the very production of those meanings and power relations' (Ewick and Silbey, 1995, p.211).

From this vantage point, therefore, it becomes apparent that, as dominant narratives of bordering are tapped into during sentencing hearings, it is not simply the case that the sentencing narratives delivered are reflecting and repeating these racialised depictions. More than this, the sentencing narratives relayed by legal professionals have become part of the process of producing these racialised ideas. The criminal courts, then, can be understood as sites where notions of the racial difference and inferiority of non-white and 'not quite white' migrants are being articulated and sustained. In her research on Operation Nexus, Parmar explains that the criminal justice system should be understood 'not only as a site of racism', but also as a space 'where race is made, reproduced and embedded through mundane 
repetition and quotidian activities' (2019, p.938; see also Aliverti, 2018b). This, I would argue, is precisely what I am tracing here. As I emphasised in the previous section, the mobilisation of racialised narratives of bordering was not pervasive across the sentencing hearings that I saw. Nonetheless, the utilisation of these depictions across a significant proportion of the hearings indicates how the criminal courts have become involved in the project of making and maintaining racially undesirable 'unwanted' migrants. Concomitantly, it can be seen how the deployment of narratives of bordering during sentencing hearings affects more than just those 'unwanted' migrant defendants being processed by the courts (see also Eaton, 1986), as this stage of the criminal process is now participating in the wider normalisation and naturalisation of the racist border.

Yet, as I explored in Chapter Six, there are also, occasionally, moments in sentencing hearings when something different appears to happen. So, I observed some instances where narratives of bordering were not re-articulated and sustained but, in fact, challenged and subverted - and, therefore, where ideas about racially different unwanted migrants were unsettled and unmade. In Tamir's hearing, then, as I explained, at one point the defence barrister refuted Tamir as an inherently lazy and parasitical migrant scrounger not by inverting this racialised narrative of bordering, and insisting that - while freeloading spongers definitely exist - Tamir was actually hard-working and selfless. Rather, the defence barrister narrated outside ideas of individual deficiency and desirability altogether. Thus, as he pointed to Tamir's clear economic disadvantage, as well as the harsh immigration restrictions to which Tamir had been subject since arriving in the UK, the defence uncovered the problematic structural conditions that helped to explain his client's involvement in criminal activity.

In Fabrice's hearing, Fabrice's barrister portrayed him as less punishable in conventional terms as she insisted that he was not intrinsically deviant and criminal but, in fact, the converse of this: an individually vulnerable and traumatised migrant. Yet, Fabrice 
himself seemed to set out a more expansive and complicated narrative. So, as he sobbed loudly at points during his hearing, he seemed to animate the civil war and political violence that he had experienced in his country of origin - to evoke the horror and terror to which he had been subjected before he came to the UK. In this way, Fabrice appeared to gesture towards a larger context of harm and violence surrounding his offences - to point towards the problematic social conditions which seemed to underpin the violence that he had subsequently inflicted on the two women he attacked. Thus, Fabrice appeared to explain that the harm he had perpetrated was not solely and individually reducible to him - that he was not, simply, a pathologically bad and deviant migrant.

Within the confines of the sentencing hearing, such challenges worked to destabilise the process of imposing punishment on these defendants. As stories about individually good and bad migrants were pushed to one side, and supplanted by narratives about the 'bitter social realities' (Norrie, 2014, p.27) underpinning the criminal offences being dealt with in these hearings, Tamir and Fabrice's individual criminalisation and punishment for 'what happened' began to seem less inevitable and justified. Ultimately, however, the disruption effected was fairly limited. The sentencing proceedings for Tamir and Fabrice certainly started to move less assuredly and smoothly as a result of these more resistant interventions but at no point did they actually stop. Yet, as the wider context to their offences was excavated and visibilised, the interventions in these hearings were also doing more than simply destabilising the practice of punishing these defendants. As Tamir's barrister, and Fabrice, narrated outside of the dominant framework of narratives of bordering, they worked to disrupt the court's articulation and reinforcement of these racialised ideas. Thus, their interventions destabilised and interrupted the criminal courts' participation in making and maintaining racially different 'unwanted' migrants.

It is, then, in relation to the wider consequences of what I have traced - in terms of the criminal courts' endeavours in producing and sustaining race, and so helping to naturalise and 
normalise the racist border - that we see the real importance of the moments of resistance that emerged. Through such resistance, the reality of racially inferior 'unwanted' migrants was unsettled and disputed - and, simultaneously, the necessity and inevitability of the racist border was challenged and undone. By delivering such subversive stories, therefore - by refusing to 'partake of and reproduce collective narratives' (Ewick and Silbey, 1995, p.222) Tamir's barrister, and Fabrice, 'provide[d] openings for creativity and invention in reshaping the social world' (Ewick and Silbey, 1995, p.222). That is, the tales that Tamir's barrister and Fabrice told engaged in the work of imagining and re-making the world in a different way. By narrating outside of racialised narratives of bordering, their individual stories pointed to the possibility of a world without such racist categorisations and depictions - and so a world without the forms of exclusion and oppression that these dominant representations function to entrench and uphold. 


\section{Bibliography}

Aas, K.F. (2014) Bordered penality: Precarious membership and abnormal justice. Punishment and Society. 16 (5), pp. 520-541.

Aas, K.F. (2013) The ordered and the bordered society: Migration control, citizenship and the Northern penal state. In: Aas, K.F. and Bosworth, M., eds., (2013) The Borders of Punishment: Migration, Citizenship, and Social Exclusion. Oxford: Oxford University Press, pp. 21-39.

Aas, K.F. (2005) Sentencing in the Age of Information: From Faust to Macintosh. London: The GlassHouse Press.

Aas, K.F. and Bosworth, M. (2013) Preface. In: Aas, K.F. and Bosworth, M., eds., (2013) The Borders of Punishment: Migration, Citizenship and Social Exclusion. Oxford: Oxford University Press, pp. vii-xii.

Ahmed, S. (2015) The Cultural Politics of Emotion. 2nd ed. Edinburgh: Edinburgh University Press.

Alexander, C. (2004) Writing race: Ethnography and the imagination of 'The Asian Gang'. In: Bulmer, M. and Solomos, J., eds., (2004) Researching Race and Racism. London: Routledge, pp. 134-149.

Alia, V. and Bull, S. (2005) Media and Ethnic Minorities. Edinburgh: Edinburgh University Press.

Aliverti, A. (2018a) Spotting foreigners inside the courtroom: Race, crime and the construction of foreignness. In: Fili, A., Jahnsen, S. and Powell, R., eds., (2018) Criminal Justice Research in an Era of Mass Mobility. Abingdon: Routledge, pp. 8599.

Aliverti, A. (2018b) Strangers in our midst: The construction of difference through cultural appeals in criminal justice litigation. In: Bosworth, M., Parmar, A. and Vázquez, Y., 
eds., (2018) Race, Criminal Justice, and Migration Control: Enforcing the Boundaries of Belonging. Oxford: Oxford University Press, pp. 127-141.

Aliverti, A. (2017) Forcing people to cooperate: The 'nationality' provisions in the Policing and Crime Act 2017. Border Criminologies Blog [blog]. 20 November. Available from: https://www.law.ox.ac.uk/research-subject-groups/centrecriminology/centreborder-criminologies/blog/2017/11/forcing-people [Accessed 17 September 2019].

Aliverti, A. (2016) Researching the global criminal court. In: Bosworth, M., Hoyle, C. and Zedner, L., eds., (2016) Changing Contours of Criminal Justice. Oxford: Oxford University Press, pp. 73-86.

Aliverti, A. (2015) Enlisting the public in the policing of immigration. British Journal of Criminology. 55 (2), pp. 215-230.

Aliverti, A. (2013a) Crimes of Mobility: Criminal Law and the Regulation of Immigration. Abingdon: Routledge.

Aliverti, A. (2013b) Sentencing in immigration-related cases: The impact of deportability and immigration status. Prison Service Journal. 205, pp. 39-44.

Aliverti, A. and Bosworth, M. (2017) Criminal justice adjudication in an age of migration. New Criminal Law Review. 20 (1), pp. 1-11.

Aliverti, A. and Seoighe, R. (2017) Lost in translation? Examining the role of court interpreters in cases involving foreign national defendants in England and Wales. New Criminal Law Review. 20 (1), pp. 130-156.

Alleyne, R. (2012) A fifth of murder and rape suspects are immigrants. The Telegraph [online]. 19 July. Available from: https://www.telegraph.co.uk/news/uknews/immigration/9410827/A-fifth-of-murderand-rape-suspects-are-immigrants.html [Accessed 18 October 2019]. 
Amnesty International UK (2015) Calais migrants: The dangerous link between rhetoric and policy. Amnesty International UK Blog [blog]. 4 August. Available from:

https://www.amnesty.org.uk/calais-migrants-dangerous-rhetoric [Accessed 12 March 2020].

Anderson, B. (2013) Us and Them? The Dangerous Politics of Immigration Control. Oxford: Oxford University Press.

Anderson, B. (2008) 'Illegal Immigrant': Victim or Villain? Working Paper Series No. 64, COMPAS, University of Oxford.

Ashworth, A. (2015) Sentencing and Criminal Justice. 6th ed. Cambridge: Cambridge University Press.

Ashworth, A. (2008) English sentencing guidelines in their public and political context. In: Frieberg, A. and Gelb, K., eds., (2008) Penal Populism, Sentencing Councils and Sentencing Policy. Cullompton: Willan, pp. 112-125.

Ashworth, A. and Horder, J. (2013) Principles of Criminal Law. 7th ed. Oxford: Oxford University Press.

Back, L. (2007) The Art of Listening. Reprint. London: Bloomsbury Academic, 2013.

Back, L., Sinha, S. and Bryan, C. (2012) New hierarchies of belonging. European Journal of Cultural Studies. 15 (2), pp. 139-154.

Baerwaldt, N. (2018) The European refugee crisis: Crisis for whom? Border Criminologies Blog [blog]. 20 March. Available from: https://www.law.ox.ac.uk/research-subjectgroups/centre-criminology/centreborder-criminologies/blog/2018/03/europeanrefugee [Accessed 20 September 2019].

Bail for Immigration Detainees (2019) 'Nothing Good Comes from Detention': Voices from Detention. London: Bail for Immigration Detainees.

Bail for Immigration Detainees (2014) Denial of Justice: The Hidden Use of UK Prisons for Immigration Detention. London: Bail for Immigration Detainees. 
Baker, S.E. and Edwards, R. (2012) Introduction. In: Baker, S.E. and Edwards, R., eds., (2012) How Many Qualitative Interviews is Enough? Expert Voices and Early Career Reflections on Sampling and Cases in Qualitative Research. Southampton: National Centre for Research Methods, pp. 3-6.

Bal, M. (2009) Narratology: Introduction to the Theory of Narrative. 3rd ed. Toronto: University of Toronto Press.

Baldwin, J. (2008) Research on the criminal courts. In: King, R.D. and Wincup, E., eds., (2008) Doing Research on Crime and Justice. 2nd ed. Oxford: Oxford University Press, pp. 375-398.

Ballinger, A. (2012) A muted voice from the past: The 'silent silencing' of Ruth Ellis. Social and Legal Studies. 21 (4), pp. 445-467.

Bar Standards Board (2019) Diversity at the Bar 2018. London: Bar Standards Board.

Barrett, D. (2013) Human rights farce: Home Office fury after drug dealer immigrant wins right to stay in UK because of 'family life'. The Sunday Telegraph. 28 April, pp. 1-2.

Barrett, D. (2009) Immigrant allowed to stay because of pet cat. The Sunday Telegraph [online]. 17 October. Available from: https://www.telegraph.co.uk/news/newstopics/howaboutthat/6360116/Immigrantallowed-to-stay-because-of-pet-cat.html [Accessed 28 September 2019].

Barrett, D. and Goldhill, O. (2013) Number of foreign nationals on benefits soars to 400,000. The Telegraph [online]. 28 August. Available from: https://www.telegraph.co.uk/news/uknews/immigration/10271855/Number-offoreign-nationals-on-benefits-soars-to-400000.html [Accessed 8 October 2019].

BBC News (2016a) Migrant crisis: Migration to Europe explained in seven charts. BBC News [online]. 4 March. Available from: https://www.bbc.co.uk/news/world-europe34131911 [Accessed 20 September 2019]. 
BBC News (2016b) Paris attacks: Who were the attackers? BBC News [online]. 27 April. Available from: https://www.bbc.co.uk/news/world-europe-34832512 [Accessed 26 October 2019].

Bell, C. and Fox, M. (1996) Telling stories of women who kill. Social and Legal Studies. 5 (4), pp. 471-494.

Bennett, W.L. and Feldman, M.S. (1981) Reconstructing Reality in the Courtroom. London: Tavistock.

Berry, M., Garcia-Blanco, I. and Moore, K. (2015) Press Coverage of the Refugee and Migrant Crisis in the EU: A Content Analysis of Five European Countries [online]. Available from: http://orca.cf.ac.uk/87078/1/UNHCR-\%20FINAL\%20REPORT.pdf [Accessed 27 September 2019].

Bhambra, G.K. (2016) Brexit, the Commonwealth, and exclusionary citizenship. Open Democracy [online]. 8 December. Available from: https://www.opendemocracy.net/en/brexit-commonwealth-and-exclusionarycitizenship/ [Accessed 20 September 2019].

Bhatia, M. (2018) Social death: The (white) racial framing of the Calais 'Jungle' and 'illegal' migrants in the British tabloids and right-wing press. In: Bhatia, M., Poynting, S. and Tufail, W., eds., (2018) Media, Crime and Racism. Cham, Switzerland: Palgrave Macmillan, pp. 181-212.

Bhui, H.S. (2016) The place of 'race' in understanding immigration control and the detention of foreign nationals. Criminology and Criminal Justice. 16 (3), pp. 267-285.

Bhui, H.S. (2009) Foreign national prisoners: Issues and debates. In: Bhui, H.S., ed., (2009) Race and Criminal Justice. London: Sage, pp. 154-169.

Bhui, H.S. (2007) Alien experience: Foreign national prisoners after the deportation crisis. Probation Journal. 54 (4), pp. 368-382. 
Bloch, A. (2000) A new era or more of the same? Asylum policy in the UK. Journal of Refugee Studies. 13 (1), pp. 29-42.

Bloch, A. and Schuster, L. (2002) Asylum and welfare: Contemporary debates. Critical Social Policy. 22 (3), pp. 393-414.

Boffey, D. and Helm, T. (2016) Vote Leave embroiled in race row over Turkey security threat claims. The Observer [online]. 22 May. Available from: https://www.theguardian.com/politics/2016/may/21/vote-leave-prejudice-turkey-eusecurity-threat [Accessed 18 October 2019].

Bosworth, M. (2017) Border criminology and the changing nature of penal power. In: Liebling, A., Maruna, S. and McAra, L., eds., (2017) The Oxford Handbook of Criminology. 6th ed. Oxford: Oxford University Press, pp. 373-390.

Bosworth, M. (2016) Border criminology: How migration is changing criminal justice. In: Bosworth, M., Hoyle, C. and Zedner, L., eds., (2016) Changing Contours of Criminal Justice. Oxford: Oxford University Press, pp. 213-226.

Bosworth, M. (2014) Inside Immigration Detention. Oxford: Oxford University Press.

Bosworth, M. (2008) Border control and the limits of the sovereign state. Social and Legal Studies. 17 (2), pp. 199-215.

Bosworth, M. and Guild, M. (2008) Governing through migration control. British Journal of Criminology. 48 (6), pp. 703-719.

Bosworth, M. and Kaufman, E. (2011) Foreigners in a carceral age: Immigration and imprisonment in the United States. Stanford Law and Policy Review. 22 (2), pp. 429454.

Bosworth, M., Parmar, A. and Vázquez, Y. (2018) Race, criminal justice, and migration control: Enforcing the boundaries of belonging. In: Bosworth, M., Parmar, A. and Vázquez, Y., eds., (2018) Race, Criminal Justice, and Migration Control: Enforcing the Boundaries of Belonging. Oxford: Oxford University Press, pp. 1-10. 
Bosworth, M. and Turnbull, S. (2015) Immigration detention and the expansion of penal power in the United Kingdom. In: Reiter, K. and Koenig, A., eds., (2015) Extreme Punishment: Comparative Studies in Detention, Incarceration and Solitary Confinement. Basingstoke: Palgrave Macmillan, pp. 50-67.

Bottoms, A.E. and McClean, J.D. (1976) Defendants in the Criminal Process. Reprint. Abingdon: Routledge, 2013.

Bowling, B. (2013) Epilogue: The borders of punishment - towards a criminology of mobility. In: Aas, K.F. and Bosworth, M., eds., (2013) The Borders of Punishment: Migration, Citizenship and Social Exclusion. Oxford: Oxford University Press, pp. 291-306.

Bowling, B. and Phillips, C. (2002) Racism, Crime and Justice. Harlow: Pearson Education. British Red Cross (2018) Still an Ordeal: The Move-on Period for New Refugees. London: British Red Cross.

Brown, L. (2012) Romanian fraudster who helped to steal $£ 10 \mathrm{~m}$ in benefits is allowed to stay in Britain to protect her human rights. Daily Mail [online]. 7 October. Available from: https://www.dailymail.co.uk/news/article-2214081/Romanian-fraudster-helped-steal10m-benefits-allowed-stay-Britain-protect-human-rights.html [Accessed 26 October 2019].

Brudner, A. (2009) Punishment and Freedom. Oxford: Oxford University Press.

Bryan, B., Dadzie, S. and Scafe, S. (1985) The Heart of the Race: Black Women's Lives in Britain. London: Virago.

Bryman, A. (2008) Social Research Methods. 3rd ed. Oxford: Oxford University Press.

Buchanan, S., Grillo, B. and Threadgold, T. (2003) What's the Story? Results from Research into Media Coverage of Refugees and Asylum Seekers in the UK. London: Article 19.

Burnett, J. (2016) Racial Violence and the Brexit State. London: Institute of Race Relations. 
Burrows, T. (2016) American mother will be deported from UK, separating her from her twoyear old daughter, because her British husband of nine years doesn't earn enough. Daily Mail [online]. 6 April. Available from: https://www.dailymail.co.uk/news/article-3526579/Mother-deported-separating-twoyear-old-daughter-British-husband-nine-years-doesn-t-earn-enough.html [Accessed 20 September 2019].

Canning, V. (2017) Gendered Harm and Structural Violence in the British Asylum System. Abingdon: Routledge.

Canton, R. and Hammond, N. (2012) Foreigners to justice: Irregular migrants and foreign national offenders in England and Wales. European Journal of Probation. 4 (3), pp. $4-20$.

Carlen, P. (1976) Magistrates' Justice. London: Martin Robertson.

Cashmore, E. and McLaughlin, E. (1991) Out of order? In: Cashmore, E. and McLaughlin, E., eds., (1991) Out of Order? Policing Black People. London: Routledge, pp. 10-41.

Cheney, D. (1993) Into the Dark Tunnel: Foreign Prisoners in the British Prison System. London: Prison Reform Trust.

Chigwada, R. (1991) The policing of black women. In: Cashmore, E. and McLaughlin, E., eds., (1991) Out of Order? Policing Black People. London: Routledge, pp. 134-150.

Clark, C. and Campbell, E. (2000) 'Gypsy invasion': A critical analysis of newspaper reaction to Czech and Slovak Romani asylum-seekers in Britain, 1997. Romani Studies. 10 (1), pp. 23-47.

Clarke, B., Chadwick, K. and Williams, P. (2017) Critical social research as a 'site of resistance': Reflections on relationships, power and positionality. Justice, Power and Resistance. 1 (2), pp. 261-282.

Cockcroft, S. and Duell, M. (2016) American Shakespeare expert who was arrested and detained for ten days without warning as an 'illegal immigrant' after nine years in 
Britain to be freed today but still faces deportation. Daily Mail [online]. 27 January. Available from: https://www.dailymail.co.uk/news/article-3418704/Americanacademic-working-Shakespeare-s-400th-anniversary-arrested-held-cells-student-visalapsed.html [Accessed 20 September 2019].

Connell, K. (2012) Photographing Handsworth: Photography, meaning and identity in a British inner city. Patterns of Prejudice. 46 (2), pp. 128-153.

Coole, C. (2002) A warm welcome? Scottish and UK media reporting of an asylum-seeker murder. Media, Culture \& Society. 24 (6), pp. 839-852.

Cooper, R. (2014) Jamaican crack dealer banned from entire London Borough cannot be deported because of his right to a family life. Daily Mail [online]. 8 January. Available from: https://www.dailymail.co.uk/news/article-2535719/Jamaican-crackdealer-banned-entire-London-Borough-deported-right-family-life.html [Accessed 26 October 2019].

Courts and Tribunals Judiciary (2019) Judicial Diversity Statistics 2019 [online]. Available from: https://www.judiciary.uk/about-the-judiciary/who-are-thejudiciary/diversity/judicial-diversity-statistics-2019/ [Accessed 26 January 2020].

Crow, I. and Cove, J. (1984) Ethnic minorities and the courts. Criminal Law Review. July, pp. $413-417$.

Crown Prosecution Service (2019) Human Trafficking, Smuggling and Slavery [online]. Available from: https://www.cps.gov.uk/legal-guidance/human-traffickingsmuggling-and-slavery\#a2 [Accessed 18 January 2020].

Dawar, A. (2015) Migrants 'milking' benefits system: Foreigners more likely to claim handouts. Daily Express [online]. 21 July. Available from: https://www.express.co.uk/news/uk/592541/Migrants-milking-benefits-systemForeigners-more-likely-to-claim-handouts [Accessed 8 October 2019]. 
Dawes, W., Harvey, P., McIntosh, B., Nunney, F. and Phillips, A. (2011) Attitudes to Guilty Plea Sentence Reductions. London: Sentencing Council.

de Castro-Rodrigues, A. and Sacau, A. (2014) Sentence pronouncements: What judges say when sentencing. European Journal of Criminology. 11 (3), pp. 379-397.

De Certeau, M. (1984) The Practice of Everyday Life. Berkeley: University of California Press.

De Genova, N. (2018) The 'migrant crisis' as racial crisis: Do Black Lives Matter in Europe? Ethnic and Racial Studies. 41 (10), pp. 1765-1782.

de Noronha, L. (2018a) Deporting 'Black Britons': Beyond and against contribution. The Sociological Review Blog [blog]. 6 November. Available from:

https://www.thesociologicalreview.com/blog/a-blog-from-the-new-sociologicalreview-fellow.html [Accessed 8 October 2019].

de Noronha, L. (2018b) The figure of the 'foreign criminal': Race, gender and the FNP. In: Bhatia, M., Poynting, S. and Tufail, W., eds., (2018) Media, Crime and Racism. Cham, Switzerland: Palgrave Macmillan, pp. 337-358.

de Noronha, L. (2015) Unpacking the Figure of the 'Foreign Criminal': Race, Gender and the Victim-Villain Binary. Working Paper Series No. 121, COMPAS, University of Oxford.

Delgado, R. (1989) Storytelling for oppositionists and others: A plea for narrative. Michigan Law Review. 87 (8), pp. 2411-2441.

Department for Work and Pensions (DWP) (2019) Universal Credit. Available from: https://www.gov.uk/universal-credit/what-youll-get [Accessed 8 October 2019].

Detention Action (2009) Detained Lives: The Real Cost of Indefinite Immigration Detention. London: Detention Action.

Dhaliwal, S. and Forkert, K. (2016) Deserving and undeserving migrants. Soundings: A Journal of Politics and Culture. 61, pp. 49-61. 
Doyle, J. (2013) Number of foreigners claiming UK benefits leaps $41 \%$ in 5 years: More than 400,000 now handed payouts that cost taxpayers billions each year. Daily Mail [online]. 29 August. Available from: https://www.dailymail.co.uk/news/article2405053/Foreigners-UK-benefits-leaps-41-5-years-400k-handed-payouts.html [Accessed 8 October 2019].

Doyle, J. (2011) Eastern European migrants to get full access to the welfare state. Daily Mail. 4 March, no page.

Dubinsky, L. (2012) Foreign National Prisoners: Law and Practice. London: Legal Action Group.

Duffy, B., Kaur-Ballagan, K., Gottfried, G. and Aslaksen, A. P. (2017) Shifting Ground: 8 Key Findings from a Longitudinal Study on Attitudes Towards Immigration and Brexit. London: Ipsos Mori.

Duneier, M. (2004) Three rules I go by in my ethnographic research on race and racism. In: Bulmer, M. and Solomos, J., eds., (2004) Researching Race and Racism. London: Routledge, pp. 92-103.

Eaton, M. (1986) Justice for Women: Family, Court and Social Control. Milton Keynes: Open University Press.

Eddo-Lodge, R. (2017) Why I'm No Longer Talking to White People About Race. London: Bloomsbury Circus.

El-Enany, N. (2016) Aylan Kurdi: The human refugee. Law and Critique. 27 (1), pp. 13-15. Erel, U., Murji, K. and Nahaboo, Z. (2016) Understanding the contemporary race-migration nexus. Ethnic and Racial Studies. 39 (8), pp. 1339-1360.

Ewick, P. and Silbey, S. (1995) Subversive stories and hegemonic tales: Toward a sociology of narrative. Law and Society Review. 29 (2), pp. 197-226.

Feeley, M. (1979) The Process is the Punishment: Handling Cases in a Lower Criminal Court. New York: Russell Sage Foundation. 
Fekete, L. (2001) The emergence of xeno-racism. Race and Class. 43 (2), pp. 23-40.

Fekete, L. and Webber, F. (2010) Foreign nationals, enemy penology and the criminal justice system. Race and Class. 51 (4), pp. 1-25.

Fielding, N. (2006) Courting Violence: Offences Against the Person Cases in Court. Oxford: Oxford University Press.

Fine, M. (1994) Working the hyphens: Reinventing self and other in qualitative research. In: Denzin, N.K. and Lincoln, Y.S., eds., (1994) Handbook of Qualitative Research. Thousand Oaks, CA: Sage, pp. 70-82.

Finney, N. and Peach, E. (2004) Attitudes Towards Asylum Seekers, Refugees and Other Immigrants: A Literature Review for the Commission for Racial Equality. London: Information Centre about Asylum and Refugees in the UK.

Fleetwood, J., Presser, L., Sandberg, S. and Ugelvik, T. (2019) Introduction. In: Fleetwood, J., Presser, L., Sandberg, S. and Ugelvik, T., eds., (2019) The Emerald Handbook of Narrative Criminology. Bingley: Emerald Group Publishing Limited, pp. 1-26.

Flick, U. (2012) How many qualitative interviews is enough? In: Baker, S.E. and Edwards, R., eds., (2012) How Many Qualitative Interviews is Enough? Expert Voices and Early Career Reflections on Sampling and Cases in Qualitative Research. Southampton: National Centre for Research Methods, pp. 27-28.

Flower, L. (2018) Doing loyalty: Defense lawyers' subtle dramas in the courtroom. Journal of Contemporary Ethnography. 47 (2), pp. 226-254.

Flynn, B. (2013) Cheeky beggars: Romanians' crime vow on bus to UK. The Sun. 31 December, pp. 1, 8-9.

Flynn, D. (2016) Frontier anxiety: Living with the stress of the every-day border. Soundings: A Journal of Politics and Culture. 61, pp. 62-71. 
Fonseca, D.S. (2018) Reimagining the sociology of punishment through the global-south:

Postcolonial social control and modernization discontents. Punishment and Society. 20 (1), pp. 54-72.

Ford, R. (1998) Straw pledges fast but fair asylum system. The Times. 27 July, p. 41.

Ford, Richard. (2011a) Migrants free to claim full benefits. The Times. 3 March, p. 1.

Ford, Robert. (2011b) Acceptable and unacceptable immigrants: How opposition to immigration in Britain is affected by migrants' region of origin. Journal of Ethnic and Migration Studies. 37 (7), pp. 1017-1037.

Ford, R. and Heath, A. (2014) Immigration: A nation divided? In: Park, A., Bryson, C. and Curtice, J., eds., (2014) British Social Attitudes: The 31st Report. London: NatCen Social Research, pp. 78-94.

Ford, R. and Lowles, N. (2016) Fear and Hope 2016: Race, Faith and Belonging in Today's England. London: HOPE not hate.

Ford, R., Morrell, G. and Heath, A. (2012) 'Fewer but better?' Public views about immigration. In: Park, A., Clery, E., Curtice, J., Phillips, M. and Utting, D., eds., (2012) British Social Attitudes: The 29th Report. London: NatCen Social Research, pp. 26-44. Foucault, M. (1980) Power/Knowledge: Selected Interviews and Other Writings 1972-1977 Edited by Colin Gordon. Brighton: Harvester.

Foucault, M. (1978) The Will to Knowledge: The History of Sexuality Volume I. Translated from the French by Robert Hurley. Reprint. London: Penguin, 1998.

Foucault, M. (1977) Discipline and Punish: The Birth of the Prison. Translated from the French by Alan Sheridan. Reprint. London: Penguin, 1999.

Fox, J.E., Moroşanu, L. and Szilassy, E. (2012) The racialization of the new European migration to the UK. Sociology. 46 (4), pp. 680-695. 
Freedland, J. (2016) We have woken up in a different country. The Guardian [online]. 24 June. Available from: https://www.theguardian.com/commentisfree/2016/jun/24/eureferendum-britain-different-country [Accessed 10 March 2020].

Full Fact (2011) Theresa May put on the spot over Human Rights cat [online]. 4 October. Available from: https://fullfact.org/news/theresa-may-put-spot-over-human-rights-cat/ [Accessed 28 September 2019].

Garner, S. (2018) Foreword. In: Bosworth, M., Parmar, A. and Vázquez, Y., eds., (2018) Race, Criminal Justice, and Migration Control: Enforcing the Boundaries of Belonging. Oxford: Oxford University Press, pp. ix-xiii.

Garner, S. (2017) Racisms: An Introduction. 4th ed. London: Sage.

Garner, S. (2015) Crimmigration: When criminology (nearly) met the sociology of race and ethnicity. Sociology of Race and Ethnicity. 1 (1), pp. 198-203.

Garner, S. (2013) The racialisation of asylum in provincial England: Class, place and whiteness. Identities. 20 (5), pp. 503-521.

Garner, S. (2007a) The European Union and the racialization of immigration, 1985-2006. Race/Ethnicity: Multidisciplinary Global Contexts. 1 (1), pp. 61-87.

Garner, S. (2007b) Whiteness: An Introduction. Abingdon: Routledge.

Garner, S. and Moran, A. (2006) Asylum seekers and the nation-state: Putting the 'order' back into 'borders' in Australia and the Republic of Ireland. In: Lentin, A. and Lentin, R., eds., (2006) Race and State. Newcastle upon Tyne: Cambridge Scholars Publishing, pp. 103-120.

Garner, S. and Selod, S. (2015) The racialization of Muslims: Empirical studies of Islamophobia. Critical Sociology. 41 (1), pp. 9-19.

Gathings, M.J. and Parrotta, K. (2013) The use of gendered narratives in the courtroom: Constructing an identity worthy of leniency. Journal of Contemporary Ethnography. 42 (6), pp. 668-689. 
Gentleman, A. (2020) 'I've been ripped from my family': Deportee struggles to cope in Jamaica. The Guardian [online]. 12 February. Available from:

https://www.theguardian.com/uk-news/2020/feb/12/ripped-from-my-family-deporteestruggles-cope-jamaica-chevon-brown [Accessed 22 February 2020].

Gerard, A. and Pickering, S. (2013) Crimmigration: Criminal justice, refugee protection and the securitisation of migration. In: Arrigo, B.A. and Bersot, H.Y., eds., (2013) The Routledge Handbook of International Crime and Justice Studies. Abingdon: Routledge, pp. 587-611.

Gibbs, P. (2017) Defendants on Video: Conveyor Belt Justice or a Revolution in Access? London: Transform Justice.

Gibson, S. (2007) Abusing our hospitality: Inhospitableness and the politics of deterrence. In: Molz, J.G. and Gibson, S., eds., (2007) Mobilizing Hospitality: The Ethics of Social Relations in a Mobile World. Aldershot: Ashgate, pp. 159-175.

Gilroy, P. (1987) There Ain't No Black in the Union Jack. Reprint. Routledge: Abingdon, 2002.

Goldberg, D.T. (2015) Are We All Postracial Yet? Cambridge: Polity.

Gordon, P. (1983a) Medicine, racism and immigration control. Critical Social Policy. 3 (7), pp. 6-20.

Gordon, P. (1983b) White Law: Racism in the Police, Courts and Prisons. London: Pluto Press.

Gove, M. (2016) Think the EU's bad now? Wait until Albania joins. Daily Mail [online]. 30 April. Available from: https://www.dailymail.co.uk/debate/article-3566620/MichaelGove-warns-EU-expansion-open-borders-88-million-Europe-s-poorest-countries.html [Accessed 18 October 2019].

Gower, M. (2018) The UK's Points-based System for Immigration. London: House of Commons Library. 
Gower, M. (2015) 'Asylum Support': Accommodation and Financial Support for Asylum Seekers. London: House of Commons Library

Gower, M. and Hawkins, O. (2013) Ending of Transitional Restrictions for Bulgarian and Romanian Workers. London: House of Commons Library

Greenslade, R. (2005) Seeking Scapegoats: The Coverage of Asylum in the UK Press. London: Institute for Public Policy Research.

Grierson, J. (2019) Police watchdogs to investigate forces over immigration referrals. The Guardian [online]. 29 March. Available from: https://www.theguardian.com/uknews/2019/mar/29/police-watchdogs-investigate-immigration-referrals-supercomplaint [Accessed 16 March 2020].

Griffiths, M. (2017) Foreign, criminal: A doubly-damned modern British folk-devil. Citizenship Studies. 21 (5), pp. 527-546.

Griffiths, M. and Yeo, C. (2021) The UK's hostile environment: Deputising immigration control. Critical Social Policy. Advance online publication, pp. 1-24, doi: 10.1177/0261018320980653 [Accessed 8 April 2021].

Grover, C. and Soothill, K. (1996) Ethnicity, the search for rapists and the press. Ethnic and Racial Studies. 19 (3), pp. 567-584.

Guma, T. and Jones, R.D. (2019) 'Where are we going to go now?' European Union migrants' experiences of hostility, anxiety, and (non-)belonging during Brexit. Population, Space and Place. 25 (1), p. e2198.

Guy, W. (2003) 'No soft Touch': Romani migration to the UK at the turn of the twenty-first century. Nationalities Papers. 31 (1), pp. 63-79.

Hall, M. (2011) 2250 a week for every migrant. Daily Express. 4 March, p. 1.

Hall, S., Critcher, C., Jefferson, T., Clarke, J. and Roberts, B. (2013). Policing the Crisis: Mugging, the State and Law and Order. 2nd ed. Basingstoke: Palgrave Macmillan. 
Hall, S. and O’Shea, A. (2013) Common-sense neoliberalism. Soundings: A Journal of Politics and Culture. 55, pp. 9-25.

Haraway, D. (1988) Situated knowledges: The science question in feminism and the privilege of partial perspective. Feminist Studies. 14 (3), pp. 575-599.

Hayes, D. (2002) From aliens to asylum seekers: A history of immigration controls and welfare in Britain. In: Cohen, S., Humphries, B. and Mynott, E., eds., (2002) From Immigration Controls to Welfare Controls. London: Routledge, pp. 30-46.

Hiro, D. (1992) Black British White British: A History of Race Relations in Britain. London: Paladin.

HM Courts and Tribunals Service (no date) Apply for a Transcript of a Court or Tribunal Hearing. Available from: https://www.gov.uk/apply-transcript-court-tribunal-hearing [Accessed 2 May 2021].

HM Inspectorate of Prisons (2012) Report on an Unannounced Inspection of HMP Lincoln, 20-24 August 2012. London: HM Inspectorate of Prisons.

HM Inspectorate of Prisons (2006) Foreign National Prisoners: A Thematic Review. London: HM Inspectorate of Prisons.

HM Inspectorate of Prisons and Independent Chief Inspector of Borders and Immigration (ICIBI) (2012) The Effectiveness and Impact of Immigration Detention Casework: A Joint Thematic Review by HM Inspectorate of Prisons and the Independent Chief Inspector of Borders and Immigration. London: HM Inspectorate of Prisons and ICIBI.

HM Inspectorate of Probation (2017) The Work of Probation Services in Courts. London: HM Inspectorate of Probation.

HM Prison and Probation Service (2019) Risk Assessment of Offenders. Available from: https://www.gov.uk/guidance/risk-assessment-of-offenders [Accessed 31 January 2020]. 
Holmes, S.M. and Castañeda, H. (2016) Representing the 'European refugee crisis' in Germany and beyond: Deservingness and difference, life and death. American Ethnologist. 43 (1), pp. 12-24.

Holzberg, B., Kolbe, K. and Zaborowski, R. (2018) Figures of crisis: The delineation of (un)deserving refugees in the German media. Sociology. 52 (3), pp. 534-550. Home Office (2020) The UK's Points-based Immigration System: Policy Statement [online]. Available from: https://www.gov.uk/government/publications/the-uks-points-basedimmigration-system-policy-statement/the-uks-points-based-immigration-systempolicy-statement [Accessed 10 March 2020].

Home Office (2019a) Asylum Support. Available from: https://www.gov.uk/asylumsupport/what-youll-get [Accessed 8 October 2019].

Home Office (2019b) EU Settlement Scheme: Suitability Requirements. London: Home Office.

Home Office (2019c) Immigration Rules Appendix V: Visitor Rules [online]. Available from: https://www.gov.uk/guidance/immigration-rules/immigration-rules-appendix-vvisitor-rules [Accessed 22 September 2019].

Home Office (2019d) Immigration Statistics, Year Ending September 2019 [online]. Available from: https://www.gov.uk/government/statistics/immigration-statisticsyear-ending-september-2019 [Accessed 23 December 2019].

Home Office (2018) The UK's Future Skills-based Immigration System. London: The Stationery Office. (Cm 9722).

Home Office (2017) Operation Nexus: High Harm. London: Home Office. Home Office (2015a) An Employer's Guide to Acceptable Right to Work Documents. London: Home Office. 
Home Office (2015b) 'Deport First, Appeal Later' Measures Start to Bite [press release]. 6 January. Available from: https://www.gov.uk/government/news/deport-first-appeallater-measures-start-to-bite [Accessed 28 September 2019].

Home Office (2015c) Immigration Directorate Instructions: Deporting Non-EEA Foreign Nationals. London: Home Office.

Home Office (2015d) New Measures Will Make it Tougher than Ever Before to Live Illegally in the $U K$ [press release]. 17 September. Available from:

https://www.gov.uk/government/news/new-measures-will-make-it-tougher-than-everbefore-to-live-illegally-in-the-uk [Accessed 28 September 2019].

Home Office (2014) New Measures to Tighten Up the Immigration System [press release]. 29 July. Available from: https://www.gov.uk/government/news/new-measures-totighten-up-the-immigration-system [Accessed 28 September 2019].

Home Office (2013) Immigration Bill Laid in Parliament [press release]. 10 October.

Available from: https://www.gov.uk/government/news/immigration-bill-laid-inparliament [Accessed 28 September 2019].

Home Office (2012) Radical Immigration Changes to Reform Family Visas [press release].

11 June. Available from: https://www.gov.uk/government/news/radical-immigrationchanges-to-reform-family-visas [Accessed 28 September 2019].

Home Office (2011) Family Migration: A Consultation. London: Home Office.

Home Office (2005) Controlling Our Borders: Making Migration Work for Britain. London:

The Stationery Office. (Cm 6472).

Home Office (2002) Secure Borders, Safe Haven: Integration with Diversity in Modern Britain. London: The Stationery Office. (Cm 5387).

Home Office (1998) Fairer, Faster, Firmer: A Modern Approach to Immigration and Asylum. London: The Stationery Office. (Cm 4018).

Hood, R. (1992) Race and Sentencing. Oxford: Clarendon Press. 
Hopkins, K. (2016) Shall I just buy a burka and get it over with? Daily Mail [online]. 7 January. Available from: https://www.dailymail.co.uk/debate/article3388711/KATIE-HOPKINS-Europe-s-governments-desperate-cover-Cologne-provesMuslim-men-NO-respect-white-women.html [Accessed 31 October 2019].

Hough, A. and Whitehead, T. (2011) New Eastern European 'benefit tourism' fears after migrant safeguards scrapped. The Telegraph [online]. 3 March. Available from: https://www.telegraph.co.uk/news/worldnews/europe/eu/8358500/New-EasternEuropean-benefit-tourism-fears-after-migrant-safeguards-scrapped.html [Accessed 8 October 2019].

Hough, M. and Roberts, J. V. (2017) Public opinion, crime and criminal justice. In: Liebling, A., Maruna, S. and McAra, L., eds., (2017) The Oxford Handbook of Criminology. 6th ed. Oxford: Oxford University Press, pp. 239-259.

Hough, M., Roberts, J. V., Jacobson, J., Bredee, A. and Moon, N. (2008) Attitudes to the Sentencing of Offences Involving Death by Driving. London: Sentencing Advisory Panel.

Hubbard, P. (2005) Accommodating otherness: Anti-asylum centre protest and the maintenance of white privilege. Transactions of the Institute of British Geographers. 30 (1), pp. 52-65.

Hudson, B. (1999) Punishment, poverty and responsibility: The case for a hardship defence. Social and Legal Studies. 8 (4), pp. 583-591.

Hutton, W. (2016) After Cologne, the uneasy question: Is cultural coexistence still possible? The Observer [online]. 10 January. Available from: https://www.theguardian.com/commentisfree/2016/jan/10/after-cologne-attacksbritish-politicians-show-share-merkel-values [Accessed 31 October 2019]. 
Independent Chief Inspector of Borders and Immigration (ICIBI) (2014) An Inspection of Immigration Enforcement Activity in London and the West Midlands ('Operation Nexus'). London: The Stationery Office.

Information Centre about Asylum and Refugees in the UK (ICAR) (2004) Media Image, Community Impact: Assessing the Impact of Media and Political Images of Refugees and Asylum Seekers on Community Relations in London. London: ICAR.

Inside Time (2016) Extended Determinate Sentences. Available from: https://insidetime.org/extended-determinate-sentences/ [Accessed 31 January 2020]. Ipsos MORI (2017) Global Views on Immigration and the Refugee Crisis. London: Ipsos MORI.

Jacobson, J. and Hough, M. (2011) Personal mitigation: An empirical analysis in England and Wales. In: Roberts, J.V., ed., (2011) Mitigation and Aggravation at Sentencing. Cambridge: Cambridge University Press, pp. 146-167.

Jacobson, J., Hunter, G. and Kirby, A. (2015) Inside Crown Court: Personal Experiences and Questions of Legitimacy. Bristol: Policy Press.

Jacobson, J., Kirby, A. and Hough, M. (2011) Public Attitudes to the Sentencing of Drug Offences. London: Sentencing Council.

Jeffries, S. and Bond, C.E.W. (2010) Narratives of mitigation: Sentencing Indigenous criminal defendants in South Australia's higher courts. Journal of Sociology. 46 (3), pp. 219-237.

Jensen, T. (2018) Parenting the Crisis: The Cultural Politics of Parent-blame. Bristol: Policy Press.

Jensen, T. (2012) How many qualitative interviews is enough? In: Baker, S.E. and Edwards, R., eds., (2012) How Many Qualitative Interviews is Enough? Expert Voices and Early Career Reflections on Sampling and Cases in Qualitative Research.

Southampton: National Centre for Research Methods, p. 39. 
Jensen, T. and Tyler, I (2015) 'Benefits broods': The cultural and political crafting of antiwelfare commonsense. Critical Social Policy. 35 (4), pp. 470-491.

Johnson, C. and Jones, R. (2014) Where is the border? In: Jones, R. and Johnson, C., eds., (2014) Placing the Border in Everyday Life. Farnham: Ashgate, pp. 1-11.

Johnson, C., Jones, R., Paasi, A., Amoore, L., Mountz, A., Salter, M. and Rumford, C. (2011) Interventions on rethinking 'the border' in border studies. Political Geography. 30 (2), pp. 61-69.

Johnson, T. (2011) On silence, sexuality and skeletons: Reconceptualizing narrative in asylum hearings. Social and Legal Studies. 20 (1), pp. 57-78.

Joint Council for the Welfare of Immigrants (JCWI) and Movement Against Xenophobia (MAX) (2015) I Am an Immigrant. Available from:

http://www.iamanimmigrant.net/i-am-immigrant-poster-campaign [Accessed 8 October 2019].

Jones, D. (2017) European migrants are already being deported - you just haven't noticed it. Another Europe is Possible [online]. 24 February. Available from:

https://www.anothereurope.org/european-migrants-are-already-being-deported-youjust-havent-noticed-it/ [Accessed 20 September 2019].

Jordan, J. (2012) Silencing rape, silencing women. In: Brown, J.M. and Walklate, S., eds., (2012) Handbook on Sexual Violence. Abingdon: Routledge, pp. 253-286.

Justice (2015) In the Dock: Reassessing the Use of the Dock in Criminal Trials. London: Justice.

Kalunta-Crumpton, A. (2000) Gender, race, and criminal justice in the United Kingdom: A case of male sexuality in criminal justice discourse. International Journal of Comparative and Applied Criminal Justice. 24 (1), pp. 43-60.

Kalunta-Crumpton, A. (1999) Race and Drug Trials: The Social Construction of Guilt and Innocence. Aldershot: Ashgate. 
Kalunta-Crumpton, A. (1998) The prosecution and defence of black defendants in drug trials: Evidence of claims-making. British Journal of Criminology. 38 (4), pp. 561-591.

Kaufman, E. (2015) Punish and Expel: Border Control, Nationalism, and the New Purpose of the Prison. Oxford: Oxford University Press.

Kaufman, E. (2013) Hubs and spokes: The transformation of the British prison. In: Aas, K.F. and Bosworth, M., eds., (2013) The Borders of Punishment: Migration, Citizenship and Social Exclusion. Oxford: Oxford University Press, pp. 166-182.

Kaufman, E. (2012) Finding foreigners: Race and the politics of memory in British prisons. Population, Space and Place. 18 (6), pp. 701-714.

Kaufman, E. and Bosworth, B. (2013) The prison and national identity: Citizenship, punishment and the sovereign state. In: Scott, D., ed., (2013) Why Prison? Cambridge: Cambridge University Press, pp. 170-188.

Kaye, R. (2001) 'Blaming the victim': An analysis of press representation of refugees and asylum-seekers in the United Kingdom in the 1990s. In: King, R. and Wood, N., eds., (2001) Media and Migration: Constructions of Mobility and Difference. Abingdon: Routledge, pp. 53-70.

Kaye, R. (1998) Redefining the refugee: The UK media portrayal of asylum seekers. In: Koseer, K. and Lutz, H., eds., (1998) The New Migration in Europe: Social Constructions and Social Realities. Basingstoke: Macmillan, pp. 163-182.

Kaye, R. (1994) Defining the agenda: British refugee policy and the role of parties. Journal of Refugee Studies. 7 (2/3), pp. 144-159.

Keenan, C. (2000) The same old story: Examining women's involvement in the initial stages of the criminal justice system. In: Bibbings, L. and Nicolson, D., eds., (2000) Feminist Perspectives on Criminal Law. London: Cavendish Publishing, pp. 29-48.

Kennedy, H. (1992) Eve Was Framed: Women and British Justice. Reprint. London: Vintage, 2005. 
Khiabany, G. (2016) Refugee crisis, imperialism and pitiless wars on the poor. Media, Culture \& Society. 38 (5), pp. 755-762.

Kirkup, J. and Winnett, R. (2012) Theresa May interview: 'We're going to give illegal migrants a really hostile reception'. The Telegraph [online]. 25 May. Available from: https://www.telegraph.co.uk/news/uknews/immigration/9291483/Theresa-Mayinterview-Were-going-to-give-illegal-migrants-a-really-hostile-reception.html [Accessed 19 September 2019].

Klug, F. (2013) Deportation and the Right to Respect for Private and Family Life under Article 8 of the Human Rights Act [online]. Available from: http://www.lse.ac.uk/sociology/assets/documents/human-rights/HRF7KlugDeportation.pdf [Accessed 29 September 2019].

Kundnani, A. (2014) The Muslims Are Coming! Islamophobia, Extremism, and the Domestic War on Terror. London: Verso.

Kundnani, A. (2004) Blair on asylum: Myth vs. reality. Institute of Race Relations Blog [blog]. 16 September. Available from: http://www.irr.org.uk/news/blair-on-asylummyth-vs-reality/ [Accessed 19 September 2019].

Kundnani, A. (2001) In a foreign land: The new popular racism. Race and Class. 43 (2), pp. $41-60$.

Kushner, T. (2005) Racialization and 'white European' immigration to Britain. In: Murji, K. and Solomos, J., eds., (2005) Racialization: Studies in Theory and Practice. Oxford: Oxford University Press, pp. 207-225.

Kushner, T. (2003) Meaning nothing but good: Ethics, history and asylum-seeker phobia in Britain. Patterns of Prejudice. 37 (3), pp. 257-276.

Lacey, N. and Zedner, L. (2017) Criminalization: Historical, legal and criminiological perspectives. In: Liebling, A., Maruna, S. and McAra, L., eds., (2017) The Oxford Handbook of Criminology. 6th ed. Oxford: Oxford University Press, pp. 57-76. 
Lal, J. (1996) Situating locations: The politics of self, identity and 'other' in living and writing the text. In: Wolf, D.L., ed., (1996) Feminist Dilemmas in Fieldwork. Boulder, CO: Westview Press, pp. 185-214.

Lamble, S. (2013) Queer necropolitics and the expanding carceral state: Interrogating sexual investments in punishment. Law and Critique. 24 (3), pp. 229-253.

Lammy, D. (2017) The Lammy Review: An Independent Review into the Treatment of, and Outcomes for, Black, Asian and Minority Ethnic Individuals in the Criminal Justice System. London: HM Government.

Legal Aid Agency (2015) Crime News: National Rollout for Crown Court Digital Case System [press release]. 3 December. Available from: https://www.gov.uk/government/news/crime-news-national-rollout-for-crown-courtdigital-case-system [Accessed 2 January 2020].

Legal Aid, Sentencing and Punishment of Offenders Act 2012 [online]. Chapter 5. (2012) Available from: http://www.legislation.gov.uk/ukpga/2012/10/part/3/chapter/5/enacted [Accessed 31 January 2020].

Lentin, A. (2014) Post-racial silences: The othering of race in Europe. In: Hund, W.D. and Lentin, A., eds., (2014) Racism and Sociology. Berlin: Lit Verlag, pp. 69-104.

Lentin, A. and Lentin, R. (2006) Introduction: Speaking of racism. In: Lentin, A. and Lentin, R., eds., (2006) Race and State. Newcastle upon Tyne: Cambridge Scholars Publishing, pp. 1-14.

Lentin, A. and Titley, G. (2011) The Crises of Multiculturalism: Racism in a Neoliberal Age. London: Zed Books.

Lewis, M. (2005) Asylum: Understanding Public Attitudes. London: IPPR. 
Light, D. and Young, C. (2009) European Union enlargement, post-accession migration and imaginative geographies of the 'New Europe': Media discourses in Romania and the United Kingdom. Journal of Cultural Geography. 26 (3), pp. 281-303.

Lightowlers, C. and Quirk, H. (2015) The 2011 English 'riots': Prosecutorial zeal and judicial abandon. British Journal of Criminology. 55 (1), pp. 65-85.

Luibhéid, E. (2013) Pregnant on Arrival: Making the Illegal Immigrant. Minneapolis: University of Minnesota Press.

Lynn, N. and Lea, S. (2003) 'A phantom menace and the new Apartheid': The social construction of asylum-seekers in the United Kingdom. Discourse and Society. 14 (4), pp. $425-452$.

Mack, K. and Roach Anleu, S. (2010) Performing impartiality: Judicial demeanor and legitimacy. Law and Social Inquiry. 35 (1), pp. 137-173.

Mann, M., Menih, H. and Smith, C. (2014) There is 'hope for you yet': The female drug offender in sentencing discourse. Australian and New Zealand Journal of Criminology. 47 (3), pp. 355-373.

Mason, J. (2012) How many qualitative interviews is enough? In: Baker, S.E. and Edwards, R., eds., (2012) How Many Qualitative Interviews is Enough? Expert Voices and Early Career Reflections on Sampling and Cases in Qualitative Research. Southampton: National Centre for Research Methods, pp. 29-30.

Mathews, J. (2013) The migrant sex beast let into Britain to rape again. Daily Express [online]. 30 August. Available from: https://www.express.co.uk/news/uk/425544/Themigrant-sex-beast-let-into-Britain-to-rape-again [Accessed 31 October 2019].

Matravers, M. (2014) Proportionality theory and popular opinion. In: Ryberg, J. and Roberts, J.V., eds., (2014) Popular Punishment: On the Normative Significance of Public Opinion. Oxford: Oxford University Press, pp. 33-53. 
Matthews, J. and Brown, A.R. (2012) Negatively shaping the asylum agenda? The representational strategy and impact of a tabloid news campaign. Journalism. 13 (6), pp. 802-817.

Mayor of London (2018) Population by Country of Birth [online]. Available from: https://data.london.gov.uk/dataset/country-of-birth [Accessed 16 December 2019]. McBarnet, D.J. (1981) Conviction: Law, the State and the Construction of Justice. London: Macmillan.

McConville, M. and Baldwin, J. (1982) Influence of race on sentencing in England. Criminal Law Review. October, pp. 652-658.

McConville, M., Hodgson, J., Bridges, L. and Pavlovic, A. (1994) Standing Accused: The Organisation and Practices of Criminal Defence Lawyers in Britain. Oxford: Clarendon Press.

McConville, M., Sanders, A. and Leng, R. (1991) The Case for the Prosecution: Police Suspects and the Construction of Criminality. London: Routledge.

McVeigh, R. and Lentin, R. (2002) Situated racisms: A theoretical introduction. In: Lentin, R. and McVeigh, R., eds., (2002) Racism and Anti-Racism in Ireland. Belfast: Beyond the Pale Publications, pp. 1-48.

Medien, K. (2016) Colonial myths, border technologies. Society and Space [online]. 28 June. Available from: http://societyandspace.org/2016/06/28/colonial-myths-bordertechnologies-kathryn-medien/ [Accessed 31 October 2019].

Migrant and Refugee Communities Forum (MRCF) (2011) Submission to the Leveson Inquiry into the Culture, Practices and Ethics of the Press. London: MRCF.

Migration Observatory (2020) UK Public Opinion toward Immigration: Overall Attitudes and Level of Concern [online]. Available from: https://migrationobservatory.ox.ac.uk/resources/briefings/uk-public-opinion-towardimmigration-overall-attitudes-and-level-of-concern/ [Accessed 1 February 2021]. 
Migration Observatory (2019) Deportation and Voluntary Departure from the UK [online]. Available from:

https://migrationobservatory.ox.ac.uk/resources/briefings/deportation-and-voluntarydeparture-from-the-uk/ [Accessed 15 September 2019].

Migration Observatory (2014) Costs and 'Benefits': Benefits Tourism, What Does it Mean? [online]. Available from: https://migrationobservatory.ox.ac.uk/resources/commentaries/costs-and-benefitsbenefits-tourism-what-does-it-mean/ [Accessed 8 October 2019].

Millie, A., Jacobson, J. and Hough, M. (2003) Understanding the growth in the prison population in England and Wales. Criminal Justice. 3 (4), pp. 369-387.

Mills, S. (2004) Discourse. 2nd ed. Abingdon: Routledge.

Minson, S. and Condry, R. (2015) The visibility of children whose mothers are being sentenced for criminal offences in the courts of England and Wales. Law in Context: A Socio-legal Journal. 32, pp. 28-45.

Mogan, A.C. (2016) Caught in the Nexus dragnet. The Justice Gap [online]. 26 April. Available from: https://www.thejusticegap.com/caught-nexus-dragnet/ [Accessed 16 September 2019].

Moore, J.M. (2016) Built for inequality in a diverse world: The historic origins of criminal justice. In: Seal, L., ed. Papers from the British Criminology Conference 2016. Nottingham, 6-8 July 2016. London: British Society of Criminology, pp. 38-56.

Moore, J.M. (2014) Is the Empire coming home? Liberalism, exclusion and the punitiveness of the British State. In: Millie, A., ed. Papers from the British Criminology Conference 2014. Liverpool, 9-12 July 2014. London: British Society of Criminology, pp. 31-48.

Moore, K. (2013) 'Asylum shopping' in the neoliberal social imaginary. Media, Culture \& Society. 35 (3), pp. 348-365. 
Moore, M. and Ramsay, G. (2017) UK Media Coverage of the EU Referendum Campaign. London: King's College.

Motsemme, N. (2004) The mute always speak: On women's silences at the Truth and Reconciliation Commission. Current Sociology. 52 (5), pp. 909-932.

Moxon, D. (1988) Sentencing Practice in the Crown Court. London: The Stationery Office.

Mulcahy, L. (2013) Putting the defendant in their place: Why do we still use the dock in criminal proceedings? British Journal of Criminology. 53 (6), pp. 1139-1156.

Murji, K. and Solomos, J. (2005) Introduction: Racialization in theory and practice. In: Murji, K. and Solomos, J., eds., (2005) Racialization: Studies in Theory and Practice. Oxford: Oxford University Press, pp. 1-27.

Nagy, V.M. (2014) Narratives in the courtroom: Female poisoners in mid-nineteenth century England. European Journal of Criminology. 11 (2), pp. 213-227.

National Police Chiefs' Council (2018) Chief Constable's Paper: Information Exchange Regarding Victims of Crime with No Leave to Remain [online]. Available from: https://assets.publishing.service.gov.uk/government/uploads/system/uploads/attachme nt_data/file/767718/Appendix_1.pdf [Accessed 16 September 2019].

Nicolson, D. (1995) Telling tales: Gender discrimination, gender construction and battered women who kill. Feminist Legal Studies. 3 (2), pp. 185-206.

Norrie, A. (2014) Crime, Reason and History: A Critical Introduction to Criminal Law. 3rd ed. Cambridge: Cambridge University Press.

Nye, C., Bloomer, N. and Jeraj, S. (2018) Victims of serious crime face arrest over immigration status. BBC News [online]. 14 May. Available from: https://www.bbc.co.uk/news/uk-44074572 [Accessed 16 September 2019].

Office for National Statistics (ONS) (2019) Population of the UK by Country of Birth and Nationality: 2018 [online]. Available from: https://www.ons.gov.uk/peoplepopulationandcommunity/populationandmigration/inte 
rnationalmigration/bulletins/ukpopulationbycountryofbirthandnationality/2018\#nonuk-populations-similar-to-2017-levels-following-previous-continual-increases [Accessed 16 December 2019].

Office for National Statistics (2017) What's Happening with International Student Migration? [online]. Available from: https://www.ons.gov.uk/peoplepopulationandcommunity/populationandmigration/inte rnationalmigration/articles/whatshappeningwithinternationalstudentmigration/201708-24 [Accessed 27 September 2019].

Ousey, G.C. and Kubrin, C.E. (2018) Immigration and crime: Assessing a contentious issue. Annual Review of Criminology. (1) 1, pp. 63-84.

Padfield, N., Morgan, R. and Maguire, M. (2012) Out of court, out of sight? Criminal sanctions and non-judicial decision-making. In: Maguire, M., Morgan, R. and Reiner, R., eds., (2012) The Oxford Handbook of Criminology. 5th ed. Oxford: Oxford University Press, pp. 955-985.

Page, B. (2009) British Attitudes to Immigration in the $21^{\text {st }}$ Century. Washington: Migration Policy Institute.

Paik, L. and Harris, A. (2015) Court ethnographies. In: Copes, H. and Mitchell Miller, J., eds., (2015) The Routledge Handbook of Qualitative Criminology. Abingdon: Routledge, pp. 283-295.

Palillo, M. (2018) 'If I die here, I'm a hero!': On masculinity and vulnerability among male asylum seekers. Journal of Extreme Anthropology. (2) 1, pp. 28-45.

Parmar, A. (2019) Policing migration and racial technologies. British Journal of Criminology. 59 (4), pp. 938-957.

Parmar, A. (2018a) Policing belonging: Race and nation in the UK. In: Bosworth, M., Parmar, A. and Vázquez, Y., eds., (2018) Race, Criminal Justice, and Migration 
Control: Enforcing the Boundaries of Belonging. Oxford: Oxford University Press, pp. 108-124.

Parmar, A. (2018b) Race at the border. In: Fili, A., Jahnsen, S. and Powell, R., eds., (2018) Criminal Justice Research in an Era of Mass Mobility. Oxford: Routledge, pp. 186200.

Parmar, A. (2017) Intersectionality, British criminology and race: Are we there yet? Theoretical Criminology. 21 (1), pp. 35-45.

Parmar, A. (2016a) Policing the boundaries of belonging. Border Criminologies Blog [blog]. 4 November. Available from: https://www.law.ox.ac.uk/research-subjectgroups/centre-criminology/centreborder-criminologies/blog/2016/11/policing [Accessed 25 September 2019].

Parmar, A. (2016b) Race, ethnicity and criminal justice: Refocusing the criminological gaze. In: Bosworth, M., Hoyle, C. and Zedner, L., eds., (2016) Changing Contours of Criminal Justice. Oxford: Oxford University Press, pp. 55-69.

Parry, R. (2012) 1-in-5 rape and murder suspects are migrants. The Sun. 19 July, p. 17.

Patel, T.G. and Connelly, L. (2019) 'Post-race' racisms in the narratives of 'Brexit' voters. The Sociological Review. 67 (5), pp. 968-984.

Pearson, A. (2016) Cologne assault: Cultural difference is no excuse for rape. The Telegraph [online]. 7 January. Available from: https://www.telegraph.co.uk/news/worldnews/europe/germany/12087780/Cologneassault-Cultural-difference-is-no-excuse-for-rape.html [Accessed 31 October 2019].

Phillips, C. (2012) The Multicultural Prison: Ethnicity, Masculinity, and Social Relations among Prisoners. Oxford: Oxford University Press.

Phillips, C. and Bowling, B. (2003) Racism, ethnicity and criminology: Developing minority perspectives. British Journal of Criminology. 43 (2), pp. 269-290. 
Phillips, C. and Earle, R. (2010) Reading difference differently? Identity, epistemology and prison ethnography. British Journal of Criminology. 50 (2), pp. 360-378.

Phillips, C., Earle, R., Parmar, A. and Smith, D. (2019) Dear British criminology: Where has all the race and racism gone? Theoretical Criminology. Advance online publication, pp. 1-20, doi: 10.1177/1362480619880345 [Accessed 15 March 2020].

Phillips, C. and Webster, C. (2014) Introduction: Bending the paradigm - new directions and new generations. In: Phillips, C. and Webster, C., eds., (2014) New Directions in Race, Ethnicity and Crime. Abingdon: Routledge, pp. 1-17.

Philo, G., Briant, E. and Donald, P. (2013) Bad News for Refugees. London: Pluto Press.

Pickering, S., Bosworth, M. and Aas, K.F. (2014) The criminology of mobility. In: Pickering, S. and Ham, J., eds., (2014) The Routledge Handbook on Crime and International Migration. Abingdon: Routledge, pp. 382-395.

Pina-Sánchez, J., Roberts, J.V. and Sferopoulos, D. (2019) Does the Crown Court discriminate against Muslim-named offenders? A novel investigation based on text mining rechniques. British Journal of Criminology. 59 (3), pp. 718-736.

Pitcher, B. (2009) The Politics of Multiculturalism: Race and Racism in Contemporary Britain. Basingstoke: Palgrave Macmillan.

Plotnikoff, J. and Woolfson, R. (2000) Evaluation of Video Link Pilot Project at Manchester Crown Court: Final Report.

Politics.co.uk (2011) Theresa May speech in full [online]. 4 October. Available from: http://www.politics.co.uk/comment-analysis/2011/10/04/theresa-may-speech-in-full [Accessed 28 September 2019].

Potter, J. (2018) Patients not passports: No borders in the NHS! Justice, Power and Resistance. 2 (2), pp. 417-429.

Presser, L. (2016) Criminology and the narrative turn. Crime, Media, Culture. 12 (2), pp. $137-151$. 
Presser, L. and Sandberg, S. (2015) Introduction: What is the story? In: Presser, L. and Sandberg, S., eds., (2015) Narrative Criminology: Understanding Stories of Crime. New York: New York University Press, pp. 1-20.

Prison Reform Trust (2019) Prison - The Facts: Bromley Briefings Summer 2019. London: Prison Reform Trust.

Redmayne, M. (2015) Character in the Criminal Trial. Oxford: Oxford University Press. Refugee Council (2015) PM Must Avoid Inflammatory Language [press release]. 30 July. Available from: https://www.refugeecouncil.org.uk/latest/news/4389_pm_must_avoid_inflammatory_ language/ [Accessed 12 March 2020].

Refugee Council (2014) 28 Days Later: The Experiences of New Refugees in the UK. London: Refugee Council.

Refugee Council (2010) Chance or Choice? Understanding Why Asylum Seekers Come to the $U K$. London: Refugee Council.

Richardson, L. (1990) Narrative and sociology. Journal of Contemporary Ethnography. 19 (1), pp. 116-135.

Right to Remain (2019) Right to Remain Toolkit. London: Right to Remain.

Roach Anleu, S., Bergman Blix, S. and Mack, K. (2015) Researching emotion in courts and the judiciary: A tale of two projects. Emotion Review. 7 (2), pp. 145-150.

Roberts, J.V. (2014) Clarifying the significance of public opinion for sentencing policy and practice. In: Ryberg, J. and Roberts, J.V., eds., (2014) Popular Punishment: On the Normative Significance of Public Opinion. Oxford: Oxford University Press, pp. 228252.

Roberts, J.V. (2011) The future of state punishment: The role of public opinion in sentencing. In: Tonry, M., ed., (2011) Retributivism Has a Past: Has it a Future? Oxford: Oxford University Press, pp. 101-129. 
Roberts, J.V. (2008) Punishing Persistent Offenders: Exploring Community and Offender Perspectives. Oxford: Oxford University Press.

Robins, J. (2019) 'Joint enterprise exposes all that is wrong with our justice system'. The Justice Gap [online]. 18 February. Available from: https://www.thejusticegap.com/joint-enterprise-exposes-all-that-is-wrong-with-ourjustice-system-2/ [Accessed 5 April 2021].

Robinson, M. (2012) Nearly a fifth of all suspected rapists and murderers arrested last year were immigrants. Daily Mail [online]. 19 July. Available from: https://www.dailymail.co.uk/news/article-2175798/A-fifth-suspected-rapistsmurderers-Britain-immigrants.html [Accessed 18 October 2019].

Rock, P. (1993) The Social World of an English Crown Court: Witness and Professionals in the Crown Court Centre at Wood Green. Oxford: Oxford University Press.

Rose, N. (2000) Government and control. British Journal of Criminology. 40 (2), pp. 321339.

Ryberg, J. and Roberts, J.V. (2014) Introduction: Exploring the normative significance of public opinion for state punishment. In: Ryberg, J. and Roberts, J.V., eds., (2014) Popular Punishment: On the Normative Significance of Public Opinion. Oxford: Oxford University Press, pp. 1-13.

Rzepnikowska, A. (2019) Racism and xenophobia experienced by Polish migrants in the UK before and after Brexit vote. Journal of Ethnic and Migration Studies. 45 (1), pp. 6177.

Sachs, A. (1976) The myth of judicial neutrality: The male monopoly cases. In: Carlen, P., ed., (1976) The Sociology of Law. Keele: University of Keele, pp. 104-133.

Said, E. (1978) Orientalism. Reprint. London: Penguin, 2003.

Sales, R. (2005) Secure borders, safe haven: A contradiction in terms. Ethnic and Racial Studies. 28 (3), pp. 445-462. 
Sales, R. (2002) The deserving and the undeserving: Refugees, asylum seekers and welfare in Britain. Critical Social Policy. 22 (3), pp. 456-478.

Sandberg, S. and Colvin, S. (2020) 'Isis is not Islam': Epistemic injustice, everyday religion, and young Muslims' narrative resistance. British Journal of Criminology. 60 (6), pp. $1585-1605$.

Sandberg, S. and Ugelvik, T. (2016) The past, present, and future of narrative criminology: A review and an invitation. Crime, Media, Culture. 12 (2), pp. 129-136.

Scheppele, K.L. (1989) Foreword: Telling stories. Michigan Law Review. 87 (8), pp. $2073-$ 2098.

Schuster, L. (2003a) Common sense or racism: The treatment of asylum-seekers in Europe. Patterns of Prejudice. 37 (3), pp. 233-255.

Schuster, L. (2003b) The Use and Abuse of Political Asylum in Britain and Germany. London: Frank Cass.

Schuster, L. and Solomos, J. (2004) Race, immigration and asylum: New Labour's agenda and its consequences. Ethnicities. 4 (2), pp. 267-300.

Scraton, P. (2016) Bearing witness to the 'pain of others': Researching power, violence and resistance in a women's prison. International Journal for Crime, Justice and Social Democracy. 5 (1), pp. 5-20.

Seal, L. (2010) Women, Murder and Femininity: Gender Representations of Women Who Kill. Basingstoke: Palgrave Macmillan.

Sentencing Council (2021a) Fine Bands. Available from: https://www.sentencingcouncil.org.uk/explanatory-material/magistratescourt/item/fines-and-financial-orders/approach-to-the-assessment-of-fines-2/2-finebands/ [Accessed 2 August 2021]. 
Sentencing Council (2021b) History. Available from:

https://www.sentencingcouncil.org.uk/sentencing-and-the-council/about-thesentencing-council/history/ [Accessed 16 April 2021].

Sentencing Council (2021c) Sentencing Guidelines for Use in Crown Court. Available from: https://www.sentencingcouncil.org.uk/crown-court/ [Accessed 29 March 2021]. Sentencing Council (2018) Sentencing Council Launches Online Sentencing Guidelines for Use in the Crown Court [press release]. 8 November. Available from: https://www.sentencingcouncil.org.uk/news/item/sentencing-council-launches-onlinesentencing-guidelines-for-use-in-the-crown-court/ [Accessed 2 January 2020]. Sentencing Council (2017) Reduction in Sentence for a Guilty Plea: Research Report [online]. Available from: https://www.sentencingcouncil.org.uk/wpcontent/uploads/Guilty-plea-research-report_final.pdf [Accessed 5 March 2021].

Sentencing Council (2015) Theft Offences: Definitive Guideline. London: Sentencing Council.

Sentencing Council (2014) Fraud, Bribery and Money Laundering Offences: Definitive Guideline. London: Sentencing Council.

Sentencing Council (2013) Sexual Offences: Definitive Guideline. London: Sentencing Council.

Sentencing Council (2012a) Courts Issued with New Guideline for Sentencing Drug Offenders [press release]. 24 January. Available from: https://www.sentencingcouncil.org.uk/news/item/courts-issued-with-new-guidelinefor-sentencing-drug-offenders/ [Accessed 5 January 2020].

Sentencing Council (2012b) Drug Offences: Definitive Guideline. London: Sentencing Council.

Sentencing Council (2011) Burglary Offences: Definitive Guideline. London: Sentencing Council. 
Shapland, J. (1981) Between Conviction and Sentence: The Process of Mitigation. London: Routledge.

Shute, S., Hood, R. and Seemungal, F. (2005) A Fair Hearing? Ethnic Minorities in the Criminal Courts. Abingdon: Routledge.

Singh, S. (2017) Criminalizing vulnerability: Protecting 'vulnerable' children and punishing 'wicked' mothers. Social and Legal Studies. 26 (4), pp. 511-533.

Smith, B.H. (1980) Narrative versions, narrative theories. Critical Inquiry. 7 (1), pp. $213-$ 236.

Smith, O. and Skinner, T. (2017) How rape myths are used and challenged in rape and sexual assault trials. Social and Legal Studies. 26 (4), pp. 441-466.

Solomos, J. (2003) Race and Racism in Britain. Basingstoke: Palgrave Macmillan.

Solomos, J. and Back, L. (1996) Racism and Society. Basingstoke: Macmillan.

Soothill, K. and Walby, S. (1991) Sex Crime in the News. London: Routledge.

Spillett, R. (2013) Let-off for immigrant rape thug. The Daily Star. 13 April, p. 2.

Stern, V. (2010) The Stern Review: A Report by Baroness Stern CBE of an Independent Review into How Rape Complaints are Handled by Public Authorities in England and Wales. London: Home Office.

Sturge, G. (2019a) Asylum Statistics. London: House of Commons Library.

Sturge, G. (2019b) UK Prison Population Statistics. London: House of Commons Library. Sudbury, J. (2006) Rethinking antiviolence strategies: Lessons from the Black Women's Movement in Britain. In: INCITE! Women of Color Against Violence, ed., (2006) Color of Violence: The INCITE! Anthology. Reprint. London, Duke University Press, 2016, pp. 13-24.

Supreme Court (2016) Press Summary: $R$ v Jogee (Appellant) [2016] UKSC 8, on Appeal from [2013] EWCA Crim 1433, and Ruddock (Appellant) v The Queen (Respondent) (Jamaica) [2016] UKPC 7, on Appeal from the Court of Appeal of Jamaica [online]. 
18 February. Available from: https://www.supremecourt.uk/cases/docs/uksc-20150015-press-summary.pdf [Accessed 5 April 2021].

Tait, D. (2002) Sentencing as performance: Restoring drama to the courtroom. In: Tata, C. and Hutton, N., eds., (2002) Sentencing and Society: International Perspectives. Aldershot: Ashgate, pp. 399-428.

Tarzi, A. and Hedges, J. (1990) A Prison Within a Prison: A Study of Foreign Prisoners. London: Inner London Probation Service.

Tata, C. (2020) Sentencing: A Social Process. Re-thinking Research and Policy. Cham, Switzerland: Palgrave Macmillan.

Tata, C. (2007) Sentencing as craftwork and the binary epistemologies of the discretionary decision process. Social and Legal Studies. 16 (3), pp. 425-447.

Tata, C. (2002) Accountability for the sentencing decision process: Towards a new understanding. In: Tata, C. and Hutton, N., eds., (2002) Sentencing and Society: International Perspectives. Aldershot: Ashgate, pp. 399-428.

Taylor, D. (2017a) Black judge claims he was discriminated against by disciplinary panel. The Guardian [online]. 8 January. Available from: https://www.theguardian.com/law/2017/jan/08/black-judge-in-racial-discriminationfurore [Accessed 16 December 2019].

Taylor, D. (2017b) Home Office policy to deport EU rough sleepers ruled unlawful. The Guardian [online]. 14 December. Available from: https://www.theguardian.com/uknews/2017/dec/14/home-office-policy-deport-eu-rough-sleepers-ruled-unlawful [Accessed 20 September 2019].

The Guardian (2016) Guardian writers on the vote to leave [online]. 24 June. Available from: https://www.theguardian.com/commentisfree/2016/jun/24/eu-referendum-our-panelon-the-vote-for-brexit [Accessed 10 March 2020]. 
The Guardian (2011) David Cameron on immigration: Full text of the speech [online]. 14 April. Available from: https://www.theguardian.com/politics/2011/apr/14/davidcameron-immigration-speech-full-text [Accessed 13 October 2019].

The Independent (2015) Theresa May’s speech to the Conservative Party conference - in full [online]. 6 October. Available from: https://www.independent.co.uk/news/uk/politics/theresa-may-s-speech-to-theconservative-party-conference-in-full-a6681901.html [Accessed 27 September 2019].

The Sun (2013) The Sun says: Beggars' bus. 31 December, p. 6.

Tombs, J. (2008) Telling sentencing stories. In: Carlen, P., ed., (2008) Imaginary Penalities. Cullompton, Devon: Willan, pp. 84-112.

Tonkiss, K. (2018) The narrative assemblage of civil society interventions into refugee and asylum policy debates in the UK. Voluntary Sector Review. 9 (2), pp. 119-135.

Townsend, M. (2019) New Met police bid to share crime victims' data with Home Office. The Observer [online]. 5 October. Available from: https://www.theguardian.com/uknews/2019/oct/05/met-police-crime-victims-data-crime-immigration-home-office [Accessed 16 March 2020].

Toynbee, P. (2016) The mood is ugly, and an MP is dead. The Guardian [online]. 16 June. Available from: https://www.theguardian.com/commentisfree/2016/jun/16/moodugly-mp-dead-jo-cox [Accessed 10 March 2020].

Travers, M. (2007) Sentencing in the children's court: An ethnographic perspective. Youth Justice. 7 (1), pp. 21-35.

Tufail, W. (2015) Rotherham, Rochdale, and the racialised threat of the 'Muslim grooming gang'. International Journal for Crime, Justice and Social Democracy [online]. 4 (3), pp. 30-43. [Accessed 24 March 2020]. 
Turnbull, S. and Hasselberg, I. (2017) From prison to detention: The carceral trajectories of foreign national prisoners in the United Kingdom. Punishment and Society. 19 (2), pp. $135-154$.

Tyler, I. (2013) Revolting Subjects: Social Abjection and Resistance in Neoliberal Britain. London: Zed Books.

United Nations (2017) International Migration Report 2017: Highlights [online]. Available from:

http://www.un.org/en/development/desa/population/migration/publications/migrationr eport/docs/MigrationReport2017_Highlights.pdf [Accessed 14 September 2019].

Wasik, M. (2014) A Practical Approach to Sentencing. 5th ed. Oxford: Oxford University Press.

Watson, L. (2014) You failed to respect Britain! Judge blasts migrant child sex gang as he sends them to jail for total of 54 years for attacks on girls as young as 12. Daily Mail [online]. 21 February. Available from: https://www.dailymail.co.uk/news/article2563966/They-said-theyd-kill-I-told-police-Victims-speak-terror-Roma-child-sexgang-preyed-girls-young-12-jailed-54-years.html [Accessed 31 October 2019].

Webber, F. (2019) Entrenching hierarchies: The new immigration white paper. Institute of Race Relations Blog [blog]. 24 January. Available from: http://www.irr.org.uk/news/entrenching-hierarchies-the-new-immigration-whitepaper/ [Accessed 20 September 2019].

Webber, F. (2015) When anonymous hearsay can get you deported. Institute of Race Relations Blog [blog]. 24 March. Available from: http://www.irr.org.uk/news/whenanonymous-hearsay-can-get-you-deported/ [Accessed 16 September 2019].

Webber, F. (2004) The war on migration. In: Hillyard, P., Pantazis, C., Tombs, S. and Gordon, D., eds., (2004) Beyond Criminology: Taking Harm Seriously. London: Pluto Press, pp. 133-155. 
Weber, L. (2002) The detention of asylum seekers: 20 reasons why criminologists should care. Current Issues in Criminal Justice. 14 (1), pp. 9-30.

Weber, L. and Bowling, B. (2004) Policing migration: A framework for investigating the regulation of global mobility. Policing and Society. 14 (3), pp. 195-212.

Wemyss, G. and Cassidy, K. (2017) 'People think that Romanians and Roma are the same': Everyday bordering and the lifting of transitional controls. Ethnic and Racial Studies. 40 (7), pp. 1132-1150.

White, H. (1987) The Content of the Form: Narrative Discourse and Historical Representation. Maryland: Johns Hopkins University Press.

Wilcox, P. (2005) Beauty and the beast: Gendered and raced discourse in the news. Social and Legal Studies. 14 (4), pp. 515-532.

Williams, P. and Clarke, B. (2018a) Contesting the single story: Collective punishment, myth-making and racialised criminalisation. In: Bhatia, M., Poynting, S. and Tufail, W., eds., (2018) Media, Crime and Racism. Cham, Switzerland: Palgrave Macmillan. pp, 317-336.

Williams, P. and Clarke, B. (2018b) The black criminal other as an object of social control. Social Sciences. 7 (11), p. 234.

Williams, P. and Clarke, B. (2016) Dangerous associations: Joint Enterprise, gangs and racism. London: Centre for Crime and Justice Studies.

Williams, W. (2020) Windrush Lessons Learned Review. London: The Stationery Office. Wincup, E. (2017) Criminological Research: Understanding Qualitative Methods. 2nd ed. London: Sage.

Winter, J. (2002) The truth will out? The role of judicial advocacy and gender in verdict construction. Social and Legal Studies. 11 (3), pp. 343-367.

Young, M. (2013) 40 crimes and still UK lets Iranian thug stay. The Daily Star. 1 April, p. 23. 
Yuval-Davis, N., Anthias, F. and Kofman, E. (2005) Secure borders and safe haven and the gendered politics of belonging: Beyond social cohesion. Ethnic and Racial Studies. 28 (3), pp. 513-535.

Yuval-Davis, N., Varjú, V., Tervonen, M., Hakim, J. and Fathi, M. (2017) Press discourses on Roma in the UK, Finland and Hungary. Ethnic and Racial Studies. 40 (7), pp. 1151-1169.

Yuval-Davis, N., Wemyss, G. and Cassidy, K. (2018) Everyday bordering, belonging and the reorientation of British immigration legislation. Sociology. 52 (2), pp. 228-244.

Yuval-Davis, N., Wemyss, G. and Cassidy, K. (2016) Changing the racialized 'common sense' of everyday bordering. Open Democracy [online]. 17 February. Available from: https://www.opendemocracy.net/uk/nira-yuval-davis-georgie-wemyss-kathryncassidy/changing-racialized-common-sense-of-everyday-bord [Accessed 19 September 2019]. 